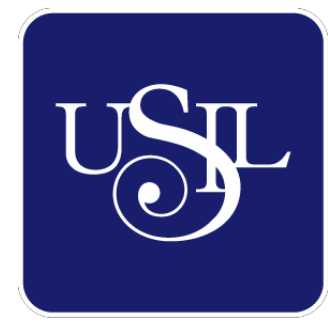

UNIVERSIDAD

SAN IGNACIO

DE LOYOLA

ESCUELA DE POSTGRADO

\title{
PLAN ESTRATÉGICO ETERNA PERÚ
}

Tesis para optar el grado de:

JOSEPH ANTHONY MONGRUT PRINCIPE

Maestro en Ciencias Empresariales con Mención en Gestión Comercial

LUIS IVAN PEÑA DELGADO

Maestro en Ciencias Empresariales con Mención en Gestión Comercial

Asesor:

Edmundo Casavilca Maldonado

Lima - Perú

2018 


\section{"PLAN ESTRATÉGICO PARA LA EMPRESA \\ ETERNA S.A. 2017 - 2021"}




\section{DEDICATORIA}

Dedicamos el presente trabajo de manera muy especial a nuestras familias,muchas gracias por su paciencia, perseverancia e apoyo incondicional que mostraron hacia nosotros para poder alcanzar con mucho sacrificio nuestras metas personales y profesionales.

Atentamente,

Joseph Mongrut e Iván Peña 


\section{AGRADECIMIENTO}

Deseamos agradecer a la empresa Eterna Perú S.A. y en particular a su Gerente General Jorge Gagliardo por todo el apoyo e información que nos sirvieron de mucha ayuda para la realización del presente trabajo, sin duda alguna su compañerismo y profesionalismo mostrado hizo posible la culminación del presente plan estratégico.

A nuestro asesor Mg. Edmundo Casavilca, quien fue nuestro líder en esta nueva experiencia,eternamente agradecido por su apoyo así como para la mejora continua de nuestro plan estratégico. 


\section{RESUMEN EJECUTIVO}

El presente trabajo es el Plan Estratégico para la empresa Eterna Perú S.A. para los años 2017 - 2021, el donde se establecen las estrategias y lineamientos que la empresas deberá seguir para mantenerse en el mercado y ser competitivo en los próximos años. Eterna Perú S.A., es una empresa dedicada a la importación y comercialización de artículos de limpieza para el hogar, con una presencia en el mercado nacional de 30 años a través de un distribuidor exclusivo y luego por los siguientes años como compañía subsidiaria de Eterna Colombia.

A fin de formular el plan estratégico, se ha realizado un análisis interno en donde se han encontrado algunos problemasen la empresa como: lafalta decompromiso para cumplir las funciones de los colaboradores, la escasa institucionalización, el mayor desarrollo de los procesos operativos, el desarrollo de nuevos canales en venta a bodegas y el proceso para formular y ejecutar un plan estratégico.También se han detectado algunas fortalezas como la planta de producción en su matriz de Colombia, el poder de negociación con los principales distribuidores, el capital propio para financiar el crecimiento medianteuna mayor penetración del mercado.

Por otro lado, se ha realizado un análisis externo de la empresa, a fin de analizar los riesgos y oportunidades del entorno. Así, actualmente existen factores externos e indicadores que favorecen un buen desarrollo a la empresa, entre ellos se menciona la estabilidad del PBI e inflación, el crecimiento de las importaciones y su permanecía de la balanza comercial (déficit), 
cultura de pagos por parte de los principales clientes y tendencia de crecimiento de la clase media lo cual cada vez tienen una tendencia al cuidado de la piel y el hogar.

A partir del análisis realizado, se han establecido los principales objetivos que se deberán desarrollarse en el periodo del presente plan, como:

- Generar y maximizar la rentabilidad a través del incremento de las ventas al desarrollar nuevos mercados.

- Desarrollar una cultura de calidad que permita brindar excelentes productos y servicios a nuestros clientes

- Formular un modelo comercial adecuado con permita brindar soporte y apoyo al área comercial de nuestros proveedores.

- Establecer políticas para una correcta ejecución de precios

- Brindar las pautas para mantener un excelente clima laboral basado en el desarrollo profesional y personal de nuestros colaboradores.

En este marco, en el Plan se propone una estrategia de desarrollo de mercado como estrategia principal y de penetración de mercado como estrategia de contingencia. A partir de estas estrategias, se hanimplementando iniciativas que tienen por finalidad desarrollar actividades que permitan responder a los principales problemas que presenta la empresa, así como aprovechar las oportunidades del entorno, lo que permitirá obtener una mayor rentabilidad y crecimiento de la empresa. 
En la actualidad los resultados financieros son optimistas para la empresa, los cuales consideramos que se pueden mejorar con la implementación del presente plan estratégicos. Por tanto, los principales gerentes y su equipo de la empresa deberían comprometerse para llevar a caboel presente plan estratégico, y de esta manera implementar la estrategiapropuesta que permitirá obtener la rentabilidad y posicionamiento esperado en el mercado. 


\section{INDICE}

Capítulo

Generalidades 26

1.1 Antecedentes 26

1.2 Determinación del problema 30

1.3 Justificación del proyecto 33

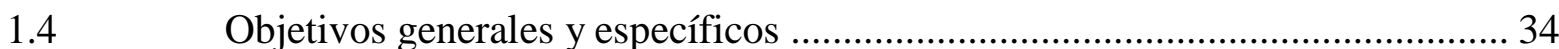

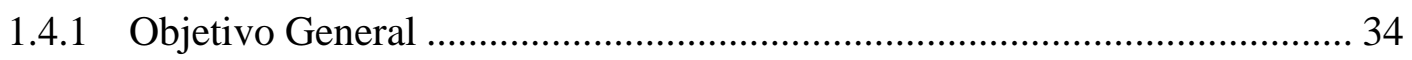

1.4.2 Objetivos Específicos ............................................................................ 35

1.5 Alcances y limitaciones de la investigación....................................................... 35

\subsubsection{Alcance 35}

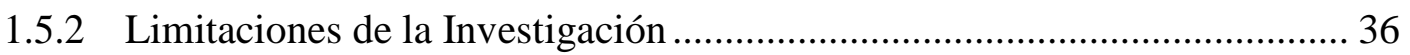

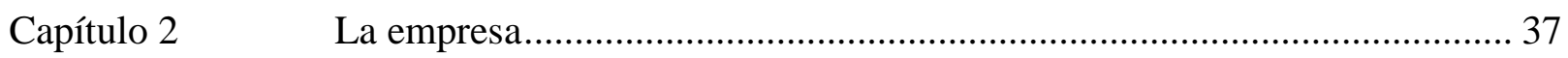

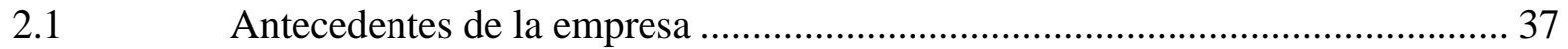

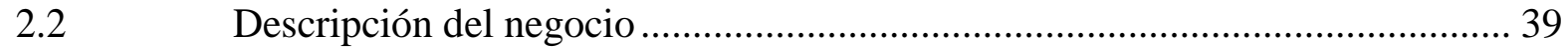

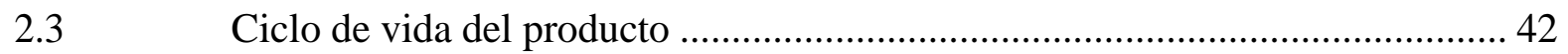

2.4 Estructura organizacional actual de la empresa ………................................... 49

2.5 Situación de mercado y financiera actual de la Industria................................... 54

Capítulo $3 \quad$ Formulación de visión, misión y valores de la empresa …………………..... 58

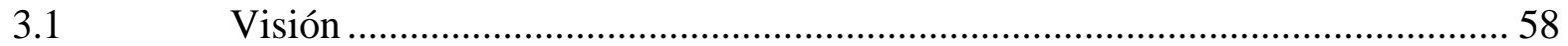

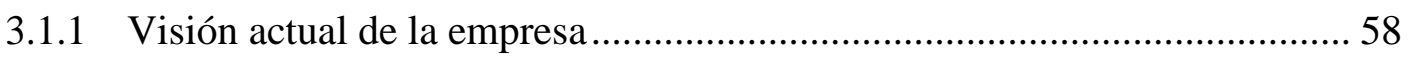




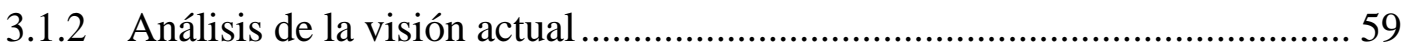

3.1.3 Matriz de la visión propuesta para la empresa ............................................. 60

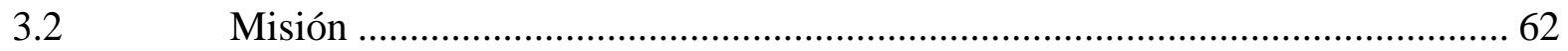

3.2.1 Misión actual de la empresa ....................................................................... 62

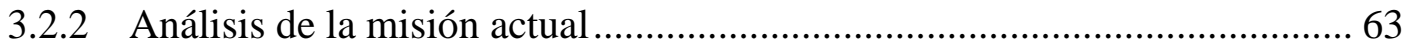

3.2.3 Elementos de la misión propuesta para la empresa ....................................... 65

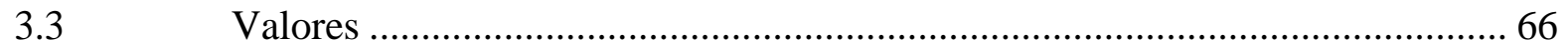

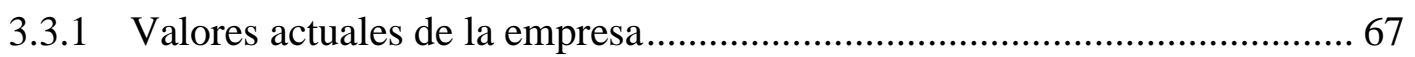

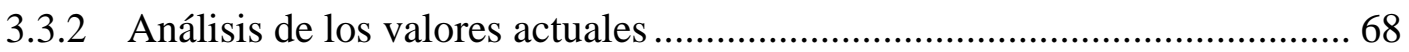

3.3.3 Elementos de los valores propuestos para la empresa................................... 68

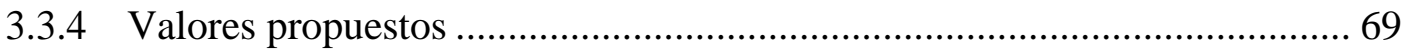

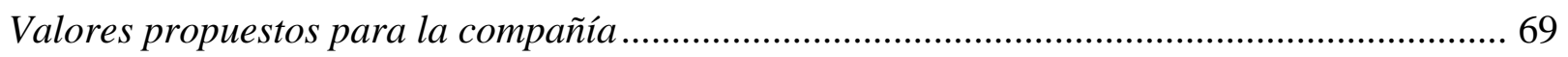

3.4 Alineamiento estratégico de la Visión, Misión y Valores de la empresa........... 70

Alineamiento estratégico de la Visión, Misión y Valores de la empresa................................... 70

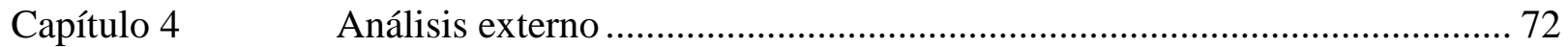

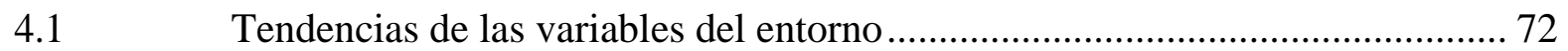

4.1.1 Análisis Político-Gubernamental .......................................................... 72

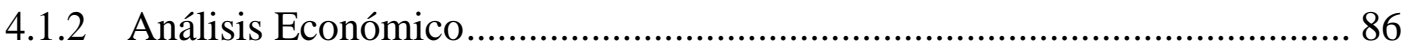

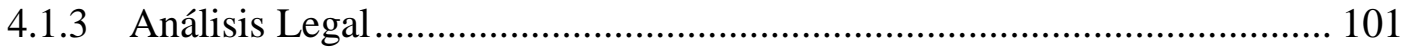

4.1.4 Análisis Cultural y Demográfico............................................................... 104 


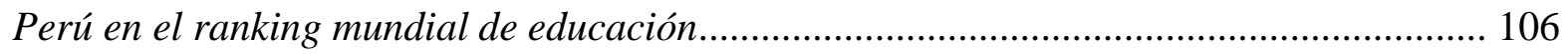

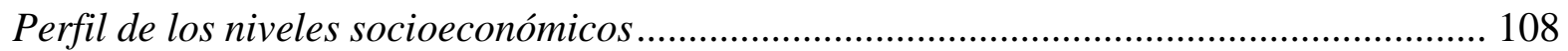

4.1.5 Análisis Tecnológico ........................................................................... 111

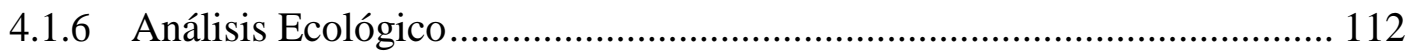

4.2 Impacto en clientes / proveedores de cada una de las variables del entorno... 114

Análisis externo impacto en clientes / proveedores ............................................................ 114

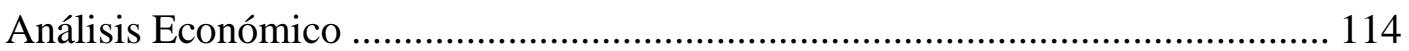

4.3 Efecto en la empresa de cada una de las variables del entorno ........................ 118

Análisis externo efecto en la empresa ................................................................................. 118

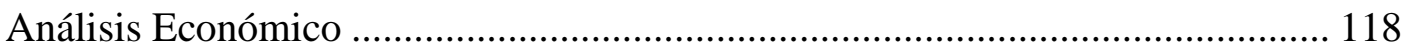

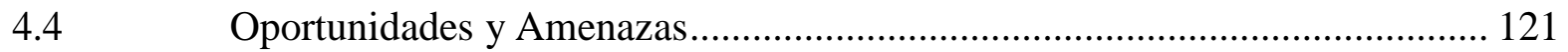

Análisis externo oportunidades y amenazas ................................................................. 121

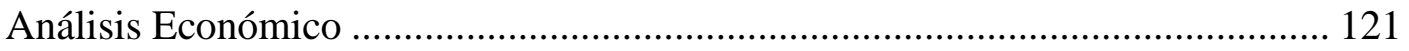

4.5 Matriz de Evaluación de los Factores Externos EFE ...................................... 123

Capítulo 5 Análisis de la industria ………………................................................. 125

5.1 Descripción del Mercado (demanda) e Industria (oferta)................................. 125

Frecuencia de uso de productos de limpieza ................................................................. 129

Marca más utilizadas en los últimos tres meses; principales respuestas (\%) ........................ 130

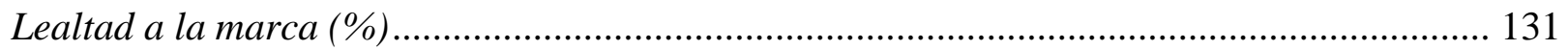

(Va a otro lugar a comprar la marca o no compra nada)................................................... 131 
Lugar frecuente de compra.

5.2 Descripción las cinco fuerzas competitivas de la industria 135

5.3 Matriz de atractividad de cada una de las cinco fuerzas 143

5.3.1. Análisis del Grado de atractividad de la industria

Matriz de Atractividad General

5.4 Matriz de Perfil Competitivo MPC 148

Capítulo 6 ANÁLISIS INTERNO 151

6.1 Descripción de las actividades de la cadena de valor de la empresa:.

6.1.1 Actividades primarias 152

6.1.2 Actividades de apoyo 163

6.2 Indicadores de cada una de las actividades de la cadena de valor 166

6.3 Benchmarking y comparación con los líderes de la industria de cada una de las actividades de la cadena de valor 168

6.4 Competencias de la empresa 170

6.5 Identificación y determinación de las ventajas competitivas de la empresa ... 173

6.6 Matriz de Evaluación de los Factores Internos EFI 175

Capítulo 7 Formulación de los objetivos y diseño de las estrategias 177

7.1 Alcance y planteamiento de los objetivos estratégicos 177

7.1.1 Objetivos Estratégicos 177

7.1.2 Análisis de los objetivos estratégicos 178 
7.2 Diseño y formulación de estrategias 183

7.2.1 Modelo Océano Azul 183

7.2.2 Matrices de formulación de estrategias 191

7.3 Resumen de las Estrategias Formuladas

Capítulo 8 Selección de la estrategia. 202

8.1 Método Factores Estratégicos Claves. 202

8.1.1 Criterios de selección 203

8.1.2 Matriz de selección 203

8.2 Método de Escenarios 205

8.2.1 Descripción de escenarios considerados 205

8.2.2 Comparación de Estrategias con escenarios 208

8.3 Matriz de Planeación Estratégica Cuantitativa MPEC 209

8.4 Descripción de estrategia seleccionada

8.5 Descripción de estrategia contingente 215

Capítulo 9 Implantación de la estrategia ..... 217

9.1 Mapa de la Estrategia 217

9.2 Objetivos específicos según el mapa de la estrategia 220

9.3 Indicadores para cada uno de los objetivos específicos

9.4 Metas para cada uno de los objetivos específicos . 222

9.5 Iniciativas (acciones a llevar a cabo para cada uno de los objetivos específicos) 
9.6 Responsable de cada una de las iniciativas 227

9.7 Presupuesto de cada una de las iniciativas 228

9.8 Cronograma de cada una de las iniciativas

Capítulo $10 \quad$ Evaluación 231

10.1 Evaluación Cualitativa 231

10.1.1 Criterios de Evaluación 232

10.1.2 Comparación de la estrategia con los criterios 234

10.2 Evaluación Financiera de la Estrategia 235

10.2.1 Histórico de los estados financieros (situación actual y con la nueva estrategia) $\quad 237$

10.2.2 Estado de resultados (situación actual y con la nueva estrategia) 241

10.2.3 Balance general (situación actual y con la nueva estrategia) 245

10.2.4 Flujo de efectivo 250

10.2.5 Proyección de flujos con la nueva estrategia 252

10.2.6 Evaluación Financiera (VAN, TIR y ratios financieros) 254

Conclusiones y Recomendaciones 261 


\section{INDICE DE FIGURAS}

Figura 1. Evaluación de las Importaciones peruanas por quinquenios 29

Figura 2. Exportación de Productos colombianos a Perú. 30

Figura 3. Ventas de Eterna Perú SAC 2015 y 2016. 31

Figura 4. Ciudades con presencia de Distribuidor Eterna y sus principales clientes ..... 32

Figura 5. Certificaciones en Calidad Eterna.......................................................... 39

Figura 6. Línea de Productos de Eterna................................................................ 41

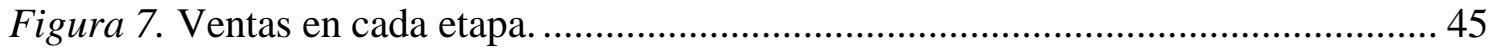

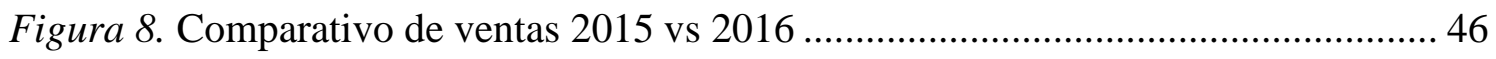

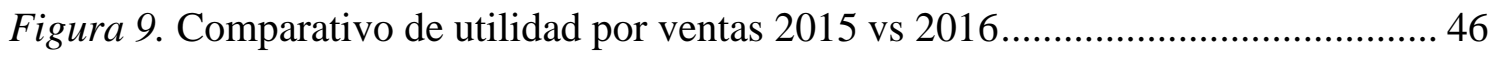

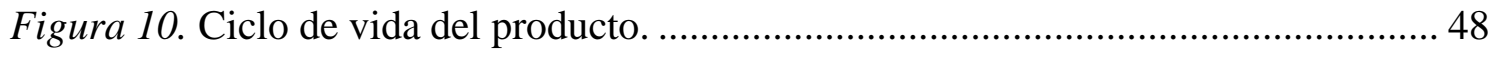

Figura 11. Organigrama de Eterna Perú S.A.C ........................................................ 49

Figura 12. Comparativo de utilidad por ventas en el sector 2015 vs $2016 \ldots \ldots \ldots \ldots \ldots \ldots . . . . . . .55$

Figura 13. Calificación principales países latinoamericanos .................................... 73

Figura 14. Los factores más problemáticos para hacer negocios ................................ 75

Figura 15. Comparación de América Latina para la creación de empresas.................... 77

Figura 16. Percepción de corrupción en el país......................................................... 80

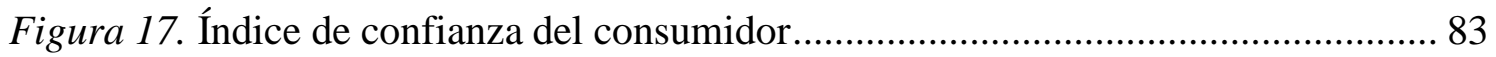

Figura 18. ICC Situación económica del hogar, país, empleo y ahorro ......................... 83

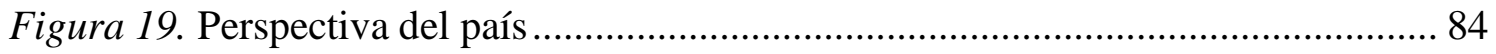

Figura 20. Acuerdos comerciales del Perú .............................................................. 85

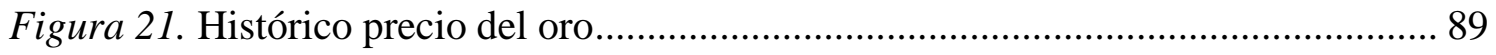




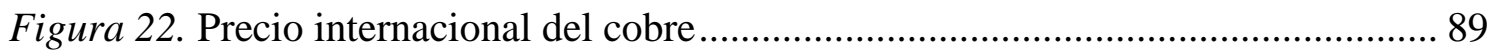

Figura 23. Evolución del precio del petróleo ............................................................... 90

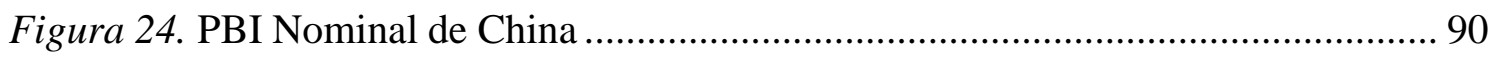

Figura 25. Producto Bruto Interno PBI de Perú ..................................................... 91

Figura 26. PBI proyectado para Chile, Colombia y Perú ......................................... 92

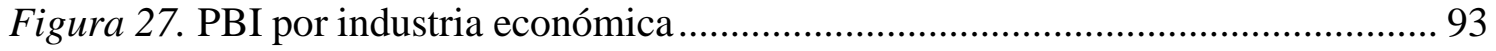

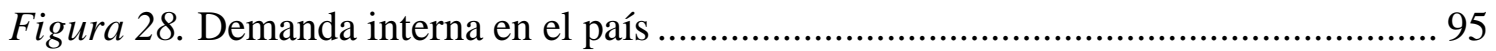

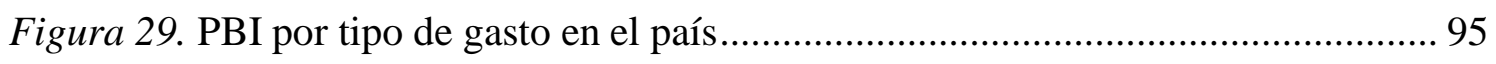

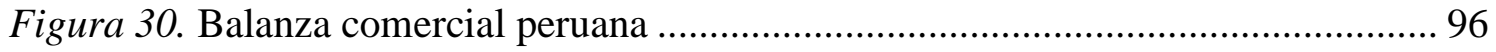

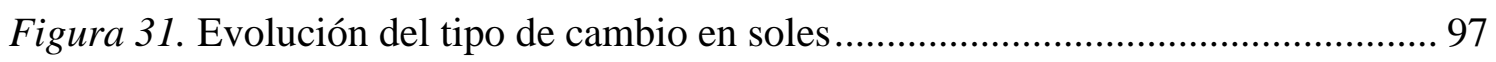

Figura 32. Encuesta de Expectativas macroeconómicas por tipo de cambio ................. 98

Figura 33. Evolución de la inflación en el país ......................................................... 99

Figura 34. Operaciones monetarias y tasa de interés .......................................... 100

Figura 35. Índice de facilidad para hacer negocios .............................................. 102

Figura 36. Costos laborales en el país ............................................................... 103

Figura 37. Morosidad vs demanda interna y empleo 1997 - 2016 ............................. 104

Figura 38. Uso de redes sociales en el Perú .......................................................... 106

Figura 39.Los estilos de vida latinoamericanos ................................................. 111

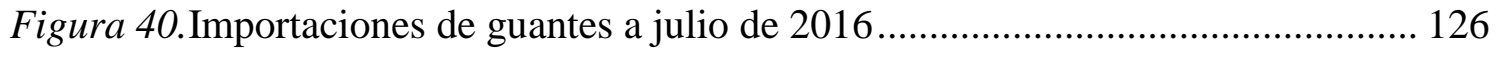

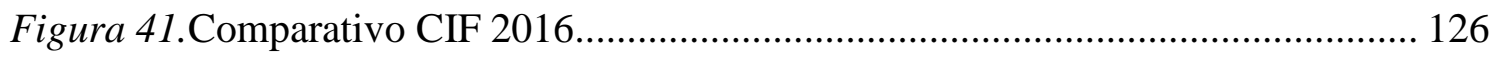

Figura 42. Perfil del ama de casa como compradora............................................ 132

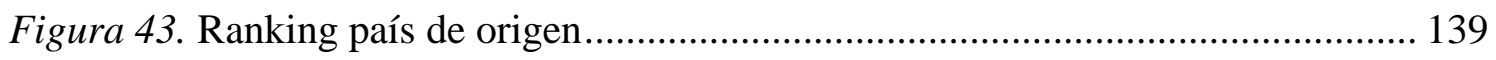

Figura 44. Ranking principales exportadores .................................................... 140 
Figura 45. Ranking principales importadores ........................................................ 142

Figura 46. Actual cadena de valor de Eterna Perú S.A.C............................................ 152

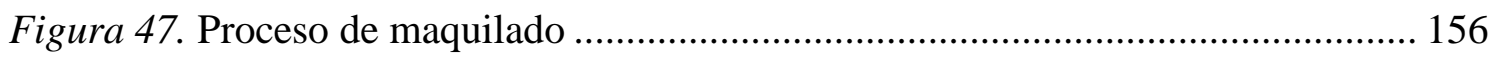

Figura 48. Nueva cadena de valor de Eterna Perú S.A.C............................................ 166

Figura 49. Lienzo de la estrategia de Eterna Perú ..................................................... 185

Figura 50. Lienzo de la estrategia de la industria...................................................... 187

Figura 51. Lienzo de la nueva estrategia de la industria ........................................... 190

Figura 52. Comparativo Océano Azul - Océano Rojo................................................... 191

Figura 53.Matriz PEYEA ………………………………….................................. 195

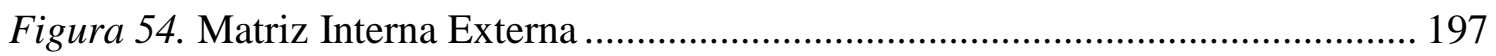

Figura 55. Matriz Boston Consulting Group........................................................... 199

Figura 56. Matriz de la Gran Estrategia .................................................................... 200

Figura 57. Mapa de la estrategia................................................................................ 219

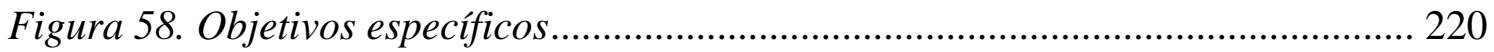

Figura 59. Indicadores para los objetivos................................................................ 222

Figura 60. Metas para cada uno de los objetivos......................................................... 224

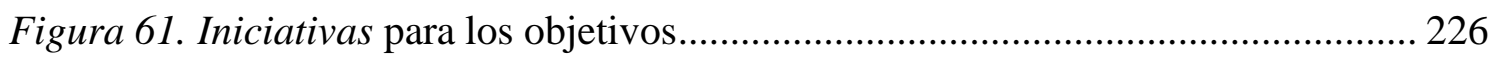




\section{INDICE DE TABLAS}

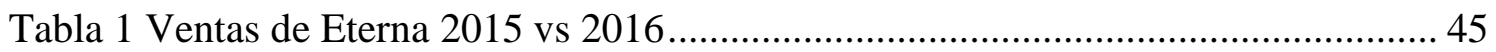

Tabla 2 Análisis de cada ciclo de vida del producto .................................................. 48

Tabla 3 Lisado de los profesionales de la compañía .............................................. 53

Tabla 4 Ventas de los principales competidores ................................................. 57

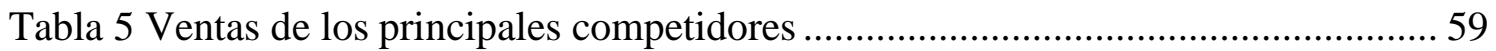

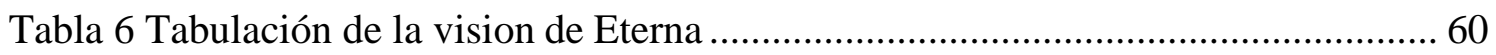

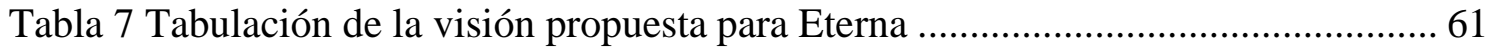

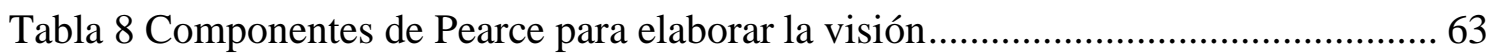

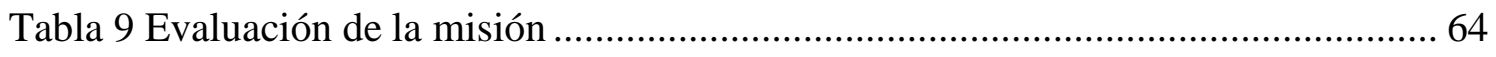

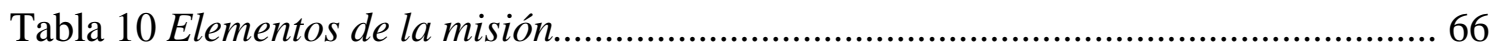

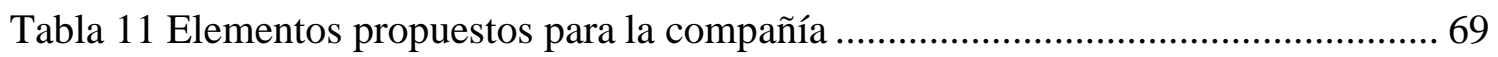

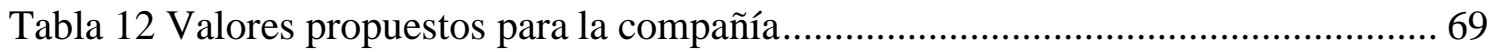

Tabla 13 Alineamiento estratégico de la Visión, Misión y Valores de la empresa......... 70

Tabla 14 Perú en el ranking mundial de educación .................................................. 106

Tabla 15 Perfil de los niveles socioeconómicos......................................................... 108

Tabla 16 Análisis externo impacto en clientes proveedores .................................... 114

Tabla 17 Análisis externo impacto en la empresa.................................................. 118

Tabla 18 Análisis externo oportunidades y amenazas ......................................... 121

Tabla 19 Matriz de Evaluación de los Factores Externos EFE .................................. 124

Tabla 20 Frecuencia de uso de productos de limpieza............................................ 129

Tabla 21 Marca más utilizadas en los últimos tres meses; principales respuestas (\%) 130 


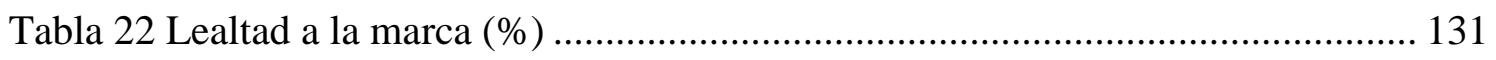

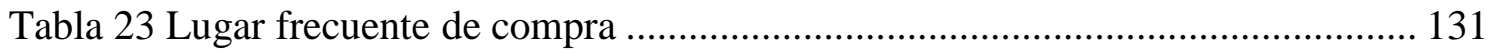

Tabla 24 Marca más utilizadas en los últimos tres meses........................................ 134

Tabla 25 Marcas que representa Eterna en el mercado........................................... 135

Tabla 26 Principales países exportadores de guantes ........................................... 138

Tabla 27 Principales empresas exportadores de guantes .......................................... 140

Tabla 28 Principales empresas importadoras de guantes ........................................ 141

Tabla 29 Amenaza de ingresos de competidores potenciales ................................. 143

Tabla 30 Poder de negociación de los proveedores .............................................. 144

Tabla 31 Poder de negociación de los clientes...................................................... 145

Tabla 32 Amenaza de productos sustitutos ......................................................... 146

Tabla 33 Rivalidad entre los competidores existentes ......................................... 146

Tabla 34 Matriz de atractividad global de las cinco fuerzas ..................................... 147

Tabla 35 Matriz de Perfil Competitivo MPC ........................................................... 149

Tabla 36 Indicadores de cada una de las actividades ............................................. 167

Tabla 37 Benchmarking y comparación con el líder de la industria ........................... 169

Tabla 38 Resumen de las ventajas competitivas de Eterna...................................... 174

Tabla 39 Matriz de Evaluación de los Factores Externos EFI .................................... 175

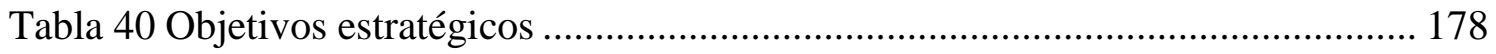

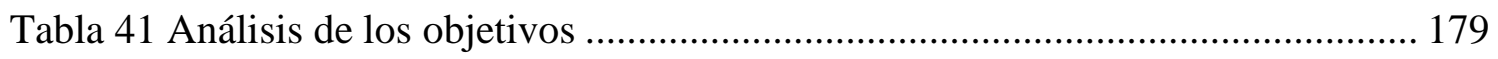

Tabla 42 Frecuencia de uso de artículos de guantes de limpieza.............................. 181

Tabla 43 Características del servicio de Eterna ........................................................ 184

Tabla 44 Características del servicio de la industria ................................................ 187 
Tabla 45 Matriz eliminar, reducir, incrementar, crear .......................................... 188

Tabla 46 Lienzo de la nueva estrategia de la industria ............................................ 189

Tabla 47 Matriz FODA de Eterna........................................................................ 191

Tabla 48 Matriz PEYEA de Eterna ....................................................................... 194

Tabla 49 Matriz Boston Consulting Group ......................................................... 198

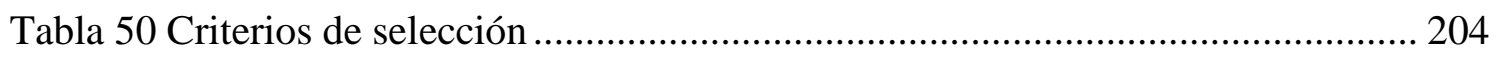

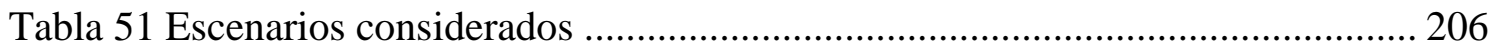

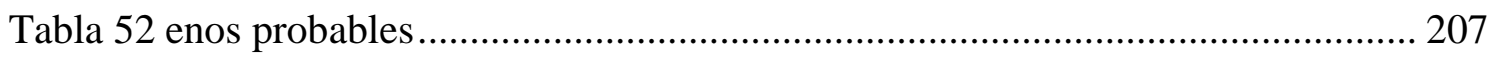

Tabla 53 Comparación de Estrategias con escenarios ........................................... 208

Tabla 54 Grado que afectan a cada una de las alternativas estratégicas ..................... 209

Tabla 55 Matriz de Planeación Estratégica Cuantitativa MPEC ............................... 210

Tabla 56 Selección de la estrategia principal ........................................................ 215

Tabla 57 Responsable de cada iniciativa ................................................................ 227

Tabla 58 Presupuesto de cada una de las iniciativasde .......................................... 228

Tabla 59 Cronograma de cada una de las iniciativas .............................................. 229

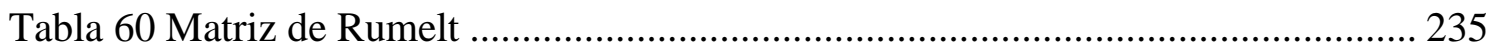

Tabla 61 Estados de resultados 2014, 2015 ......................................................... 238

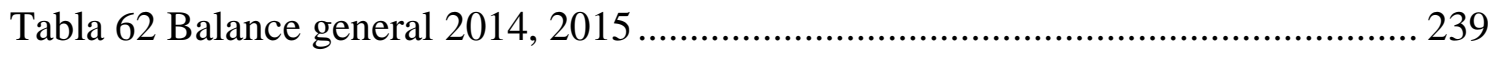

Tabla 63 Estados de Resultados sin estrategia ................................................... 242

Tabla 64 Estados de Resultados con estrategia...................................................... 245

Tabla 65 Balance General sin estrategia ............................................................ 247

Tabla 66 Balance General con estrategia ............................................................. 249

Tabla 67 Flujo de caja sin estrategia ............................................................... 251 
Tabla 68 Flujo de caja con estrategia................................................................. 253

Tabla 69 Ratios financieros de Eterna con la nueva ................................................ 256 
ANEXOS

Anexo 1: Entrevista al Gerente General de Eterna Perú S.A.C ......................................... 267

Anexo 2: Análisis de la entrevista al Gerente General de Eterna Perú S.A.C ....................... 270

Anexo 3: Análisis de la entrevista al gerente de ventas Colgate Palmolive Perú.................. 281

Anexo 4: Análisis de la entrevista al ejecutivo de planeamiento de Ilko Perú.................... 286

Anexo 5: Ficha técnica investigación cualitativa: entrevista clima organizacional................290

Anexo 6: Ficha técnica investigación cualitativa: entrevista clima organizacional................296

Anexo 7: Escala de clasificación terminología estándar y procedimientos .......................... 304

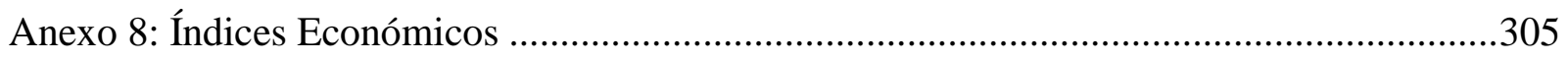

Anexo 9: Señales de alerta “artículo de diario Gestión”.................................................. 308

Anexo 10: Beneficios arancelarios de productos de caucho con Colombia .............................309

Anexo 11: Industria de Fabricación de Productos y Limpieza ......................................... 310

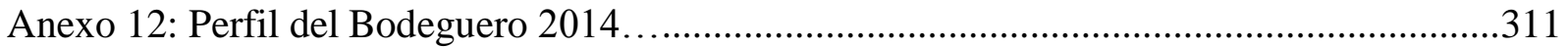

Anexo 13: Liderazgo en productos de cuidado personal y limpieza del hogar ......................318

Anexo 14: Oportunidades de negocio con el estado....................................................... 323 


\section{INTRODUCCIÓN}

En el presente trabajo se desarrolla un plan estratégico para la empresa Eterna Perú S.A para el periodo 2017-2021, donde se han planteado todos los lineamientos necesarios para que la empresa tenga una proyección de desarrollo sostenida en el tiempo.

Eterna Perú, es una empresa de capitales colombianos, dedicada a la importación y comercialización de artículos de limpieza para el hogar, industria médica descartable y productos industriales a base de caucho látex y plástico. Entre los productos que se importan tenemos a los guantes domésticos, guantes quirúrgicos de hospitalización, gastronomía, trabajo de tintes para el cabello, guantes industriales, esponjas multiusos, fibras abrasivas paños multiusos, esponjas metálicas y desarrollos industriales para vehículos y la construcción.

El presente plan estratégico contiene los siguientes capítulos:

\section{Capítulo 1: Generalidades}

En este capítulo se describen los antecedentes del proyecto, se determina el problema u oportunidad, se justifica la ejecución del proyecto, así como los objetivos del mismo y por último se presenta los alcances y limitaciones que se han presentado para llevar a cabo la presente investigación. 


\section{Capítulo 2: La empresa}

En este capítulo se revisan los antecedentes de la empresa, se describe el negocio y se define el ciclo de vida del producto. Asimismo, se muestra la estructura organizacional de la empresa y por último se revisa la situación actual de mercado y la situación financiera de la Industria.

Capítulo 3: Formulación de visión, misión y valores de la empresa

En este capítulo, se revisa y se analiza la visión, misión y los valores de la empresa, bajo los conceptos teóricos y formatos propuestos que nos han servido para reformular las mismas. Por último, se realizó el alineamiento estratégico de la visión, misión y valores redefinidos para la empresa.

\section{Capítulo 4: Análisis externo}

En el presente capítulo se analiza las tendencias de las principales variables del entorno, a partir de las variables PESTEL, se evalúa el impacto de cada variable en los clientes, proveedores y empresa. A partir del análisis realizado, se han identificado las oportunidades y amenazas de la empresa y finalmente se confeccionó la Matriz de Evaluación de los Factores Externos (EFE)

\section{Capítulo 5: Análisis de la industria}

En este capítulo se describe el mercado y la industria, con la finalidad de conocer la oferta y demanda existente. El análisis se realiza a partir del modelo de las cinco fuerzas 
competitivas de la industria. Para reforzar el análisis de este capítulo se confeccionó la matriz de atractividadde cada una de las cinco fuerzas, el análisis del grado de atractividad de la industria y finalmente la Matriz de Perfil Competitivo.

\section{Capítulo 6: Análisis interno}

En el presente capítulo,primero se realiza la descripción de las actividades de la cadena de valor de la empresa, a nivel logístico, operaciones, mercadotecnia, servicios, adquisiciones, recursos humanos, tecnología e infraestructura; luego, se realiza un benchmarking y una comparación con los líderes de la industria de cada una de las actividades de la cadena de valor; posteriormente,se define la competencia directa e indirecta, así como las ventajas competitivas de la empresa. Finalmente, se ha elaborado la Matriz de Evaluación de los Factores Internos.

Capítulo 7: Formulación de los objetivos y diseño de las estrategias

En este capítulo se defineen primer lugar, el alcance y el planteamiento de los objetivos estratégicos. A partir de los objetivos estratégicos planteados,se han diseñado y formuladolas estrategias para la empresa haciendo uso del modelo de Océano Azul, así como de las matrices de formulación de estrategias. Finalmente, se presenta un resumen de las estrategias formuladas previamente.

Capítulo 8: Selección de la estrategia

En el capítulo se ha desarrolladola selección de la estrategia mediante el Método de Factores Estratégicos Claves, el Método de Escenarios, y la Matriz de Planeación Estratégica Cuantitativa (MPEC), las cuales nos han permitido realizar la selección de la mejor estrategia a 
implementar. Luego de la selección se realiza la descripción de la estrategia seleccionada y la descripción de la estrategia contingente.

Capítulo 9: Implantación de la estrategia

En este capítulo se presenta el mapa estratégico, el cual contiene los objetivos específicos, se han confeccionado los indicadores para cada uno de los objetivos, se presentan las metas, las iniciativas o proyectos; Asimismo, se ha detallado quienes son los responsables, el presupuesto asignado y el cronograma de cada una de las iniciativas.

\section{Capítulo 10: Evaluación}

En este capítulo se ha llevado a cabo una evaluación cualitativa y cuantitativa de la estrategia. Para la evaluación cualitativa se ha usado los criteriosestablecidos por Rumeltparael análisis de una estrategia. Para la evaluación cuantitativa, se ha realizado una evaluación financiera considerando dos escenarios: que la empresa implemente la estrategia y el otro es que no se implemente la estrategia propuesta. A partir deestos escenarios se ha realizado la proyección de los estados financieros en el periodo de duración del plan como: estado de resultados, balance general, flujo de caja, proyección de flujos. Finalmente, se llevó a cabo el análisis del VAN ydel TIR de los flujos proyectado para ambos escenarios, así comoel análisis de otros ratios financieros. 


\section{Capítulo 1 Generalidades}

\subsection{Antecedentes}

a) Reseña histórica

Elárbol del caucho y su resina fue descubierto en 1736 por Charles Marie de La Condamine, botánico francésque utilizó el látex de estas plantas para el forrado de sus maletas al quedar asombrado de las características de elasticidad e impermeabilidad que estas mostraba.Posteriormente, La Condamine propuso que este material podría ser usado para fabricar toldos, mangos para bombas, trajes para buceadores y otros artículos que serían muy útiles.

En 1839 Charles Goodyear,considerado como el inventor del caucho vulcanizado,tras un accidente en el que vertió látex y azufre en un recipiente obtuvo el endurecimiento de la goma.Posteriormente, Charlespermaneció muchos años investigando la manera de como mejorar la calidad del caucho natural, de modo que no se convirtiera quebradizo con el frío óflácido y pegadizo con el calor. En la década de 1830, varios inventores trataron de ampliar un producto de goma que podría perdurar todo el año. Pero, fue Charles Goodyearuno de los forjadores de este producto yfue quién consiguió los resultados que son utilizados hasta el día de hoy.

Durante la Primera Guerra Mundial 1914 - 1918, Alemania soportó un intenso bloqueo comercial que lo impidió importar látex del continente americano y de Asia, lo cual era necesaria para obtener de caucho. Como este material era necesario para la 
elaboraciónde armamento militar, los ingenieros y químicos alemanes concentraron sus esfuerzos en originar un látex sintético a partir de los derivados del petróleo, logrando tener éxito al respecto. A partir de entonces, el látex natural comenzaría a ser reemplazado por el látex sintético como materia prima principal para la producción del caucho. Sin embargo, cuando el precio del petróleo estaba en crecimiento muchos países recurrían a la importación de látex natural para la fabricación de diversos bienes.

A partir del látex como materia prima, se realizar la fabricación de los guantes. Estos productos se usan principalmente para trabajos relacionados con la limpieza que requiere sustancias químicas. Asimismo, los guantes de látex son muy utilizados para la limpieza del hogar en actividades como lavadode platos, ropa, cuartos de baño; proteger las manos de los detergentes y del agua caliente; también son utilizados en la industria médica para la esterilización de elementos, estudios y exámenes con pacientes, las intervenciones quirúrgicas, socorrismo, entre otros.

b) La industria en la actualidad

La demanda de los productosde limpieza del hogar viene en alza debido al crecimiento poblacional. Así, en la actualidad se está generando el nacimiento de mega ciudades principalmente en Asia y Latinoamérica con poblaciones mayores a cinco millones. Estas grandes concentraciones traen consigo el incremento de necesidades primaria como son agua, energía, sanitarios, servicios médicos, transporte, entre otros. Las ciudades que encabezan la lista con mayor crecimiento poblacional en Latinoamérica son Sao Paulo, Rio de Janeiro en Brasil y Ciudad de México, en México. 
Estatendencia determina para las empresas nuevos retos, entre los que podemos señalar a: como mejorar sus estándares de calidad para brindar soluciones a bajo costo, tener la capacidad para poder atender grandes demandas generadas por estos mercados, mantener y potenciar las habilidades de su personal calificado. En este contexto, el desarrollo del talentohumano es un factor muy importante porque impacta directamente en la mejora de la industria de limpieza, que tiene el gran reto de la profesionalización de sus servicios.

Por su parte, la tecnología también muestra un papel importante en el desarrollo de la industria de limpieza; dado que la tecnologíatienen como finalidad preservar la salud y conservación del medio ambiente, al permitir a los empleados producir más con menor esfuerzo ygenerar productos novedosos que faciliten la vida de las personas.

Finalmente, en el mundo se ha incrementado el consumo de productos de limpieza; no sólo de insumos como los detergentes, disolventes, desinfectantes, sino también de artículos como las esponjas, fibras, guantes, y otros artículos que facilitan el aseo en el hogar y protegen la salud y estética de la piel. Precisamente, los guantes domésticos de Eterna son el principal producto que se comercializa dentro de este rubro.

c) La industria y el comercio exterior

Cesar (2016) precisa que las importaciones el Perú crecieron un 12.8\% anual de en los últimos 15 años, sumando un global de US\$326.099 millones.Este crecimientose 
sustenta en los incrementos alcanzados en los principales rubros como: los insumos, $(13,1 \%)$, bienes para el consumo $(12,8 \%)$ y bienes de capital $(12,8 \%)$.

No obstante, tras analizar los quinquenios, Cesar (2016) señaló que a inicios del año 2000 se han identificado marcadas diferencias en el desarrollo de estos rubros. Estos cambios, responden a la dinámica de los primeros componentes del gasto (consumo privado e inversión). Así, se puede observar un aumento en la compra de bienes de capital, y de bienes de consumo tal como se muestra en la Figura 1. En la Figura 2 se muestra la exportación de productos de Colombia a Perú

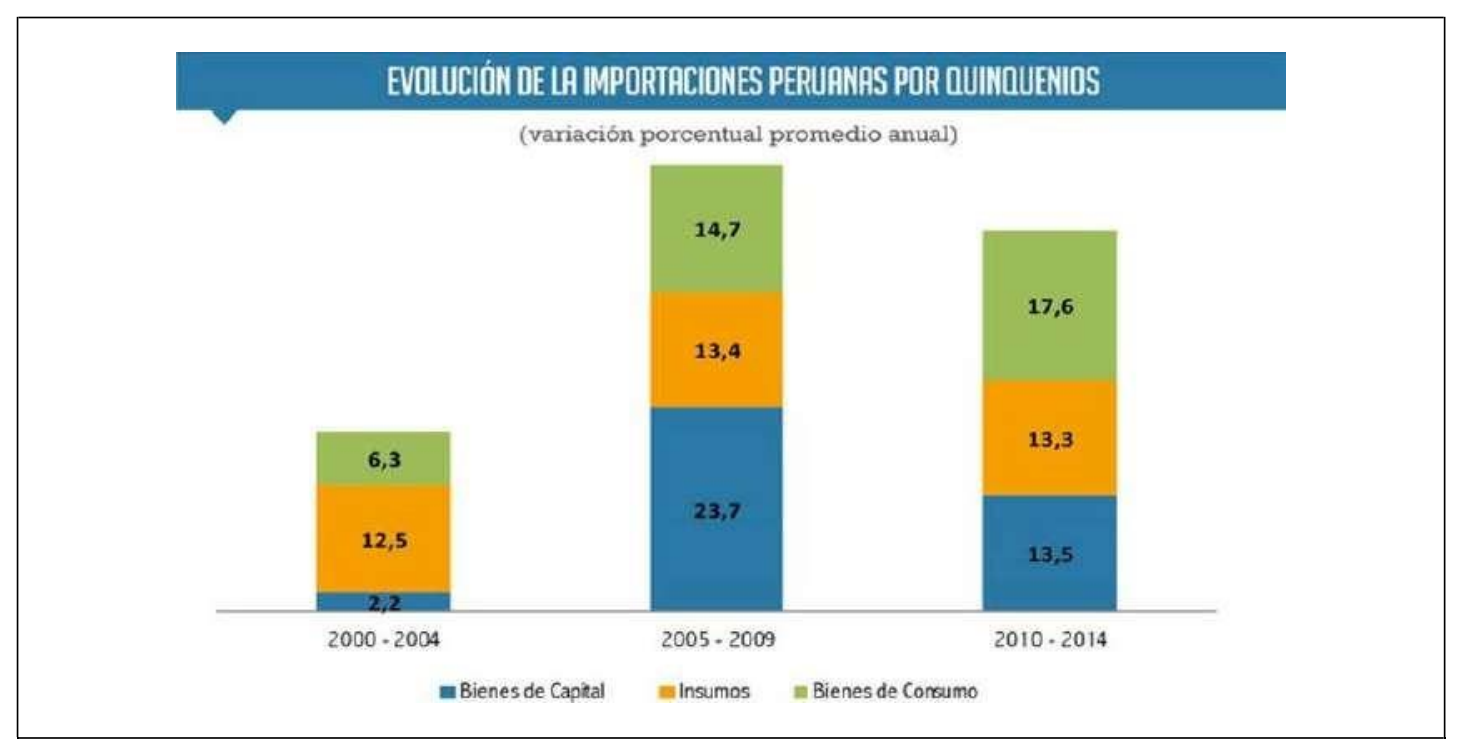

Figura 1.Evaluación de las Importaciones peruanas por quinquenios. Tomada del Banco Central de Reserva (BCR) 2014. Recuperado de http://gestion.pe/economia/importaciones-peruanas-crecieron-128-anual-ultimos-15-anos2154664 


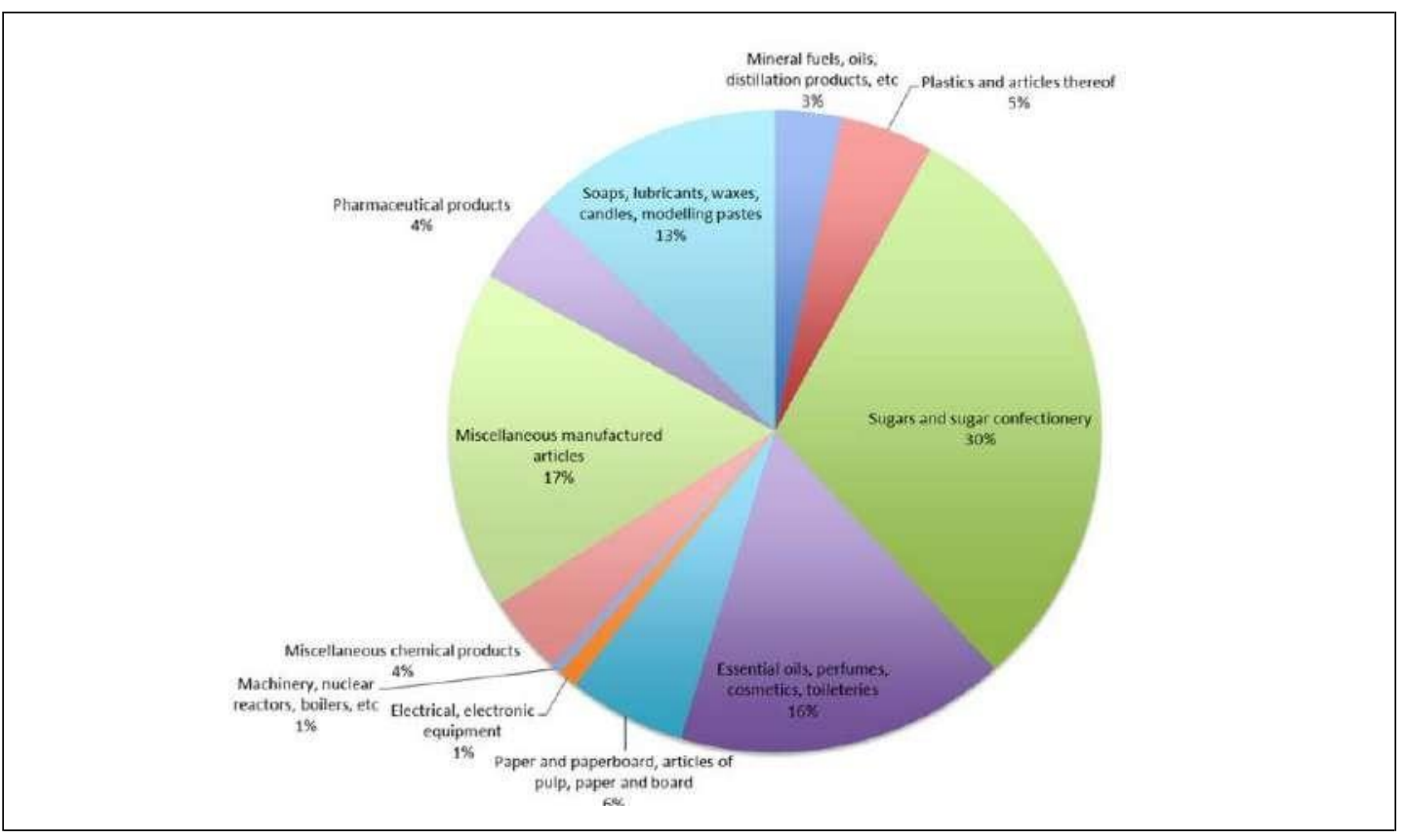

Figura 2. Exportación de Productos colombianos a Perú.

Recuperado de http://gestion.pe/economia/mas-70-exportaciones-colombia-al-peru-son-valoragregado-2083636

\subsection{Determinación del problema}

\section{Antecedentes}

En el año 2014, la empresa ETERNA Colombia decidió fundar en el mercado nacional su propia filial denominado como Eterna Perú S.A.C. La apertura de la filial fue debido a la ruptura de relaciones con su cliente exclusivo de guantes y principal distribuidor Drokasa Perú S.A.

Esta separación se generó por la entrega por parte de la matriz de Colombia de un lote con productos en mal estado a su Distribuidor principal en Perú, ocasionando que se devuelva parte de este inventario a Eterna Colombia. Frente a esta situación, el Distribuidor tomó la decisión de empezar con la venta de su propia marca en guantes para la limpieza denominada Dkasa. 
Ante la decisión de Drokasa por dar mayor participación de ventas a su propia marca, Eterna Colombia (empresa matriz), decidió constituir en Perú su propia filial, con la finalidad de atender en forma directa a los distribuidores de sus guantes.

\section{Problema}

Al terminar su relación con su principal distribuidor en el mercado nacional (Drokasa) la empresa ETERNA, ingresó al Perú a fines del año 2014 sin conocer a profundidad el mercado nacional, así como el sistema de distribución de su principal producto que son los guantes de uso doméstico.

Esta situación ha ocasionado que el volumen de ventas de la empresa Eterna Perú S.A, durante el año 2016 con relación al año 2015 se haya reducido de manera significativa (ver Figura 3), debido a la decisión de la dirección de la empresa de realizar el manejo directo de las ventas mediante su propio equipo de vendedores y sin la participación de distribuidores externos.

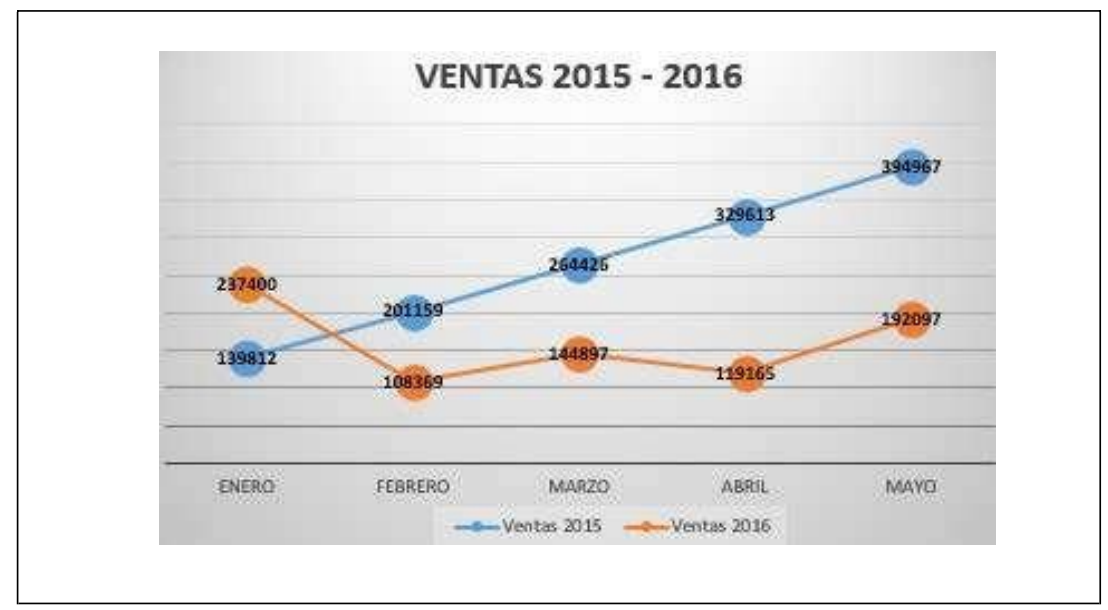

Figura 3. Ventas de Eterna Perú SAC 2015 y 2016

Tomado de "Eterna Perú SAC", 2016. 
Asimismo, esta decisión de la dirección de la empresas ha determinado que en la actualidad Eterna, haya reducido su participación de mercado en Lima, así como una presencia limitada en el mercado nacional (ver Figura 4).

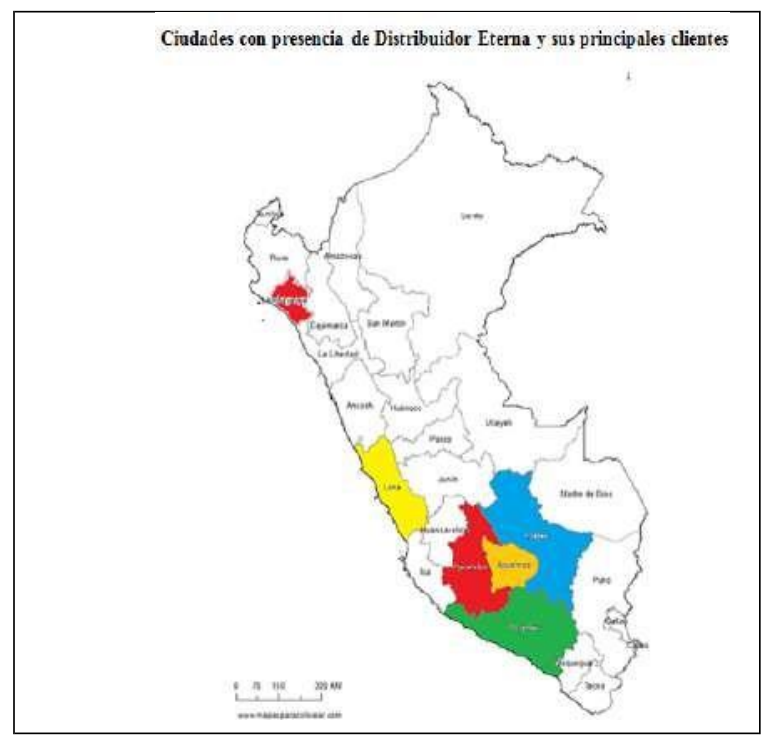

Figura 4. Ciudades con presencia de Distribuidor Eterna y sus principales clientes. Tomado de "Gerencia comercial de Eterna Perú SAC", 2016.

Asimismo, se puede señalar que partir del ingreso de la empresa a Perú se han implementado políticas y se han ejecutado actividades en las diferentes áreas de la empresa sin responder a un plan estratégico del negocio, que permita el crecimiento y desarrollo integral de la empresa.Un caso tangible son las políticas comerciales establecidas por la dirección de la empresa y que han sido implementadas por la Gerencia Comercial, que traen consigo problemas de gestión con los vendedores en la principal área del negocio.

Así por ejemplo, las políticas comerciales sin un conocimiento del mercado llevan a que un vendedor termine visitando los mismos canales de venta y establecimientos de los distribuidores, generando conflictos con los distribuidores multi-marca (son empresas dedicadas a la comercialización de productos de diversos proveedores con una fuerza de ventas especializada).Es decir, se requiere que las políticas comerciales deben tener la finalidad que los vendedores de la empresa lleguen a los canales de venta donde los distribuidores no 
tienenpresencia y generar de esta manera una mayor participación y presencia a nivel nacional de la empresa ETERNA PERÚ S.A.

Por consiguiente, a partir de lo anterior se puede señalar, que la empresa Eterna Perú S.A. enfrenta un problema de gestión al no contar con un plan general que permita establecer pautas generales para elaborar planes operativos para el área comercial y otras áreas de la empresa. Es decir, existe la necesidad de desarrollar un plan estratégico para los próximos años que sirva como un instrumento de gestión y permita tomar mejores decisiones para la administración de la empresa en el mercado nacional de aproximadamente 6 millones de soles.

También, se requiere un plan estratégico conla finalidad de establecer de una manera clara los objetivos estratégicos para los próximos años a fin que la empresa consolide su presencia en el mercado nacional. En este sentido, se considera que el plan estratégicodeberá servir de base para fortalecerlas operaciones de la empresa en el mercado nacional al establecer las pautas para desarrollar el plan de ventas, el plan para la retención del talento humano, el plan financiero, entre otros.

\subsection{Justificación del proyecto}

El proyecto para elaborar el plan estratégico de la empresa ETERNA se justifica por los siguientes aspectos:

Mercado: se buscará desarrollar un plan estratégico que permita a la empresa ETERNA Perú contar con una herramienta de gestión para alcanzar los niveles de competitividad en el mercado de productos de limpieza para el hogar especialmente en el mercado de guantes domésticos.

Asimismo, mediante el plan estratégico se busca formular una estrategia para la empresa ETERNA, que sirva de guía para el desarrollo de las actividades que se generan durante su proceso de operación. 
Gestión: se buscará formular un plan estratégico que permitiráa la empresa, establecer prácticas orientadas a lograr la competitividad en el mercado local e implementar políticas de calidad con la finalidad de lograr los objetivos de rentabilidad esperados y de participación de mercado del negocio.

También, el plan estratégico permitirá formular políticas para el área comercial acorde a los objetivos de la empresa sin generar conflictos con los distribuidores locales y más bien trabajar en programas de venta de manera conjunta.

Académica: la formulación de un plan estratégico requiere el uso de un modelo teórico que fue aprendido durante los estudios de la maestría. Así, el desarrollo del plan estratégico de la empresa ETERNA Perú, permitirá aplicar el modelo de David presentado en el curso respectivo de la maestría.

Durante el desarrollo del presente trabajo, se podrá tener un enfoque práctico sobre la elaboración de un plan estratégico que permitirá consolidar el aprendizaje obtenido sobre, el análisis estratégico, la formulación de estrategias de un negocio y su proceso de implementación en una situación real.

\subsection{Objetivos generales y específicos}

\subsubsection{Objetivo General.}

Desarrollar un plan estratégico para la empresa Eterna Perú S.A. para los años 2017 2021 con la finalidad de contar con un sistema de gestión que apoye el crecimiento sostenible del negocio. 


\subsubsection{Objetivos Específicos.}

- Determinar la situación actual de la empresa mediante un análisis interno

- Analizar el medio ambiente externo de la empresa a fin de determinar los riesgos y oportunidades del negocio.

- Definir la estrategia adecuada para la compañía con base en los resultados obtenidospor las matrices trabajadas.

- Evaluar financieramente la implementación del plan estratégico, que permita medir el impacto económico de las estrategias formuladas.

\subsection{Alcances y limitaciones de la investigación}

\subsubsection{Alcance}

El plan estratégico para la empresa Eterna Perú SAC se formula para un horizonte de proyección de cinco años. Este periodo comprende los años del 2017 al 2021.

El mercado que se analizará para el estudio es la línea de guantes de jebe para la limpieza del hogar y de la industria.

El plan estratégico se elabora con la finalidad de brindar una herramienta para gestionar la empresa ETERNA Perú con sede en la ciudad de Lima.

El plan estratégico se enfocará a plantear acciones concretas para un mayor conocimiento del mercado que permita el crecimiento de la empresa en las principales ciudades del país. 


\subsubsection{Limitaciones de la Investigación}

Establecer la situación actual de la empresa a través del análisis interno y externo podría ser afectada por la falta de información sobre los productos derivados del caucho al momento de la ejecución del presente trabajo de investigación.

El desarrollo de la evaluación financiera del plan y medir el impacto económico con base en las estrategias formuladas no podrían desarrollarse completamente por la disponibilidad de la información financiera actualizada de la empresa.

El estudio del mercado nacional y de la competencia no se podría llevar a cabo de manera amplia dado que la base de datos de las compañías dedicadas al rubro limpieza del hogar está incompleta y en su mayoría no está actualizada, así como existe poca información bibliográfica y virtual del sector de guantes para limpieza del hogar en el país.

El análisis externo del negocio, la evaluación de la competencia y el estudio de la industria seránrealizadas principalmente a partir de la informaciónque se obtenga de fuentes primarias, la que está limitada a la disponibilidad de los expertos en el negocio y de los gerentes de los principales competidores para realizar las entrevistas a profundidad. 


\section{Capítulo 2 La empresa}

Eterna S.A. fue fundada hace más 60 años en Colombia. En Perú viene operando desde el año 2015 como Eterna Perú S.A. Esta empresa tiene como propósito atender las necesidades del consumidor con productos de limpieza del hogar en diferentes categorías, además, cuenta con productos para aseo mecánico, protección física y desinfección.

\subsection{Antecedentes de la empresa}

Eterna S.A. nace en 1953 cuando un inmigrante Austriaco llamado Heinz Husserl junto con un grupo de empresarios colombianos funda en la ciudad de Bogotá una fábrica para la preparación de productos a base de caucho, iniciando operaciones con una docena de personas, un gerente, una secretaria, un supervisor y ocho obreros. En sus inicios producen pelotas de caucho para la temporada navideña, un año después empieza a diversificar y adicionan en sus líneas el rencauche de llantas, suelas para zapatos y otras láminas a base de caucho; años más tarde Eterna empieza a desarrollar productos a base de látex natural, entre estos productos destacan los guantes de uso domésticos y guantes para cirugía medica; a través de estos años Eterna ha desarrollado su portafolio y mejorado sus procesos bajo estándares de la más alta calidad.

En 1957 desarrolló un pegamento comercial para la industria del calzado, con este producto complementó su línea de suelas y láminas para esta industria y se convirtió en el principal producto de venta de la compañía y único en el país hasta el año 1961. Mientras, que 
en los años 60's monta la primera línea de extruidos y empieza con la fabricación de perfiles y mangueras de caucho para abastecer el mercado automotriz en el ensamble de autobuses y en la construcción.

En 1963 empieza su internacionalización en los mercados de Perú y Ecuador; para el año 1987 incursiona con productos a base de plástico con su línea para bebes. Para los años noventa y con el crecimiento de la compañía reafirma su posición de liderazgo en el mercado con un enfoque comercial en tres grandes áreas: Consumo de aseo en el hogar, médicohospitalario e insumos industriales; con la gran oportunidad del mercado Eterna adquiere una firma de paños y fibras para aseo doméstico. En el año 2002 inicia un ambicioso proyecto de instalación de una planta de producción de líquidos para limpieza y ceras, con esto se especializa en productos relacionados con labores de aseo a nivel doméstico e institucional.

En Perú, Eterna es conocida principalmente por su línea de guantes domésticos y para la línea industrial con la marca Protex. Los productos de la empresa en Perú fueron comercializados por dos grandes distribuidoras situadas en Lima:

(a) Drokasa S.A., encargada de la venta de guantes para la línea doméstica incluyendo los paños y fibras

(b) Plesa S.A., encargada de la venta de los guantes Protex enfocado en la industria.

A finales del 2014 la matriz retira la distribución de la línea doméstica a Drokasa para constituir una filial en Perú, llamándola Eterna Perú SAC, esto debido a que Drokasa no estaba manejando la línea de guantes domésticos como se esperaba. Mientras quea la fecha de la 
elaboración del presente estudio en el caso de Plesa SA, la empresa continúa con la distribución de los guantes Protex para fines industriales.

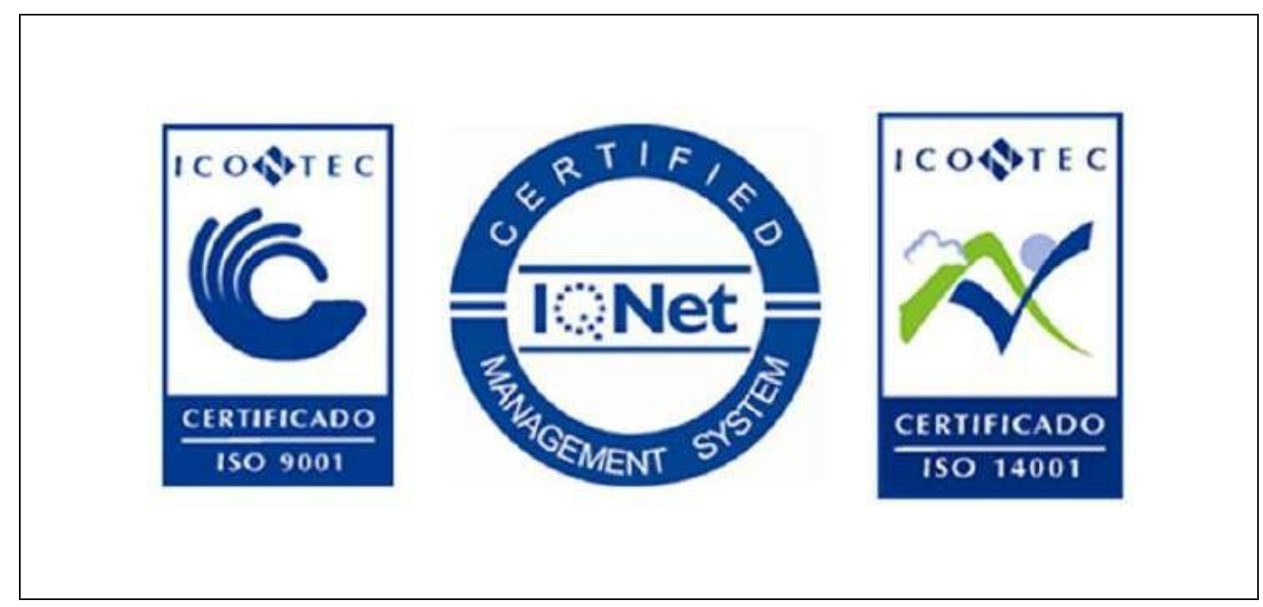

Figura 5.Certificaciones en Calidad Eterna

Tomado de "Certificaciones de calidad", Eterna, 2011. Recuperado de http://www.eterna.com.co/index.php?option=com_content \&view=article\&id=29\&Itemid=115 \&lang=es

Para enero del 2015 Eterna inicia operaciones con la cartera de clientes atendidos en su momento por Drokasa. Los productos que ofrece Eterna en el Perú, tienen estándares de calidad muy altos, además de certificaciones de calidad externas como ISO 9001:2000 expedida por el ICONTEC, que respalda la calidad en todos los procesos de producción (ver Figura 5).

\subsection{Descripción del negocio}

Eterna S.A. cuenta con cuatro plantas en Colombia para la confección de artículos para limpieza del hogar, industria y hospital; hechos a base de látex de caucho y plásticos. Las plantas son de última tecnología, que producen el $65 \%$ de los productos que comercializa en el mercado. La diferencia porcentual de los productos que ofrece se completa con los que envían 
los proveedores con sedes en Asia y Europa; debido a estos factores Eterna S.A. maneja precios muy competitivos en los mercados donde la empresa atiende, ofertando producto con muy alta calidad.

La compañía ofrece al mercadocolombiano, ecuatoriano y peruano los siguientes productos (ver Figura 6):

- Guantes domésticos: Producidos para realizar tareas en el hogar, como por ejemplo, lavado de platos, limpieza interior y exterior, trabajos menores de refacción, corte, etc. Son elaborados en látex de alta duración y calidad, con diferentes beneficios tales como aromas, texturas, espesores y colores.

- Guantes quirúrgicos: Ideales para el uso de exámenes médicos, odontológicos, servicios de hospitalización, gastronomía y para el trabajo de tintes para el cabello.

- Guantes Industriales: Ideales para industria, agronomía y seguridad industrial; su presentación son en diferentes calibres (espesores), generalmente de color negro.

- Esponjas Multiusos: Especialmente diseñados para lavar utensilios, superficies lisas como loza, cristales, utensilios de la cocina y de hogar.

- Fibras abrasivas: Ideales para lavar superficies muy sucias y fuertes donde es imposible raspar porque genera daño a la piel y al utensilio.

- Paños multiusos: Ideales para secar eficazmente cualquier tipo de superficie o utensilio.

- Esponjas Metálicas: Espaciales para raspar utensilios metálicos o de acero inoxidable. 


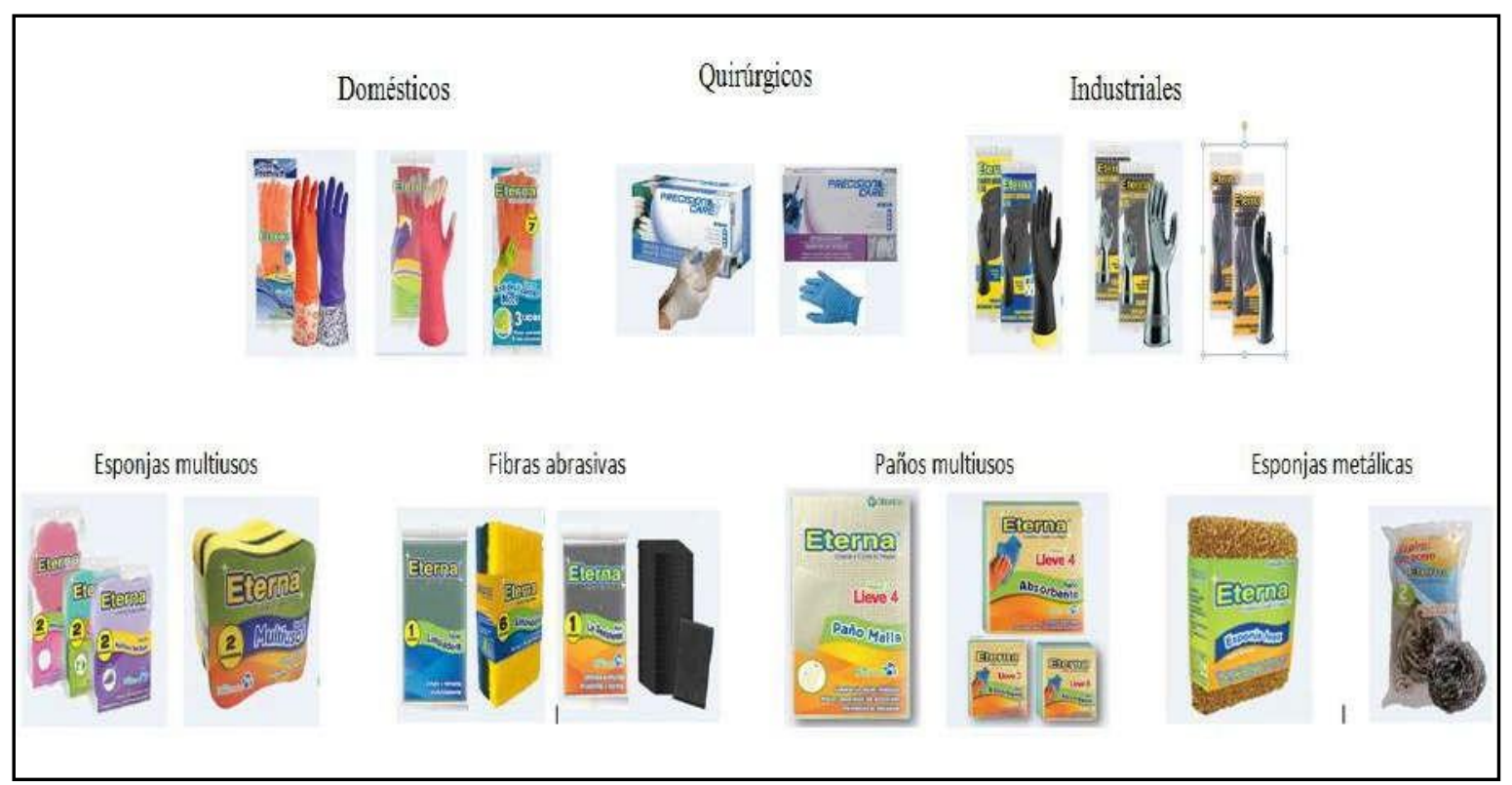

Figura 6. Linea de Productos de Eterna

Tomado de "Línea de productos," por Eterna, 2011. Recuperado de http://www.eterna.com.co/index.php?option=com_content $\&$ view=article \&id=9\&Itemid=3\&lan $\mathrm{g}=\mathrm{es}$

El guante de látex representa para la empresa un $80 \%$ de las ventas, dado que es un producto de muy alta rotación utilizado para el cuidado de las manos contra elementos químicos. Actualmente, cada vez son más personas que lo utilizan en los siguientes sectores: (a) El sector salud, llamados también guantes de examen, su finalidad es protegeral personal de transmisiones de enfermedades, reacciones químicas, aguas tratables y gases medicinales (b) Sector de limpieza del hogar u otros, fabricados en base de látex y plástico, cuidan las manos del ama de casa en las actividades diarias

En la actualidad, los productos de Eterna son comercializados por tres canales (puntos de venta) liderados por un gerente comercial, estos canales son: 
- Canal moderno: Establecimientos donde los protagonistas son los principales operadores comerciales como: (a) autoservicios, (b) home center, (c) club mayorista, (d) tiendas de conveniencia, (e) cadenas de farmacias.

- Canal tradicional: Son locales donde se existe más variedad y adaptación al mercado local como: (a) bodegas, (b) puestos de mercado, (c) mayoristas, (d) ferreterías, (e) farmacias del canal tradicional.El canal Tradicional representa el 70\% del peso de la venta de la compañía enfocada en seis campos: (a) Atención a distribuidores, venta realizada a distribuidores multi-marca y con fuerza de ventas propia; (b)Venta directa minorista, venta realizada a mercados menores donde no llega el distribuidor; (c) Mayoristas, clientes, en zonas mayoristas definidas de Lima con grandes volúmenes de venta; (d) Venta institucional, realizada a clientes o industrias las cuales no comercializan los productos,: empresas de limpieza, entidades gubernamentales y agroindustrias (e) Venta industrial, venta de productos a base de caucho para la construcción y automotriz, perfiles para vidrios y ventanas, jebes, topes, retenes; (f) Venta médica, venta de guantes quirúrgicos y jeringas descartables a distribuidores de productos médicos, clínicas y hospitales.

- Canal industrial: En este mercado se tiene como clientes a empresas de los siguientes rubros: (a) industria automotriz, (b) industria de la construcción.

\subsection{Ciclo de vida del producto}

Cyry Gray (2003) definen el ciclo de vida como un periodo determinado, donde los productos tienen un valor de vida limitado en el mercado que la empresa se desarrolla, cada etapa representa para la organización diferentes oportunidades y problemas.Así, el ciclo de vida 
brinda un útil modelo que permite al área de Marketing evaluar diferentes estrategias, las cuales son implementadas dependiendo de la etapa del ciclo en que se encuentra el producto.

Por su parte, Kotler y Armstrong (2012) definen el ciclo de vida como la colocación de un nuevo producto en el mercado, el principal objetivo de este producto es que experimente y disfrute de una prolongada y exitosa existencia en el mercado. Aunque no hay expectativa de que el bien tenga unas ventas perpetuas, la compañía sí quiere lograr un beneficio que cubra toda la inversión y el riesgo que asumieron al lanzar al mercado el producto. El directorio y gerencia son conscientes de que el bien tendrá un ciclo de vida, aunque su extensión y forma no se conozcan de antemano.

El ciclo de vida tiene cinco etapas bien definidas (ver Figura 7), que muestran el curso que sigue un producto y su evolución en ventas y utilidades, estas son:

- Desarrollo del producto: Esta etapa inicia en el momento en que la empresa nace con una idea de producto y esta es desarrollada por el área de investigación y desarrollo. En esta etapa no existen ventas y los costos de inversión de la compañía va en aumento continuo; puede el producto tener un lanzamiento o se puede mantener su estudio y desarrollo por tiempos prolongado hasta cubrir toda imperfección.

- Introducción: Etapa en la cual existe pococrecimiento de las ventas del producto tras su lanzamiento al mercado debido a que aún no está posicionada en la mente del consumidor o simplemente tiene desconocimiento del producto en el mercado. Los 
beneficios y utilidades son mínimas en esta fase por los altos costos de introducción y la publicidad que se hace del bien o servicio para su lanzamiento.

- Crecimiento: Etapa de una ágil aceptación en el mercado, se inicia la producción del producto con base a la demanda de los cliente; se diversifica el producto realizando varios modelos; aquí se establece un precio alto y también aparece la competencia, la publicidad se hace al usuario en general; en esta etapa se experimenta el aumento de las utilidades y beneficios de la empresa.

- Madurez: Etapa en la cual disminuye el crecimiento de las ventas y se llega a un momento en que no se puede aumentar más las producción; la publicidad debe ser agresiva para conservar la atención del mercado por los productos. Las utilidades se mantienen, no se experimenta un crecimientoen las utilidades o caen por el desembolso de publicidad y se realiza la implementación de otras estrategias de marketing para defender el producto de la competencia.

- Decadencia: Periodo en que las ventas disminuyen en gran proporción, primero se reduce el precio del producto para lograr alguna venta y consecutivamente se abandonará el producto. Las utilidades de la compañía también caen a una etapa que no cubre los costos de producción. 


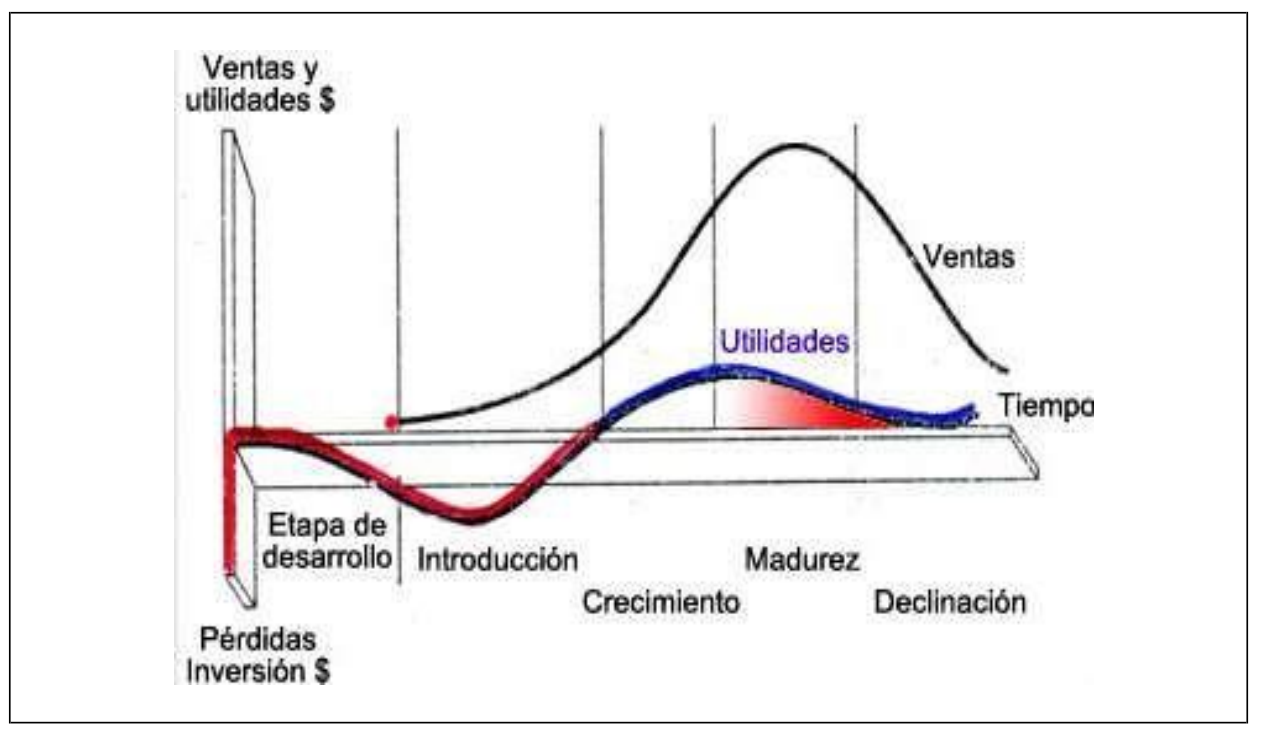

Figura 7. Ventas en cada etapa.

Tomado de "Ciclo de Vida del Producto," por Juan Vigil Quijano (2016). Recuperado de http://www.monografias.com/trabajos69/ciclo-vida-producto/ciclo-vida-producto2.shtml

Con base a la información proporcionada por la gerencia de finanzas de la empresa (ver Tabla 1), se ha identificado las tendencias de la ventaen la que se encuentra los guantes de látex, con el objetivo de que la gerencia de Marketing identifique la evolución de las ventas en el mercado.

Tabla 1

Ventas de Guantes de Latex2012 al 2016 en US. \$

\begin{tabular}{lrrrrr}
\hline & $\mathbf{2 , 0 1 2}$ & $\mathbf{2 , 0 1 3}$ & $\mathbf{2 , 0 1 4}$ & $\mathbf{2 , 0 1 5}$ & $\mathbf{2 , 0 1 6}$ \\
\hline PLAN ENTERPRISE S.A. & $2,420,611$ & $1,844,655$ & $2,454,192$ & $1,911,174$ & $2,289,359$ \\
\hline DROKASA PERU S.A. & $1,273,178$ & $1,275,778$ & $1,001,385$ & 500,985 & 531,495 \\
\hline ILKO PERU S.A.C. & $1,249,021$ & $1,887,807$ & $2,010,363$ & $1,761,828$ & $1,379,157$ \\
\hline CAPLAN S.A.C. & 63,180 & 191,253 & $1,144,340$ & $1,276,768$ & 947,783 \\
\hline 3M PERU S A & 571,320 & 591,365 & 462,030 & 380,483 & 306,561 \\
\hline TOTAL & $5,577,309^{\prime \prime}$ & $5,790,858$ & $7,072,311$ & $5,831,237$ & $5,454,354$ \\
\end{tabular}

Nota. Elaborado con datos de Eterna Perú S.A.C. 


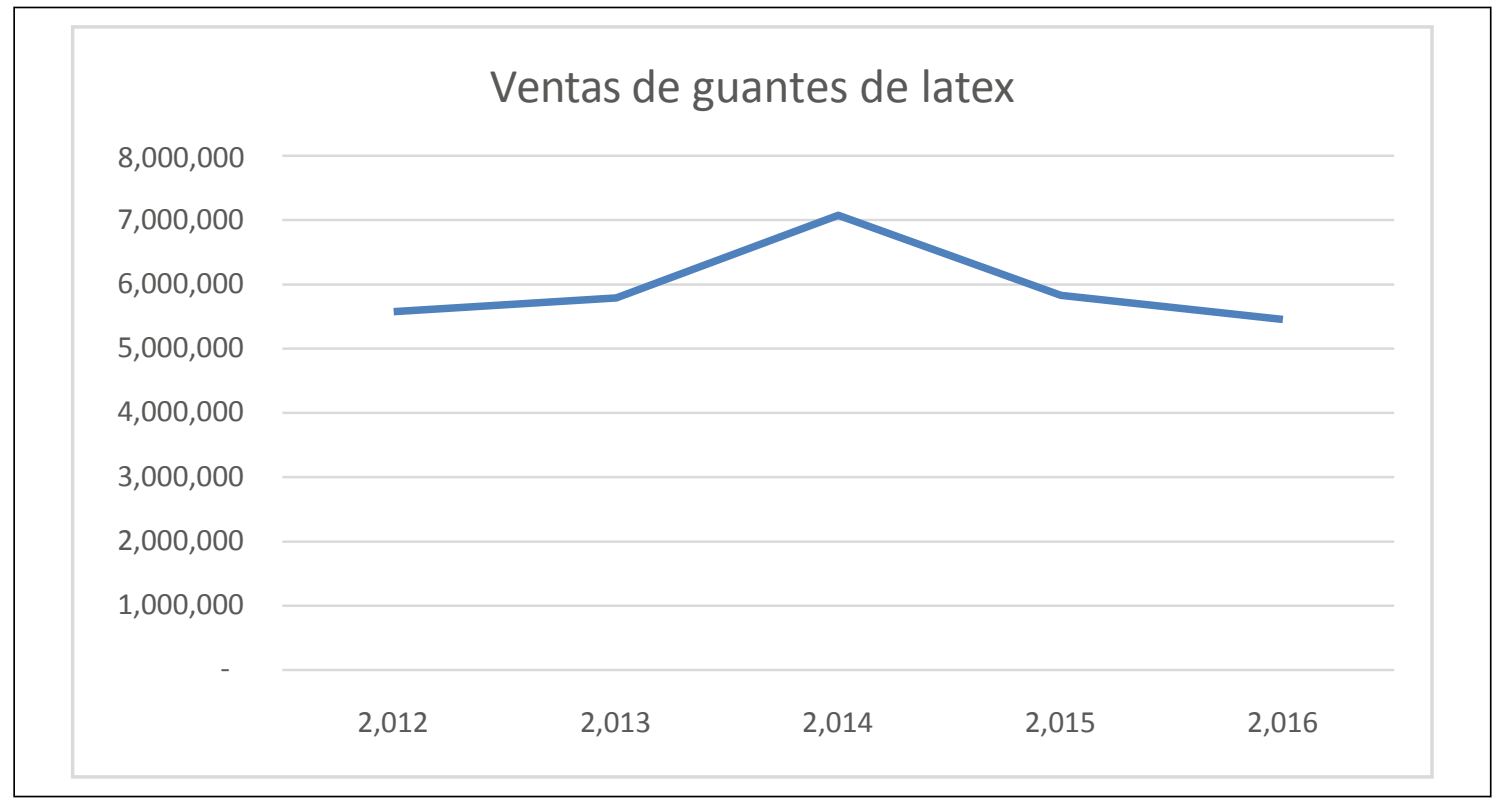

Figura 8.Ventas 2012 al 2016

Nota.Elaborado con datos de Eterna Perú S.A.C.

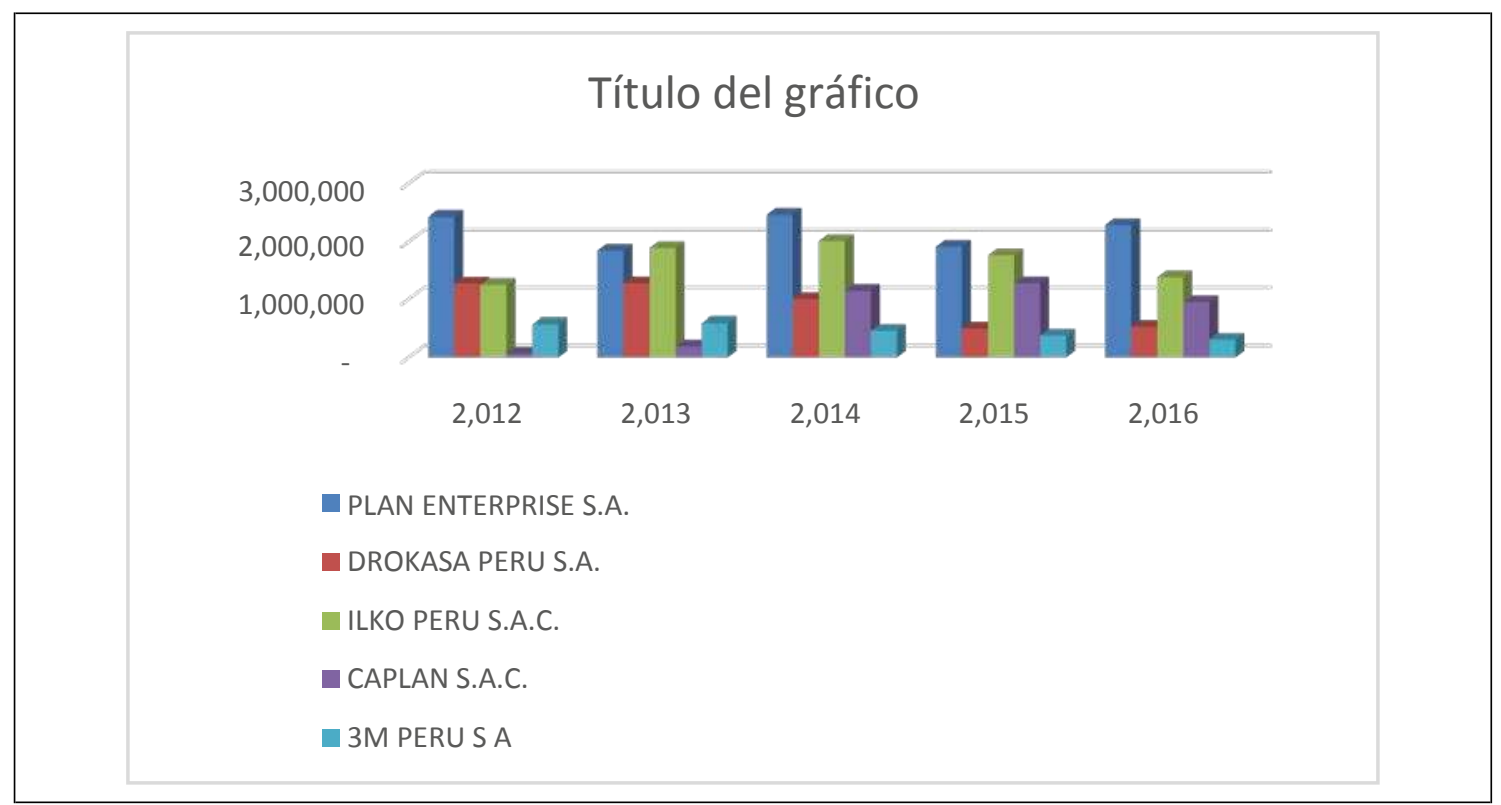

Figura 9. Ventas de las principales empresas 2012 al 2016 Nota. Elaborado con datos de Eterna Perú S.A.C. 
Actualmente en el mercado nacional, se considera que losguantes fabricados de látex, se encuentran enuna etapa de madurez (ver Figura 10).El sustento para realizar esta afirmación se basa en las ventas de la industria en los tres últimos años:

- Las ventas de la industria en unidades de productos son las siguientes

$$
\begin{array}{ll}
2,012 & 5,577,309 \\
2,013 & 5,790,858 \\
2,014 & 7,072,311 \\
2,015 & 5,831,237 \\
2,016 & 5,454,354
\end{array}
$$

Asimismo existen otros hechos que se observan en el mercado y que permiten respaldar la afirmación sobre el ciclo de vida de la industria.

- Existenmuchos competidores en el mercado

- Las utilidades se mantienen constantes

- No se produce un crecimiento de la utilidad o caen por el desembolso de publicidad y otras estrategias que realizan las aéreas de marketing para defender el producto de la competencia.

- Las empresas que ofrecen este productoestán cada vez más agresivas por mantener un porcentaje de participación (ver Tabla 2) 
Tabla 2

Análisis de cada ciclo de vida del producto

\begin{tabular}{lll}
\hline Etapas del ciclo & Competencia & Ventas y Beneficios \\
\hline Desarrollo & Pocos competidores & $\begin{array}{l}\text { No existen ventas y los costos de inversión } \\
\text { van en aumento }\end{array}$ \\
Introducción & Pocos competidores & $\begin{array}{l}\text { Poco crecimiento en ventas } \\
\text { Utilidades son mínimas }\end{array}$ \\
\hline Crecimiento & Muchos ingresantes & $\begin{array}{l}\text { Aceptación en el mercado } \\
\text { Aumento de las utilidades y beneficios }\end{array}$ \\
Madurez & Competencia agresiva & $\begin{array}{l}\text { Disminuye el crecimiento de las ventas } \\
\text { Las utilidades se mantienen }\end{array}$ \\
Decadencia & Pocas competidores & $\begin{array}{l}\text { Las ventas disminuyen en gran proporción } \\
\text { Las utilidades también caen }\end{array}$ \\
& & \\
\hline
\end{tabular}

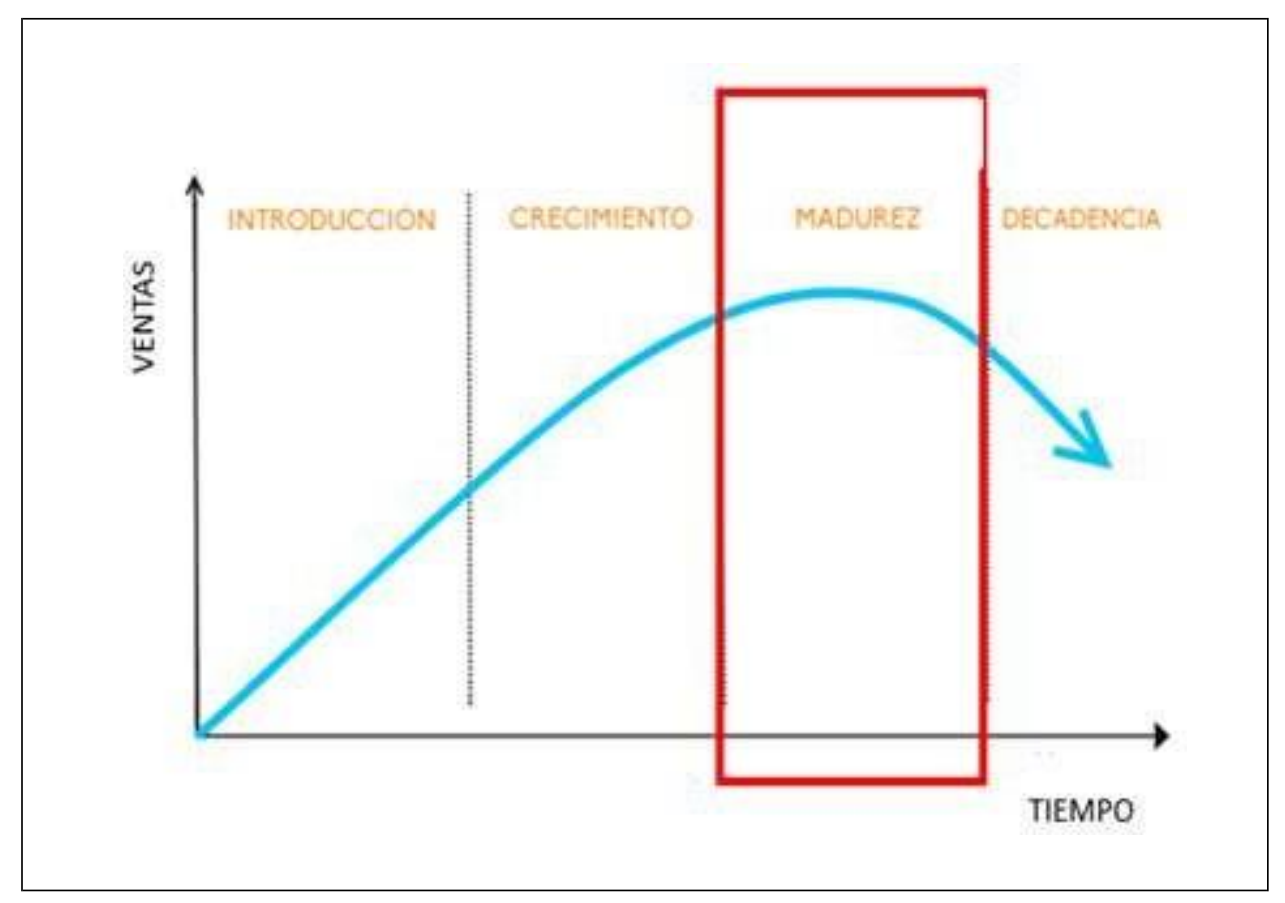

Figura 10.Ciclo de vida del producto.

Tomado de Marketing en la pequeña y mediana empresa (p. 83), por Donald Cyr\& Douglas Gray, 2003, Bogotá: Editorial Norma. 2004. 


\subsection{Estructura organizacional actual de la empresa}

En esta etapa se presenta el organigrama de Eterna Perú, actualmente vigente. La estructura organizacional fue elaborada en el 2014 por la administraciónde ese momento (ver Figura 11).

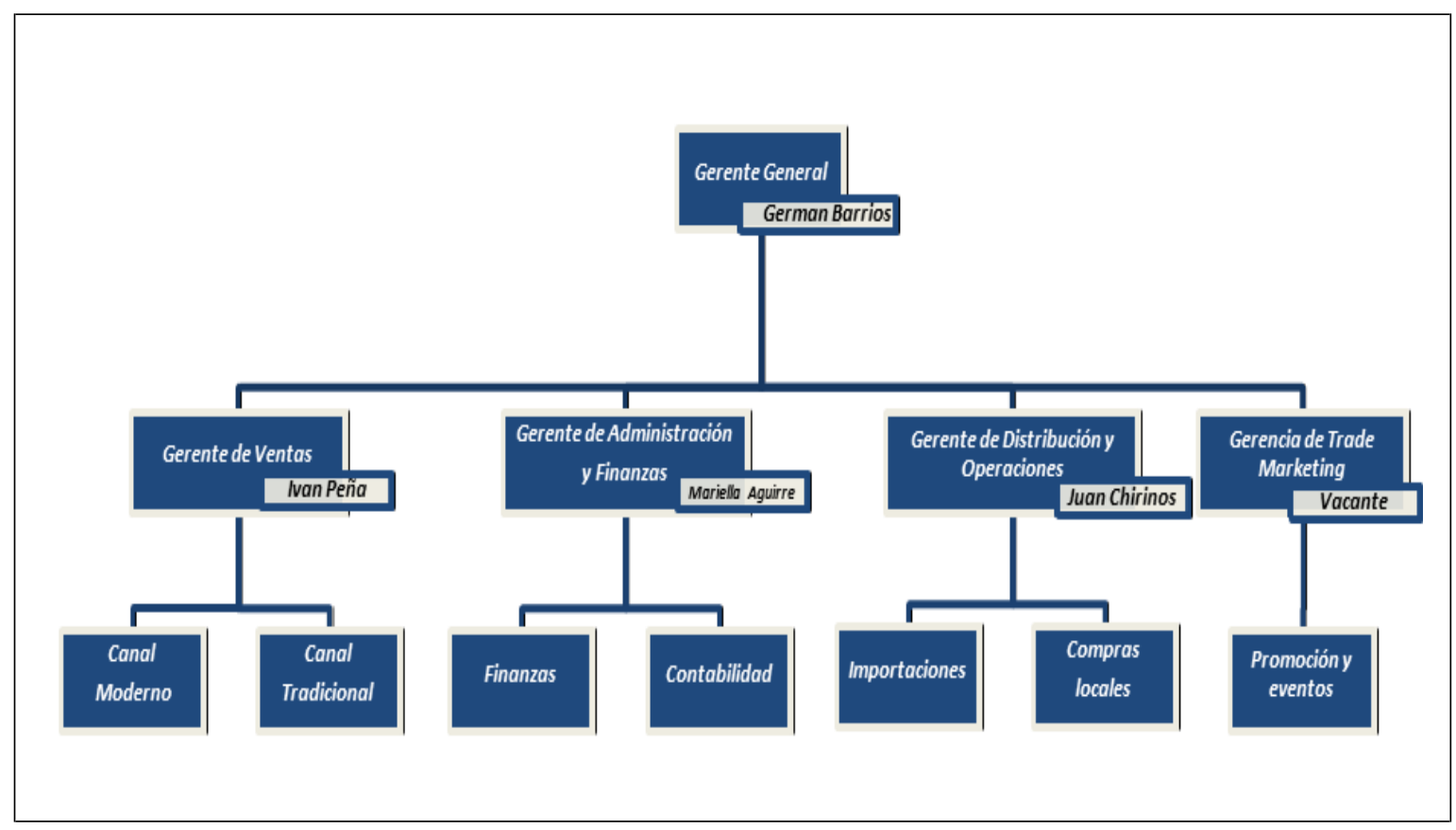

Figura 11. Organigrama de Eterna Perú S.A.C.

Eterna Perú es una subsidiaria de Eterna Colombia por tal motivo la oficina de Perú es responsable de rendir los resultados a la alta dirección en Colombia la cual está conformada por un Presidente de Directorio, el director de ventas y el director de finanzas, estos representan a los accionistas de la compañía. Estos representantes se reúnen periódicamente para evaluar los resultados de la empresa, revisar nuevas propuestas y los resultados de la subsidiaria en Lima presentados por la Gerencia General de Eterna Perú. 
La estructura organizacional de Eterna Perú se puede definir como una estructura organizacional funcional. De acuerdo a Daft (2015) las actividades en el organigrama se pueden agrupar por funciones comunes del nivel inferior al superior de la organización como es el caso de Eterna Perú. Por ejemplo en el área de ventas están agrupadas todas las actividades comerciales, lo mismo ocurre para las áreas que se encargan de las actividades de administración, logística y marketing.

\section{Funciones del personal de Eterna Perú}

A partir de la estructura actual, se procede a describir las funciones de cada ejecutivo de la organización y sus principales responsabilidades.

1. Gerencia General: Reporta al Directorio de Colombia, sus funciones son dirigir y administrar la subsidiaria de Perú, siguiendo las políticas, valores de la compañía y lineamientos que el Directorio le brinda para el logro de los objetivos, busca la mayor efectividad posible para la organización, se reúne constantemente con las gerencias de soporte para tener información de cómo vienen evolucionando el negocio.

Actualmente es el Representante Legal de la empresa ante la SUNAT y tienen facultades para representar a la compañía en muchas etapas del negocio como licitaciones, eventos gubernamentales, representar a la empresa en nuevos mercados internacionales. Asimismo, asume responsabilidades y cuentas con facultadas para gestionar con autoridades públicas y otras de índole empresarial. 
2. Gerente de Ventas : Reporta al Gerente General, es la persona encargada de dirigir, organizar y controlar el departamento de ventas; preparar planes y presupuestos de ventas para el año en ejercicio, encargado de establecer las metas y objetivos para el cierre del año del área, realizar un cálculo de la demanda y establecer un pronóstico de ventas; con base en lo anterior debe gestionar y determinar el tamaño de su fuerza de ventas y ver el reclutamiento, selección y capacitación continua de los vendedores, establecer las cuotas de ventas mensuales y crear los estándares de desempeño, evaluar el trabajo de los colaboradores y monitorear los canales de venta (tradicional y moderno).

3. Gerente de Administración y finanzas: Reporta al Gerente General, sus funciones son velar por la evolución financiera del negocio, coordinar con los contadores la elaboración de los flujos y estados de ganancia y perdidas de la compañía, firmar los cheques de gerencia para el pago a los proveedores, plantear a la gerencia general el plan anual de adquisiciones, formular y proponer el presupuesto anual, gestionar y coordinar la administración de bienes, alquiler, servicios generales, proponer el presupuesto para el pago de planillas, aprobar el plan para la capacitación del colaborador en coordinación con las demás gerencias, plantear a la gerencia general el reglamento interno de trabajo para la compañía.

4. Gerente de Distribución y Operaciones: Reporta al Gerente General, es responsable de las operaciones diarias de la empresa. El propósito de su labor es encontrar los modos para hacer a la compañía más productiva facilitando métodos efectivos para los 
procedimientos de la empresa. Sus principales funciones dentro de la compañía es la de preparar presupuestos de productos a importar, maneja la logística de importaciones y su logística integral una vez llegada la mercadería a puerto de destino, controlar el inventario de los productos cuando lleguen al almacén, gestionar las compras locales, supervisión continua de los empleados en sus funciones encomendadas, retroalimentación a los colaboradores que lidera, coordinar con los operadores que realizan los servicios de maquila y por ultimo supervisar y manejar los ingresos de los productos a los almacenes de los clientes.

5. Trade Marketing: Reporte al Gerente General, sus funciones son: verificar que las estrategias establecidas sean ejecutadas en los establecimientos del cliente, elaborar estrategias y promocionar al cliente el merchandising, cuyo fin es fidelizar al cliente; comunicar los futuros eventos y lanzamientos de nuevos productos, conocer los perfiles del producto para comunicarlos al cliente y consumidor, asumir la toma de decisiones en temas de distribución, conseguir espacios en los puntos de ventas para exhibir la marca de manera eficiente para lograr los objetivos de la compañía, reconocer las decisiones de compra en los establecimientos, desarrollar promociones atractivas para el cliente y consumidor final y generar promociones de venta para incrementar la participación de mercado.

6. Contabilidad, sistemas y legal: La empresa actualmente contrata los servicios de outsourcing especializados para realizar estas actividades. De acuerdo a Daft (2015), Outsourcing se refiere a la contratación de ciertas tareas o funciones a otras empresas. 
Estas actividades son supervisadas continuamente por la gerencia de administración y finanzas quien recibe los reportes de estas empresas especializadas. En Eterna se considera que estas actividades son de soporte y deben ser vistas por profesionales especialistas, dado que la compañía quiere enfocarse en los puntos críticos que generan valor para la organización.

Tabla 3

Listado de los profesionales de Eterna

\begin{tabular}{|c|c|c|c|}
\hline $\mathrm{N}^{\circ}$ & Cargo en la empresa & Personal & $\begin{array}{c}\mathrm{N}^{\circ} \text { de } \\
\text { empleados }\end{array}$ \\
\hline 1 & Gerente General & & 1 \\
\hline \multirow[t]{9}{*}{2} & Gerencia de ventas & & 1 \\
\hline & Canal Moderno & Kam & 1 \\
\hline & & Ejecutivo & 1 \\
\hline & & Promotoras & 3 \\
\hline & Canal Tradicional & Kam & 1 \\
\hline & & Ejecutivo & 2 \\
\hline & & Promotor Sénior & 4 \\
\hline & & Promotor & 8 \\
\hline & & Asistente Comercial & 1 \\
\hline \multirow[t]{5}{*}{3} & $\begin{array}{l}\text { Gerente de Administración } \\
\text { y Finanzas }\end{array}$ & & \\
\hline & & Controler & 1 \\
\hline & & Asistente de Finanzas & 1 \\
\hline & & Facturación & 1 \\
\hline & & Cobranzas y Tramite & 1 \\
\hline \multirow[t]{3}{*}{4} & $\begin{array}{l}\text { Gerente de Distribución y } \\
\text { Operaciones }\end{array}$ & Documentario & 1 \\
\hline & & Jefe de Logística & 1 \\
\hline & & Asistente de Logística & 1 \\
\hline
\end{tabular}




\begin{tabular}{lllc}
5 & Contabilidad & Contador & 1 \\
& & Asistente contable & 1 \\
6 & Gerente de Trade Marketing & & 1 \\
7 & Sistemas & Externos & $-/-$ \\
8 & Legal & Externos & $-/-$ \\
9 & Auditoría Contable & Externos & $-/-$ \\
\hline
\end{tabular}

\subsection{Situación de mercado y financiera actual de la Industria.}

La industria de fabricación de productos de tocador y limpieza está ubicada en la clase CIIU 2023 (Clasificación Industrial Internacional Uniforme). Esta clase industrial comprende las actividades de fabricación de jabón, detergentes para lavar en polvo o líquidos, lavavajillas, productos para limpiar y pulir, preparados para perfumar y desodorizar ambientes, y, perfumes y preparados de tocador, entre otros productos.

De acuerdo a la información, los productos que marcan la tendencia de este sector industrial, son los detergentes los que tienen un mayor peso en la estructura sectorial, además de los jabones para ropa, jabones de tocador, limpiadores y lavavajillas, entre otros. En los últimos años, la mayor fabricación de productos de tocador y artículos de limpieza, ha estado relacionada a la mejora en los ingresos de la población, que ha impulsado una mayor oferta y renovación de productos, nuevas marcas y formatos de presentación, requiriendo una mayor inversión de las empresas. En este sentido, la capacidad instalada de las industrias de este sector, se ha venido incrementando los últimos años, cerrando el año 2013 con una tasa de utilización del 81,4\% (Banco Central de Reserva del Perú BCRP). 
La Sociedad Nacional de Industrias (SIN), en un reporte del 2014 sectorial, presentó la situación de la industria de Fabricación de Productos de Tocador y Limpieza (ver Anexo 11.Esta industria experimentó un crecimiento de 7,4\% en el año 2014, ligeramente menor al registrado en similar período del año anterior cuando creció en 9,5\%.

Para el año 2015 el crecimiento continuo y llego a un valor de más de 57 millones. En el año de 2016 las ventas del sectoren el mercado se estiman pueden continuar con la misma tendencia, dado que hasta mayo las ventas son casi un 50\% de las ventas del año anterior, tal como se puede apreciar en la Figura 12. Por tanto, las ventas del año 2016se estima puede ser mayores a las ventas del 2015. Es decir, la tendencia de crecimiento se prevé debe continuar en los próximos años.

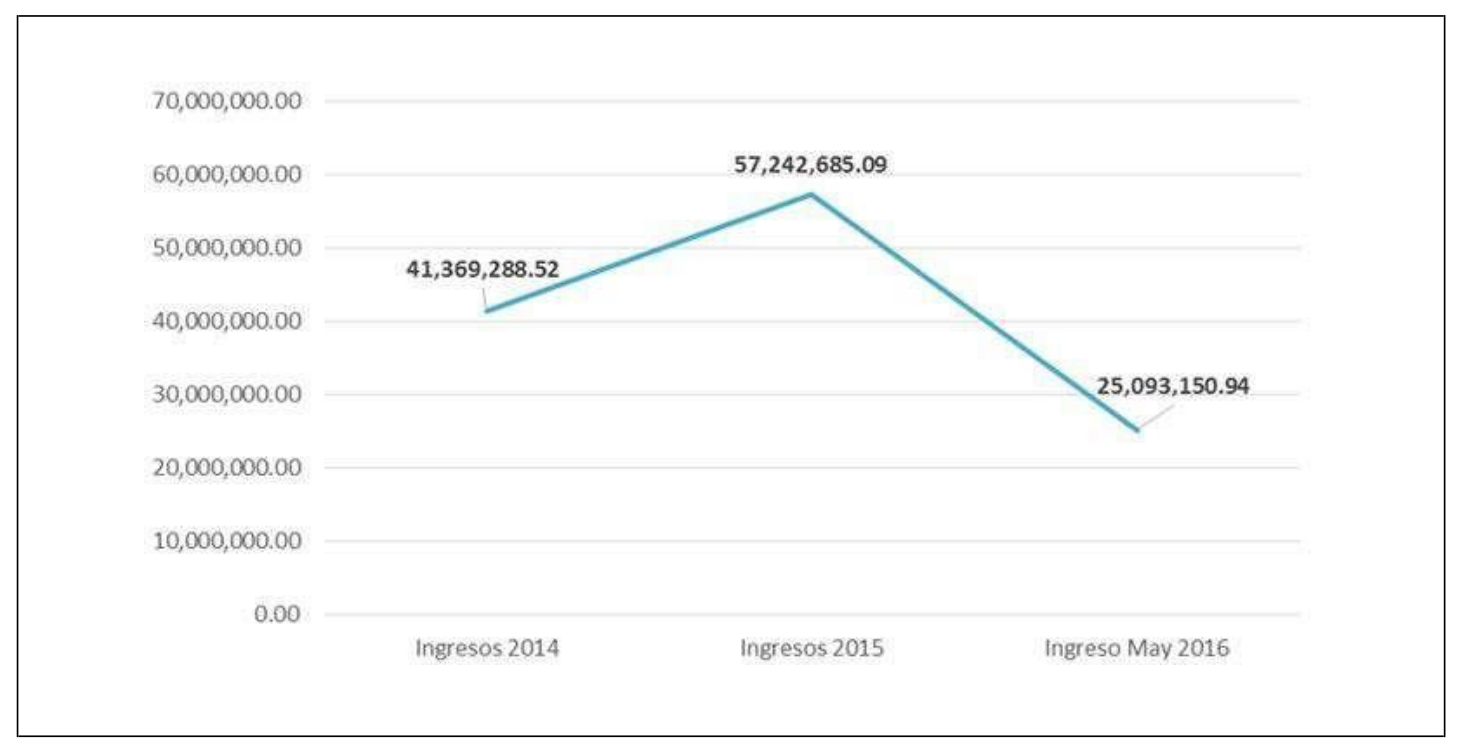

Figura 12. Comparativo de utilidad por ventas en el sector 2015 vs 2016 Nota.Elaborado con datos de Eterna SA. 
En el Perú se venden S/.2 mil millones de soles en productos de limpieza y cuidado personal, donde la clase media impulsa la demanda. Productos como el jabón en líquido, el enjuague bucal y los paños húmedos se incorporaron a la canasta de consumo. Hasta hace algunos años, el consumidor peruano solo compraba detergente y lejía, hoy además lleva ambientador para el hogar y jabón líquido para el lavado de manos.

La industria de los artículos de limpieza del hogar está conformada en promedio por más de diecisiete empresas, donde ocho compañías tienen la mayor participación de mercado, (ver Tabla 4) ycada una representa ingresos por más de cinco millones de soles anuales en promedio; luego viene la participación de las pequeñas empresas que tienen anualmente un promedio de ingreso de un millón y medio de soles anuales.

Eterna Perú es una empresa importadora y distribuidora de artículos de limpieza del hogar, el producto que actualmente representa el $80 \%$ de sus ventas en el mercado son los guantes de látex bajo la marca Eterna. En el mercado Eterna Perú (Kaplan) en la actualidad se ubica en el sexto lugar teniendo ingresos por encima de un millón de soles en promedio anualmente.

A partir de lo anterior, se puede señalar que el consumo de guantes para la limpieza del hogar se encuentra en mayor crecimiento, lo que determina que en la actualidad los objetivos que se plantean en la organización sean incrementar la rentabilidad del negocio y crecer en mayor porcentaje su participación en el mercado. 
Tabla 4

Ventas de los principales competidores

\begin{tabular}{|c|c|c|c|c|c|c|c|c|c|}
\hline $\mathrm{N}^{\circ}$ & Importadores & CIUU & Sector específico & $\begin{array}{c}\text { Tamaño de } \\
\text { empresa }\end{array}$ & $\begin{array}{c}\text { Total CIF } \\
\text { US\$ }\end{array}$ & $\%$ & Ingresos 2014 & Ingresos 2015 & may-16 \\
\hline 1 & Plan Enterprise S.A. & 4690 & Ventas por mayor & Pequeña & $7,010,345$ & 0.114 & $5,873,099.49$ & $6,525,666.10$ & $2,860,619.21$ \\
\hline 2 & IlkoPerú S.A.C. & 4649 & Limpieza del hogar & Mediana & $6,369,013$ & 0.104 & $5,357,915.32$ & $5,953,239.25$ & $2,609,687.70$ \\
\hline 3 & Prosemedic S A & 4690 & Ventas por mayor & Pequeña & $5,778,709$ & 0.094 & $4,842,731.16$ & $5,380,812.40$ & $2,358,756.19$ \\
\hline 4 & Medical Full Import S.A. & 4649 & Ventas por mayor & Pequeña & $4,494,912$ & 0.073 & $3,760,844.41$ & $4,178,716.01$ & $1,831,800.02$ \\
\hline 5 & Nipro Medical & 4649 & Limpieza del hogar & Mediana & $4,157,027$ & 0.068 & $3,503,252.33$ & $3,892,502.59$ & $1,706,334.26$ \\
\hline 6 & Caplan S.A.C. & 2013 & Ventas por mayor & Mediana & $3,255,743$ & 0.053 & $2,730,476.08$ & $3,033,862.31$ & $1,329,937.00$ \\
\hline 7 & Drokasa Perú S.A. & 4649 & Limpieza del hogar & Mediana & $3,021,463$ & 0.049 & $2,524,402.41$ & $2,804,891.57$ & $1,229,564.40$ \\
\hline 8 & Sekur Perú S.A. & 4649 & Limpieza del hogar & Mediana & $2,869,424$ & 0.047 & $2,421,365.58$ & $2,690,406.20$ & $1,179,378.09$ \\
\hline 9 & Kimberly-Clark S.R.L. & 4649 & Limpieza del hogar & Grande & $2,305,839$ & 0.038 & $1,957,699.83$ & $2,175,222.03$ & $953,539.74$ \\
\hline 10 & Indejebe Sociedad & 4649 & Limpieza del hogar & Mediana & $1,717,763$ & 0.028 & $1,442,515.66$ & $1,602,795.18$ & $702,608.23$ \\
\hline 11 & 3M Perú S.A. & 4649 & Limpieza del hogar & Grande & $1,575,268$ & 0.026 & $1,339,478.83$ & $1,488,309.81$ & $652,421.92$ \\
\hline 12 & R\&G S.A.C. & 4649 & Limpieza del hogar & Pequeña & $1,532,535$ & 0.025 & $1,287,960.41$ & $1,431,067.13$ & $627,328.77$ \\
\hline 13 & BufaloImport S.A.C & 4649 & Limpieza del hogar & Pequeña & $1,316,891$ & 0.021 & $1,081,886.75$ & $1,202,096.39$ & $526,956.17$ \\
\hline 14 & Eficiencia Laboral S.A. & 4649 & Limpieza del hogar & Pequeña & $1,174,136$ & 0.019 & $978,849.92$ & $1,087,611.02$ & $476,769.87$ \\
\hline 15 & Representaciones Lanus & 4649 & Limpieza del hogar & Pequeña & $1,083,283$ & 0.018 & $927,331.50$ & $1,030,368.33$ & $451,676.72$ \\
\hline 16 & $\begin{array}{l}\text { American industrial } \\
\text { Equipment S.A.C. }\end{array}$ & 4649 & Limpieza del hogar & Pequeña & 877,639 & 0.014 & $721,257.83$ & $801,397.59$ & $351,304.11$ \\
\hline 17 & Distribuidora Continental & 4649 & Limpieza del hogar & Pequeña & 711,751 & 0.012 & $618,221.00$ & $686,912.22$ & $301,117.81$ \\
\hline
\end{tabular}

Nota. Elaborado por Eterna SA. 


\section{Capítulo 3 Formulación de visión, misión y valores de la empresa}

\subsection{Visión}

La visión es adonde quiere llegar unaempresa, en donde se ve la organización a lo largo de los años, como quiere ser reconocida cuando crezca y logre su permanencia y estabilidad. La visión se puede definir de la siguiente manera: "El sueño de lo que una organización quiere llegar a ser en un largo plazo".

\subsubsection{Visión actual de la empresa}

La compañía en su página web presenta la siguiente visión de Eterna Colombia, lo que también es aplicable a las matrices en Ecuador y Perú:

En el2020, seremos reconocidos como una organización con gran capacidad de ejecución, que reacciona ágil y efectivamente a las necesidades del mercado, entregando productos maravillosos y servicios extraordinarios.

En los mercados nacionales e internacionales en los que actuaremos, seremos percibidos como un equipo humano que genera riqueza y actúa con profundo sentido de responsabilidad social y ambiental trabajando con mística, con profesionalismo y con una visión compartida de futuro.

Por ello, nuestros clientes estarán encantados de repetir su experiencia con nosotros. Eterna (2011). 


\subsubsection{Análisis de la visión actual}

D’Alessio (2008) define nueve aspecto a considerar para establecer la visión (ver Tabla 5).Estos aspectos deberán fijar un futuro retador que sirva de inspiración y guía a los colaboradores en el proceso de establecimiento de la visión de una organización.

\section{Tabla 5}

Aspectos de la visión según D’Alessio

\begin{tabular}{ll}
\hline $\mathrm{N}^{\circ}$ & Aspectos de la visión \\
\hline 1 & Ideología central (carácter) \\
2 & Visión de futuro \\
3 & Simple, clara y comprensible \\
4 & Ambiciosa , convincente y realista \\
5 & Definida en un horizonte de tiempo \\
6 & Alcance geográfico \\
7 & Conocida por todos \\
8 & Sentido de urgencia \\
9 & Idea clara de a donde se desea ir \\
\hline
\end{tabular}

Nota:Adaptado de "El proceso estratégico: un enfoque de gerencia," Por F.A.D’Alessio, 2008. México D.F., México. Pearson.

A partir del análisis de la teoría propuesta por D’Alessio (2008), se haidentificadoque actualmente la visión de la organización cuenta conalgunos aspectos que si cumple para una correcta elaboración de la visión,pero por otro lado, existen varios aspectos que no están cumpliendo con los aspectos que se deben considerar en una visión(ver Tabla 6). 
Tabla 6

Tabulación de la vision de Eterna

\begin{tabular}{lc}
\hline Elementos de la visión & ¿Cumple? \\
\hline Ideología central (carácter) & Sí \\
Visión de futuro & Ní \\
Simple, clara y comprensible & Sí \\
Ambiciosa , convincente y realista & Sí \\
Definida en un horizonte de tiempo & No \\
Alcance geográfico & No \\
Conocida por todos & Sí \\
Sentido de urgencia & No \\
Idea clara de a donde se desea ir & Nota:Adaptado de “El proceso estratégico: un enfoque de gerencia,” \\
porF.A.D’Alessio, 2008. México D.F., México. Pearson.
\end{tabular}

\subsubsection{Matriz de la visión propuesta para la empresa}

Para D’Alessio (2008), la visión es la definición de lo que se quiere en el futuro, esto implica entender la naturaleza del negocio, fijar un futuro que sea retador y contar con la capacidad de difundirla para que sirva de inspiración y motivación.

En la visión de Eterna que se propone se reflejan los siguientes elementos propuestos por el autor indicado anteriormente (ver Tabla 7):

- Una visión corta que se entienda por todos los colaboradores;

- Ser la empresa número uno en ventas en el territorio nacional; 
Tabla 7Tabulación de la visión propuesta para Eterna

Tabulación de la visión propuesta para Eterna

Elementos de la visión ¿Cumple?

Ideología central (carácter)

Sí

Visión de futuro

Sí

Simple, clara y comprensible

Sí

Ambiciosa , convincente y realista

Sí

Definida en un horizonte de tiempo

Sí

Alcance geográfico

Sí

Conocida por todos

Sí

Sentido de urgencia

Sí

Idea clara de a donde se desea ir

Sí

Nota:Adaptado de "El proceso estratégico: un enfoque de gerencia,"

porF.A.D’Alessio, 2008. México D.F., México. Pearson.

Se propone la siguiente visión para la empresa Eterna, dentro del margen del presente plan estratégico periodo 2017 - 2021:

"Para el año 2021, seremos la empresa número uno a nivel nacional en la venta de guantes domésticos, reconocidos por la calidad del producto y el servicio de atención a nuestros clientes en el país"

Esta visión propuesta se considera es más amigable y retadora para la empresa. A fin de dar a conocer la nueva visión se comunicará por medio de los directivos la propuesta a todo el personal de la empresa. 


\subsection{Misión}

Drucker (2013) define que la misión de una empresa es la base de sus planes, prioridades y asignación de deberes. Es el punto de inicio para diseñar el trabajo gerencial y, sobre todo, para elaborar las estructuras gerenciales.

A simple vista parece que no hay nada más simple que reconocer el negocio de una compañía, pero, en la realidad esdifícil responder sobre ¿Cuál es nuestro negocio? Puede ser un cuestionamiento difícil de responder, pues a veces los aspectos que determinan un negocio no son tan evidentes. Por consiguiente, responder esta pregunta debe ser la primera respuesta para definir la misión de un negocio.

\subsubsection{Misión actual de la empresa}

La compañía en su página web brinda a los autores la siguiente misión de Eterna Colombia esto también es aplicable a las matrices en Ecuador y Perú:

Comprender con claridad los mensajes del mercado para entregar soluciones integrales efectivas, con productos y servicios en los segmentos de mercado que atendemos; asegurando la rentabilidad que nos garantiza la sostenibilidad y la generación de oportunidades de crecimiento y desarrollo para todos los grupos de interés involucrados con Eterna. (2011) 


\subsubsection{Análisis de la misión actual}

Pearce (1982), define nueve principales componentes que deben ser considerados cuando la empresa declara su misión (ver Tabla $N^{\circ} 8$ ).

Tabla 8

Componentes de Pearce para elaborar la visión

Componentes de Pearce

Clientes

Productos: Bienes o Servicios

Mercados

Tecnologías

Objetivo de la organización: Supervivencia, crecimiento y rentabilidad

Filosofía de la organización

Autoconcepto de la organización

Preocupación por la imagen publica

Preocupación por los empleados

Nota:Adaptado de "El proceso estratégico: un enfoque de gerencia," por

F.A.D’Alessio, 2008. México D.F., México. Pearson.

En la visión se identificaron que existen algunos vacíos (ver Tabla 9). Por ejemplo:

(a) clientes, no es mencionado

(b) productos, no menciona los principales productos que la empresa produce

(c) mercados, no describe geográficamente donde son sus mercados

(d) tecnologías, tampoco se menciona

(e) objetivo de la organización, si es mencionada, asegurar la rentabilidad 
(f) filosofía de la organización, no muestra una manera de pensar;

(g) autoconcepto de la organización, muestra su ventaja competitiva frente a las demás compañías

(h) Preocupación por la imagen pública, la empresa muestra generación de oportunidades de crecimiento y desarrollo para todos los grupos de interés

(i) Preocupación por los empleados, menciona oportunidad de crecimiento a sus empleados (grupos de interés).

Tabla 9

Evaluación de la misión

\begin{tabular}{ll}
\hline Componentes de Pearce & Resultado \\
& del análisis
\end{tabular}

$\begin{array}{ll}\text { Clientes } & \text { No }\end{array}$

Productos: Bienes o Servicios

No

Mercados

No

Tecnologías

No

Objetivo de la organización: Supervivencia, crecimiento y rentabilidad

Filosofía de la organización

No

Autoconcepto de la organización

No

Preocupación por la imagen publica

$\mathrm{Si}$

Preocupación por los empleados

Sí

Nota: Adaptado de “El proceso estratégico: un enfoque de gerencia," por F.A.D’Alessio, 2008. México D.F., México. Pearson. 


\subsubsection{Elementos de la misión propuesta para la empresa}

Para D’Alessio (2008), la misión es lo que impulsa a la empresa al futuro deseado y debe ser bien realizado para llegar al éxito; debe mencionar los mercados y los productos que ofertara, enlazando de manera eficaz sus recursos y competencias. La misión debe ser fácil de interpretar y convencedora; debe ser relacionada con la visión que se propone.

Se propone la siguiente misión para la empresa Eterna Perú S.A., dentro del margen del presente plan estratégico periodo 2017 - 2021:

"Nuestro propósito es ofrecer guantes domésticos al mercado nacional, desarrollados con tecnología de vanguardia, alta calidad y precios competitivos. Asimismo, reconocemos que nuestros distribuidores son nuestro principal compromiso, buscando siempre generar valor para nuestros clientes, accionistas, personal y la comunidad en la que nos desarrollamos como empresa"

El análisis de la misión propuesta indica que cumple con los componentes que establece Pearce para una misión. 
Tabla 10

Elementos de la misión

\begin{tabular}{ll}
\hline Componentes de Pearce & Resultado \\
\hline Clientes & Sí \\
Productos: Bienes o Servicios & Sí \\
Mercados & Sí \\
Tecnologías & Sí \\
Objetivo de la organización: & Sí \\
Filosofía de la organización & Sí \\
Autoconcepto de la organización & Sí \\
Preocupación por la imagen publica & Si \\
Preocupación por los empleados & Sí
\end{tabular}

Nota: Adaptado de "El proceso estratégico: un enfoque de gerencia," por F.A.D'Alessio, 2008. México D.F., México.Pearson.

A partir de este análisis se considera que la misión propuesta cumple con los requisitos indicados por D'Alessio (2008). Respecto a la difusión, la misión será comunicada al personal de la empresa a través de los directivos, al igual que la visión.

\subsection{Valores}

Los valores en una organización son los que siempre apoyan la visión, le dan forma a la misión y la cultura organizacional y manifiestan los estándares de la empresa. Muchas empresas se concentran solamente en las competencias y habilidades técnicas, pero comúnmente se 
olvidan ¿Cuáles son las principales capacidades subyacentes como los valores esenciales que hacen que sus empresas funcionen de manera correcta?; la creación y formalización de los valores en una compañía brinda ventajas esenciales tanto internas como externas:

\subsubsection{Valores actuales de la empresa}

La compañía en su página web brinda los siguientes valores de Eterna Colombia, lo que también es aplicable a las matrices en Ecuador y Perú:

- Responsabilidad: Confiamos en aquellas personas que son responsables. Ser responsable en Eterna, es asumir las consecuencias de nuestras acciones y decisiones; también es buscar que todos nuestros actos sean realizados de acuerdo con una noción de justicia, ética, moral y cumplimiento del deber en todos los sentidos. Ponemos nuestra fe y lealtad en aquellos que siempre cumplen lo que han prometido.

- Honestidad: Somos transparentes, realizamos todas nuestras actividades dentro del marco legal, no promovemos, no consentimos y no toleramos actos que vayan contra la verdad, sus políticas y sus valores empresariales.

- Respeto: Trabajamos dando un trato amable y cortés, aceptando y valorando las cualidades, actitudes y opiniones de los demás, para garantizar un ambiente de cordialidad a sus colaboradores y a la sociedad. 
- Colaboración: Capacidad de fomentar e integrar un ambiente de trabajo en equipo, mediante relaciones de confianza y respeto, entendiendo que lo que hago por el otro, contribuya al logro de los objetivos de la empresa.

- Lealtad: La lealtad es el resultado del discernimiento para elegir lo que es correcto. Eterna S.A. se compromete con el fortalecimiento de su valor de Lealtad, entendido este como hacer aquello con lo que uno se ha comprometido, aún ante lo cambiante del entorno, aplicándolo a todos los grupos de interés, generando la confianza y el respeto mutuo para alcanzar los objetivos de la empresa.

\subsubsection{Análisis de los valores actuales}

- Responsabilidad: se considera que este valor está bien definido.

- Honestidad: Se considera que la honestidad está dentro de ética y moral y por eso este valor ya no debería ser considerado.

- Respeto: Este valor está muy ligado a responsabilidad debería ser retirado.

- Colaboración: Este valor es muy fundamental para el desarrollo de la compañía, está bien definido.

- Lealtad: Valor muy bien definido esto conlleva a que en un futuro la empresa logre los objetivos trazados.

\subsubsection{Elementos de los valores propuestos para la empresa}

D’Alessio (2008) indicó que los valores de una empresa pueden ser supuestos como las políticas más importantes, forman el estándar de actuación que guía el proceso de toma de 
decisiones. Los valores tienen la finalidad de entablar la filosofía de la organización al representar a los grupos de interés sus creencias, actitudes, tradiciones y su personalidad.Con lo mencionado, los autores proponenotros valores que son complementarios y que llevaran a lograr la visión.

\section{Tabla 11}

Elementos propuestos para la compañía

\begin{tabular}{ll}
\hline Valor & \multicolumn{1}{c}{ Elementos } \\
\hline Innovación & $\begin{array}{l}\text { Proponer y ejecutar productos que generen mayor valor al } \\
\text { cliente y a la empresa. } \\
\text { Velar por el cuidado del personal y la sociedad. }\end{array}$ \\
\hline
\end{tabular}

\subsubsection{Valores propuestos}

Los valores propuestos para la compañía tienen la finalidad de que se cumplan con todos los valores que se consideran deben tener una empresa.

\section{Tabla 12}

Valores propuestos para la compañía

\begin{tabular}{ll}
\hline Valor & Elementos \\
\hline Responsabilidad & $\begin{array}{l}\text { Justicia, ética, moral y cumplimiento del deber en todos } \\
\text { los sentidos. }\end{array}$ \\
Colaboración & $\begin{array}{l}\text { Fomentar e integrar un ambiente de trabajo en equipo, } \\
\text { mediante relaciones de confianza y respeto } \\
\text { Confianza y el respeto mutuo para alcanzar los objetivos } \\
\text { de la empresa. } \\
\text { Lealtad }\end{array}$ \\
Innovación & $\begin{array}{l}\text { cliente y a la empresa. } \\
\text { Velar por el cuidado del personal y la sociedad. }\end{array}$ \\
\hline Seguridad &
\end{tabular}




\subsection{Alineamiento estratégico de la Visión, Misión y Valores de la empresa}

Con base a lo analizado previamente,se considera que existe una alineación estratégica entre la nueva visión, la misión propuesta y los valores para la compañía.

Tabla 13

Alineamiento estratégico de la Visión, Misión y Valores de la empresa Visión

En el caso de la visión propuesta, se puede apreciar que se reflejan los valores de innovación (calidad del producto), así como de colaboración y de responsabilidad (servicio de atención a nuestros clientes), que permitirán el logro de los fines que el negocio desea lograr en el futuro.

"Para el año 2021, seremos la empresa número uno a nivel nacional en la venta de guantes domésticos, reconocidos por la calidad del producto y el servicio de atención a nuestros clientes en el país".

Misión

En el caso de la misión se puede apreciar los valores de responsabilidad, colaboración y lealtad (nuestros distribuidores son nuestro principal compromiso), así como innovación y seguridad en el negocio (tecnología de vanguardia, alta calidad y precios competitivos). El cumplimiento de estos valores permitirá alcanzar el propósito de la organización.

"Nuestro propósito es ofrecer guantes domésticos al mercado nacional, desarrollados con tecnología de vanguardia, alta calidad y precios competitivos. Asimismo, 
reconocemos que nuestros distribuidores son nuestro principal compromiso, buscando siempre generar valor para nuestros clientes, accionistas, personal y la comunidad en la que nos desarrollamos como empresa"

Por consiguiente, se puede señalar que existe una alienación entre lo que se expresa en la visión, misión y los valore de la empresa.

Valores

\begin{tabular}{ll}
\hline Valor & Alineación \\
Responsabilidad & Justicia, ética, moral y cumplimiento del deber en todos los \\
& sentidos. \\
Colaboración & Fomentar e integrar un ambiente de trabajo en equipo, \\
& mediante relaciones de confianza y respeto \\
Lealtad & Confianza y el respeto mutuo para alcanzar los objetivos de \\
& la empresa. \\
Innovación & Proponer y ejecutar productos que generen mayor valor al \\
& cliente y a la empresa. \\
Seguridad & Velar por el cuidado del personal y la sociedad.
\end{tabular}




\section{Capítulo 4 Análisis externo}

El presente capítulo contiene un análisis externo de la empresa, dondea partir de las tendencias de sus principales variables se evaluara el cambio del macroentrono mundial y nacional, con la finalidad de identificar las oportunidades y las amenazas que podría enfrentar la empresa en los siguientes años.

\subsection{Tendencias de las variables del entorno}

\subsubsection{Análisis Político-Gubernamental}

En el ámbito político el nuevo Presidente que gobernara durante el periodo 2016 - 2021, Pedro Pablo Kuczynski, tiene cuatro principales retos: (a) mejorar la economía del país, (b) promover la minería, principal generador del PBI, (c) disminuir la inseguridad ciudadana, (d) promover y mejorar la imagen de las instituciones públicas; lo mencionado anteriormente dentro del país nos hace ver como un país con miras al desarrollo.

Actualmente el Perú es un país democrático, lleva 16 años con gobiernos elegidos, desde el gobierno de transición de Valentín Paniagua Corazao,que empezó el 22 de noviembre de 2000 a la fecha.

Durante, este periodo se ha venido incrementando el PBI del país e incentivando la inversión extranjera, lo que conlleva a que en la actualidad las empresas calificadoras de riesgo 
a nivel internacional, como la calificadora de riesgo crediticio Moody'sInvestorsService,subala calificación de los bonos de largo plazo en moneda extranjera y local de Perú A3; otra agencia calificadora S\&P muestra para la inversión de largo plazo en moneda local un A- y BBB+ para la moneda extranjera; mientras que FITCH mantiene igualmenteuna calificación de A- y BBB+.

Esta mejora refleja factores como la disminución de las vulnerabilidades asociadas a sucesos de riesgo político, un continuo crecimiento en la economía y por ultimo un sólido desempeño fiscal. Asimismo, se refleja mejoras en los índices de deuda del gobierno y una disminución de la exposición del país a la deuda extranjera.

Deuda de LP en moneda local

\begin{tabular}{|l|l|l|l|l|l|}
\hline PAISES & MOODY'S & S\&P & FITCH & DBRS & NICE \\
\hline
\end{tabular}

\begin{tabular}{|l|l|l|l|l|l|}
\hline ARGENTINA & WR & B- & WD & $\mathrm{B}(\mathrm{H})$ & $\mathrm{B}-$ \\
\hline BOLIMA & $\mathrm{Ba} 3$ & $\mathrm{BB}$ & $\mathrm{BB}-$ & - & - \\
\hline BRASIL & $\mathrm{Ba} 2$ & $\mathrm{BB}$ & $\mathrm{BB}$ & $\mathrm{BBB}(\mathrm{L})$ & $\mathrm{BBB}+$ \\
\hline CHILE & $\mathrm{Aa3}$ & $\mathrm{AA}$ & $\mathrm{AA}-$ & $\mathrm{AA}$ & - \\
\hline COLOMBIA & $\mathrm{Baa} 2$ & $\mathrm{BBB}+$ & $\mathrm{BBB}$ & $\mathrm{BBB}(\mathrm{H})$ & - \\
\hline COSTA RICA & $\mathrm{Ba} 1$ & $\mathrm{BB}-$ & $\mathrm{BB}+$ & - & - \\
\hline ECUADOR & WR & $\mathrm{B}$ & - & - & - \\
\hline EL SALVADOR & WR & $\mathrm{B}+$ & $\mathrm{B}+$ & - & - \\
\hline MÉXICO & $\mathrm{A} 3$ & $\mathrm{~A}$ & $\mathrm{BBB}+$ & $\mathrm{A}(\mathrm{L})$ & $\mathrm{A}-$ \\
\hline PANAMÁ & - & $\mathrm{BBB}$ & $\mathrm{BBB}$ & - & - \\
\hline PARAGUAY & Ba1 & $\mathrm{BB}$ & $\mathrm{BB}$ & - & - \\
\hline PERÚ & $\mathrm{A} 3$ & $\mathrm{~A}-$ & $\mathrm{A}-$ & $\mathrm{BBB}(\mathrm{H})$ & $\mathrm{A}-$ \\
\hline URUGUAY & Baa2 & $\mathrm{BBB}$ & $\mathrm{BBB}-$ & $\mathrm{BBB}(\mathrm{L})$ & - \\
\hline VENEZUELA & Caa3 & $\mathrm{CCC}$ & $\mathrm{CCC}$ & - & - \\
Para DBRS: (H) & equivale a (+) y (L) & equivale a (-) &
\end{tabular}

Para DBRS: $(\mathrm{H})$ equivale a $(+)$ y $(\mathrm{L})$ equivale a $(-)$

Deuda de LP en moneda extranjera
\begin{tabular}{|l|l|l|l|l|l|}
\hline PAISES & MOODY'S & S\&P & FITCH & DBRS & NICE \\
\hline ARGENTINA & B3 & B- & WD & B & SD \\
\hline BOLIVIA & Ba3 & BB & BB- & - & - \\
\hline BRASIL & Ba2 & BB & BB & BB(H) & BBB \\
\hline CHILE & Aa3 & AA- & A+ & AA(L) & - \\
\hline COLOMBIA & Baa2 & BBB & BBB & BBB & - \\
\hline COSTA RICA & Ba1 & BB- & BB+ & - & - \\
\hline ECUADOR & B3 & B & B & - & - \\
\hline EL SALVADOR & Ba3 & B+ & B+ & - & - \\
\hline MÉXICO & A3 & BBB+ & BBB+ & BBB(H) & BBB+ \\
\hline PANAMÁ & Baa2 & BBB & BBB & - & - \\
\hline PARAGUAY & Ba1 & BB & BB & - & - \\
\hline PERÚ & A3 & BBB+ & BBB+ & BBB(H) & BBB+ \\
\hline URUGUAY & Baa2 & BBB & BBB- & BBB(L) & - \\
\hline VENEZUELA & Caa3 & CCC & CCC & - & - \\
\hline Para DBRS: (H) equivale a (+) y (L) equivale a (-) & \\
\hline
\end{tabular}

Para DBRS: $(\mathrm{H})$ equivale a $(+)$ y $(\mathrm{L})$ equivale a $(-)$

Figura 13.Calificación principales países latinoamericanos

Nota. Tomado de "Principales calificaciones de riesgo soberano," por MEF, 2016.

Recuperado

dehttps://www.mef.gob.pe/index.php?option=com_content\&view=article\&id=222\%3Aprincipa les-calificaciones-de-riesgo-soberano \&catid=90\%3Aconsulta-4\&Itemid $=101017 \&$ lang $=e s$ 
Esta situación conlleva a un impacto positivo en las diferentes industrias que se desarrollan en el país, generando oportunidades para las empresas de artículos de limpieza para el hogar.

Sin embargo dentro de los cuatro retos que tiene el gobierno el que más golpea a la industria es el de la inseguridad, actualmente muchas empresas invierten fuertes cantidades de dinero para que su negocio no se vea afectado por la delincuencia, estos costos lleva a que el inversionista tenga un margen reducido en sus ganancias y menor inversión en el mercado, generando una fuerte amenaza que afecta en general a toda la industria.Para corroborar lo mencionado sobre los retos del país se detalla un informe deJoaquín Valle, socio y gerente de la consultora BCG que publicó el diario el Comercio, el informe detalla porque el Perú se encuentra dentro del top 30 de progreso en desarrollo sostenible.

Según un reciente estudio publicado por Boston ConsultingGroup (BCG), el Perú se encuentra entre los treinta países a escala global que lograron el mayor progreso en el ranking de desarrollo SustainableEconomicDevelopmentAssessment (SEDA), elaborado por la consultora. El indicador busca medir el desarrollo no solo en términos económicos, sino que suma factores que generan bienestar y no necesariamente son recogidos en el cálculo del PBI. Ejemplos de esto son el avance tecnológico, el acceso a mayor información por el canal digital y otros factores que puedan estar impactando en elevar la calidad de vida de las personas, explica Joaquín Valle, socio y 'managing director' de BCG en el Perú. 
Así, el índice se centra en tres pilares centrales: el económico, la inversión y la sostenibilidad de esta generación de bienestar en el tiempo. Valle (2016) resalta que, en el caso peruano, hemos demostrado un desempeño sólido en cuanto a los indicadores económicos, manteniéndonos por encima del promedio regional, como lo evidencia este resultado. Sin embargo, el ámbito más crítico para el país fue el pilar de las inversiones, en el que obtenemos un puntaje deficiente. Este pilar, añade Valle, incluye la inversión en sectores centrales como infraestructura, educación y salud, y es aquel con la evaluación más crítica. Finalmente, añade que en el eje de la sostenibilidad -que refleja en mayor medida el bienestar de la ciudadaníapreocupan aún los indicadores de seguridad ciudadana y la corrupción.

En el informe de BCG, se enfatiza la inclusión financiera como estrategia para la generación de bienestar. Valle afirma que, para el Perú, impulsar esto generaría mayor transparencia en los pagos y disminuiría la corrupción. BSG (2016)

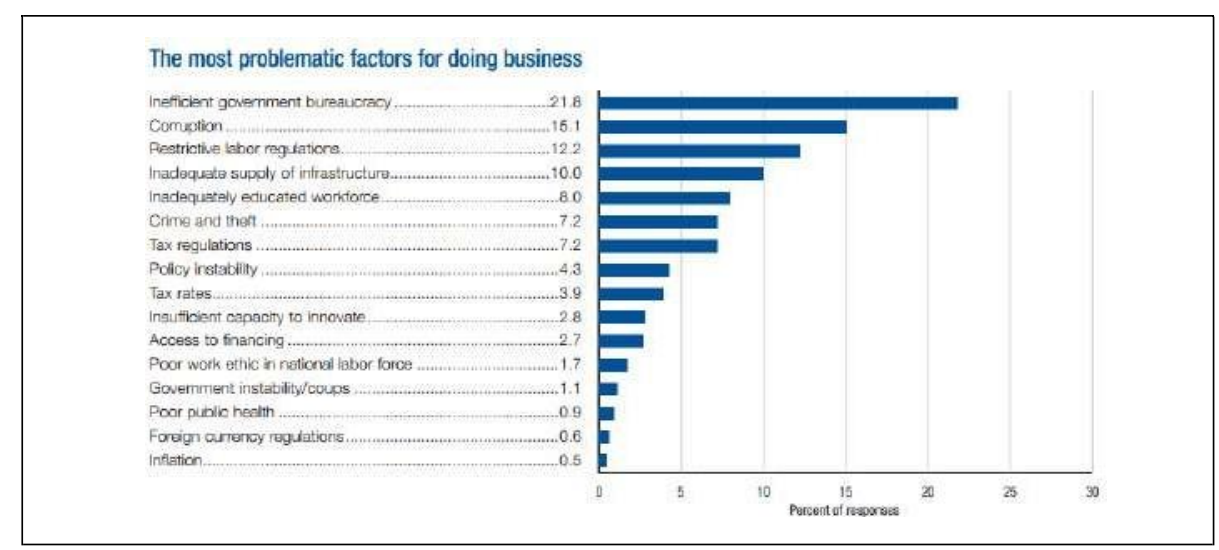

Figura 14. Los factores más problemáticos para hacer negocios Nota. Tomado de "Country EconomyProfiles, " por el WorldEconomicForum, 2014. Recuperado de http://reports.weforum.org/global-competitiveness-report-2014-2015/wpcontent/blogs.dir/54/mp/files/pages/files/wef-ceprofiles-globalcompetitivenessreport-201415.pdf 


\section{a). La inversión privada y satisfacción de los empresarios:}

En el caso de existir un ambiente desfavorable para la inversión, los inversionistas tienden a desanimarse al momento de generar nuevos negociosal considerar que es una amenaza para el sector en el que se desarrollan. Esta situación se debe en su mayoría a los siguientes aspectos:

1. Actualmente el país, es el octavo país con la mayor carga burocrática del mundo, esto es considerado por los inversionistas como el principal obstáculo para hacer negocios en el Perú. Según el ranking del WordEconomicForum 2015, el Perú tiene el puesto 133 de los 140 países, en la carga de normatividad gubernamental (burocracia).Por ejemplo, la Sociedad Nacional de Industrias SNI (2016), explica que la carga burocrática en el Perú es principalmente por dos razones:

- Existencia de normas irracionales e ilegales que carecen de un estudio detallado económico-legal serios que carecen de soporte

- Ineficiente gestión pública en los trámites, estos resaltan por su incumplimientos de plazos legales en las formas que evalúa, esto se ve en mayoría en los gobiernos locales, por la mínima calidad institucional.

Durante, el gobierno de Ollanta Humala se promovió normas para mejorar la simplificación administrativa por parte de las entidades estatales (decretos legislativos $\mathrm{N}^{\circ} 1200,1203,1211,1212,1222$ y 1225), pero estos aun requieren de implementación urgentey adicional. Para ello se necesita reformas que vuelva más atractiva la inversión, las cuales deben ser propuestas por el gobierno de turno. 


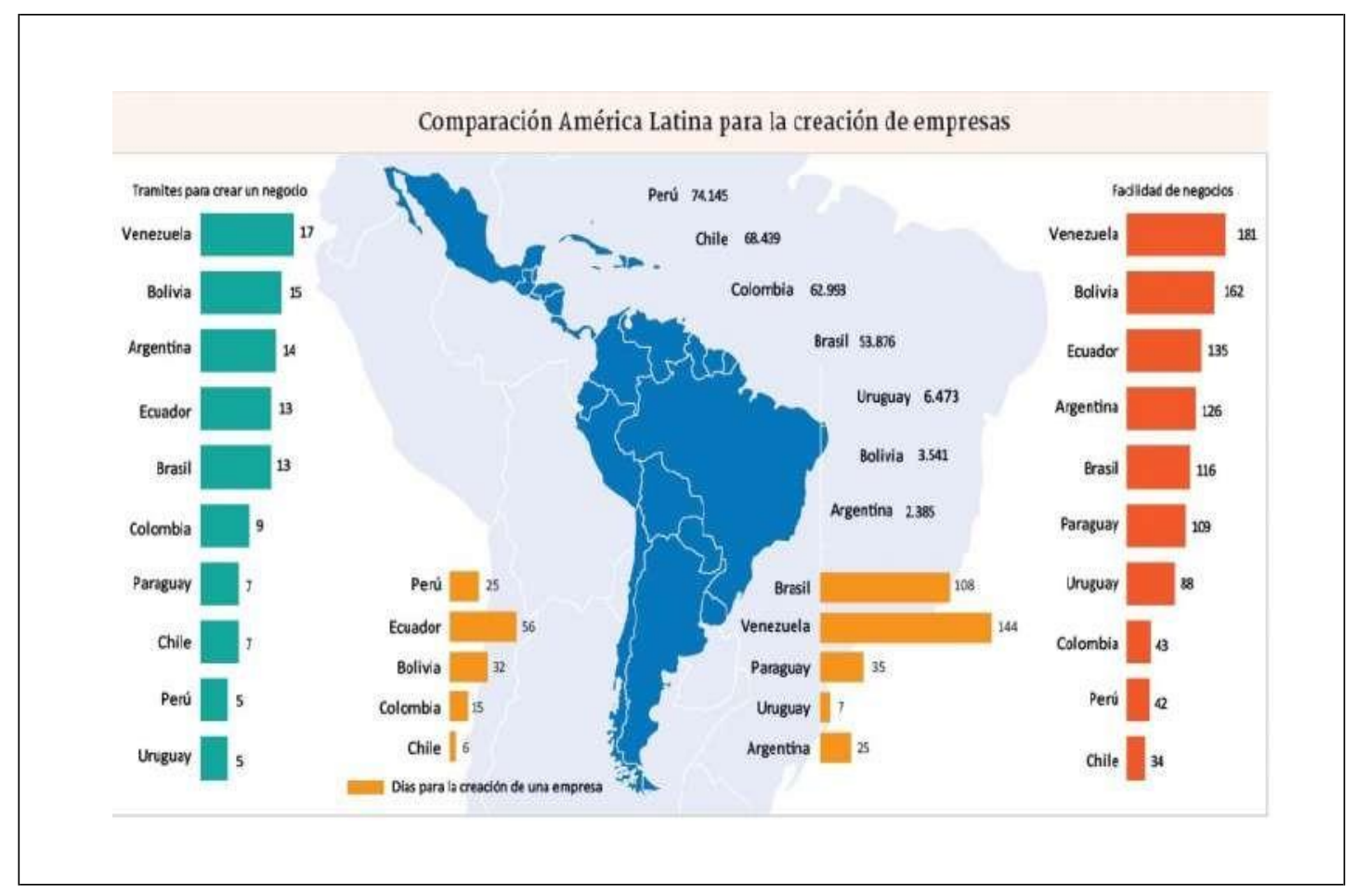

Figura 15.Comparación de América Latina para la creación de empresas Nota. Tomado de “Economía y negocios - 5dias.com," por Santiago Zavattiero, 2014. Recuperado de http://www.5dias.com.py/36815-gobierno-debe-impulsar-la-creacion-deempresas-reduciendo-las-trabas

2. Actualmente en el país la corrupción se está generalizando a tal punto que hoy es, un gran problema que demanda urgentes normas legales y medidas para eliminarlas por parte del actual gobierno; La corrupción actualmente se encuentra de manera consistente entre las preocupaciones más graves de los ciudadanos. Para Ipsos (2010), el $52 \%$ de los peruanos considera que es uno de los tres principales problemas del país. La percepción general es de que cada vez se encuentra este problema detrás de cada licitación, licencias de funcionamiento, trámites burocráticos, concesiones privadas y funcionarios del ente público es cada vez más extendida. 
Para fundamentar a mayor detalle el tema de corrupción en el país, Diego Maceda en un artículo publicado en El Diario el comercio, nos informa de cuál es el efecto de la corrupción en el Perú.

- Debilita el ambiente de negocios y distorsiona los incentivos

La economía de mercado se basa en el supuesto de que las empresas que puedan ofrecer un mejor servicio al menor costo serán premiadas con mayores ventas y mejores ingresos. Cuando los acuerdos dejan de depender de este mecanismo y más bien dependen de quién sea el amigo o pariente del alcalde de turno, la economía deja de funcionar y las empresas pierden el incentivo para competir. En el caso de las licitaciones públicas, las empresas serias que pueden ofrecer, por ejemplo, la construcción de una carretera con buenos materiales y tiempos oportunos son desplazadas por empresas de menor fiabilidad que se prestan a actos de corrupción. Previendo esta situación, muchas compañías serias prefieren no presentarse a algunos concursos y se pierden acuerdos convenientes tanto para el sector privado como para el sector público. El sistema de incentivos para mejorar los servicios de los privados ya no opera.

En consecuencia, la inversión privada se ve perjudicada. Según el Fondo Monetario Internacional (FMI), un país sin problemas de corrupción podría incrementar en 5\% su inversión privada fortaleciendo el marco institucional que protege a los inversionistas de estas prácticas. Además, el Foro Económico Mundial (WEF) estima que la corrupción encarece en $10 \%$ el costo de hacer 
negocios, y en hasta $25 \%$ el costo de celebrar contratos en los países en desarrollo. Finalmente, el WEF señala también que trasladar un negocio de un país con bajos niveles de corrupción a uno con medianos o altos niveles de corrupción es equivalente a un impuesto adicional del $20 \%$.

- Genera malas decisiones

Cuando un alcalde corrupto planea el trazo de una carretera de un modo ineficiente pero que le permite obtener una comisión, contrata con una empresa constructora que usará materiales deficientes pero que le asegura además una “comisión” del proyecto. En este caso, el verdadero costo de la corrupción no está en el monto que aparece en la cuenta del burgomaestre, sino en los defectos de la carretera. Por citar un caso, la contraloría demostró que José Panta Quiroga, mano derecha de Gregorio Santos en Cajamarca, recibió poco más de S/.403 mil en sus cuentas de Interbank y el BCP. El motivo habría sido la irregular adjudicación de obras por S/.130 millones a empresas que no contaban con los requisitos mínimos para realizarlas. En esta situación, la coima representó el 0,3\% del valor total de las obras. La infraestructura mal concebida, mal construida y que, posiblemente, tendrá que rehacerse cuesta varios millones. Este, posiblemente, sea el costo escondido más importante de la corrupción: las malas decisiones que genera por la búsqueda del incentivo ilegal.

A nivel agregado, trabajos de la Universidad de Londres calculan que para países de ingresos medios y bajos un punto adicional en el índice de corrupción de 
Transparencia Internacional (estandarizado desde 0 para el país más corrupto y 12 para el menos corrupto) agrega 0,59 puntos porcentuales adicionales a la tasa de crecimiento del PBI. (Diego Maceda, 2016)

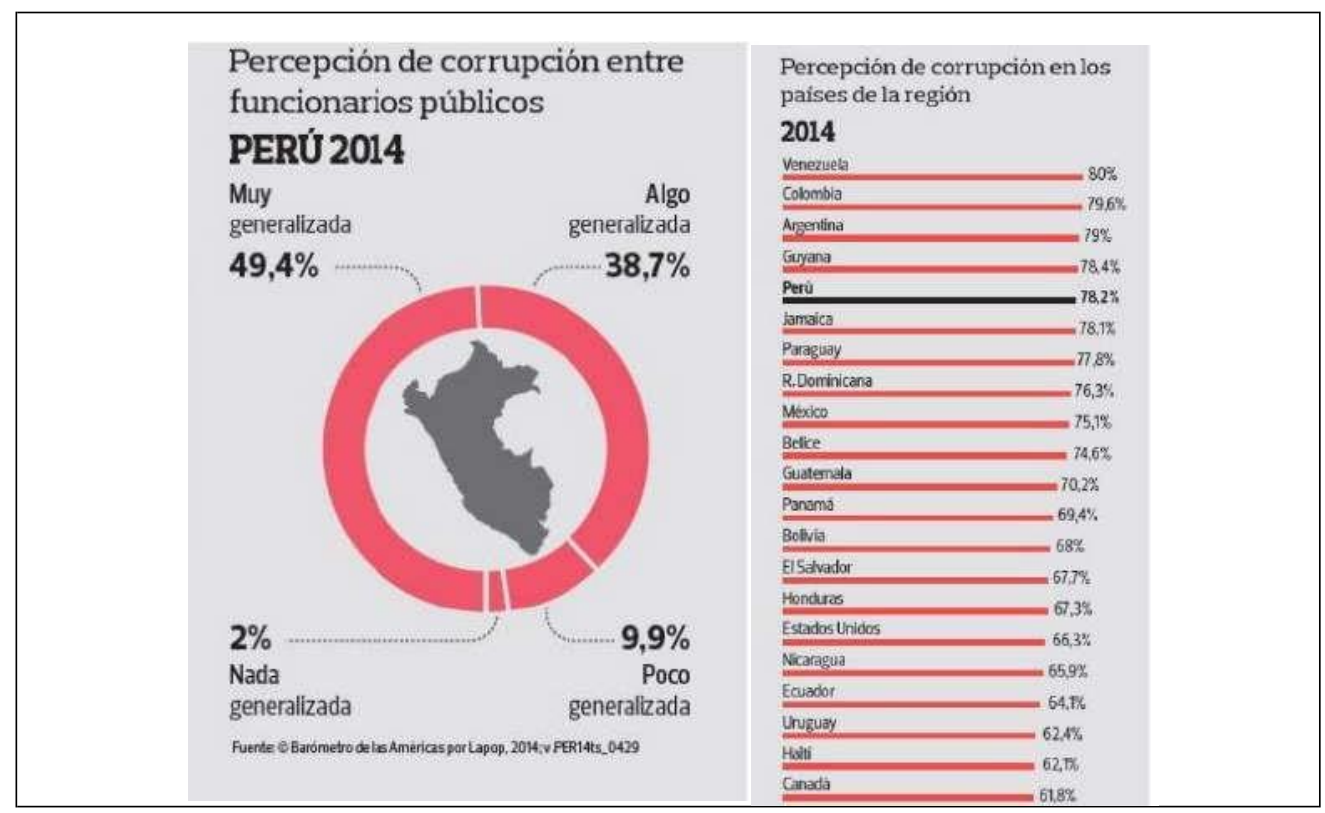

Figura 16. Percepción de corrupción en el país

Nota. Tomado de “¿Cuál es el costo de la corrupción en el Perú?,” por Diego Macera, 2016. Recuperado de http://elcomercio.pe/politica/actualidad/cual-costo-corrupcion-peru-informenoticia-1820300

El Banco mundial reporta que existe una baja confianza empresarial, de lenta implementación de algunos proyectos mineros y baja actividad del rubro inmobiliario, la inversión privada se redujo en un 7,5\%. La inflación terminópor encima del rango del BCR $(4,4 \%)$ por la depreciación del tipo de cambio que se reflejaen un aumento de las tarifas de electricidad y los precios de las inmobiliarias al vender sus inmuebles. 
Para el presente año se espera que el crecimiento del país seaparecido al 2015 y que, en el futuro, se recupere progresivamente a un ritmo promedio de $3,8 \%$ en 2017 2018. Bajo este criterio, las expectativas están en que se inicie los grandes proyectos en el rubro de la minería para los próximos años así como la mayor inversión pública y privada brindenun buen soporte a la demanda nacional.

\section{b). La política gubernamental y el consumidor}

El nivel de confianza del consumidor con base en la gestión del gobierno y el entorno económico, genera los efectos que se detallan a continuación según GFK, (ver anexo 8), en su encuesta nacional urbano rural realizada en Julio del presente año.

Se mantiene el nivel optimismo en los habitantes, actualmente se refleja un $110 \%$ (julio) dentro del rango optimista aumentando en $1 \%$, respecto al mes de junio del 109\%; se puede observar en el estudio, el nivel socioeconómico A y B refleja un $119 \%$ disminuyo en $6 \%$ en base al mes anterior $125 \%$; el nivel C se mantiene constante con un 114\%; el nivel D aumento en un 11\% llegando a este mes en $114 \%$; y en nivel E se contrajo en un $4 \%$ menos respecto al mes anterior, al pasar de $102 \%$ a $98 \%$.

En el tema de cómo percibe la familia peruana la situación económica en su empleo, ahorro, hogar y país para los próximos 12 meses, se obtuvo como resultado el siguiente análisis:

- Mejorará la situación de mi hogar, para el presente mes es de $42 \%$ comparado con el año pasado de $30 \%$, se refleja un aumento del $12 \%$. 
- El peruano podrá ahorrar, se refleja lo mismo al punto anterior $42 \%$ comparado con el año pasadode $30 \%$, se refleja un aumento del $12 \%$.

- Crecerá el empleo, para el presente mes es de $42 \%$ comparado con el año pasado de $20 \%$, se refleja un aumento del $22 \%$.

- Mejorará la situación del país, para el presente mes es de $42 \%$ comparado con el año pasado de $22 \%$, se refleja un aumento del $20 \%$.

Laura Amaya (2016) menciona que a pesar de que la confianza del consumidor sigue siendo de optimismo, existe una gran perspectiva de que la economía está detenida (66\% a nivel nacional, $72 \%$ en Lima). Es decir, no disminuimos pero tampoco sumamos. El 70\% de los encuestados opina que su economía personal sigue siendo la misma que la del 2015: ni buena, ni mala, el ciudadano percibe sabe que hay que cuidar los ingresos.

Se considera que la percepción sobre la mejora de la economía, según el índice de confianza del consumidor es una oportunidad para la empresa, ya que el aumento que experimenta de acuerdo al estudio podría generarun mayor consumo en la población, incremento de la demanda y una mayor oferta en el mercado. 


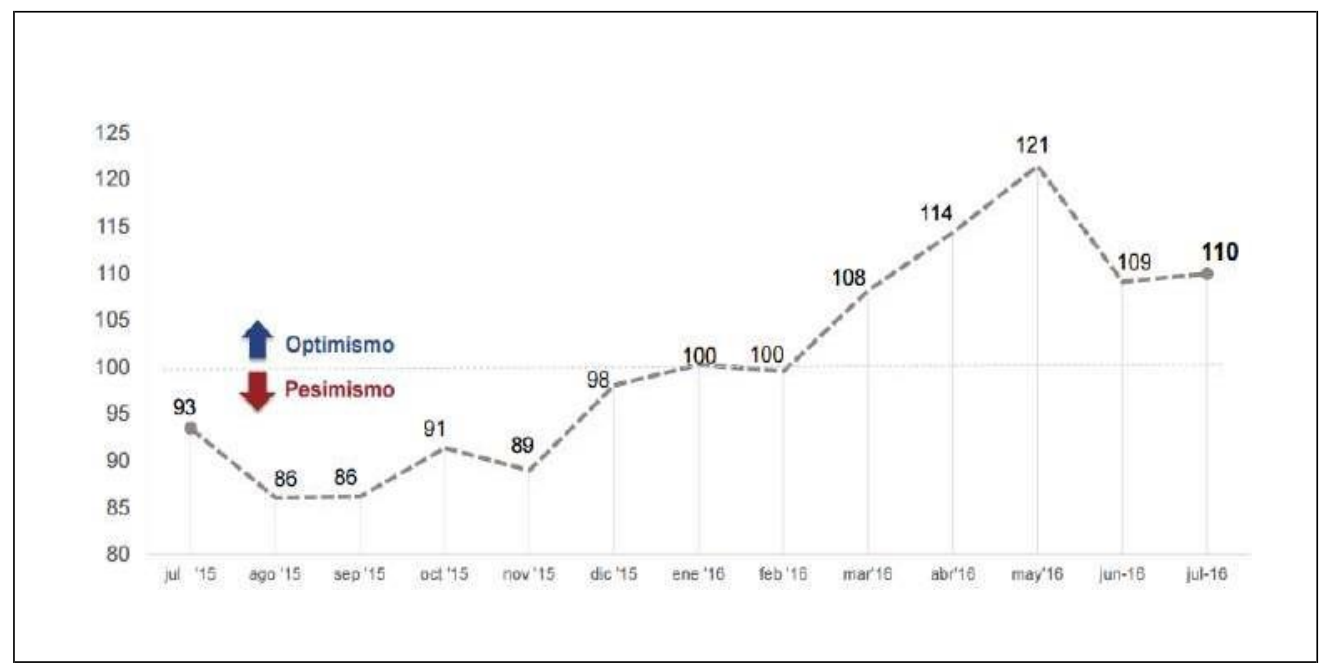

Figura 17. Índice de confianza del consumidor

Nota. Tomado de "GfK ICC y actitudes hacia la economía,” por Laura Amaya, 2016.

Recuperado de

https://www.gfk.com/fileadmin/user_upload/dyna_content/PE/GfK_Opinion_Julio_2016_Econo mia.pdf

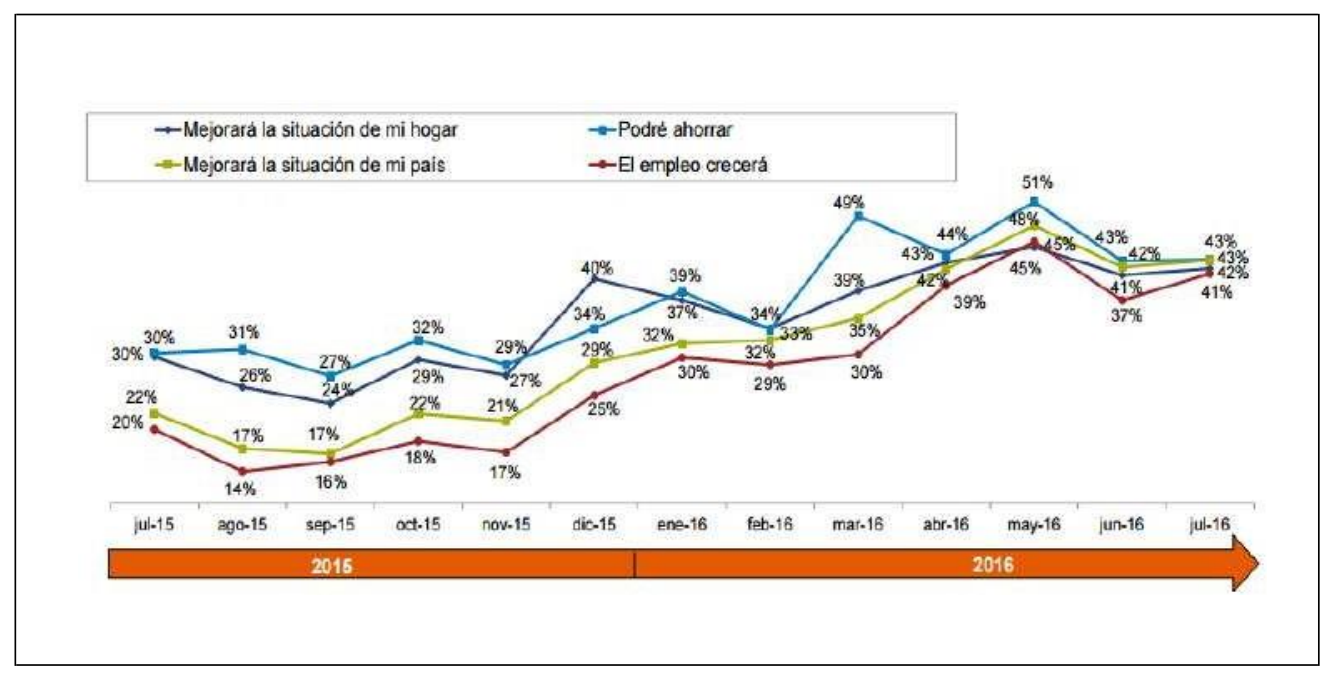

Figura 18. ICC Situación económica del hogar, país, empleo y ahorro

Nota. Tomado de "GfK ICC y actitudes hacia la economía," por Laura Amaya, 2016.

Recuperado de

https://www.gfk.com/fileadmin/user_upload/dyna_content/PE/GfK_Opinion_Julio_2016_Econo

mia.pdf 


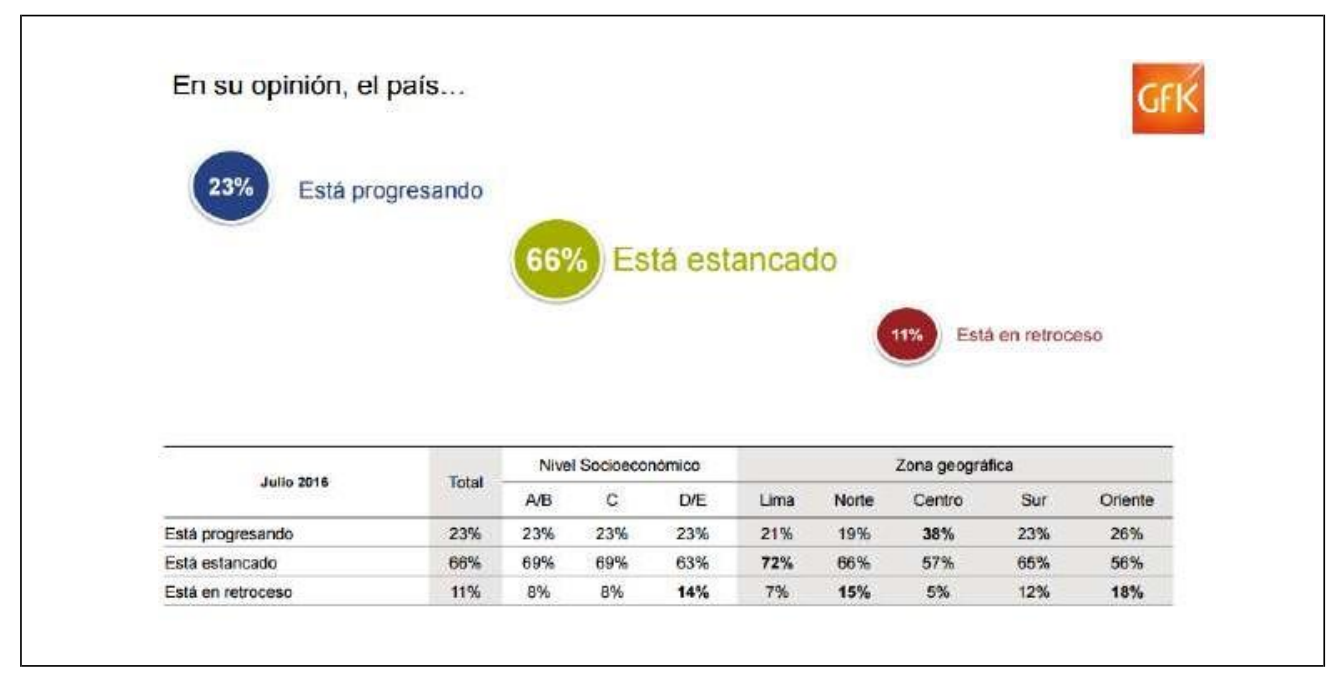

Figura 19. Perspectiva del país

Nota. Tomado de "GfK ICC y actitudes hacia la economía," por Laura Amaya, 2016.

Recuperado de

https://www.gfk.com/fileadmin/user_upload/dyna_content/PE/GfK_Opinion_Julio_2016_Econ omia.pdf

\section{c). Tratados Internacionales Vigentes}

El Ministerio de Comercio Exterior y Turismo,brinda en su página web, los tratados que en la actualidad tiene el país con el mundo. Los tratados internacionales son acuerdos vinculantes, con carácter de perpetuidad, que suscriben dos o más países para acordar la concesión de preferencias arancelarias.En la figura 20, se detallan los acuerdos con las cuales Perú tiene vigencia.

Estos tratados representan una oportunidad para el sector, debido a que los artículos que importa la empresa son de Colombia, Israel y China. Estas nacionestienen preferencias arancelarias, lo que podría generar la reducción de los costos. 


\begin{tabular}{|c|c|c|}
\hline \multicolumn{3}{|c|}{ Tratados Internaciones que tiene el Perú } \\
\hline \multicolumn{3}{|c|}{ Acuerdos multilaterales } \\
\hline Acuerdo pactado & \multicolumn{2}{|c|}{ firmado el: } \\
\hline Miembros de la OMC & \multicolumn{2}{|c|}{ ene-95 } \\
\hline \multicolumn{3}{|c|}{ Union de Aduanas } \\
\hline Acuerdo pactado & \multicolumn{2}{|c|}{ firmado el: } \\
\hline Comunidad Andina de Naciones & \multicolumn{2}{|c|}{ may-69 } \\
\hline \multicolumn{3}{|c|}{ TLC Vigente } \\
\hline Acuerdo pactado & firmado el: & Vigencia \\
\hline Alianza del Pacífico & feb-14 & jul-15 \\
\hline Unión Europea & jun-12 & $\begin{array}{c}\text { Aplicación provisional } \\
01 / 03 / 2013\end{array}$ \\
\hline Japón & may-11 & mar-12 \\
\hline Costa Rica & may-11 & jun-13 \\
\hline Panamá & may-11 & may-12 \\
\hline México (ACE 67) & $a b r-11$ & feb-12 \\
\hline Corea del Sur & nov-10 & ago-11 \\
\hline China & abr-09 & mar-10 \\
\hline AELC (Asociación Europea de Libre Come & jul-08 & jul-10 \\
\hline Singapur & may-08 & ago-09 \\
\hline Canadá & may-08 & ago-09 \\
\hline Chile & ago-06 & mar-09 \\
\hline Estados Unidos & abr-06 & feb-09 \\
\hline MERCOSUR (ACE 58) & nov-05 & \\
\hline Tailandia & & dic-11 \\
\hline \multicolumn{3}{|c|}{ TLC que no estan en vigencia } \\
\hline Acuerdo pactado & \multicolumn{2}{|c|}{ firmado el: } \\
\hline Honduras & \multicolumn{2}{|c|}{ may-15 } \\
\hline Guatemala & \multicolumn{2}{|c|}{ dic-11 } \\
\hline
\end{tabular}

Figura 20. Acuerdos comerciales del Perú

Nota. Tomado de "Acuerdos Comerciales del Perú," por Ministerio de Comercio Exterior y Turismo, 2016. Recuperado de http://www.acuerdoscomerciales.gob.pel 


\subsubsection{Análisis Económico}

\subsubsection{1 Ámbito Mundial}

Según, el Fondo Monetario Internacional FMI (2016), la economía mundial no está teniendo el crecimiento esperado en los últimos años, esto se debe, a un crecimiento muy lento y por un periodo muy largo, el cual se pronostica alrededor de un 3.2\% para el final del 2016 con una recuperación del 3,5\% para el 2017.El crecimiento de las economías de los países avanzados oscilará en el orden del 2\% anual siendo está muy baja y débil, esta desaceleración es provocada por factores demográficos adversos y productividad baja.

EnEstados Unidos se prevé un crecimiento del orden de $2.4 \%$ con un repunte moderado en el 2017;la demanda interna será impulsada por el mejoramiento del mercado inmobiliario, se espera que estos factores incidan sobre el freno de las exportaciones debido al fortalecimiento del dólar y la baja en el sector manufacturero.

Para la zona del Euro la baja inversión, los altos niveles de desempleo y los balances deteriorados perjudican el crecimiento, el cual será del orden del 1.5\% para el 2016 y se prevé del $1.6 \%$ para el 2017.

En Japón se espera un crecimiento del 0,5\% para el 2016 por descenso del consumo privado con tendencia a reducirse en el 2017 a - $-0.1 \%$ cuando se establezca el aumento del impuesto al consumo. 
Las economías emergentes y en desarrollo mostraran mayor desaceleración aunque estas son muy desiguales entre los países y se muestran más débiles en las últimas dos décadas. Este crecimiento será moderado y estará alrededor del 4.1\% mientras que para el 2017 sería del orden del $4.6 \%$.

Los factores que sustenta este pronóstico son:

- Los países exportadores de petróleo experimentan una desaceleración debido a la baja en los precios del barril y también existe incertidumbre para los países exportadores de materia prima de América Latina.

- Desaceleración de China donde el sector manufacturero se reorienta al consumo interno y de servicios.

- Recesión de Brasil y de Rusia acompañado por el crecimiento muy lento de países de América Latina y Oriente Medio, en espacial los afectados por el descenso del precio del petróleo y con problemas de inseguridad.

- Crecimientos de los países africanos con baja expectativas debido a problemas y conflictos internos y una desfavorable coyuntura internacional.

- Los países del ASEAN - 5, Indonesia, Filipinas, Malasia, Tailandia y Vietnam muestran un buen desempeño, en la India la situación sigue siendo buena mientras que los países de América Central se benefician con la recuperación de Estados Unidos. También estos países mejoran la parte manufacturera por la baja del petróleo.

Para Mongrut (2014), la economía mundial está recuperándose del fuerte impacto que le genero la crisis que inicio en el 2008, sin duda estamos a una década en que los grandes países 
no generan un PBI más de 1\%, por otro lado, los países que no dependen en su balanza comercial de estas grandes economías han sabido diversificar y crecer países como Perú, Panamá, Chile, Colombia, entre otros son ejemplo de ellas.

A continuación se detalla un breve resumen de la situación existente en el mundo:

- Menores precios de metales industriales

- Menor demanda por exportaciones no tradicionales

- Volatilidad en variables financieras:

- Tipo de cambio más alto

- Mayores costos de financiamiento

Los sectores más afectados en esta crisis que se vive en el mundo son:

- Minería e hidrocarburos

- Empresas orientadas a la construcción

- Sectores vinculados a la importación de bienes

- Inversión privada 


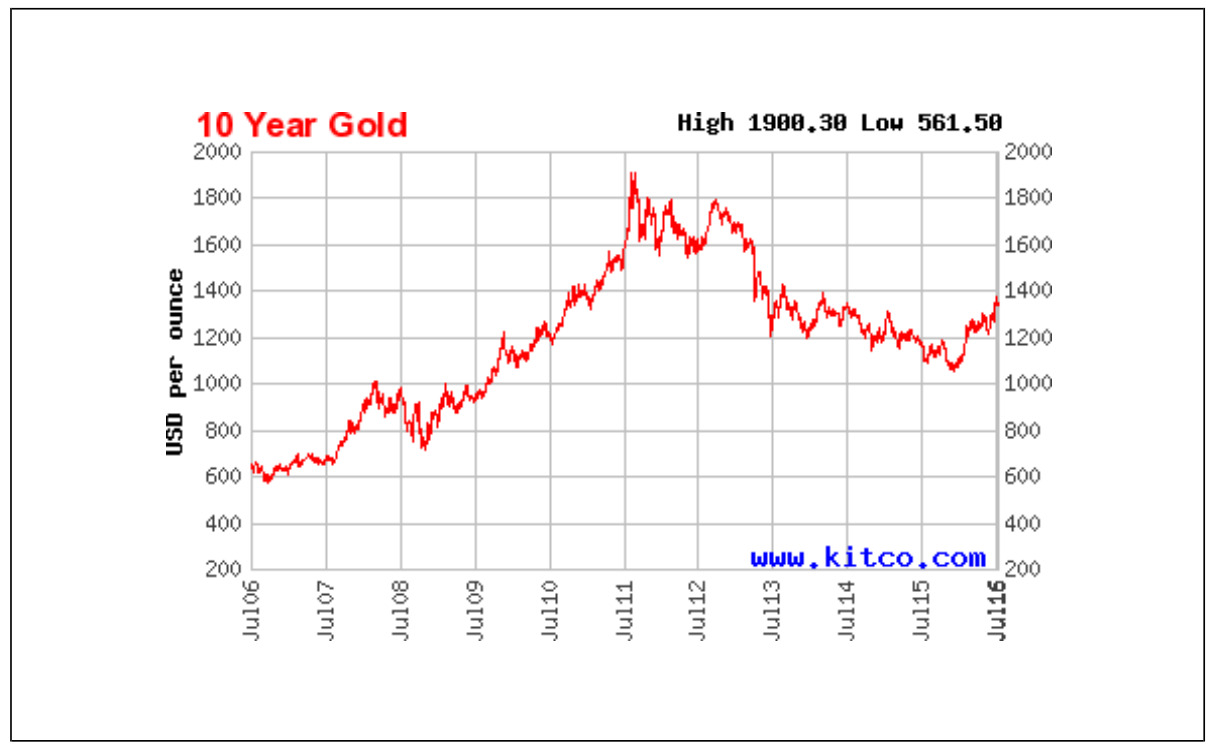

Figura 21. Histórico precio del oro

Nota. Tomado de “Latest Gold News," por Kitco, 2016. Recuperado de http://www.kitco.com/charts/popup/au24hr3day.html

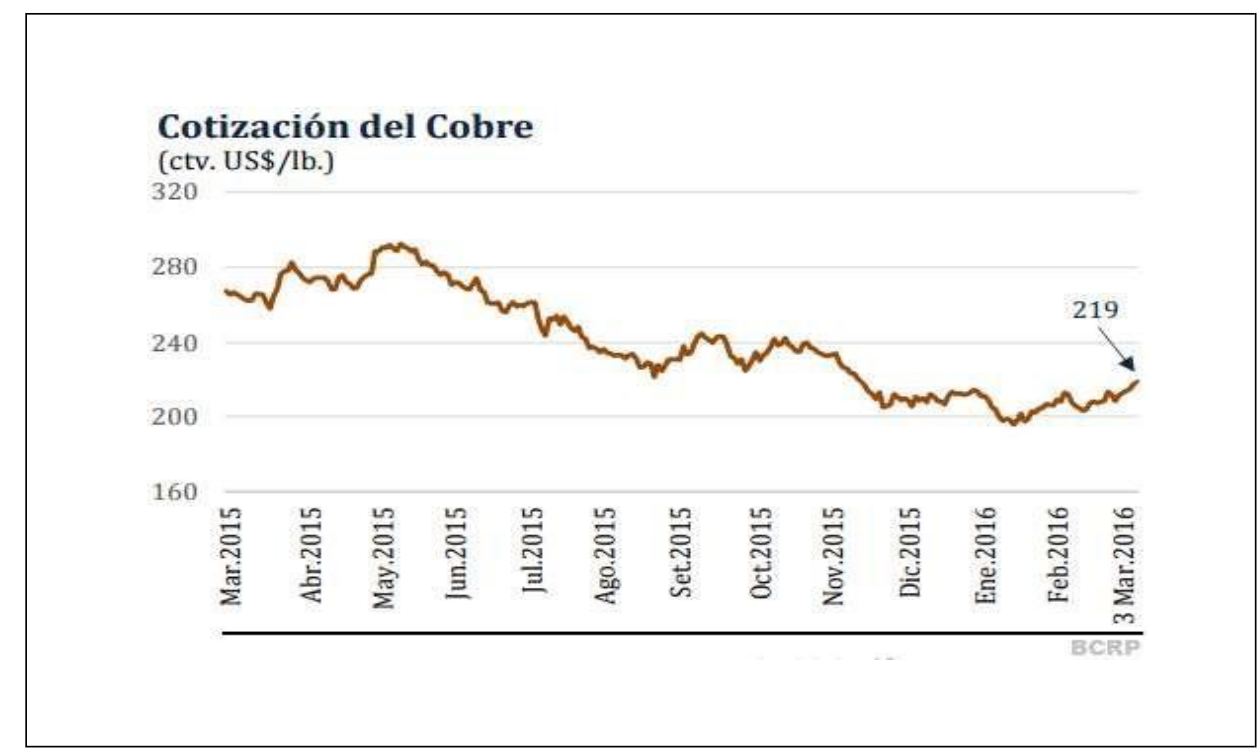

Figura 22. Precio internacional del cobre Nota. Tomado de "Cotización del cobre," por BCR, 2016. Recuperado de https://www.mef.gob.pe/contenidos/pol_econ/marco_macro/MMM_2017_2019.pdf 


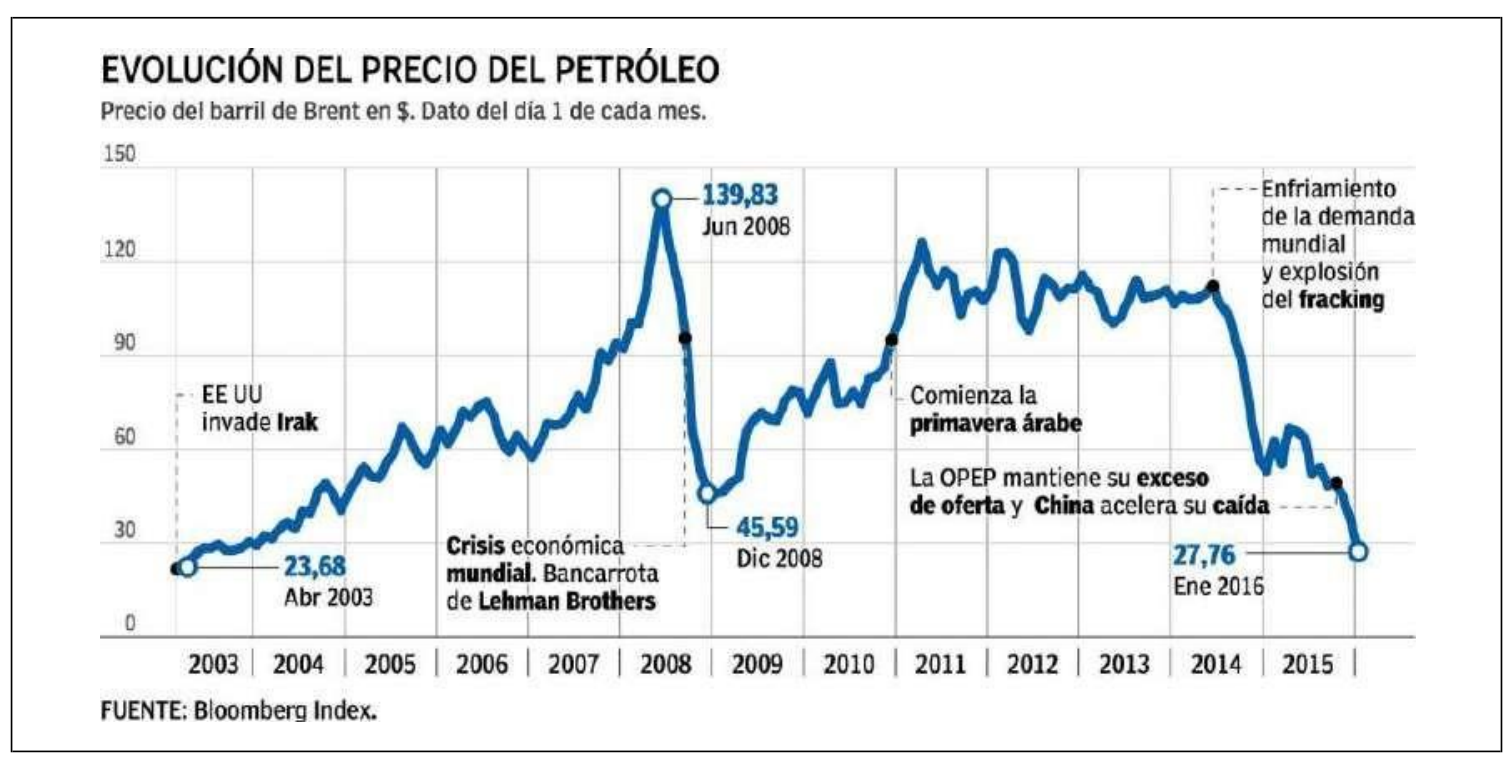

Figura 23. Evolución del precio del petróleo

Nota. Tomado de "Las 5 causas y 10 efectos de la crisis del petróleo," por 20 minutos noticias, 2016. Recuperado de http://www.20minutos.es/noticia/2653191/0/causas-efectos/crisispetroleo-barato/perjudicados-beneficiados/

\section{China: PIB Nominal}

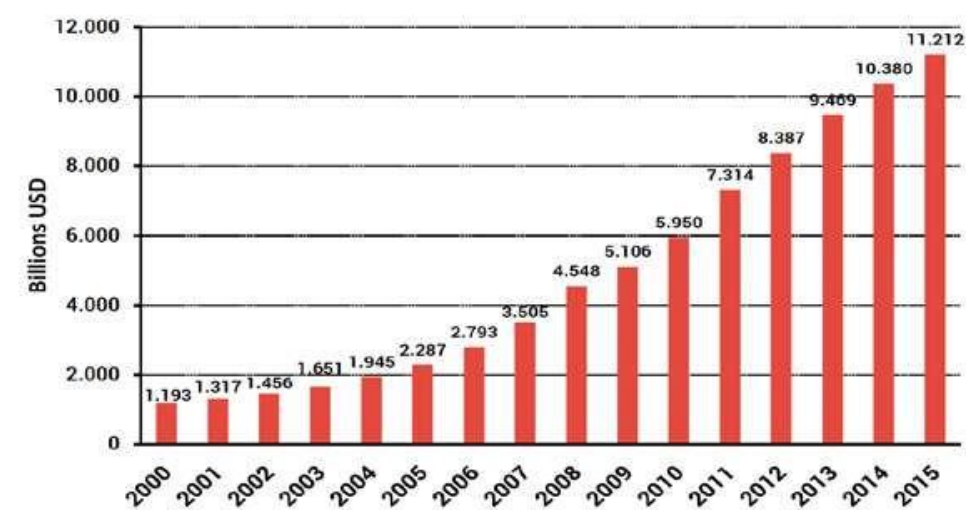

Figura 24. PBI Nominal de China

Nota. Tomado de “PBI de las principales potencias," por BCR, 2016. Recuperado de https://www.mef.gob.pe/contenidos/pol_econ/marco_macro/MMM_2017_2019.pdf 


\subsubsection{2 Ámbito Nacional}

\section{a. Producto Bruto Interno (PBI)}

Actualmente la economía nacional se encuentra en etapa de desaceleración,no estamos creciendo como en los años 2005 al 2012 donde existía un crecimiento por encima de 6\%, a excepción del año 2009 donde fue el mínimo crecimiento de todos apenas 1\%, la razón del desplome fue la crisis económica que golpeo a los principales países del mundo. En el año 2014 al año 2015 la economía genero un promedio de 4\%, aquí ya se muestra el descenso esto debido a las malas gestiones del gobierno y ante un mundo que experimento crisis en la minería e hidrocarburos, el último año se genera un PBI de 3.3\% debido al alza de los minerales. Los especialistas estiman un crecimiento de 4.0\% del PBI para el cierre del año 2016. (Ver figuras 25 у 26)

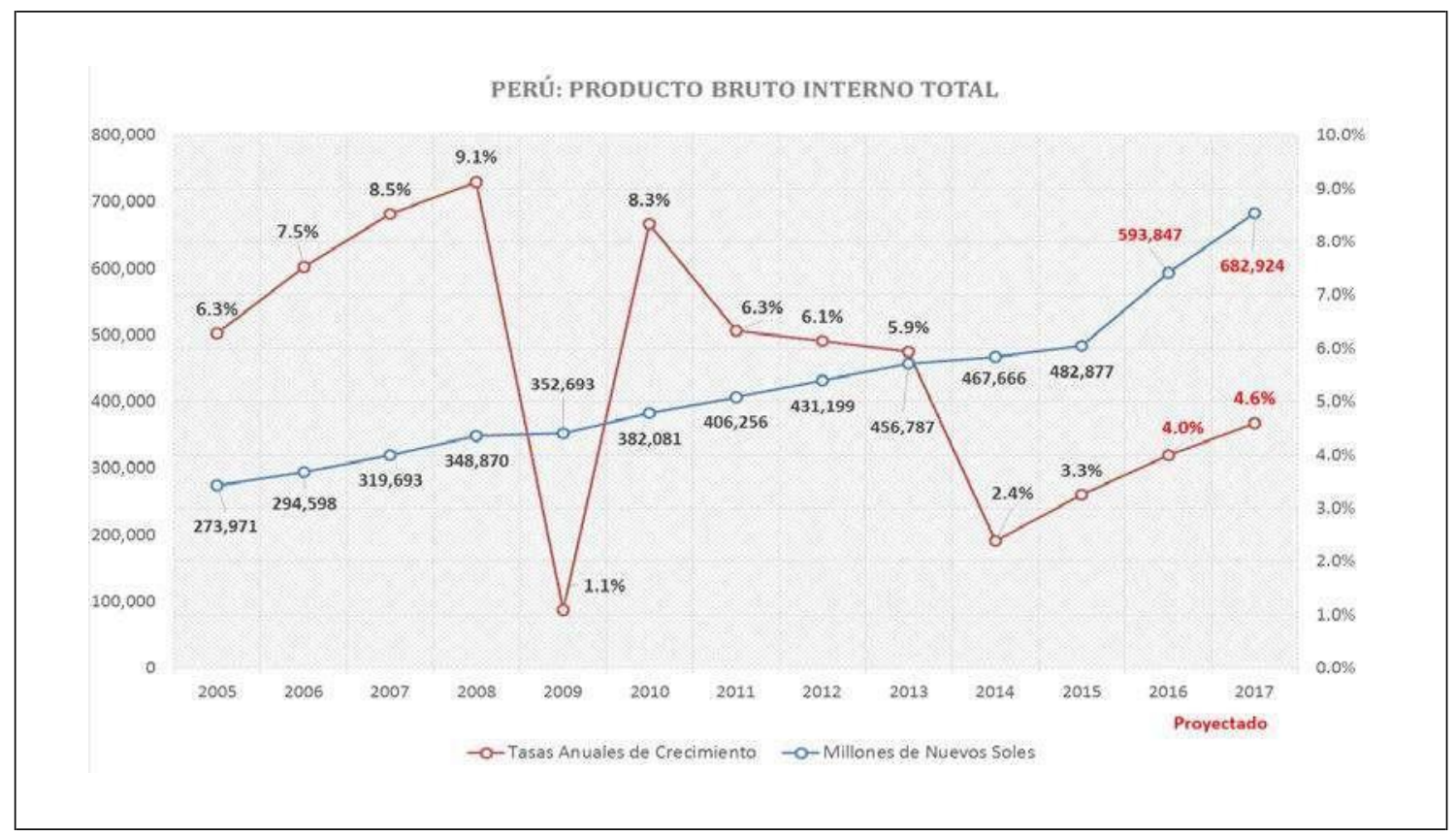

Figura 25. Producto Bruto Interno PBI de Perú

Nota. Tomado de "Perú más allá del 2016," por Apoyo consultoría, 2015. 


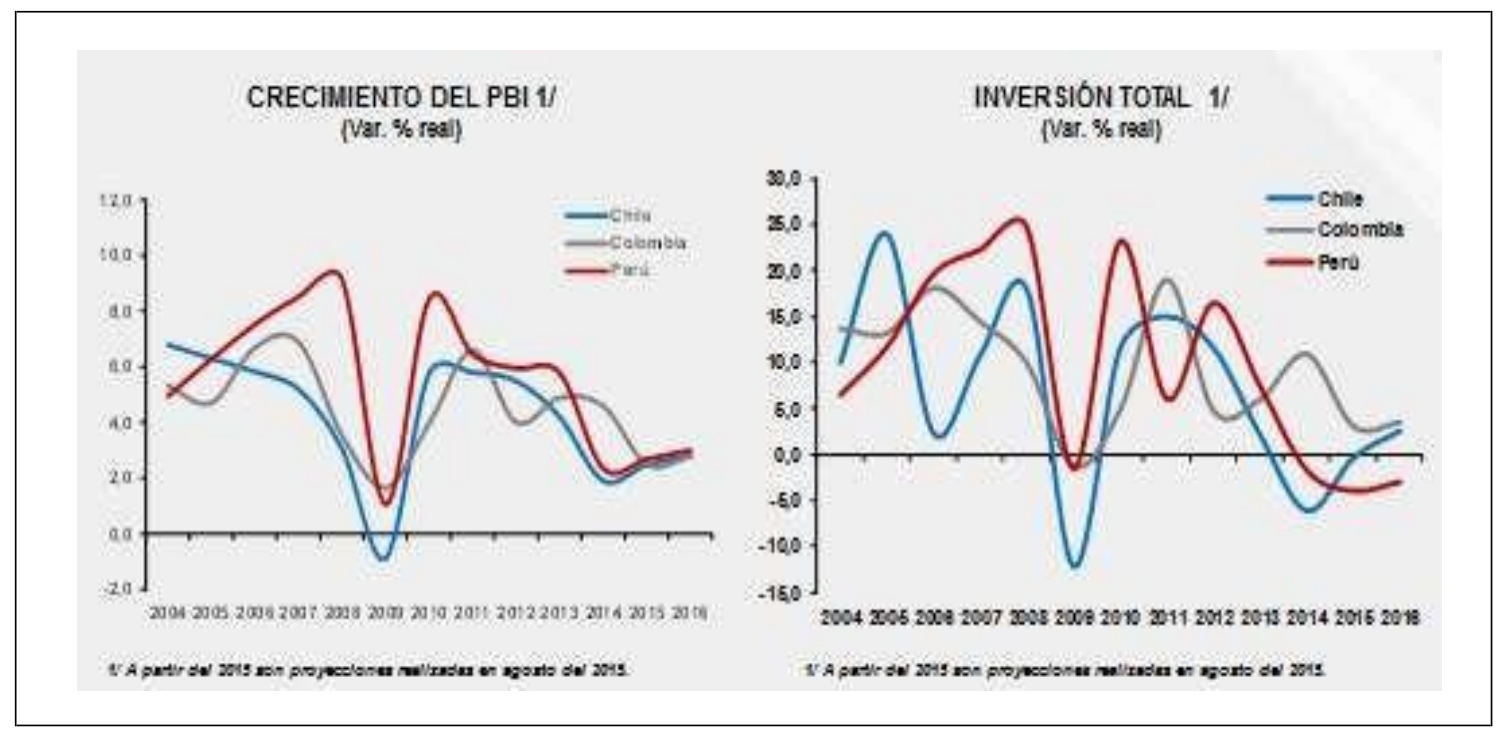

Figura 26.PBI proyectado para Chile, Colombia y Perú

Nota. Tomado de "Perú más allá del 2016," por Apoyo consultoría, 2015.

En la figura 27, se ve el compartamiento de los principales industrias en ellas se identifica que en el periodo 2009 comparado con 2008 todos los sectores experimentan una caida a excepción del hidrocarburos, esto por que el barril del petroleo se cotiza a mayor precio despues del impacto a la economia mundial; el año 2010 los sectores que mas contribuyeron con al incremento del PBI fueron la pesca, hidrocarburos; los minerales, la principal fuente de ingresos economicos al pais sigue teniendo una tendencia a la baja debido a los precios de los metales en el mercado mundial. La pesca se convierte en el actorcentral en el 2011 y es el principal protagonista en la recuperación del pais que junto con la industria minera que se incrementa lentamente. En el 2012 el comercio, otros servicios y la agricultura ayudan al pais a mantenerse sobre el $6 \%$ anual, aquí la pesca muestra una caida impresionante; nuevamente en el 2013 la pesca con la mineria vuelven a crecer representando en conjunto un 22\% del PBI. El 2014 fue un mal año ya que solo el sector comercio y otros servicios se mantuvieron en crecimiento. Mientras que en el año 2015, los restaurante, hoteles y turismo comienzan a tener 
mayor inversión; la pesca tiene un crecimiento y la minería repunta por el incremento de los metales.

\begin{tabular}{|c|c|c|c|c|c|c|c|c|c|c|}
\hline \multicolumn{11}{|c|}{ PBI por industria económica (porcentaje de variación anual) } \\
\hline & 2008 & 2009 & 2010 & 2011 & 2012 & 2013 & 2014 & 2015 & $2016^{*}$ & $2017^{\star}$ \\
\hline Agricultura y ganado & 8.0 & 1.3 & 4.3 & 4.1 & 5.9 & 1.0 & 1.4 & 2.8 & 2.3 & 3.9 \\
\hline Pesca & 3.0 & -3.4 & -19.6 & 52.9 & -32.2 & 18.1 & -27.9 & 15.9 & -2.4 & 29.7 \\
\hline Minería & 7.3 & -1.4 & -0.7 & -1.1 & 2.2 & 4.3 & -2.2 & 15.5 & 18.2 & 8.4 \\
\hline Hidrocarburos & 10.3 & 16.1 & 28.4 & 19.7 & 2.3 & 72 & 3.9 & -11.5 & -4.1 & 8.5 \\
\hline Manufactura & 8.6 & -6.7 & 10.8 & 8.6 & 1.5 & 5.1 & -3.3 & -1.7 & -1.8 & 3.8 \\
\hline Electricidad, gas y agua & 8.1 & 1.1 & 8.1 & 7.6 & 5.8 & 5.5 & 5.0 & 6.2 & 7.8 & 5.5 \\
\hline Construcción & 11.0 & -0.5 & 12.5 & 8.9 & 7.2 & 8.9 & 1.7 & -5.9 & 0.0 & 3.5 \\
\hline Comercio & 16.8 & 6.8 & 17.8 & 3.6 & 15.8 & 5.9 & 4.4 & 3.9 & 3.2 & 3.8 \\
\hline Otros servicios & 8.7 & 3.6 & 8.8 & 7.0 & 7.3 & 6.2 & 4.8 & 4.2 & 3.9 & 3.9 \\
\hline PBI & 9.1 & 1.0 & 8.5 & 6.5 & 6.0 & 5.8 & 2.4 & 3.3 & 4.0 & 4.6 \\
\hline $\begin{array}{l}\text { "Estimado } \\
\text { Fuente: BCRP / INEI (2015) }\end{array}$ & & & & & & & & & & \\
\hline
\end{tabular}

Figura 27. PBI por industria económica

Nota. Tomado de "Guía de negocios e inversión en el Perú," por EY, 2016. Recuperado de http://www.ey.com/Publication/vwLUAssets/EY-guia-de-negocios-e-inversion-peru-20162017/\%24FILE/EY-guia-de-negocios-e-inversion-2016-2017.pdf

Según los expertos entrevistados, el sector comercio y otros servicios se mantienen constante en la evolución del PBI en los últimos cinco años y también en la proyección al 2017, esto genera una gran oportunidad para el desarrollo de productos,se estima la inyección de capital por parte de los inversionistas, y la estabilidad dela industria de artículos de limpieza para el cuidado de la piel y el hogar. 


\section{b. Demanda Interna}

Según elBCP (2016), en un artículo en Gestión (ver anexo 8), se estima que el último tramo del anterior Gobierno perturbórígidamente la demanda y el consumo interno. El PBI del segundo trimestre solo crecióen un 3.7\%, una tasa menor a la de los dos trimestres anteriores, en tanto que la demanda interna escasamente creció $0.5 \%$ su menor registro en los últimos seis años y medio, llegando a $2.2 \%$ al cierre de agosto. Esto simboliza que el enfriamiento de la economía se ha pronunciado con mayor rigidez entre los peruanos de menores ingresos.

Esta mínima disposición de los consumidores a gastar sería uno de los factores que manifiestan que entre los meses de abril y julio la inflación haya sido tan baja, y que la tasa de esta inflación se haya reducido hasta situarse dentro dela meta del Banco Central de Reserva (entre $2 \%$ y $3 \%$ ). Esto podría causar preocupación en sectores como comercio o servicios, y generar tranquilidad en los consumidores al no subir el precio de los productos.

La recuperación en parte de la demanda y del consumo dependerá de que el Gobierno actué con celeridad, aprovechando que las perspectivas de compañías y personas están muy optimistas de invertir y consumir.

Según, los datos económicos: (a) Inversión privada: Negativo en -1.5\% en 2,014 y $3.8 \%$ en el 2,015; (b) Exportaciones: Negativo en $-1 \%$ en 2,014 y $-3.1 \%$ en el tercer trimestre de 2,015, (c) Inversión pública: Poco inversión en -2.5\% en el 2,014 y -27\% en el 2,015. 
Demanda interna (variación porcentual)

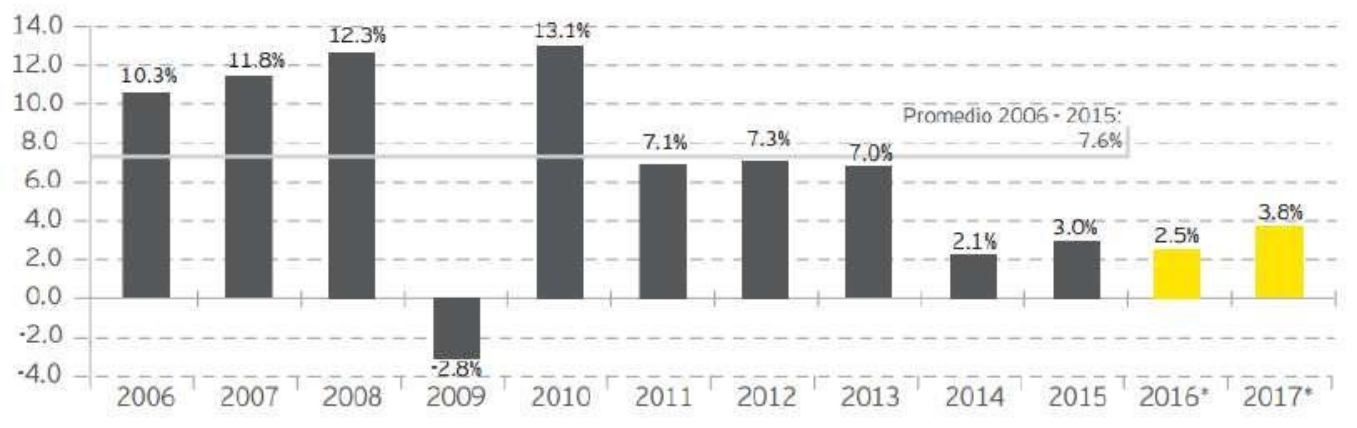

*Estimado

Fuente: BCRP

Figura 28. Demanda interna en el país

Nota. Tomado de "Guía de negocios e inversión en el Perú," por EY, 2016. Recuperado de http://www.ey.com/Publication/vwLUAssets/EY-guia-de-negocios-e-inversion-peru-20162017/\%24FILE/EY-guia-de-negocios-e-inversion-2016-2017.pdf

\begin{tabular}{|c|c|c|c|c|c|c|c|c|c|c|}
\hline \multicolumn{11}{|c|}{ PBI por tipo de gasto (variación porcentual) } \\
\hline Variables & 2008 & 2009 & 2010 & 2011 & 2012 & 2013 & 2014 & 2015 & $2016^{*}$ & $2017^{*}$ \\
\hline Producto Bruto Interno & 9.1 & 1.0 & 8.5 & 6.5 & 6.0 & 5.8 & 2.4 & 3.3 & 4.0 & 4.6 \\
\hline Importaciones & 26.2 & -16.0 & 29.3 & 9.8 & 10.4 & 3.6 & -1.4 & 2.4 & 0.3 & 3.5 \\
\hline Demanda Interna & 12.3 & -2.8 & 13.1 & 7.1 & 7.3 & 7.0 & 2.1 & 3.0 & 25 & 3.8 \\
\hline a. Consumo privado & 8.7 & 2.4 & 6.3 & 6.4 & 5.8 & 5.3 & 4.1 & 3.4 & 3.5 & 3.8 \\
\hline b. Consumo püblico & 2.1 & 16.5 & 7.9 & 4.8 & 9.4 & 6.7 & 10.1 & 9.5 & 4.7 & 1.0 \\
\hline Inversión Privada & 25.9 & -15.1 & 221 & 11.4 & 13.5 & 6.4 & -21 & -4.3 & 0.0 & 4.0 \\
\hline Inversión Pública & 33.6 & 21.2 & 26.7 & -18.0 & 20.8 & 12.1 & -2.0 & -7.5 & 10.3 & 7.9 \\
\hline Exportaciones & 9.9 & -2.9 & 4.8 & 8.8 & 5.4 & -0.9 & -0.8 & 3.3 & 6.4 & 6.4 \\
\hline $\begin{array}{l}\text { *Estimado } \\
\text { Fuente: BCRP }\end{array}$ & & & & & & & & & & \\
\hline
\end{tabular}

Figura 29. PBI por tipo de gasto en el país

Nota. Tomado de "Guía de negocios e inversión en el Perú," por EY, 2016. Recuperado de http://www.ey.com/Publication/vwLUAssets/EY-guia-de-negocios-e-inversion-peru-20162017/\%24FILE/EY-guia-de-negocios-e-inversion-2016-2017.pdf 


\section{c. Balanza Comercial}

El BCR (2016), informo que en diciembre las exportaciones totales fueron US\$ 3,170 millones, y un total de US\$34,157 millones en el año 2015, por otro lado, las importaciones dieron un total de US\$ 2960 millones en diciembre yun total de US\$ 37021 millones en el año generando un déficit comercial en los últimos dos años (ver figura 31).

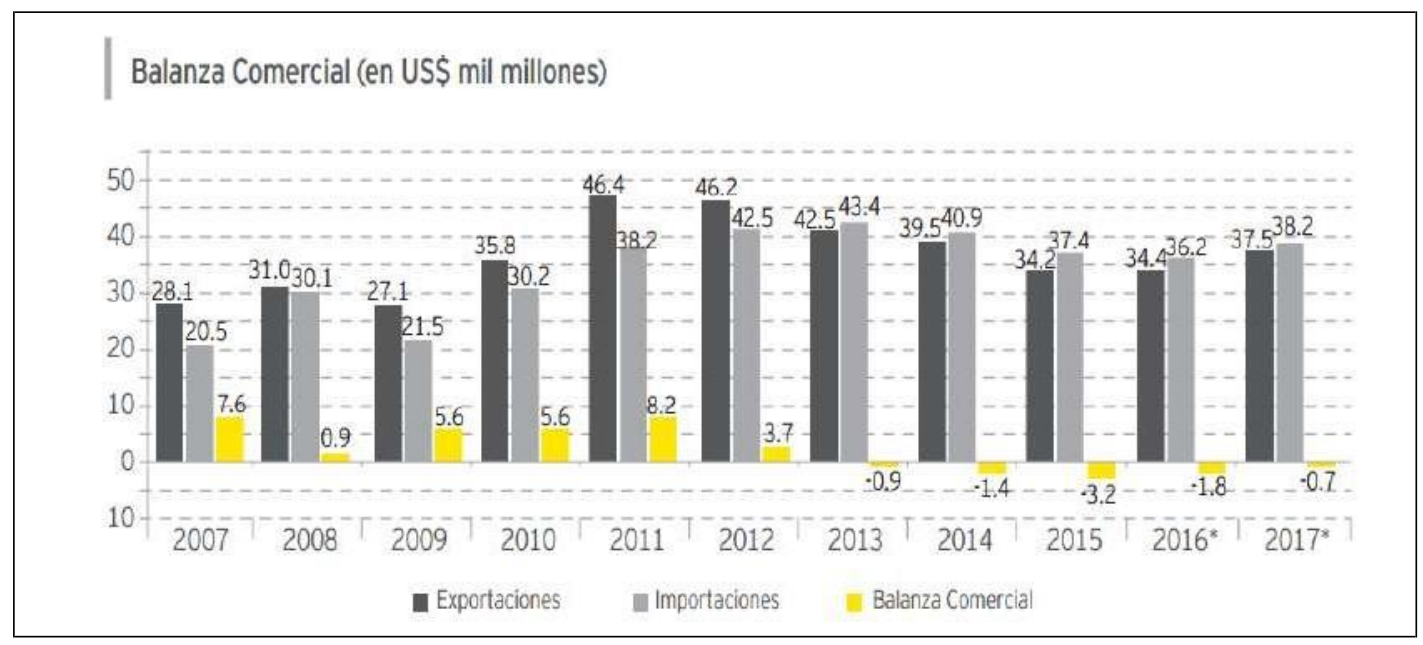

Figura 30. Balanza comercial peruana

Nota. Tomado de "Guía de negocios e inversión en el Perú," por EY, 2016. Recuperado de http://www.ey.com/Publication/vwLUAssets/EY-guia-de-negocios-e-inversion-peru-20162017/\%24FILE/EY-guia-de-negocios-e-inversion-2016-2017.pdf

El déficit comercial representa una gran amenaza, dado que la empresa importa de Colombia los guantes de látex para su comercialización en el país; los efectos que causarían el déficit en la balanza comercial para la industria son:

- Incremento en el tipo de cambio, esto tendrá un efecto de mayor costo del producto reduciendo el margen de ganancia.

- Alza de precios en los productos importados (inflación), donde al subir el precio en divisas, genera la subida del precio de los productos importados. 
- Incremento de los conflictos sociales, se darían a raíz del alza del tipo de cambio, la disminución de reservas, medidas urgentes de disminución y desempleo en el país.

\section{d. Tipo de cambio}

Para el BCR (2016) la cotización del dólar, llegará en un rango entre S/ 3.45 y S/ 3.50, la depreciación del sol en los últimos días,coincide con la debilidad en curso en la economía, debido a la desaceleración de exportación de materias primas y la caída de precios de los minerales entre ellos el cobre y estaño.

Se considera que la tendencia al alza del dólar, representa una amenaza, ya que los productos de Eterna son importados y se pagan con dólares, esto tendrá un efecto de mayor costo del producto reduciendo el margen de ganancia en la corporación.

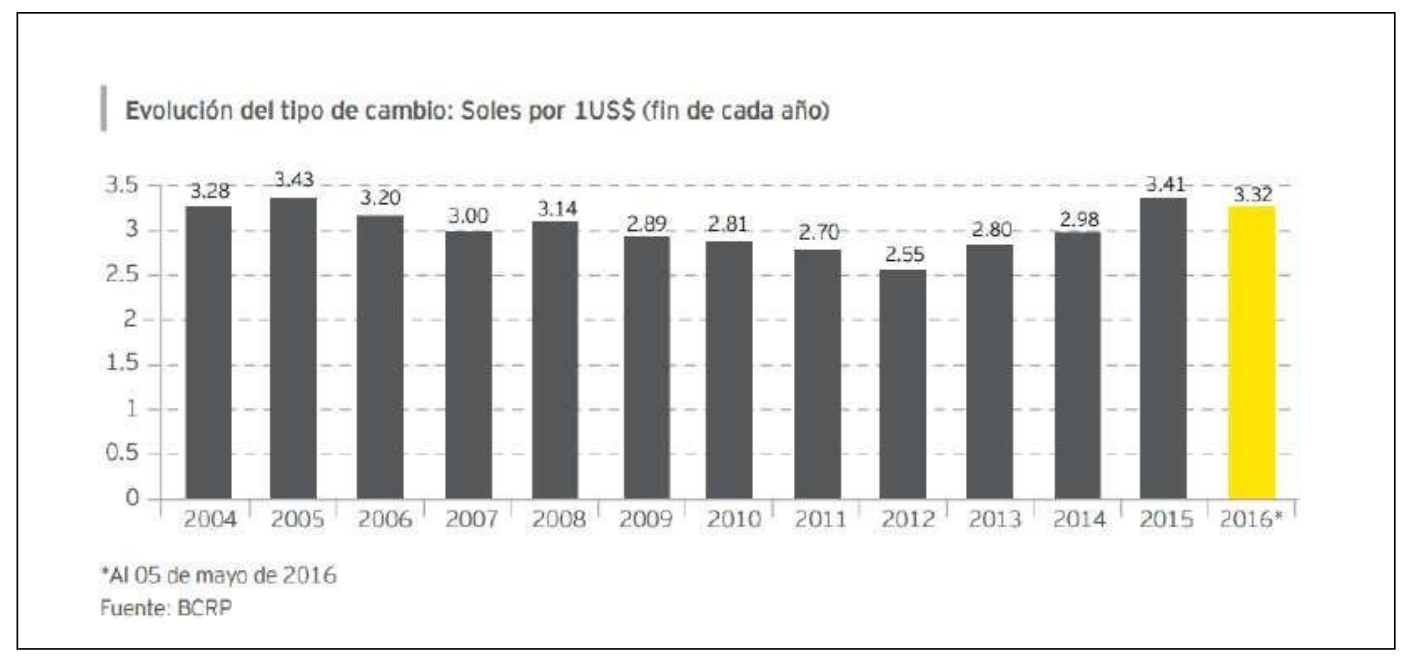

Figura 31. Evolución del tipo de cambio en soles

Nota.Tomado de "Guía de negocios e inversión en el Perú," por EY, 2016. Recuperado de http://www.ey.com/Publication/vwLUAssets/EY-guia-de-negocios-e-inversion-peru-20162017/\%24FILE/EY-guia-de-negocios-e-inversion-2016-2017.pdf 


\begin{tabular}{|c|c|c|c|}
\hline & \multicolumn{3}{|c|}{ Encuesta realizada al: } \\
\hline & 31 Mar.2016 & 29 Abr. 2016 & 30 May.2016 \\
\hline \multicolumn{4}{|c|}{ Analistas Económicos $1 /$} \\
\hline 2016 & 3,63 & 352 & 3,50 \\
\hline 2017 & 3,68 & 3.63 & 3,60 \\
\hline 2018 & 3,70 & 365 & 3,65 \\
\hline \multicolumn{4}{|c|}{ Sistema Financiero $2 /$} \\
\hline 2016 & 3,55 & 3,50 & 3,45 \\
\hline 2017 & 3,65 & 3,50 & 3,53 \\
\hline 2018 & 3,70 & 360 & 3,58 \\
\hline \multicolumn{4}{|c|}{ Empresas No financieras 3 / } \\
\hline 2016 & 3,55 & 350 & 3,50 \\
\hline 2017 & 3,60 & 3,54 & 3,52 \\
\hline 2018 & 3,65 & 3,60 & 3,60 \\
\hline \multicolumn{4}{|c|}{ 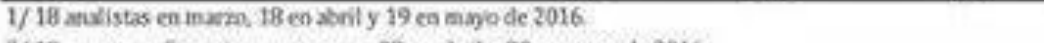 } \\
\hline \multicolumn{4}{|c|}{ 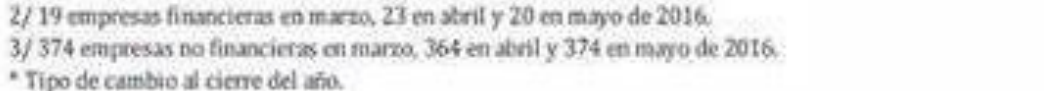 } \\
\hline
\end{tabular}

Figura 32. Encuesta de Expectativas macroeconómicas por tipo de cambio Nota. Tomado de “En cuánto cerrará el dólar el 2016 y 2017?,” por LatinFocus, 2016. Recuperado de http://rpp.peleconomialeconomia/en-cuanto-cerrara-el-dolar-el-2016-aquitodas-las-proyecciones-noticia-938975

\section{e. Inflación}

La inflación fue de $4.4 \%$ en el 2015, a pesar que el BCR estimo un promedio de 3.0\%; empleo creció menos de 1\%; el aumento del sueldo real según la CEPAL fue de 0\%; asimismo, el BCR proyectó que la inflación cerrara en $3.5 \%$ o $2.0 \%$ este año y llegaría al 2017 en 2\% (ver figura 33)

Los efectos de esta inflación afectan directamente la economía de los hogares en el país, generando un ajuste en su presupuesto diario, dejando de comprar algunos productos que en su momento consideraban indispensables; el guante para limpieza del hogar puede ser considerado 
por estas personas como un bien que no tendría un efecto en su calidad de vida si lo deja de usar representando una amenaza, pero si la inflación se mantiene dentro del rango meta del BCR (3.5\%), esto impulsara su consumo generando oportunidades a la compañía.

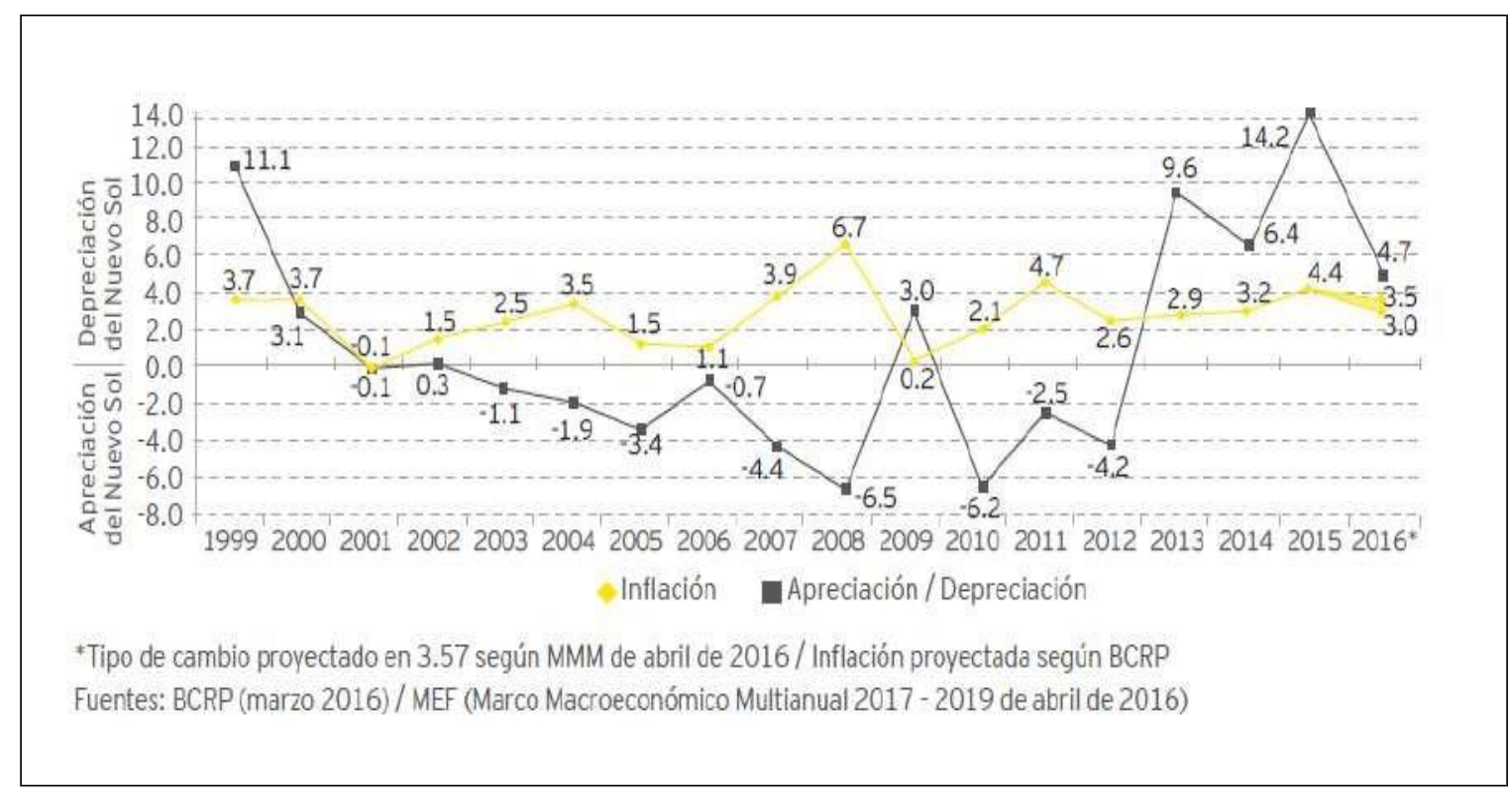

Figura 33. Evolución de la inflación en el país

Nota. Tomado de "Guía de negocios e inversión en el Perú," por EY, 2016. Recuperado de http://www.ey.com/Publication/vwLUAssets/EY-guia-de-negocios-e-inversion-peru-20162017/\%24FILE/EY-guia-de-negocios-e-inversion-2016-2017.pdf

\section{f. Tasa de referencia Interbancaria}

En lo que va del año y por sexto mes consecutivo, el BCR mantiene la tasa de referencia en $4.25 \%$, con intención de mantenerse estable por todo el 2016, este rango se mantiene porque la inflación se encuentra dentro del rango meta a lo que va del año, otro motivo es que algunos alimentos y el tipo de cambio sobre la inflación se han venido invirtiendo y la agilidad económica local viene ascendiendo a un ritmo próximo a su potencial.A esto se complementa que la economía mundial continúa registrando signos mixtos de recuperación en el 
empleoformal y la producción, así como una mínima volatilidad en los principales mercados financieros.

Se considera que la baja tasa de referencia es una oportunidad para Eterna, al haber más dinero circulando en la entidades financieras para financiamiento a las compañías, esto genera inversión y mayor utilidad, oportunidades de empleo y aumento del consumo en el mercado nacional.

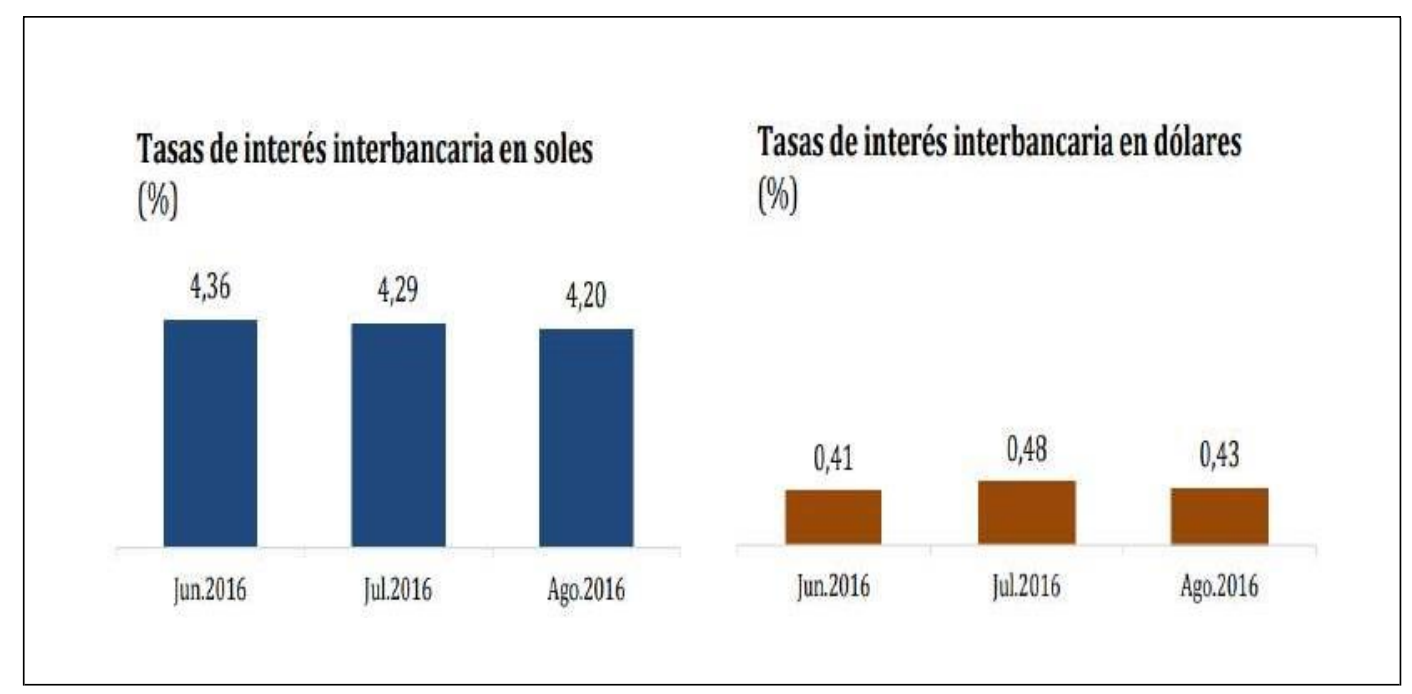

Figura 34. Operaciones monetarias y tasa de interés

Nota. Tomado de "Nota semanal $N^{\circ} 33$," por BCR, 2016. Recuperado de

http://www.bcrp.gob.pe/docs/Publicaciones/Nota-Semanal/2016/ns-33-2016.pdf

\section{g. Política arancelaria}

El Perú tiene un convenio internacional con el país de Colombia, en el Acuerdo de la Alianza del Pacifico; esto genera que los productos de caucho actualmente no paguen arancel (ver anexo 10). Esto representa una oportunidad ya que aumentaran las utilidades netas al 
reducir los costos de importación de los artículos de caucho (guantes) importados por Eterna, de la casa matriz colombiana.

\subsubsection{Análisis Legal}

\section{a. Hacer negocios en el País}

El país tiene un marco jurídico que no requiere solicitarautorizaciónprevia para la inversión internacional. De esta forma, las inversiones de los países de la región son permitidas sin mostrar restricción en la mayoría de las actividades económicas. Son pocas actualmente las empresas que cuentan con restricciones económicas entre ellas figuran las industrias aéreas, transporte víamarítima, seguridad y custodia privada, y elaboración de armas de Guerra.

Las normas, regulaciones y ejecución de las leyes peruanas aplican al principio dela no discriminación en la empresa extranjera y nacional. No hay restricción para repartir las utilidades, la transferencia de capital internacional, o practicas del cambio de moneda. Las regalías e inversión tampoco tienen restricción alguna. La moneda internacional puede utilizarse para cubrir obligaciones financieras, siempre que se cumpla con la norma tributaria.

Respecto a las regulaciones, si bien no se observan demasiadas variaciones legales que afecte al negocio, se observa que las empresas internacionales tienen apoyo del gobierno para que estas inviertan en el país, a continuación se detallan: 
(a) Ámbito legal aplicado a empresas internacionales, con la finalidad de promover la inversión privada, el Perú ha establecido un marco legal estable y atractivo para la inversión, tanto nacional como extranjera;

(b) El Decreto Legislativo $\mathrm{N}^{\circ}$ 662, que Aprueba el Régimen de Estabilidad Jurídica a la Inversión Extranjera, El Decreto Legislativo $N^{\circ} 757$, que aprueba la Ley Marco para el Crecimiento de la Inversión Privada, y

(c) El Reglamento de los Regímenes de Garantía a la Inversión Privada aprobado por el Decreto Supremo 162-92-EF.

Las inversiones extranjeras son permitidas sin restricciones en la gran mayoría de actividades económicas y no requieren de autorización previa generando gran amenaza a las empresas del rubro artículos de limpieza que en su mayoría son empresas internacionales con sucursales en el Perú.

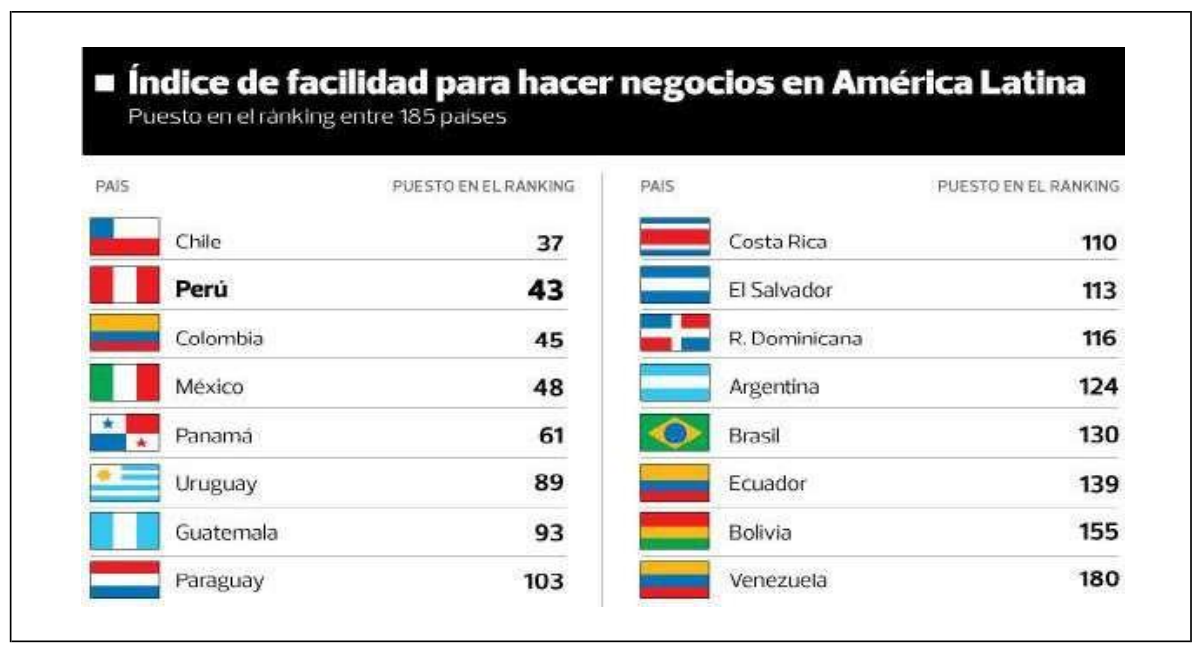

Figura 35. Índice de facilidad para hacer negocios

Nota. Tomado de "Índice de facilidad para hacer negocios en américa latina," por Banco mundial, 2016. Recuperado de http://www.bcrp.gob.pe/docs/Publicaciones/NotaSemanal/2016/ns-33-2016.pdf 


\section{b. Régimen Laboral}

Para JorgeGonzález (2015) el Perú es uno de los países con mayor informalidad en el ámbito laboral, superando a México, Argentina y Chile, por lo que se encuentra entre los 15 países con mayor rigidez en el mundo en contratación y despido. La situación actual en el campo laboral no es propicio, dado que las leyes peruanas y su interpretación son tan rígidas que frenan el avance adecuado del desarrollo del empleo formal. Se considera, que una regulación laboral debe garantizar la sostenibilidad de las compañías y la defensa social de los trabajadores, sin embargo ello no sucede actualmente en el país.

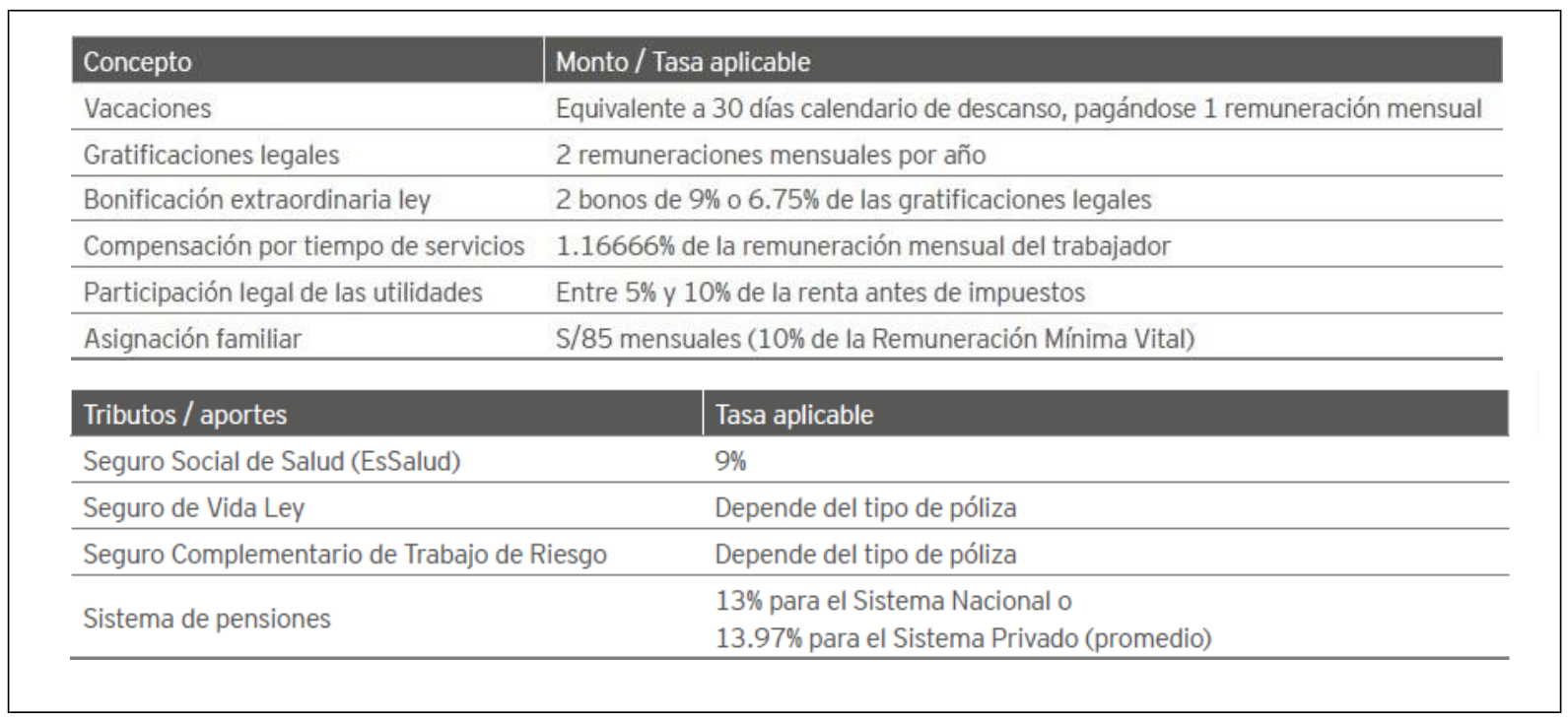

Figura 36. Costos laborales en el país Nota. Tomado de "Guía de negocios e inversión en el Perú," por EY, 2016. Recuperado de http://www.ey.com/Publication/vwLUAssets/EY-guia-de-negocios-e-inversion-peru-20162017/\%24FILE/EY-guia-de-negocios-e-inversion-2016-2017.pdf 
Por otro lado, los altos costos laborales desaniman al inversionista, generando una amenaza al empleador, por lo que significa los altos costos que requiere contratar al personal generando una menor utilidad y un alto gasto administrativo para la compañía (ver figura 36).

\subsubsection{Análisis Cultural y Demográfico}

\section{a).Cliente intermediario y canales modernos}

En la actualidad los clientes (distribuidores para este caso) tiene su propia política de pagos, las empresas que comercializan los guantes de látex en su mayoría tiene un bajo poder de negociación, ya que existen muchas competencia en el mercado y una guerra de precios. A pesar de esta situación, la tasa de morosidad ha estado disminuyendo en los años anteriores. Ver figura 37.

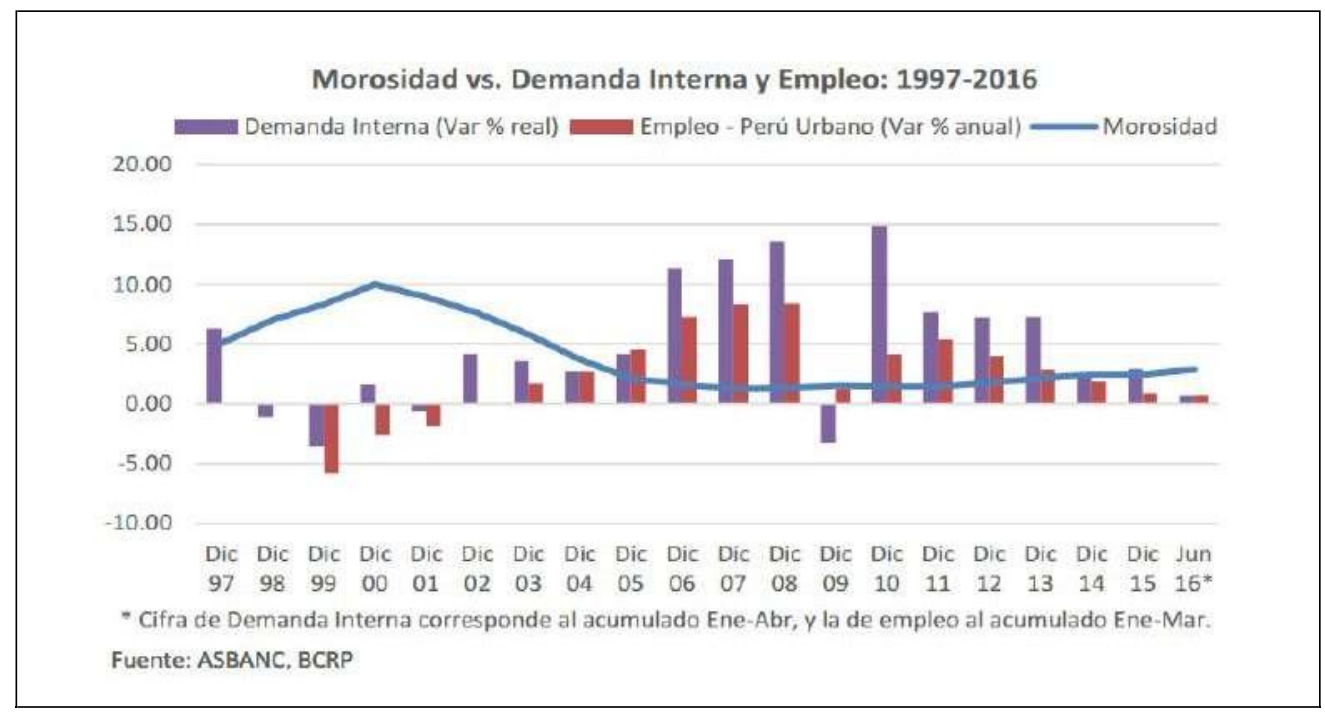

Figura 37.Morosidad vs demanda interna y empleo 1997 - 2016

Nota.Tomado de "Asbanc prevé reducción de morosidad bancaria por repunte de demanda interna," por Asbanc, BCR, 2016. Recuperado de http://semanaeconomica.com/article/mercados-y-finanzas/banca-y-finanzas/195029-asbancpreve-reduccion-de-morosidad-bancaria-por-repunte-de-demanda-internal 
Otro aspecto, en la cultura de compras por parte de los distribuidores es comprar quincenal y otros semanal. Esta compra se realiza a solicituddirecta y no se realiza el uso de la tecnología, lo mismo sucede con el canal moderno se estipula reuniones para saber el día de entrega y medio de pago que en su mayoría sobrepasa los tres meses, generando poco flujo de caja para la empresa representando una amenaza ya que mantiene sin efectivo a la compañía para cubrir los costos.

\section{b). El Perú y la educación}

Respecto al nivel de educación en el país, se puedeindicar un incremento de egresados entre ellos profesionales y técnicos. Así, los profesionales del rubro de ingeniería tienen cada vez mayor demanda de acuerdo a un artículo periodístico del diario Gestión. También, se señala que la ingeniería civil está dentro de las 10 carreras más demandada, lo que representa mayor oportunidad para los peruanos, trayendo como consecuencia la mejora de estilo de vida de los profesionales que egresan de las universidades.

El actual nivel de educación favorece a las empresas al contar con profesionales peruanos capacitados. En la tabla 14 se puede apreciar el nivel de competencias respecto a la innovación en el Perú

Por otro lado, debido a la situación actual en España y otros países hay una ola de inmigrantes europeos altamente calificados que buscan laborar en las empresas en Perú. Desafortunadamente, su contratación implica un alto costo para las empresas. 
Tabla 14

Perú en el ranking mundial de educación

\begin{tabular}{lccc}
\hline Principal Indicador & 2012 & \multicolumn{2}{c}{$2012-2013$} \\
& Puesto 1 & Puesto 2 & Puntos 3 \\
\hline Innovación & 110 & 113 & 2.7 \\
1. Capacidad de Innovación & 95 & 99 & 2.7 \\
2. Calidad de las instituciones de investigación científica & 109 & 109 & 2.9 \\
3. Gastos de las empresas en investigación y desarrollo & 113 & 118 & 2.6 \\
4. Colaboración universidad - Industrias en I\&D & 95 & 103 & 3.2 \\
5. Adquisición del gobierno de tecnología avanzada & 93 & 98 & 3.3 \\
6. Disponibilidad de científicos e ingenieros & 101 & 102 & 3.5 \\
7. Patentes concedidas & 85 & 83 & 0 \\
\hline
\end{tabular}

Nota. Tomado de WorldEconomicForum. The Global Competitiveness

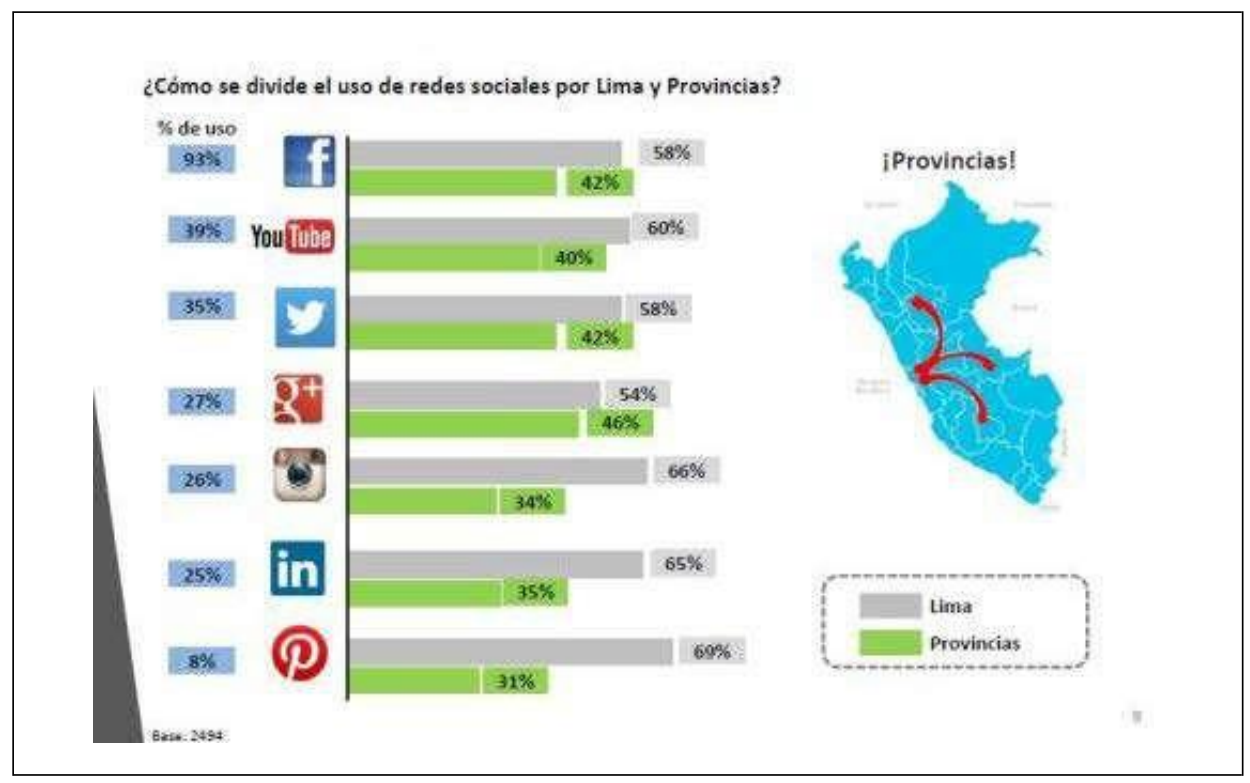

Figura 38. Uso de redes sociales en el Perú

Nota. Tomado de "Redes sociales en Perú," por Arellano Marketing, 2016. Recuperado de http://arrobisima.com/redes-sociales-en-el-peru/ 


\section{c).Perfil del ciudadano peruano por NSE}

Actualmente, según APEIM 2015 el perfil del ciudadano peruano se encuentra marcado por cinco niveles socio económico A, B, C, D y E.(ver Tabla 15). Cada perfil representa una oportunidad para la adquisición de guantes, debido que hay un manejo estable de la economía del consumidor.

Así, para los sectores que obtienen ingresos por encima de los 6000 soles en promedio, los guantes pueden ser un producto de la canasta básica en el futuro; mientras que para los sectores de menor nivel adquisitivo el uso de guantes puede ser ocasional y no tiene una demanda permanente.

Por otro lado, Arellano (2011) identifico que existen determinados estilos de vida entre la población del país. Así tenemos;

- Los modernos, es el más amplio del país (27\%)

- Los progresistas (21\%)

- Los adaptados (18\%),

- Las conservadoras (18\%)

- Los sofisticados $(8 \%)$

- Los resignados $(8 \%)$ 
Tabla 15

Perfil de los niveles socioeconómicos

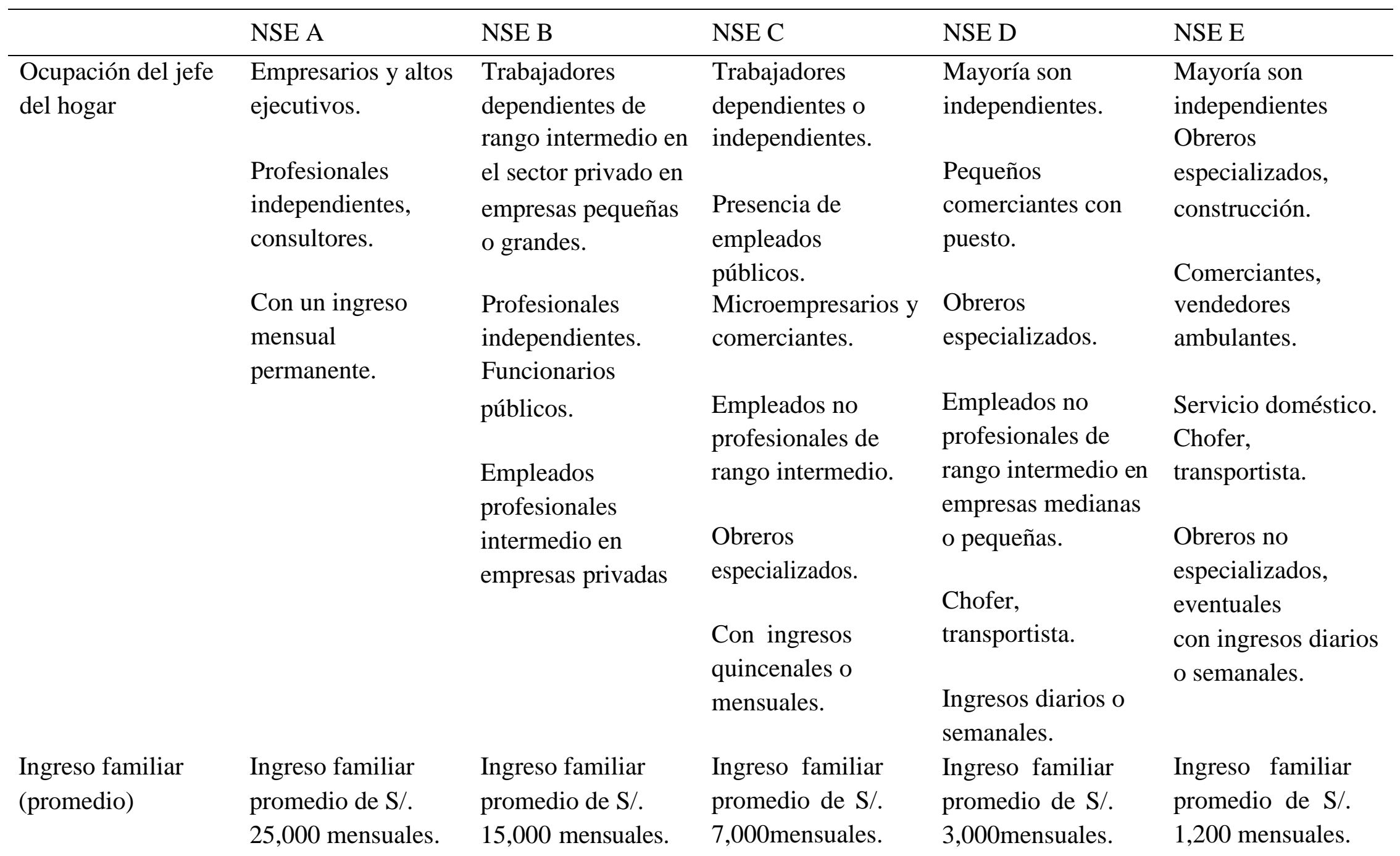




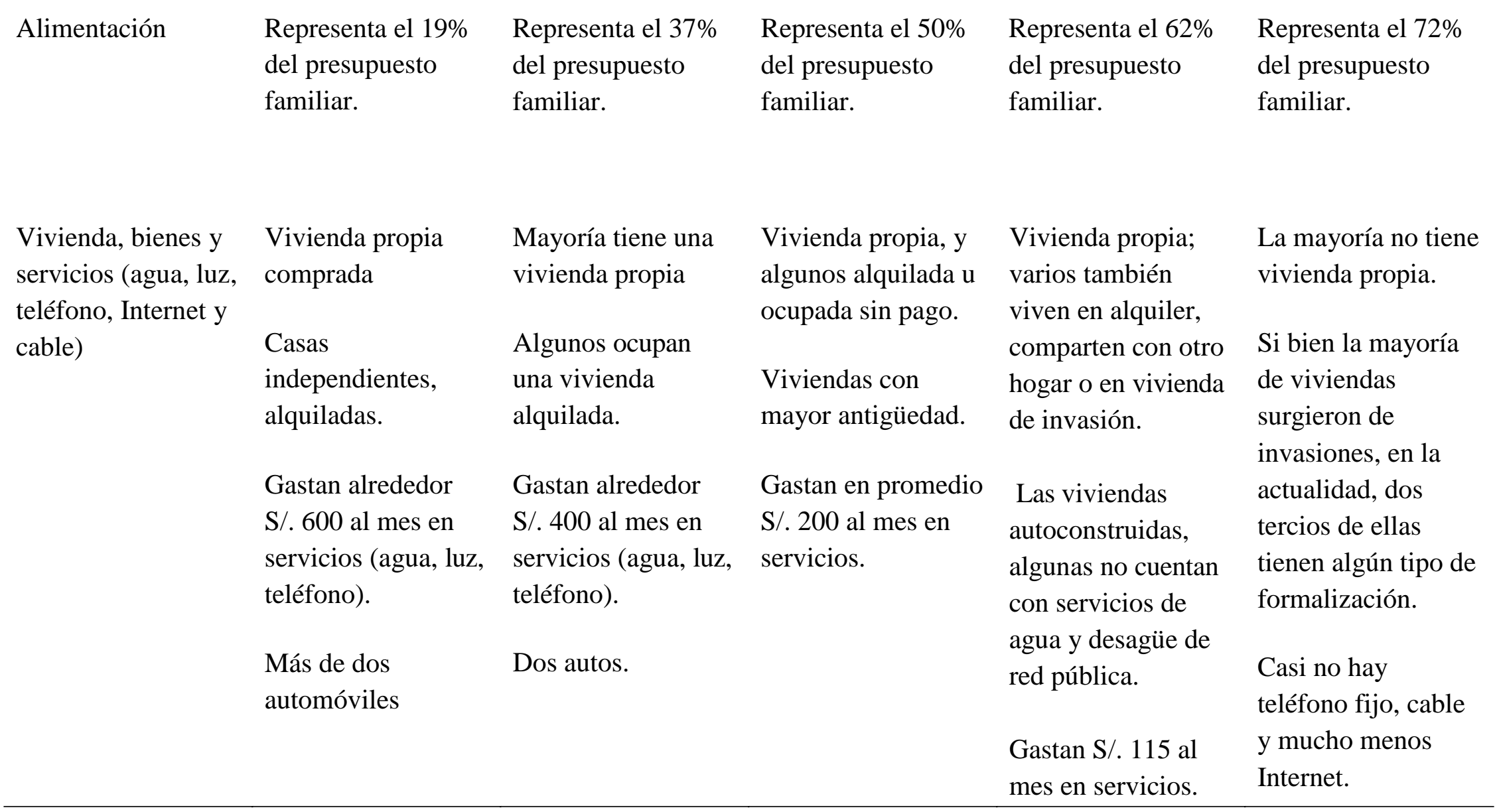

Nota. Elaboración a partir de los datos de APEIM 2015. 
1. Los Sofisticados: Segmento mixto, con un nivel de ingresos más altos que el promedio. Son muy modernos, educados, liberales, cosmopolitas y valoran mucho la imagen personal. Son innovadores en el consumo y cazadores de tendencias. Le importa mucho su estatus, siguen la moda y son asiduos consumidores de productos "light". En su mayoría son más jóvenes que el promedio de la población.

2. Los Progresistas: Hombres que buscan permanentemente el progreso personal o familiar. Aunque están en todos los NSE, en su mayoría son obreros y empresarios emprendedores (formales e informales). Los mueve el deseo de revertir su situación y avanzar, y están siempre en busca de oportunidades. Son extremadamente prácticos y modernos, tienden a estudiar carreras cortas para salir a producir lo antes posible.

3. Las Modernas: Mujeres que trabajan o estudian y que buscan su realización personal también como madres. Se maquillan, se arreglan y buscan el reconocimiento de la sociedad. Son modernas, reniegan del machismo y les encanta salir de compras, donde gustan de comprar productos de marca. Están en todos los NSE.

4. Los Formales / Adaptados:Hombres trabajadores y orientados a la familia que valoran mucho su estatus social. Admiran a los Sofisticados, aunque son mucho más tradicionales que estos. Llegan siempre un "poco tarde" en la adopción de las modas. Trabajan usualmente como oficinistas, empleados de nivel medio, profesores, obreros o en actividades independientes de mediano nivel. 
5. Las Conservadoras: Mujeres de tendencia bastante religiosa y tradicional. Típicas “mamá gallina", siempre persiguen el bienestar de los hijos y la familia, y son responsables de casi todos los gastos relacionados al hogar. Se visten básicamente para "cubrirse" y solo utilizan maquillaje de forma ocasional.

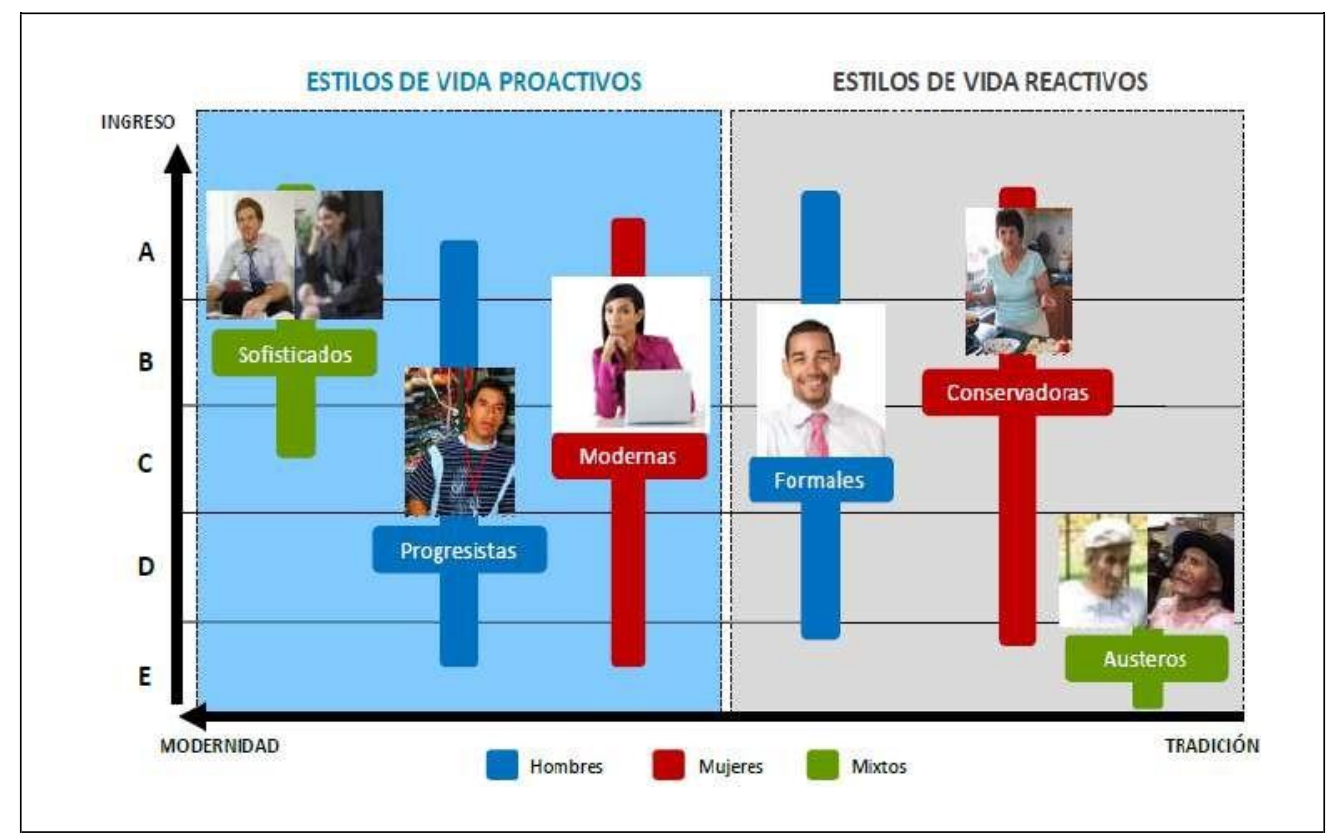

Figura 39.Los estilos de vida latinoamericanos

Nota. Tomado de “Los estilos de vida latinoamericanos," por Arellano Marketing, 2016. Recuperado de http://www.arellanomarketing.com/inicio/estilos-de-vida/

\subsubsection{Análisis Tecnológico}

Un estudio publicado por la Universidad de Oxford (2017), basándose en las 700 profesiones más comunes en Norteamérica, concluye que en un intervalo de 10-20 años, el 47\% de los trabajos serán realizados por máquinas. 
En el caso de la elaboración de los guantes de látex se utilizan máquinas de procedencia europea, estas máquinas son sinónimo de calidad y durabilidad. Respecto a los insumos para la fabricación de guantes tenemos al látex natural, nitrilo (sustituto principal del látex natural), vinilo y el polietileno.

Por otro lado; el mercado asiático viene elaborando el producto a un menor precio y con la calidad deseada con robots que reemplazan el trabajo humano en gran parte del proceso de producción de los guantes.

Esta situación, significa una oportunidad para la empresa ya que al fabricar el producto con la nueva tecnología, estaría optimizando sus costos fijos y logrando una mayor eficiencia en la línea de producción.

\subsubsection{Análisis Ecológico}

\section{a). ISO 14001: 2015}

En el Perú las empresas medianas y grandes en su mayoría, cuentan con la certificación ISO 14001, conla finalidad de apoyar la aplicación de un plan de manejo ambiental en la sociedad, tener este certificado refleja que una empresa está comprometida con la conservación del medio ambiente y cuenta con una responsabilidad social empresarial que le otorgas un valor agregado al cliente.

\section{b). Las empresas y el medio ambiente}

El Perú es un país “mega diverso”, característica que lo define como uno de los países con mayor índice de biodiversidad del planeta. Este hecho, sin embargo, ha puesto en mayor 
evidencia su vulnerabilidad a los efectos del cambio climático en la región y en el mundo entero tal como indica el Instituto Tyndall Center:

El Perú, es después de Bangladesh y Honduras, el país más vulnerable frente al cambio climático debido a su ubicación en el planeta, según un reporte publicado por el Instituto Tyndall Centre. La pesca, la ganadería altoandina y la agricultura serían los sectores más afectados por el cambio climático en Perú en los próximos años, según un estudio conjunto del Gobierno peruano, la Comisión Económica para América Latina y el Caribe (Cepal) y el Banco Interamericano de Desarrollo (2015).

Algunas empresas en el país optan por cuidar el medio ambiente reciclando en tacho de colores la basura y residuos (cada color compete a una elemento ya sea papel, toners, orgánicos, plásticos y vidrio), otra es usando materiales biodegradables y reciclables. 


\subsection{Impacto en clientes / proveedores de cada una de las variables del entorno}

Tabla 16

Análisis externo impacto en clientes / proveedores

Tendencia Impacto en Clientes / Proveedores

Análisis Político-Gubernamental

Presidente democrático periodo 2016

Existe en la actualidad muy buena perspectiva de los

- 2017 / Riesgo país

inversionistas en el País, esto genera mayores ingresos y mayor consumo para los clientes y proveedores.

Conflictos sociales / seguridad

Incurre en mayor costo que disminuye la rentabilidad, nacional generando que los clientes inviertan más en seguridad para evitar riesgos, estos costos son difíciles de trasladar al costo del producto, consecuencia de ello hay reducción de margen.

Inversión privada y satisfacción de los Los clientes y proveedores no tienden a invertir por el empresarios alto grado de corrupción que hay en los funcionarios públicos y los plazos en algunos casos interminables de los trámites burocráticos, logrando paralizar y en otros casos dejando solo en desarrollo de negocios futuras inversiones que generen oportunidades al país.

La política gubernamental y el consumidor

Tratados Internacionales Vigentes

Análisis Económico

Ámbito Mundial
La empresa solo vende a distribuidores, este punto no es aplicable, pero no deja de ser atractivo para los vendedores que interactúan con los clientes finales de los productos de guantes de látex.

Desfavorece al negocio de Eterna, podría generar que los principales distribuidores hagan marca blanca al importar directamente con las compañías internacionales dispuestas a captar mayor mercado.

Menor demanda de los países de los productos tradicionales. 
Ámbito nacional

Producto Bruto Interno (PBI)

Demanda Interna actual

Demanda Interna proyectada 2017

Balanza Comercial

Tipo de cambio

Inflación

Tasa de referencia Interbancaria
Disminuye la inversión de capitales generando menos interés de inversión. Apuntan objetivos a otros países emergentes o al país potencia (EEUU).

El sector comercio y otros servicios se mantienen constante en la evolución del PBI y también en la proyección al 2017, generando mayor consumo para los clientes e incremento de ventas a los proveedores.

Disminución del consumo afectando las ventas de los clientes de Eterna.

Mayor demanda de los guantes de látex por parte del cliente generando mayor rentabilidad, los mismos efectos ocurrirán con los proveedores al ver una tendencia al alza el consumo del producto.

Debido a la tendencia al alza del dólar podría traer un incremento del precio al cliente debido a que Eterna compra los productos en dólares y necesita la empresa cubrir sus costos, por otro lado los proveedores no se verían afectados ya que ellos venden sus productos al país de origen en moneda extranjera.

La tendencia al alza genera un mayor precio del producto para el distribuidor generándole una amenaza, por otro lado, el distribuidor por ser un exportador no se vería afectado.

Al existir una estabilidad de precios tanto cliente como proveedor no se verían afectados, la proyección está dentro del rango proyectado por el BCR.

El cliente se ve beneficiado a futro con la tasa de referencia si este se mantiene estable; por otro lado, el distribuidor por ser un exportador no se vería afectado

Tanto cliente como proveedor no se verán afectados debido a que no son importadores. 
Análisis Legal

Hacer negocios en el País

Régimen laboral

Análisis Cultural y Demográfico

Los clientes y la política de pagos

El país y la educación

Perfil del ciudadano por NSE

Estilos de Vida

Análisis tecnológico

Mayor presupuesto en procesos tecnológicos
Los clientes podrían tener mayor poder de negociación con el ingreso de nuevos competidores de productos de artículos de limpieza; los proveedores podrían abrir una filial en el país generando ingresos de divisas y mayor participación del mercado.

Los altos costos laborales generan que el cliente no contrate más profesionales e incrementas su fuerza de ventas, esto genera que los guantes de Eterna no llego a distintos lugares del país; Los proveedores no se ven afectados por ser exportadores.

Los clientes de canales modernos tienen mayor poder de negociación debido a que su marca está consolidada en el mercado poniendo condiciones de pago a Eterna; Los proveedores debido a ser internacionales mantienen una política de pago teniendo como base las entidades financieras.

La demanda por parte de los profesionales de los productos de Eterna al estar en la opinión pública genera valor a la marca y a la empresa, además, tienen mayor conocimiento del producto; los proveedores no se ven afectados por ser exportadores.

Los clientes de cierto NSE tendrán mayor rotación de productos; el proveedor no se ve afectado por ser exportador.

Los clientes tienen mayor demanda de productos por tendencia al cuidado de la piel; el proveedor no se ve afectado por ser exportador.

El cliente obtienen un producto a menor costo y con valor agregado; mayor inversión por parte de los 
proveedores para innovar en sus procesos tecnológicos.

Uso del e- comerce

Obtener productos sin salir de sus instalaciones solo coordinando mediante la web y otros aplicativos móviles; proveedores al ser internaciones ya tiene sus proceso definidos este factor no le afecta.

Análisis ecológico

ISO $14001: 2015$

El cliente tiene plena seguridad que los productos adquiridos son elaborados con procesos que cuidan el medio ambiente; para los proveedores es obligatorio estos procesos porque cada vez es mayor la exigencia de las empresas.

Las empresas y el medio ambiente Las empresas implementaran medidas de reciclaje de los desechos generando un mayor compromiso hacia la sociedad y medio ambiente. 


\subsection{Efecto en la empresa de cada una de las variables del entorno}

Tabla 17

Análisis externo efecto en la empresa

Tendencia

Efecto en la empresa Eterna

Análisis Político-Gubernamental

Presidente democrático periodo 2016 2017 / Riesgo país

Disposición de la empresa para invertir mayor presupuestos en el país, ofreciendo una mayor oferta al mercado y cubriendo la demanda de los principales distribuidores, Eterna cumplirá sus objetivos de obtener mayor rentabilidad y posicionamiento en el mercado de artículos de limpieza del hogar.

Conflictos sociales / seguridad nacional Eterna actualmente no asigna presupuesto en seguridad para la empresa, las instalaciones de la compañía de encuentran ubicadas en un edificio donde hay una administración que se encarga del resguardo.

Inversión privada y satisfacción de los empresarios

La política gubernamental y el consumidor

Tratados Internacionales Vigentes
La empresa actualmente no tiene la confianza suficiente para realizar inversiones en el sector.

La empresa solo vende a distribuidores, este punto no es aplicable a la compañía.

Es decisión de la empresa matriz en Colombia diversificar la mercadería en otros países de Sudamérica, este punto permite a la compañíaque no pague aranceles por los productos importados.

La recesión de la economía mundial genera menor consumos en el país, trayendo consigo la reducción de la utilidad neta, volatilidad en el mercado de caucho.

Actualmente el menor dinamismo de consumos hace

Ámbito nacional 
Producto Bruto Interno (PBI)

Demanda Interna actual

Demanda Interna proyectada 2017

\section{Balanza Comercial}

Tipo de cambio

Inflación

Tasa de referencia Interbancaria

Política arancelaria

Análisis Legal

Hacer negocios en el País

Régimen laboral

Análisis Cultural y Demográfico

Los clientes y la política de pagos que Eterna se vea afectada, se tiene que reducir los precios de los productos.

Se ve una mejora de la demanda interna en el futuro con planes al 2017 generando oportunidades.

Disminución del consumo afectando las ventas de guantes en la empresa.

Mayor demanda de los guantes de látex por parte del cliente generando mayor rentabilidad.

Al existir en el mercado mayor importación, el precio del dólar se mantiene al alza afectando la rentabilidad de la empresa generando una amenaza.

La tendencia al alza genera un mayor precio del producto puesta en destino representando una amenaza.

Al existir una estabilidad de precios según la metadel $\mathrm{BCR}$, la demanda por parte de los clientes se tiende a subir.

La empresa se verá beneficiada con futuros créditos por la tendencia a la baja tasa de interés bancario.

Colombia el principal proveedor de guantes, tiene preferencia arancelaria por convenio alianza del pacifico, gran oportunidad.

Mayor participación de empresas o filiales en la industria de artículos de limpieza.

Los altos costos laborales generan mayor presupuesto en la mano de obra y gastos administrativos.

Los pagos a través de medios digitales favorecen a la empresa. 
El país y la educación

Perfil del ciudadano peruano por NSE

Estilos de Vida

Análisis tecnológico

Mayor presupuesto en procesos

tecnológicos

Uso del e-comerce

Análisis ecológico

ISO $14001: 2015$

Las empresas y el medio ambiente
Mayor mano de obra calificada para la comercialización del producto.

No afecta a la empresa por vender a distribuidores nacionales y no al cliente final.

No afecta a la empresa por vender a distribuidores nacionales y no al cliente final. La demanda del producto determina que la empresa tenga mayores pedidos de sus distribuidores.

La empresa es una empresa importadora adquiere el producto terminado, no afecta a la empresa.

La empresa no cuenta con un medio electrónico en la web para la adquisición de los guantes. Es amenaza si no consigue

Genera oportunidades de negocios con clientes más exigentes y comprometidos con la sociedad y medio ambiente.

La empresa no cuenta con la política de reciclaje generando una amenaza. 


\subsection{Oportunidades y Amenazas}

A partir del análisis externo y la evaluación del impacto directo que tienen las tendencias de las variables en la empresa,se identificaron oportunidades y amenazas para la empresa Eterna Perú SAC que se muestran en la Tabla 18.

Las oportunidades y amenazasresultantes serán usadas por la compañía para generar las estrategias más adecuadas para enfrentar los cambios que se estiman se producirán en el entorno.

Tabla 18

Análisis externo oportunidades y amenazas

Variables del entorno indirecto Impacto en el sector

Análisis Político-Gubernamental

Presidente democrático periodo 2016 - 2017 / Riesgo país

Oportunidad

Conflictos sociales / seguridad nacional

Amenaza

Inversión privada y satisfacción de los empresarios

Oportunidad

La política gubernamental y el consumidor

Amenaza

Tratados Internacionales Vigentes

Amenaza

Análisis Económico

Ámbito Mundial - Cambió el Mundo

Amenaza

Ámbito nacional / Producto Bruto Interno (PBI)

Amenaza

Demanda Interna actual

Amenaza 
Balanza Comercial

Tipo de cambio

Inflación

Tasa de referencia Interbancaria

Política arancelaria

Análisis Legal

Hacer negocios en el País

Régimen laboral

Análisis Cultural y Demográfico

Los clientes y la política de pagos

El país y la educación

Perfil del ciudadano peruano por NSE

Estilos de Vida

Análisis tecnológico

Mayor presupuesto en procesos tecnológicos

Uso del e-comerce

Análisis ecológico

ISO $14001: 2015$

Las empresas y el medio ambiente
Amenaza

Amenaza

Oportunidad

Oportunidad

Oportunidad

Amenaza

Amenaza

Amenaza

Oportunidad

Oportunidad

Oportunidad

Amenaza

Oportunidad

Oportunidad

Amenaza 


\subsection{Matriz de Evaluación de los Factores Externos EFE}

A partir de las oportunidades y amenazas detectadas se puede elaborar la matriz de evaluación de los factores externos (EFE), en donde se indican las principales oportunidades y amenazas del entorno que impactan en la empresa ETERNA Perú de manera significativa. Este impacto puede ser favorable para la empresa al crear oportunidades ó puede tener un impacto negativo al crear amenazas para el negocio.

La matriz EFE según David (2013) permite consolidar las oportunidades y amenazas para ser evaluadas a fin de determinar a posición actual de la empresa con relación a los cambios esperados en las variables del entorno. La importancia de cada variable se establece a partir de la experiencia de los expertos consultados, quienes indicaron sobre el nivel de importancia de cada variable como factor crítico de éxito del negocio.

Posteriormente, se realizó la calificación de cada variable a partir de la experiencia de los expertos y de la gerencia de la empresa. Para la evaluación se utilizó una escala de 1 a 4, en donde:

- 1 la respuesta al cambio es deficiente,

- 2 la respuesta promedio,

- 3 la respuesta está por encima del promedio,

- 4 la respuesta al cambio es superior

El nivel de impacto o peso de cada variable, así como la evaluación de las variables en la escala indicada, fue realizado de manera considerando la opinión de los expertos entrevistados y con colaboración de la gerencia de la empresa. Posteriormente, se multiplicó el peso de cada variable por su calificación obteniendo la evaluación realizada que se muestra en la Tabla 19. Finalmente, se realizó la sumatoria de los resultados parciales obtenidos a fin calcular el resultado total de los factores externos sobre la empresa. 
Tabla 19

Matriz de Evaluación de los Factores Externos EFE

\begin{tabular}{|c|c|c|c|c|}
\hline $\mathrm{N}^{\circ}$ & Factores Críticos de éxito & Peso & Calificación & $\begin{array}{l}\text { Total } \\
\text { Ponderado }\end{array}$ \\
\hline & Oportunidades & & & \\
\hline 1 & Estabilidad política & 0.06 & 2 & 0.12 \\
\hline 2 & Comercio minorista al alza & 0.08 & 2 & 0.16 \\
\hline 3 & Retail moderno: las ventas totales crecerán $6 \%$ & 0.07 & 3 & 0.21 \\
\hline 4 & Búsqueda de productos de calidad por los clientes & 0.09 & 4 & 0.36 \\
\hline 5 & Crecimiento del PBI & 0.08 & 3 & 0.24 \\
\hline \multirow[t]{2}{*}{6} & Tipo de cambio estable & 0.09 & 4 & 0.36 \\
\hline & Amenazas & & & \\
\hline 1 & Crecimiento acelerado del canal online & 0.05 & 1 & 0.05 \\
\hline 2 & Menor evolución del empleo y salario & 0.07 & 2 & 0.14 \\
\hline 3 & Familias que pasaron a la clases media & 0.08 & 2 & 0.16 \\
\hline 4 & País con mayor rigidez laboral & 0.07 & 2 & 0.14 \\
\hline 5 & Políticas de reciclaje & 0.03 & 1 & 0.03 \\
\hline 6 & Producción local a bajo costo & 0.09 & 3 & 0.27 \\
\hline 7 & Importaciones de bajo costo y menor calidad & 0.09 & 3 & 0.27 \\
\hline 8 & Inseguridad ciudadana & 0.03 & 1 & 0.03 \\
\hline \multicolumn{2}{|c|}{ Total } & 1 & & 2.54 \\
\hline
\end{tabular}

El valor promedio de 2.54 alcanzado permite señalar que en general la empresa ofrece respuestas ligeramente encima del promedio para responder a los cambios del entorno, lo que no está permitiendo que Eterna Perú SAC aproveche plenamente las oportunidades que se presentan en el entorno. 


\section{Capítulo 5 Análisis de la industria}

En este capítulo se realizará el análisis de la industria a partir del modelo de las cinco fuerzas de Porter. Este modelo permitirá reconocer el grado de atractividad de la industria de guantes para uso doméstico e industrial con relación a las fuerzas que lo afectan.

\subsection{Descripción del Mercado (demanda) e Industria (oferta)}

\section{Mercado (Demanda)}

En el Perú según Veritrade (2016), se importa más de dos millones de dólaresen guantes de caucho y látex que figuran con el código arancelario “40.15.19.90.00 prendas de vestir, guantes y demás accesorios de vestir para cualquier uso de caucho vulcanizado sin endurecer".

El costo de importación promedio de este producto es de $\$ 0.065$ por cada par de guantes, mientras que en el mercado se observa que el precio promedio para el consumidor final varía entre S/. 8.00 y S/. 12.00 soles. (ver figura 40).

Respecto al monto de las importaciones, este año se proyecta que las importaciones de guantes serían mayores de los últimos tres años, superando los 19 millones de dólares. (ver figura 41). 


\begin{tabular}{|c|c|c|}
\hline $\begin{array}{l}\text { Total } \\
\text { Importado }\end{array}$ & $\bigoplus \begin{array}{l}\text { Cantidad } \\
\text { Importada }\end{array}$ & (5) Unitario \\
\hline $\begin{array}{c}2,845,271 \\
\text { us\$ }\end{array}$ & $\begin{array}{c}43,880,660 \\
2 \mathrm{U}(\mathrm{s})\end{array}$ & $\begin{array}{l}0.065 \\
\text { US } \$ / 2 U\end{array}$ \\
\hline
\end{tabular}

Figura 40.Importaciones de guantes a julio de 2016

Tomado de "LoginVeritrade," por Veritrade, 2016. Recuperado de

http://www.veritrade.info/pruebagratis/31230?utm_source=google\&utm_medium=cpc\&utm_con tent=search_pc\&utm_campaign=brandterms_veritrade_peru2016\&gclid=Cj0KEQjwpNmBRCJ3rDNmOuKi9IBEiQAlzDJH63dUplbSsvFhU2mlpiSjqxioLZR0HLQUPdOupfldMaAucx8P8HAQ

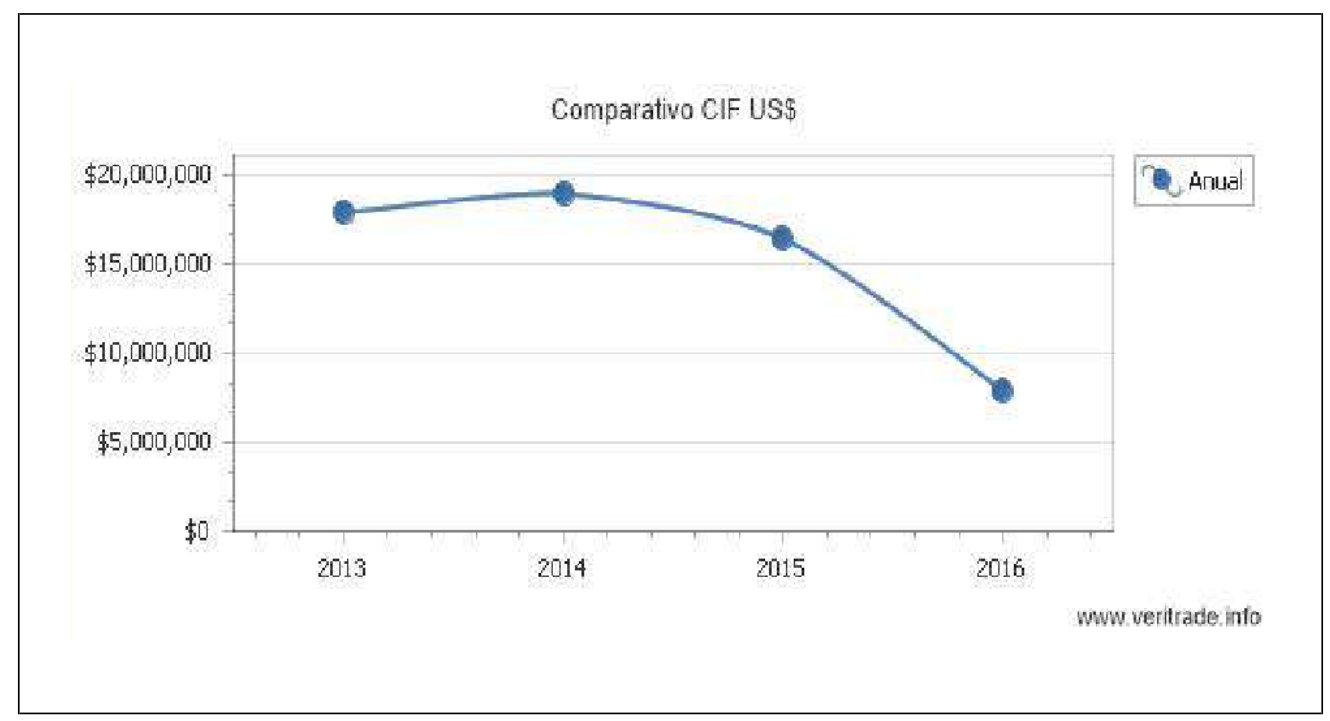

Figura 41.Comparativo CIF 2016

Tomado de "LoginVeritrade," por Veritrade, 2016. Recuperado de http://www.veritrade.info/pruebagratis/31230?utm_source=google\&utm_medium=cpc\&utm_con tent=search_pc\&utm_campaign=brandterms_veritrade_peru2016\&gclid=Cj0KEQjwpNmBRCJ3rDNmOuKi9IBEiQAlzDJH63dUplbSsvFhU2mlpiSjqxioLZR0HLQUPdOupfldMaAucx8P8HAQ 
Invera (2015) publicó un estudio llamado “Hábitos del mercado de limpieza del hogar”, Su finalidad fue mostrar un estudio de investigación de mercado, en la cual reportan que las mujeres (amas de casa) que radica en Lima gastan en promedio S/. 80 soles mensuales en artículos de limpieza para el hogar. Entre sus resultados se identifica que este ticket de consumo se da en los sectores B, C y D. Otro punto a tocar es que las bodegas son los lugares más frecuente para la compra de estos productos. El estudio también informa que en el canal tradicional la compra es más frecuente (semanal) y en los autoservicios es menos la recurrencia de clientes. Los investigadores muestran que las categorías como otros productos para limpieza donde los guantes de jebe tienen presencia, vienen despegando entre ellos también suavizante de ropa, desinfectantes y los ambientadores tanto en spray como también en pastillas.

Por su parte, Ipsos (2011) realizó un trabajo de investigación denominado "Liderazgo en productos de cuidado personal y limpieza del hogar 2011," que tuvo como objetivo conocer los hábitos de compra y de uso de las primeras categorías de bienes de aseo y cuidado personal y limpieza del hogar. Entre los resultados encontrados se logró identificar la penetración de mercado de acuerdo a las veces que se usa el producto por semana, con base en este hallazgose obtiene los hábitos de uso, quese puede dividir en alta, mediana y baja penetración.

La frecuencia de compra es otro resultado que muestra el estudio, donde hace hincapié el periodo que predomina para la compra para los artículos de limpieza: como la quincena y a fin de mes. Otro punto que se detalla es la lealtad a la marca donde los productos de guantes de jebe no tienen lealtad por la marca no mostrando ninguna preferencia para la seleccióndel bien. Los lugares de compra son: supermercados, bodegas, otras adicionales como los mercados y los 
puestos. El estudio muestra por último que las marcas que ofertan artículos de limpieza del hogar no están dentro de las marcas más utilizadas, lo cual implica que las empresas deberán enfocar sus esfuerzos para mejorar sus resultados en el mercado.

También, en la Universidad Privada AntenorOrrego de Trujillo e Investiga Estudio de Mercado y de Opinión (1998) realizaron un estudio denominado "Estudio de Mercados y Supermercados en Trujillo," cuya finalidad era conocer el comportamiento de las amas de casa respecto a la adquisición de productos de primera necesidad entre ellos artículos de limpieza del hogar. Entre sus resultados se logró identificar que:

- Los factores que, primordialmente, toman en cuenta las amas de casa al escoger el lugar de compra son: el precio del bien, la calidad del producto y diversidad de productos.

- Los canales de venta preferidos para realizar la compra son: supermercados, mercados y bodegas.

- También se identificó que de cada 100 amas de casa el 64 cierran la compra en un supermercado, porque son lugares limpios y ordenado, diversidad de productos de limpieza, ofertas y promociones.

- El motivo por la cual las amas de casa no asisten a supermercados son los precios altos, la distancia y el tiempo de demora en la cola para pagar.

Asimismo, IPSOS (2015) realizó un estudio a las amas de casa de Lima metropolitana del NSE A, B, C, D y E, entre los 25 y 70 años de edad. Este estudio brinda un panorama de cómo se comporta el mercado en la actualidad en los siguientes temas:

(a) frecuencia de uso, 
(b) las marcas más utilizadas,

(c) lealtad hacia la marca,

(e) lugares frecuentes de compra en las amas de casa.

Al analizar los resultados alcanzados se pudo identificar lo siguiente:

(a) Frecuencia de uso: Se identificó que hay un tendencia al alza en el uso diario/varias veces. Asimismo, el estudio muestra un descenso en comparación al año 2011 en cuanto a la pregunta si nunca usan guantes (ver Tabla 20). Estos resultados son muy atractivos para la empresa Eterna Perú.

(b) Marcas más utilizadas: Se identificó que la marca ScotchBrite viene ganando preferencia en la categoría a expensas de Virutex que viene decreciendo y por ultimo Eterna poco o nada está haciendo para captar más participación de mercado. (ver Tabla 21).

(c) Lealtad hacia la marca: Se identificó que cada vez se incrementa la preferencia de los consumidores hacia determinada marca de guante de jebe. Asimismo, los estudios de mercados evaluados para investigación indican que al 2018 la lealtad a la marca incrementara en un $60 \%$. Esta situación brinda un panorama positivo para la compañía para elaborar estrategias a largo plazo.(ver Tabla 22)

Tabla 20

Frecuencia de uso de productos de limpieza

\begin{tabular}{cccccc}
\hline \multirow{3}{*}{ Productos } & Diario / Varias & & Quincenal / & Ocasional & Nunca \\
& veces semana & Semanal (\%) & Mensual (\%) & $(\%)$ & $(\%)$ \\
& $(\%)$ & & & & \\
\hline
\end{tabular}




\begin{tabular}{|c|c|c|c|c|c|c|c|c|c|c|}
\hline & 2011 & 2015 & 2011 & 2015 & 2011 & 2015 & 2011 & 2015 & 2011 & 2015 \\
\hline Detergente & 71 & 76 & 29 & 22 & 0 & 2 & 0 & 0 & 0 & 0 \\
\hline Papel higiénico & 100 & 99 & 0 & 1 & 0 & 0 & 0 & 0 & 0 & 0 \\
\hline Jabón de tocador & 93 & 92 & 1 & 0 & 1 & 0 & 1 & 1 & 4 & 6 \\
\hline Lejía & 60 & 67 & 21 & 21 & 9 & 4 & 4 & 4 & 6 & 4 \\
\hline Jabón para ropa & 53 & 55 & 30 & 22 & 5 & 5 & 5 & 6 & 7 & 12 \\
\hline Betún & 80 & 75 & 5 & 8 & 2 & 4 & 6 & 7 & 7 & 6 \\
\hline Desinfectante & 54 & 71 & 14 & 14 & 6 & 5 & 3 & 3 & 23 & 7 \\
\hline Lavavajilla & 72 & 81 & 0 & 3 & 1 & 2 & 1 & 1 & 26 & 13 \\
\hline Esponja de & 67 & 74 & 3 & 4 & 1 & 3 & 7 & 0 & 22 & 18 \\
\hline \multicolumn{11}{|l|}{ limpieza } \\
\hline Servilletas & 43 & 53 & 9 & 3 & 3 & 2 & 17 & 14 & 28 & 28 \\
\hline Cera para pisos & 8 & 13 & 25 & 19 & 16 & 15 & 6 & 6 & 45 & 47 \\
\hline Desengrasantes & 36 & 42 & 7 & 13 & 5 & 8 & 6 & 4 & 46 & 32 \\
\hline Suavizantes ropa & 27 & 49 & 18 & 17 & 2 & 4 & 11 & 5 & 41 & 25 \\
\hline $\begin{array}{l}\text { Guantes de jebe } \\
\text { para limpieza }\end{array}$ & 24 & 44 & 9 & 11 & 4 & 5 & 18 & 5 & 45 & 35 \\
\hline
\end{tabular}

Nota:Adaptado de “Liderazgo en productos de cuidado personal y limpieza del hogar, " por IPSOS Apoyo. 2015, pág. 21. Lima, Perú.

Tabla 21

Marca más utilizadas en los últimos tres meses; principales respuestas (\%)

\begin{tabular}{lcccc}
\hline Marca & 2011 & 2012 & 2013 & 2014 \\
\hline ScotchBrite & 7 & 13 & 20 & 36 \\
Virutex & 6 & 13 & 18 & 11
\end{tabular}




\begin{tabular}{lllll}
$3 \mathrm{M}$ & 1 & 1 & 2 & 4 \\
Vileda & 1 & 4 & 3 & 3 \\
Eterna & 3 & 2 & 1 & 1 \\
\hline
\end{tabular}

Nota:Adaptado de "Liderazgo en productos de cuidado personal y limpieza del hogar, " por IPSOS Apoyo. 2015, Lima, Perú.

Tabla 22

Lealtad a la marca (\%)

(Va a otro lugar a comprar la marca o no compra nada)

\begin{tabular}{lccccc}
\hline Lealtad a la marca & 2010 & 2011 & 2012 & 2013 & 2014 \\
\hline Lealtad a la marca & 13 & 24 & 24 & 29 & 33 \\
Compra otra marca & 70 & 64 & 65 & 63 & 60 \\
No precisa & 17 & 12 & 11 & 8 & 7 \\
\hline
\end{tabular}

Nota:Adaptado de "Liderazgo en productos de cuidado personal y limpieza del hogar," por IPSOS Apoyo. 2015, Lima, Perú.

(d) Lugares frecuentes de compra: El estudio identifica que los sectores A, B y C son los que mayor frecuencia de compra tienen en los supermercado y principales autoservicios; mientras que el sector D y E tiene mayor preferencia en adquirir estos productos en los mercados y bodegas de su comunidad. (ver Tabla 23).

Tabla 23

Lugar frecuente de compra

\begin{tabular}{lcccccc}
\hline & \multicolumn{1}{c}{ NSE } \\
Lugar frecuente de compra & Total & A & B & C & D & E \\
& 2015 & $\%$ & $\%$ & $\%$ & $\%$ & $\%$ \\
\hline
\end{tabular}




\begin{tabular}{|c|c|c|c|c|c|c|}
\hline Supermercado / autoservicios & 49 & 83 & 66 & 53 & 20 & 1 \\
\hline Mercados / puestos & 47 & 13 & 28 & 42 & 70 & 15 \\
\hline Bodega & 2 & 2 & 3 & 3 & 0 & 7 \\
\hline Distribuidor & 2 & 1 & 1 & 0 & 4 & 0 \\
\hline Base & 273 & 62 & 79 & 54 & 32 & 26 \\
\hline
\end{tabular}

Nota: Adaptado de "Liderazgo en productos de cuidado personal y limpieza del hogar, ” por IPSOS Apoyo. 2015, Lima, Perú.

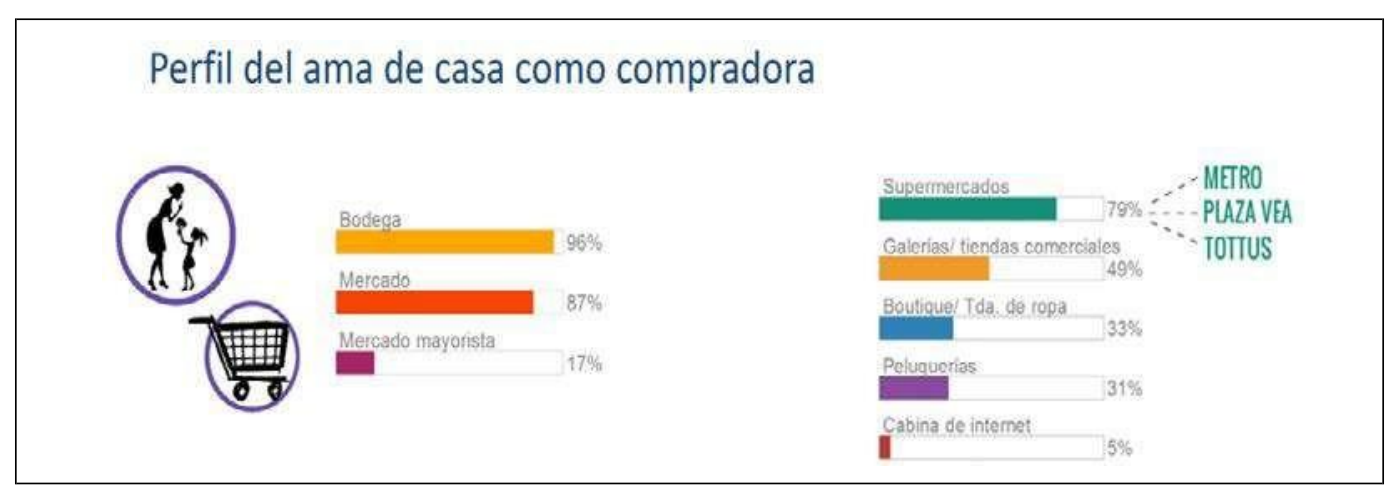

Figura 42.Perfil del ama de casa como compradora

Tomado de “Estudios multiclientesIpsos, ” por Ipsos Marketing, 2015. Recuperado de Adaptado de “Liderazgo en productos de cuidado personal y limpieza del hogar, ” por IPSOS Apoyo. 2015, Lima, Perú

\section{Industria (oferta)}

En el Perú la oferta de guantes de látex está dividida en cuatro grupos, los cuales tienen mayor participación y son de gran conocimiento por el cliente.

- Limpieza del hogar

- Medica

- Aseo Institucional

- Industria 
Las líneas medicas e industria tienen una mayor demanda en el mercado nacional, superando a los de aseo del hogar e institucional, debido, a que este mercado aún se encuentra en crecimiento según el análisis de IPSOS sobre el comportamiento de las amas de casa en la compras de artículos de limpieza.

La oferta de guantes para la limpieza del hogar a nivel nacional está concentrada por las siguientes empresas, de acuerdo a su participación de mercado:

- Plan Enterprise S.A.

- Ilko Perú S.A.C.

- Prosemedic S A

- Medical Full Import S.A.

- Nipro Medical Corporation Sucursal

- Caplan S.A.C. (Eterna Perú SAC)

- Drokasa Perú S.A.

- Kimberly-Clark S.R.L.

- 3M Perú S.A.

En la actualidadla empresa 3M, con la marcaScotchBrite,viene ganando preferencia en la categoría a expensas de los guantes Virutexde Ilko Perú,que viene decreciendo. La empresa Eterna Perú se encuentra en la última posición dado que obtiene sólo una participación de 1\% del mercado. En este sentido, se puede señalarque el esfuerzo para captar más participación de mercadopor parte de la empresa no ve reflejado en su participación final. (Ver Tabla 24). 
Tabla 24

Marca más utilizadas en los últimos tres meses; Principales respuestas (\%)

\begin{tabular}{ll}
\hline Marca & 2014 \\
\hline ScotchBrite & $36 \%$ \\
Virutex & $11 \%$ \\
$3 \mathrm{M}$ & $4 \%$ \\
Vileda & $3 \%$ \\
Eterna & $1 \%$ \\
\hline
\end{tabular}

Nota: Adaptado de "Liderazgo en productos de cuidado

personal y limpieza del hogar, ” por IPSOS Apoyo. 2015,

Lima, Perú.

En la Tabla 25 se muestra las marcas de los productos que Eterna Perú ofrece en el mercado del país. Losproductos de guantes de látex para el aseo del hogar, industria y aseo institucional son importados desde Colombia. En lo respecta al rubro de guantes para el sectormédico son importados del mercado asiático 
Tabla 25

Marcas que representa Eterna en el mercado

\begin{tabular}{ll}
\hline Línea de guantes & Marca \\
\hline Limpieza del hogar & Eterna \\
Medica & Precisión Care \\
Aseo institucional & Eterna \\
Industria & Eterna
\end{tabular}

Nota:Adaptado de “Nuestros productos," por Eterna. 2016,

Lima, Perú.

\subsection{Descripción las cinco fuerzas competitivas de la industria}

Las fuerzas competitivas de la industria según el modelo propuesto por Porter son cinco: productos sustitutos, ingresantes potenciales, clientes, proveedores y al competencia del sector.

\subsubsection{Sustitutos.}

Actualmente, no existen productos sustitutos para la Industria de guantes para la limpieza del hogar, lo más cercano son los guantes con fines médicos u otros tipo de guantes con tienen otrafinalidad (para abrigar las manos). Las empresas ven esto como algo atractivo ya que no hay sustitutos.

\subsubsection{Potenciales.}

Son aquellas empresas que tratan de ingresar al sector. Para evaluar la atractividad del sector respecto al ingreso de nuevos competidores o potenciales se deben tomar en cuenta los siguientes factores: 
- Costos de importación altos, generalmente al inicio la compra a los proveedores extranjeros se realizan al contado y se debe consolidar un volumen adecuado para llenar el contenedor para bajar los costos unitarios de importación. De poder completar el contendor implica mantener muchos días de inventarios los cuales eleva los costos de almacenaje. Otra alternativa es consolidar carga con otra empresa y compartir los gastos de importación del contenedor, este proceso es complicado por encontrar productos con los que se pueda compartir importación. Otra medida que podrían optar las empresas es la de utilizar almacenes de tránsito y nacionalizar sólo los productos que se van a comercializar a corto plazo, si bien es cierto no comprometes un exceso de capital de trabajo nacionalizando toda la carga, los costos del almacén temporal son altos.

- Costos de distribución altos, la distribución directa de los productos genera elevados costos logísticos, comercialización, transporte, administrativos y desgaste del departamento de finanzas por el manejo de la cartera de cobranza.

- Restricciones gubernamentales de importación, como lo mencionado en el capítulo 4.1.1 no existen restricciones para la importación de guantes de uso doméstico.

- Crecimiento en el nivel de consumo de artículos de limpieza en general: como resultado del crecimiento poblacional, formación de nuevas familias y expansión inmobiliaria aún positiva en NSE B y C.

\subsubsection{Clientes}

Se refiere que tanto puede influir la presión de los clientes en las decisiones de las empresas, para obtener mejores productos a menores precios y con mejores condiciones. 
Al respecto, se puede decir que no se ha encontrado lealtad de marca en la compra de guantes de látex, que existe presión de parte de los clientes se orienta a mantener precios promedio en guantes de características similares. Asimismo, la existencia de competidores directos permite a los clientes poder manejar una banda de precios estándar.

Por otro lado, existe una tendencia de los clientes por la protección y cuidado de las manos, mantener la piel saludable además de la protección contra el frio en temporada de invierno. En este marco, las empresas del sector apuestan por la diferenciación de los productos que ofrecen en el mercado.

Los clientes de Eterna están divididos en 3 principales rubros

- Canal Directo

- Autoservicios

- Cadenas de Farmacias

- Home Center

- Canal Tradicional

- Distribuidores.- Para atención a bodegas y mercados

- Mayoristas

- Canal Institucional

- Industria

- Médica 


\subsubsection{Proveedores}

El principal país proveedor en esta industria es Malasia, que representaen el mercado un $45 \%$ de las ventas al Perú, seguido deColombia que representa un 27\% - este país lidera el mercado de producción de artículos de caucho -, y China con un 6.4\%, que es conocido en este negocio por el bajo precio de sus productos, pero no son de muy buena calidad. (Ver Tabla 26).En las Figuras 43 y 44 se muestra el ranking depaísesque exportan este producto, y de las empresas que lo importan.

Tabla 26

Principales países exportadores de guantes

\begin{tabular}{lcc}
\hline Países Origen & Total CIF US\$ & $\%$ \\
\hline Malaysia & $27,643,104$ & 45.1 \\
Colombia & $16,624,985$ & 27.1 \\
China & $3,953,132$ & 6.4 \\
Sri Lanka & $2,811,051$ & 4.6 \\
UnitedStates & $2,462,079$ & 4.0 \\
Thailand & $1,898,965$ & 3.1 \\
Ecuador & $1,520,277$ & 2.5 \\
México & $1,209,620$ & 2.0 \\
Indonesia & 884,676 & 1.4 \\
France & 691,541 & 1.1 \\
Guatemala & 289,599 & 0.5 \\
India & 257,864 & 0.4 \\
Pakistan & 225,591 & 0.4 \\
Vietnam & 174,723 & 0.3 \\
& &
\end{tabular}




\begin{tabular}{lcc} 
Ukraine & 173,659 & 0.3 \\
Korea & 129,931 & 0.2 \\
Chile & 100,328 & 0.2 \\
Argentina & 80,706 & 0.1 \\
Taiwan, & 54,687 & 0.1 \\
Spain & 38,255 & 0.1 \\
Brazil & 33,465 & 0.1 \\
\hline
\end{tabular}

Nota: tomado de Veritrade

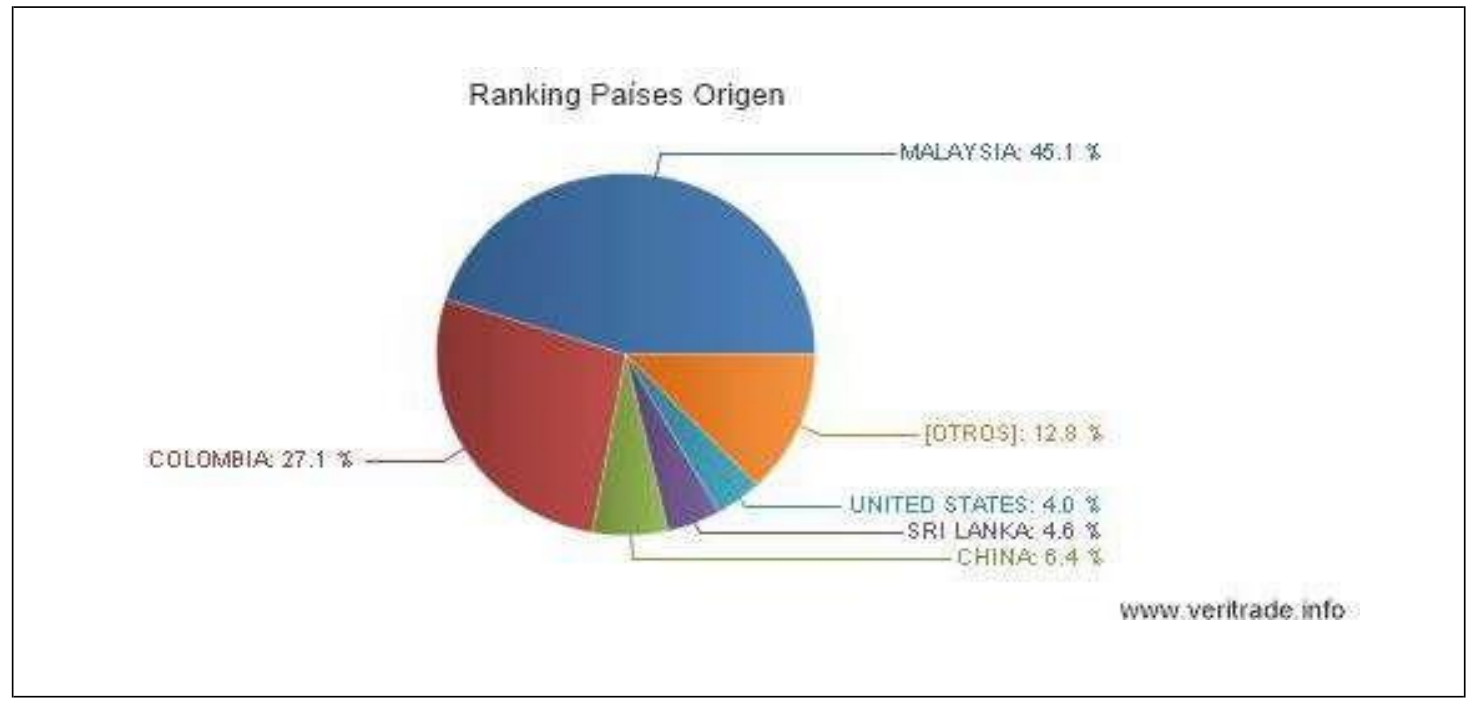

Figura 43.Ranking país de origen

Nota: Tomado de “LoginVeritrade," por Veritrade, 2016. Recuperado de http://www.veritrade.info/pruebagratis/31230?utm_source $=$ google \&utm_medium $=c p c \& u t m \_c o$ $\underline{n t e n t=s e a r c h \_p c \& u t m \_c a m p a i g n=b r a n d t e r m s \_v e r i t r a d e \_p e r u 2016 \& g c l i d=c j 0 k e q j w p n m-}$ brcj3rdnmouki9ibeiqalzdjh63du-plbssvfhu2mlpisjqxiolzrOhlqupdoupfldmaaucx8p8haq 


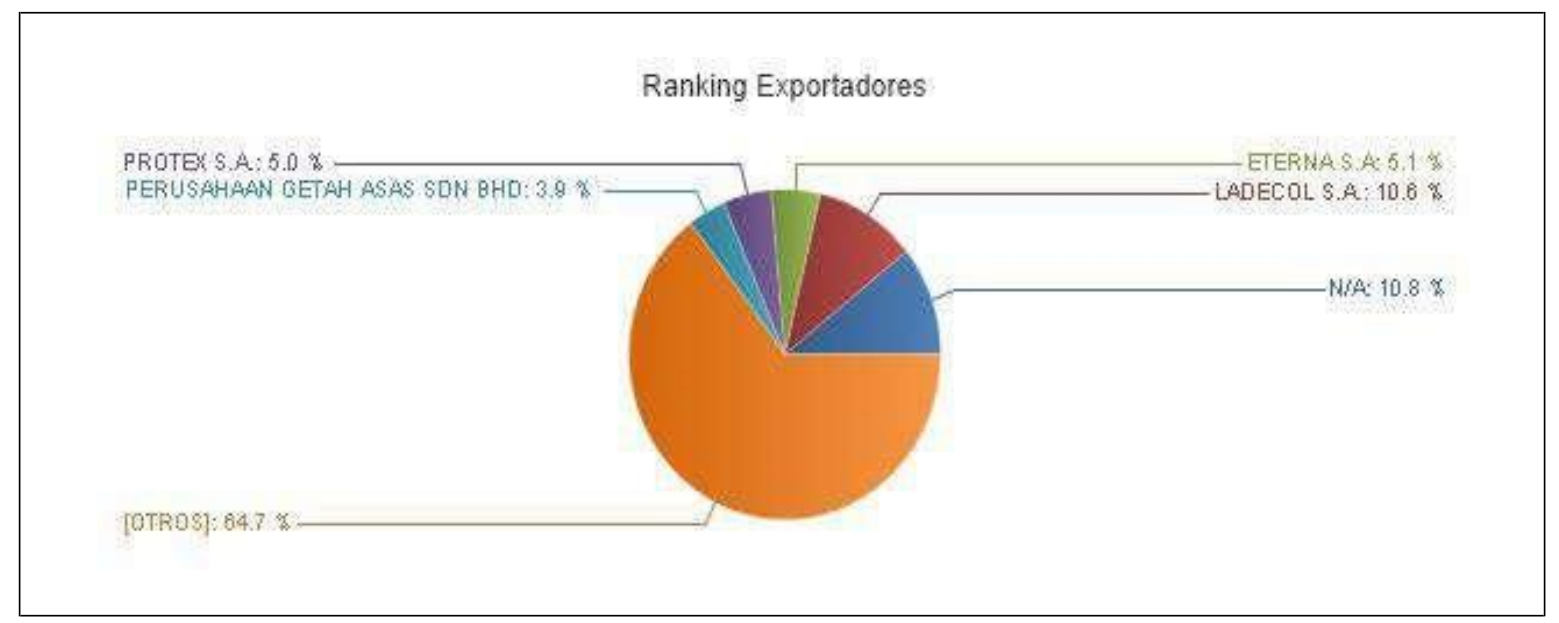

Figura 44.Ranking principales importadores

Nota: Tomado de “LoginVeritrade,” por Veritrade, 2016. Recuperado de

http://www.veritrade.info/pruebagratis/31230?utm_source $=$ google\&utm_medium $=c p c \& u t m \_c o$

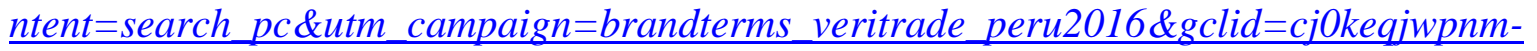
brcj3rdnmouki9ibeiqalzdjh63du-plbssvfhu2mlpisjqxiolzrOhlqupdoupfldmaaucx8p8haq

Tabla 27

Principales empresas exportadoras de guantes

\begin{tabular}{lll}
\hline Exportadores & Total CIF US\$ & $\%$ \\
\hline N/A & $6,594,536$ & 10.8 \\
Ladecol S.A. & $6,497,737$ & 10.6 \\
Eterna S.A & $3,123,863$ & 5.1 \\
Protex S.A. & $3,049,627$ & 5.0 \\
PerusahaanGetah & $2,416,510$ & 3.9 \\
Top Glove & $2,287,966$ & 3.7 \\
IndecauchoLtda. & $1,338,870$ & 2.2 \\
DippedProducts PLC & $1,129,198$ & 1.8 \\
Products SA & 890,096 & 1.5 \\
PerusahaanGetah Asas & 825,532 & 1.3
\end{tabular}




\begin{tabular}{lll} 
ShowaBestGloveInc & 782,991 & 1.3 \\
NiproCorporation & 745,642 & 1.2 \\
SupermaxLatex Products & 693,621 & 1.1 \\
Titi Glove & 678,761 & 1.1 \\
BrightwayHoldings & 663,586 & 1.1 \\
IndulatexS.A. & 628,551 & 1.0 \\
Maxter Glove Manufacturing & 626,721 & 1.0 \\
GloryGloveCoLtda. & 618,663 & 1.0 \\
\hline
\end{tabular}

Nota: tomado de Veritrade

\subsubsection{Competencia en el mismo sector}

El sector está conformado por cuatro principales competidores Eterna, Ilko, 3M y

Drokasa. El consumidor tiene muchas opciones para elegir debido a la gran variedad de marcas y modelos que se presenta en los principales canales de venta.

Tabla 28

Principales empresas importadoras de guantes

\begin{tabular}{|c|c|c|}
\hline Importadores & $\begin{array}{l}\text { Total CIF } \\
\text { US\$ }\end{array}$ & $\%$ \\
\hline Plan Enterprise S.A. & $7,010,345$ & 11.4 \\
\hline IlkoPerú S.A.C. & $6,369,013$ & 10.4 \\
\hline Prosemedic S A & $5,778,709$ & 9.4 \\
\hline Medical Full Import S.A. & $4,494,912$ & 7.3 \\
\hline Nipro Medical Corporation Sucursal & $4,157,027$ & 6.8 \\
\hline CaplanS.A.C. & $3,255,743$ & 5.3 \\
\hline Drokasa Perú S.A. & $3,021,463$ & 4.9 \\
\hline Sekur Perú S.A. & $2,869,424$ & 4.7 \\
\hline
\end{tabular}




\begin{tabular}{lcc} 
Kimberly-Clark S.R.L. & $2,305,839$ & 3.8 \\
Indejebe Sociedad Comercial & $1,717,763$ & 2.8 \\
3M Perú S.A. & $1,575,268$ & 2.6 \\
R\&G Seguridad E Higiene Industrial S.A.C. & $1,532,535$ & 2.5 \\
BufaloImport S.A.C & $1,316,891$ & 2.1 \\
Eficiencia Laboral S.A. & $1,174,136$ & 1.9 \\
Representaciones Lanus EIRL & $1,083,283$ & 1.8 \\
American industrial Equipment S.A.C. & 877,639 & 1.4 \\
Distribuidora Continental & 711,751 & 1.2 \\
\hline
\end{tabular}

Nota: tomado de Veritrade

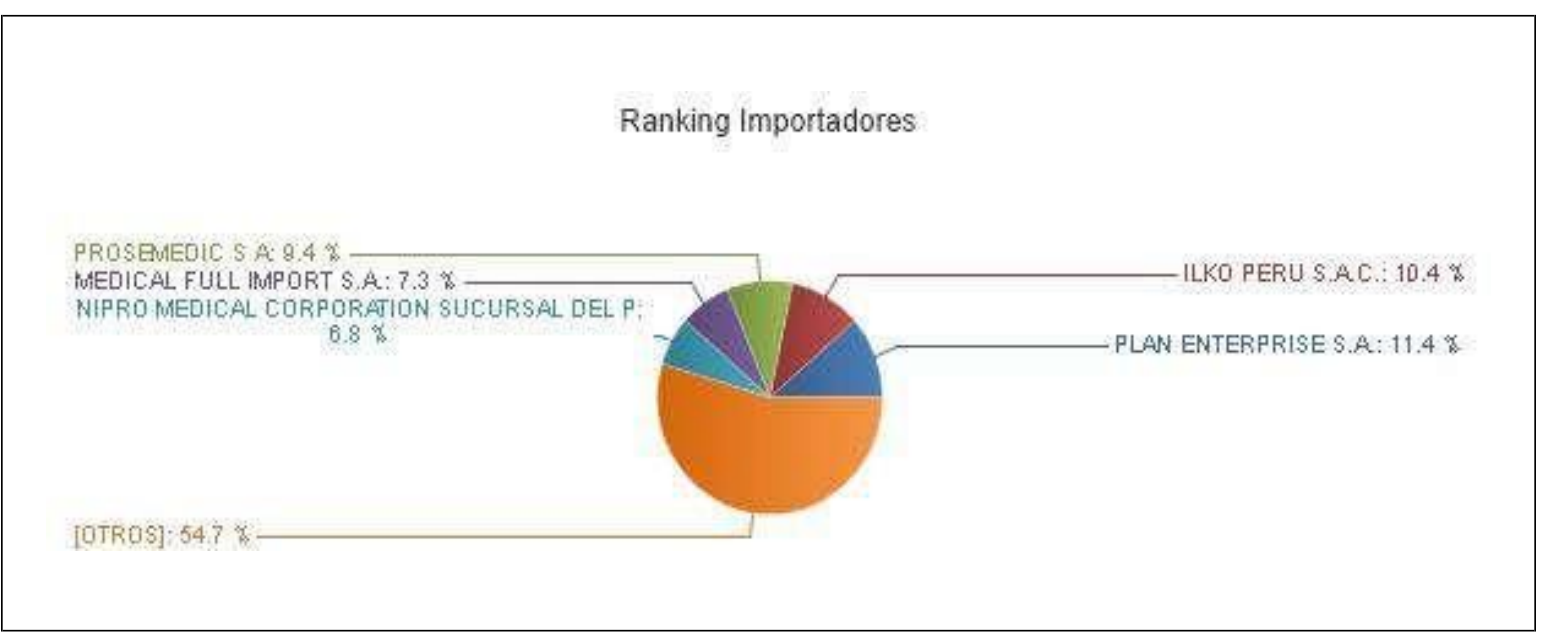

Figura 45. Ranking principales importadores

Nota. Tomado de “LoginVeritrade," por Veritrade, 2016. Recuperado de

http://www.veritrade.info/pruebagratis/31230?utm_source $=$ google \&utm_medium $=$ cpc\&utm_co

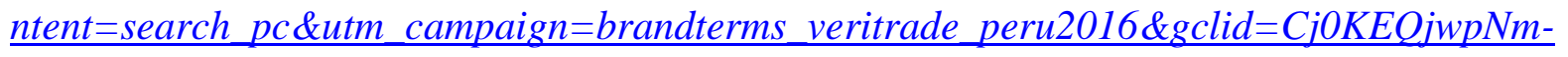
BRCJ3rDNmOuKi9IBEiQAlzDJH63dUplbSsvFhU2mlpiSjqxioLZROHLQUPdOupfldMaAucx8P8HAQ 


\subsection{Matriz de atractividad de cada una de las cinco fuerzas}

\section{i. Análisis del Grado de atractividad de la industria}

En la actualidad la Empresa ETERNA Perú, compite con muchas empresas en el sector de guantes para la limpieza del hogar.

\section{Barreras de entrada:}

El tamaño de mercado y el nivel de rentabilidad alcanzado en el sector, determina que exista interés por el ingreso de los nuevos competidores. En general, en el sector no hay barreras de entrada que impidan el ingreso de otras empresas en el mercado, generando un alto interés en los inversionistas que quieran invertir en este tipo de negocios a fin de obtener una participación en el mercado local. El análisis de atractividad de las barreras de entrada se muestra en la Tabla 30

Tabla 29

Barreras de Entrada

\begin{tabular}{|c|c|c|c|c|c|c|c|}
\hline \multirow[t]{2}{*}{$\begin{array}{c}\text { Amenaza de Ingreso de competidores } \\
\text { potenciales }\end{array}$} & \multirow[t]{2}{*}{ Nivel } & \multicolumn{5}{|c|}{$\begin{array}{c}1<\text { ATRACTIVIDAD }<5 \\
\text { De: } 1 \text { muy poco atractivo, a } 5 \text { muy } \\
\text { atractivo }\end{array}$} & \multirow[t]{2}{*}{ Nivel } \\
\hline & & 1 & 2 & 3 & 4 & 5 & \\
\hline Aparición de nuevos participantes & Alto & & 2 & & & & Bajo \\
\hline Atracción del mercado para nuevos participantes & Alto & & 2 & & & & Bajo \\
\hline Precio de los nuevos participantes & Bajo & & & 3 & & & Alto \\
\hline Accesibilidad de los nuevos participantes & Alto & 1 & & & & & Bajo \\
\hline Nivel de venta de los nuevos participantes & Alto & & & 3 & & & Bajo \\
\hline Mensaje comunicacional de los nuevos participantes & Bajo & & & & 4 & & Alto \\
\hline Nivel de calidad de los nuevos participantes & Alto & & & 3 & & & Bajo \\
\hline Nivel de crecimiento de los nuevos participantes & Alto & & & & 4 & & Bajo \\
\hline Resultado & 2.75 & & & & act & & \\
\hline
\end{tabular}


El resultado de 2.75 obtenido muestra que el nivel de atractividad de las barreras de entrada sea medianamente atractivo, dado que existe la posibilidad que otras empresas interesadas puedan ingresar al sector.

\section{Poder de Negociación de los Proveedores}

El poder de negociación de proveedores es bajo debido a que existe una cantidad grande de empresas importadores (ver Tabla 31), lo que genera que la competencia pueda contar con alternativas para la compra de guantes de limpieza del hogar y competir con diferentes precios en el mercado;

Tabla 30

Poder de negociación de los proveedores

\begin{tabular}{|c|c|c|c|c|c|c|c|}
\hline \multirow[t]{2}{*}{ Poder de Negociación de los proveedores } & \multirow[t]{2}{*}{ Nivel } & \multicolumn{5}{|c|}{$\begin{array}{c}1<\text { ATRACTIVIDAD }<5 \\
\text { De: } 1 \text { muy poco atractivo, a } 5 \text { muy } \\
\text { atractivo }\end{array}$} & \multirow[t]{2}{*}{ Nivel } \\
\hline & & 1 & 2 & 3 & 4 & 5 & \\
\hline Nivel de calidad de los insumos de los proveedores & Alto & & & & & 5 & Bajo \\
\hline Demanda de proveedores & Bajo & & & & 4 & & Alto \\
\hline Diversificación y concentración del proveedor & Poco & & & 5 & & & Mucho \\
\hline Grado de responsabilidad de los proveedores & Mucho & & & & 4 & & Poco \\
\hline Capacidad de distribución de los proveedores & Alto & & & 3 & & & Bajo \\
\hline Facilidad de accesibilidad de los proveedores & Mucho & & 2 & & & & Poco \\
\hline Imagen de los proveedores al mercado & Alto & & & 3 & & & Bajo \\
\hline Imagen de los proveedores hacia la empresa & Alto & & & & 4 & & Bajo \\
\hline Resultado & 3.50 & & & & act1 & & \\
\hline
\end{tabular}

El resultado de 3.5 muestra que el nivel de atractividad del poder de negociación de los proveedores sea atractivo, dado que las empresas del sector no dependen de un grupo reducido de proveedores que surten el producto. 


\section{Poder de negociación de los clientes}

El poder de negociación de los clientes se evalúa con relación a los distribuidores del canal tradicional y distribuidores del canal modernos (supermercado, otros).En este caso, se puede señalar que los proveedores tienen un mayor poder de negociación, lo determina quelos clientes soliciten un margen adecuado de inversión en las ventas. Así, por ejemplo buscan que las empresas del sector les proporcionen apoyo para la venta como impulsadores, material publicitario, promociones. En la Tabla No. 32 se muestra el nivel de atractividad del poder de negociación de los clientes.

Tabla 31

Poder de negociación de los clientes

\begin{tabular}{|c|c|c|c|c|c|c|c|}
\hline \multirow[t]{2}{*}{ Poder de Negociación de los clientes } & \multirow[t]{2}{*}{ Nivel } & \multicolumn{5}{|c|}{$\begin{array}{c}1<\text { ATRACTIVIDAD }<5 \\
\text { De: } 1 \text { muy poco atractivo, a } 5 \text { muy } \\
\text { atractivo }\end{array}$} & \multirow[t]{2}{*}{ Nivel } \\
\hline & & 1 & 2 & 3 & 4 & 5 & \\
\hline Nivel Preferencia de los clientes & Bajo & & & & 4 & & Alto \\
\hline Nivel de satisfacción de los clientes & Alto & & & & 4 & & Bajo \\
\hline Nivel de demanda & Grande & & & 3 & & & Pequeño \\
\hline Frecuencia de compra de los clientes & Bajo & & & 3 & & & Alto \\
\hline Nivel de renovación de clientes & Continuo & & & & 4 & & Estable \\
\hline Nivel de motivación de adquisición del producto & Alto & & & & 4 & & Bajo \\
\hline Nivel de fidelización de los clientes & Bajo & & & & 4 & & Alto \\
\hline Percepción de los clientes sobre la competencia & Grande & & 2 & & & & Pequeño \\
\hline Resultado & 3.50 & & & & act & & \\
\hline
\end{tabular}

El resultado de 3.5 alcanzado muestra que el poder de negociación de los clientes es atractivo en la industria, dado que si bien demandan un apoyo mayor para las ventas a las empresas del sector, por otro lado los proveedores buscan tener siempre disponible el producto lo que reduce su poder de negociación. 


\section{Sustitutos}

Respecto a los productos sustitutos Eterna y las demás empresas ven muy atractivo el negocio ya que a la fecha no existe una amenaza de productos sustitutos en el mercado para los guantes de nitrilo y látex que se usan para la limpieza del hogar. En la Tabla 33 se muestra la evaluación de esta fuerza.

Tabla 32

Amenaza de productos sustitutos

\begin{tabular}{|c|c|c|c|c|c|c|c|}
\hline \multirow[t]{2}{*}{ Amenaza de productos sustitutos } & \multirow[t]{2}{*}{ Nivel } & \multicolumn{5}{|c|}{$\begin{array}{c}1<\text { ATRACTIVIDAD }<5 \\
\text { De: } 1 \text { muy poco atractivo, a } 5 \text { muy } \\
\text { atractivo }\end{array}$} & \multirow[t]{2}{*}{ Nivel } \\
\hline & & 1 & 2 & 3 & 4 & 5 & \\
\hline Disponibilidad de servicios sustitutos & Grande & & & & & 5 & Pequeño \\
\hline Resultado & 5.00 & \multicolumn{6}{|c|}{ Muy atractivo } \\
\hline
\end{tabular}

El resultado de la evaluación de la amenaza de productos sustitutos muestra que con la relación a los productos sustitutos es muy atractiva para el sector.

\section{Rivalidad entre competidores}

La rivalidad entre los competidores en el mercado se encuentra liderado por empresas como Plan Enterprise, IlkoPerú,Prosemedic, Medical Full Import, Caplan SAC, Eterna Perú, y otros de menor participación. La competencias en el mercado, se produce por precio, promoción y establecimientos más cercanos al cliente, a fin de obtener más participación. En la Tabla No. 34 se presenta la evaluación de la rivalidad entre los competidores de la industria.

Tabla 33 
Rivalidad entre los competidores existentes

\begin{tabular}{|c|c|c|c|c|c|c|c|}
\hline \multirow[t]{2}{*}{ Rivalidad entre los competidores existentes } & \multirow[t]{2}{*}{ Nivel } & \multicolumn{5}{|c|}{$\begin{array}{c}1<\text { ATRACTIVIDAD }<5 \\
\text { De: } 1 \text { muy poco atractivo, a } 5 \text { muy } \\
\text { atractivo }\end{array}$} & \multirow[t]{2}{*}{ Nivel } \\
\hline & & 1 & 2 & 3 & 4 & 5 & \\
\hline Nivel de competencia en el mercado & Alto & & 2 & & & & Bajo \\
\hline Nivel de accesibilidad de la competencia & Alto & & 2 & & & & Bajo \\
\hline Nivel de precio de la competencia & Grande & & & 3 & & & Pequeño \\
\hline Nivel de calidad de la competencia & Alto & & & & 4 & & Bajo \\
\hline Nivel de venta de la competencia & Grande & & 2 & & & & Pequeño \\
\hline Tasa de crecimiento del mercado & Bajo & & & & 4 & & Alto \\
\hline Resultado & 3.00 & & & & eutra & & \\
\hline
\end{tabular}

\section{Matriz de AtractividadGeneral}

La matriz de atractividad de cada una de las cinco fuerzas brinda información general respecto al comportamiento de las cinco fuerzas de Porter en el sector y como influyen en su desempeño.

En la Tabla 35 se muestra la matriz de atractividad global que se elaboró considerando los resultados parciales del nivel de atractividad de cada una de las cinco fuerzas y luego se realizó un promedio general a fin de calcular el resultado final del nivel de atractividad de la industria de guantes para la limpieza del hogar.

Tabla 34 
Matriz de atractividad global de las cinco fuerzas

\section{$1<$ ATRACTIVIDAD $<5$}

Factores competitivos

Nivel

De: 1 muy poco atractivo, a Concepto

5 muy atractivo

Amenaza de Ingreso de

competidores potenciales

2.75

Poder de Negociación de los

proveedores

Poder de negociación de los

clientes

Existe probabilidad

de ingreso

Alto poder de

negociación

Amenaza de productos

sustitutos

Sector atractivo baja

amenaza de

sustitutos

Rivalidad entre los

competidores existentes

Competencia fuerte

Evaluación General

Atractivo

En general, el resultado que se obtiene de 3.5 indica un resultado atractivo para la industria de guantes de limpieza del hogar. Una de las fuerzas que no muestra un impacto sobre la industria es la amenaza de productos sustitutos.

Es decir, que la industria de guantes es atractiva por el comportamiento esperado de las variables de las cinco fuerzas, así como por el nivel de crecimiento del mercado y por la rentabilidad esperada.

\subsection{Matriz de Perfil Competitivo MPC}


Losfactores claves de éxito en la industria, se identificó con base en el análisis de la industria yel análisis externo. Luego, los factores determinados fueron confrontados a través de las entrevistas a expertos yalgunos colaboradores de cada una de las empresas de la industria.

Los factores seleccionados fueron precio, atención al cliente, calidad del producto, tiempo de respuesta para atender los pedidos, entre otros. Respecto, a los valores que se usaron para el nivel de importancia se obtuvieron a partir de la opinión de los expertos, de la gerencia de la empresa y otras personas de la industria.

Para realizar el proceso de comparación se seleccionaron exclusivamente a las empresas que tienen mayor cobertura en la venta de guantes para la limpieza del hogar. Entre las empresas escogidas tenemos a:

- 3M Perú:que lidera el mercado en muchos factores clave menos en precio.

- Ilko Perú por su liderazgo en participación de mercado y posición financiera

- Droksa S.A. por la capacidad de distribución y contacto con el cliente final en el canal tradicional.

La evaluación de los factores claves de éxito se realizó con una escala de 1 a 4 donde 1 es una debilidad mayor, 2 es una debilidad menor, 3 es una fortaleza menor y 4 es una fortaleza menor respecto a los factores claves de éxito de la industria. Los resultados se muestran en la tabla 35 .

Tabla 35

Matriz de Perfil Competitivo MPC 


\begin{tabular}{|c|c|c|c|c|c|c|c|c|c|}
\hline \multirow[b]{3}{*}{ Ponderación } & \multirow[b]{3}{*}{ Ponderación } & \multicolumn{2}{|c|}{ Iko Perú S.A.C. } & \multicolumn{2}{|c|}{ Drokasa Perú S.A. } & \multicolumn{2}{|c|}{ 3M Perú S.A. } & \multicolumn{2}{|l|}{ Eterna S.A. } \\
\hline & & & Resultado & & Resultado & & Resultado & & Resultado \\
\hline & & Calificación & Ponderado & Calificación & Ponderado & Calificación & Ponderado & Calificación & Ponderado \\
\hline Precio & 0.20 & 4 & 0.80 & 3 & 0.60 & 2 & 0.40 & 3 & 0.60 \\
\hline Calidad & 0.25 & 3 & 0.75 & 3 & 0.75 & 4 & 1.00 & 4 & 1.00 \\
\hline Servicio al cliente & 0.25 & 3 & 0.75 & 2 & 0.50 & 4 & 1.00 & 2 & 0.50 \\
\hline Costo bajo & 0.20 & 3 & 0.60 & 2 & 0.40 & 3 & 0.60 & 3 & 0.60 \\
\hline Tiempo de respuesta & 0.10 & 3 & 0.30 & 3 & 0.30 & 4 & 0.40 & 4 & 0.40 \\
\hline & 1.00 & & 3.20 & & 2.55 & & 3.40 & & 3.10 \\
\hline
\end{tabular}

El resultado indica que la empresa 3M Perú tiene el mejor perfil competitivo en el mercado respecto a la percepción en calidad del producto y servicio al cliente, mientras los precios de su productos obtieneunabaja percepción

Por su parte, la empresa Iko Perú SAC se percibe como la empresa que tiene precios competitivos en el mercado. Pero, la calidad del producto, servicio al cliente y tiempo de respuesta tienen una percepción moderada.

Respecto a la empresa ETERNA Perú S.A,se tiene una baja percepción respecto al servicio al cliente, lo que determina que sea un elemento que le resta competividad en el mercado, por lo que se consideraque este factor estratégico debe mejorar de manera significativa. 


\section{Capítulo 6 ANÁLISIS INTERNO}

En este capítulo se presenta el análisis interno de la empresa a través de evaluar su cadena de valor para establecer las actividades que generan valor al negocio, para posteriormente compararlo con las actividades similares que realiza la competencia. Esta comparación permitirá reconocer las fortalezas y debilidades de Eterna Perú que harán posible enfrentar los retos que implican los cambios en el entorno e implementar estrategias para lograr ser competitiva en el mercado.

\subsection{Descripción de las actividades de la cadena de valor de la empresa}

Para Porter(2003),la cadena de valor es una herramienta teórica que nos ayuda a identificar y describir las actividades dentro de una organización para la generación de valor para el cliente final y para la empresa, identificando luego la ventaja competitiva del negocio. Con este concepto podemos entender como una empresa logra obtener ventaja competitiva frente a su competencia, cuando a través de sus actividades de su cadena de valor sea capaz de incrementar los márgenes bajando los costos o incrementar los volúmenes de venta en el mercado.

A partir de estos conceptos se elabora la cadena de valor de la empresa (ver Figura 46). La finalidad es identificar los principales eslabones que generan valor y aquellos que crean sobrecostos a fin de mejorarlos a través de planes de acción que en un corto plazo permita a la empresa superar a la competencia. 


\begin{tabular}{|c|c|c|c|c|c|}
\hline Infraestructura & \multicolumn{4}{|l|}{$\begin{array}{l}\text { - Contabilidad y Legal tercerizado } \\
\text { - Administración y finanzas local }\end{array}$} & \\
\hline Recuersos Humanos & \multicolumn{4}{|l|}{$\begin{array}{l}\text { - Manejado por administración } \\
\text { - No genera valor diferencial }\end{array}$} & \\
\hline Finanzas & \multicolumn{4}{|c|}{$\begin{array}{l}\text { - Mantenimiento de cartera y actualización de flujo de caja } \\
\text { - Elaboración del P\&LL proyectado y Presupuesto de gastos }\end{array}$} & $\frac{\vec{v}}{2}$ \\
\hline \begin{tabular}{|l|} 
Adquisiciones \\
\end{tabular} & \multicolumn{4}{|l|}{$\begin{array}{l}\text { - No existe un procedimiento de adquisiciones } \\
\text { - No genera valor }\end{array}$} & 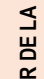 \\
\hline \begin{tabular}{l}
\multicolumn{1}{c}{ Logística Interna } \\
- Importación de productos \\
- Revisión de inventario deficiente \\
- Coordinación con operador logistico \\
- No genera valor
\end{tabular} & $\begin{array}{l}\text { Operaciones } \\
\text { - Envio de mercadería para maquila } \\
\text { - Compra de bolsas y envase local } \\
\text { - Coordinación con proveedor de maquila }\end{array}$ & $\begin{array}{l}\text { Logística Externa } \\
\text { - Coordinación con transporte } \\
\text { - Despacho de mercadería }\end{array}$ & \begin{tabular}{l}
\multicolumn{1}{c}{ Marketing y Ventas } \\
- Elaborar plan de ventas anual \\
- Mantenimiento de clientes
\end{tabular} & \begin{tabular}{l}
\multicolumn{1}{c}{ Servicios } \\
- Pagos de incentivos al distribuidor \\
- Mantenimiento de cuenta de clientes \\
- No genera valor
\end{tabular} & 5 \\
\hline
\end{tabular}

ACTIVIDADES PRIMARIAS

Figura 46.Actual cadena de valor de Eterna Perú S.A.C.

\subsubsection{Actividades primarias}

\section{a. Logística de entrada}

Responsables: Juan Chirinos - Jefe de Logística.

En cuanto al desarrollo de las operaciones de la empresa, el área de logística de Eterna

Perú S.A. realiza las siguientes actividades:

- Análisis de inventarios actuales, revisión del pronóstico de ventas (cantidad de productos a importar), en conjunto con el departamento comercial

- Análisis de costo de importación, almacenamiento

- Coordinar con el proveedor internacional, la documentación (invoice, packinglist, B/L y certificado de origen) de los productos que serán nacionalizados.

- Contactar y coordinar con la agencia de carga la consolidación del producto y con el agente de aduana, el desaduanaje y entrega de mercadería en los almacenes del operador logístico TRANSEL S.A.C. (empresa que nos brinda los servicios de almacenaje hasta la fecha).

Situación actual del área delogística de la empresa: 
Con base a la entrevista en profundidad realizadas al gerente general y el jefe de logística, se llega a la conclusión que, Eterna Perú no cuenta actualmente con un óptimo planeamiento de los productos que tienen que importar; consecuencia de ello, el área responsable continua comprando mercadería adicionalcon la finalidad de poder completar la capacidad de llenado del contenedor (full container), esto genera un sobre inventario del producto en los almacenes del operador logístico que a la fecha viene siendo tercerizado por la compañía logística TranselS.A.C.

Fuentes de generación de valor:

\section{a.1. Reducir los costos logísticos en almacén de productos descontinuados: A fin de} reducir los costos logísticos se proponenegociar con Eterna Colombia para la aceptación de una nota de crédito, con ello se buscara reducir el inventario de los productos descontinuados, llevando a optimizar las ubicaciones (espacio que alquila el operador logístico) en los almacenes.Para calcular el \% de productos de baja rotación con respecto al inventario total, se propone el siguiente indicador:

$\mathrm{Sbr}=\mathrm{Ibj} / \mathrm{Ivt}$

donde:

Sbr: Sku de baja rotación

Ibj: Inventario de productos de baja rotación

Ivt: Inventario total 
a.2. Manejar inventarios menores a 60 días: se considera necesario que el área de ventas en conjunto con logística trabaje en manera simultánea, para así poder eliminar los productos con 180 días de inventarios a través de promociones. Con esta finalidad se plantea el siguiente indicador:

DInv=Inv.In / (ProV3/26)

donde:

DInv: Días de inventario

Inv.In:Inventario Inicial

ProV3/26: promedio de ventas 3 meses/26

\section{b. Operaciones}

Responsables: Juan Chirinos - Jefe de Logística.

En cuanto al desarrollo de las actividades de operaciones de la empresa, el área de operaciones de Eterna S.A. está básicamente relacionada con el maquilado de guantes con marcas propias.A este departamento llegan los guantes a granel en diversas presentaciones y tallas (las que figuran dentro del portafolio de productos de Eterna), luego se procede con el empacado, con las marcas que se ofrecen a los clientes en el canal moderno (supermercados y otros), dentro de las actividadesse realiza lo siguiente:

- Distribución de los guantes a granel al outsourcing (empresa tercerizada) A\&M Servicios Generales, una vez recepcionada la mercadería, esta se encarga con su personal calificado 
delmaquilado (empaquetados de guantes para los clientes estratégicos como Wong, Metro y Plaza Vea.

- Reingreso a la compañía logística Transel S.A.C., procediendo así con el empacado en cajas con unidades de almacenaje de acuerdo a la unidad de medida del cliente, ejemplo: Plaza Vea recibe cajas con doce pares de guantes cada una, en Cencosud las unidades por caja son Veinticuatro pares.

Con base en las conversaciones a profundidad realizadas al gerente general y al jefe de operaciones, se llega a la conclusión que; en la actualidad la recepción de la mercadería e insumos para maquilado es recibida y puesta en marcha por personal de A\&M Servicios Generales, sin la supervisión del personal calificado deEterna Perú.Esto situación trae consecuencias muy comprometedoras entre ellas, la generación de sobrecostos por los riesgos que existen en el traslado de la mercadería como: la pérdida y/o robo del traslado de la mercancía al almacén de TranselS.A.C., una vez culminado el proceso de maquilado.

Otro aspecto a considerar, es que no se cuenta con un adecuado proceso de control de calidad al momento de recepción del producto, una vez que estos llegan a puerto peruano para el proceso de nacionalización del producto. Esta falta de control implica queEterna está asumiendo con esta acción que toda la mercancía llegada a la aduana se encuentra en buen estado y sin mayor daño alguno (Ver Figura 47). 


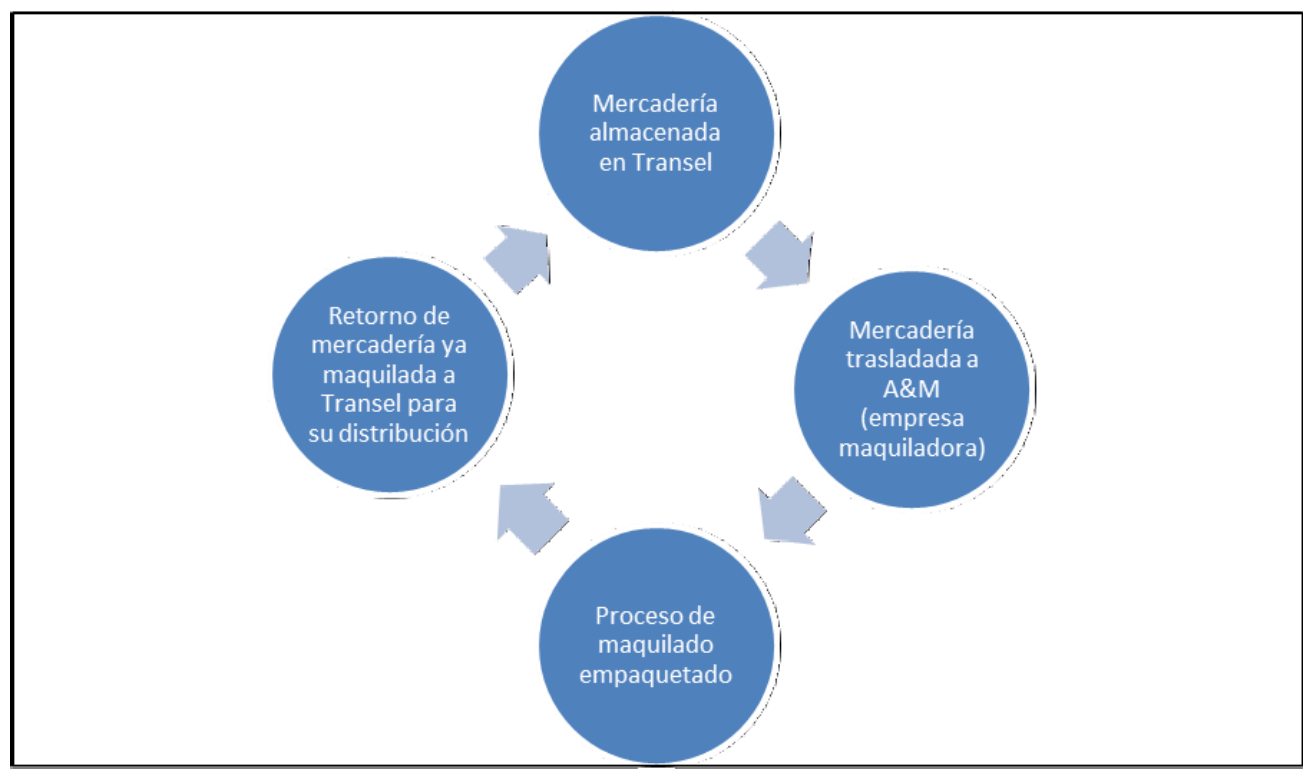

Figura 47.Proceso de maquilado

Fuentes de generación de valor:

\section{b.1. Solicitar al proveedor de origen que brinden el producto terminado para}

nuestros los clientes de canal moderno:Con esta alternativase buscan la reducción del costo de transformación de productos (maquila) en los guantes que solicite el cliente con marca propia (Wong, Metro, Plaza vea), esto generara ahorro en pago a proveedores y también reducirá la incidencia de errores de empaquetado y perdida de productos.Para medir esta propuesta se debe considerar el siguiente indicador:

$\mathrm{MgG}=(\mathrm{Pv}-\mathrm{Cs}) / \mathrm{Pv}$

donde:

MgG: Margen de ganancia 
Pv: Precio de venta

Cs: Costo

\section{b.2. Implementar dentro del área de operaciones el proceso de calidad:se estima}

conveniente contratar personal calificado, que brinde servicios de mediciones de acabado

y buen estado de los productos una vez llegado a los almacenes de Transel. También se

busca con este propuesta reducir las mermas en los productos finales tanto para los

clientes que solicitan marca propia y los guantes de la propia marca; esto la realizara

aplicando sus conocimientos técnicos, enviando indicadores de la mercancía

defectuosa.Se propone el siguiente indicador para medir esta actividad:

$\mathrm{Idm}=\mathrm{Ncdp} / \mathrm{Vt}$

Idm: Indicador de devolución de la mercadería

Ncdp: Nota de crédito por devoluciones de producto

Vt: venta

\section{c. Logística Externa:}

Responsable: Juan Chirinos- Jefe de Logística.

Las actividades que se realizan en esta área son las siguientes:Coordinar con el transportista el traslado de la mercadería a los clientes (Distribuidores, autoservicios, mayoristas y minoristas) en Lima y provincias, actualmente lo realiza la empresa CofeserEIRL. 
En la actualidad se generan altos costos dado que existen muchos agentes involucrados en los procesos de la cadena de valor; tampoco se realiza un control adecuado de inventarios de entrada y salida de mercadería.

Fuentes de generación de valor:

\section{c.1. Realizar una alianza estratégica a largo plazo con una compañía que brinde los} servicios de logística integral: se consideran que se podría generar ahorro de tiempo, menor pérdida de inventario, responsabilidad en caso exista riesgos o accidentes con los productos, buscando una óptima distribución hacia los clientes en Lima y provincias. Para evaluar esta actividad se propone el siguiente indicador:

$\mathrm{OpC}=\mathrm{Mcdm} / \mathrm{Vtm}$

donde:

OpC: Optimización de costos

Mcdm: Medición de Costo de distribución mensual Vtm:Venta mensual

\section{d. Marketing y ventas:}

Responsable: Ivan Peña Delgado - Gerente Comercial

Dentro de las actividades que se llevan a cabo en esta área de la compañía tenemos a las siguientes:

- Atención al canal tradicional (mayoristas, minoristas, distribuidores). 
- Atención al canal moderno (autoservicios, home center).

- Elaborar el plan de ventas anual.

- Revisión trimestral del plan de ventas.

- Búsqueda de nuevos clientes.

- Mantenimiento de información al distribuidor (generar buenas relaciones).

- Elaborar un plan de promociones y evaluar los resultados del mismo.

El canal tradicional representa el $70 \%$ de las ventas, la empresa viene atendiendo a este sector en forma directa, sin una lista de precios adecuada diferenciada por canal, lo que le genera al distribuidor (principales clientes de Eterna), una insatisfacción ya que tienen la perspectiva de no sentirse respaldados por la marca y siente que existe una competencia desleal en cuanto a precios; es decir Eterna les vende a los mismos clientes del distribuidor (minoristas y mayoristas) en forma directa y a un menor precio, trayendo como consecuencia desorden de precios en el mercado y decrecimiento en el volumen de ventas afectando el ingreso de la compañía.

Respecto a autoservicios se sigue vendiendo directamente esto genera buenos resultados para la empresa, representando un $30 \%$ de las ventas.Eterna en la actualidad no cuenta con un área de trade marketing (Promoción de ventas al consumidor final).

El precio de venta en las cadenas es mayor, lo que permite un mayor margen y que una parte de este margen se reutilice para actividades promocionales dentro de estas. 
Fuentes de generación de valor:

\section{d.1. Eliminar la venta directa en minoristas y fortalecer la red de ventas con los}

distribuidores: Se considera que esta propuesta llevara a la empresa a generar menores costos en transportes y despacho, ya que solamente tendrán al personal adecuado para las ventas a los distribuidores y canal moderno. El indicador es el siguiente:

Red.Vt= Vend $\min >1$

donde:

Red.vt: Reducción de venta

Vend min: Vendedores minoristas

d.2. Realizar un adecuado GotoMarket (G2M): Con este indicador Eterna garantiza una adecuada escala de precios en el mercado es decir que por cualquiera de las rutas llegue al consumidor el mismo precio.El indicador es el siguiente:

$\mathrm{GtM}=\mathrm{Pvs}>\mathrm{Pvmin}>\mathrm{Pvmay}>\mathrm{Pvd}$

donde:

Pvs $=$ Precio de venta sugerido

Pvmin $=$ Precio de venta minorista

Pvmay $=$ Precio de venta mayorista

Pvd $=$ Precio de venta distribuidor 
d.3. crear un área de Trade Marketing: se esperan con esta alternativa impulsar la marca y generar un mayor acercamiento con el cliente final (ama de casa, empleadas del hogar, etc.). El indicador es el siguiente:

IAP = Inversión en actividades promocionales

donde:

IAP $($ Autoservicios $)=$ Hasta 15\% del Margen

IAP $($ Canal Tradicional $=$ Hasta $9 \%$ del Margen

En el caso de los autoservicios el precio es el de PVS

\section{e. Servicios}

Responsable: Mirela Aguirre - Jefa de Administración y finanzas

En cuanto a servicios al cliente tenemos las actividades relacionadas con el mantenimiento de los estados de cuenta, pago de extra márgenes a los distribuidores, control y pago de incentivos a la fuerza de ventas del distribuidor. Eterna en la actualidad no realiza la actividades que conlleven a un buen desempeño y compromiso del distribuidor a la marca.

Fuentes de generación de valor:

\section{e.1. Capacitación a la fuerza de ventas del distribuidor para una mayor efectividad} en el desalojo del producto:Con esta alternativa se busca que los vendedores de las distribuidoras puedan absolver objeciones de sus compradores mediante cualidades y beneficios del producto. El indicador es el siguiente: 
$\mathrm{CM}>60 \%$ la evaluación de da en la FFVV de los distribuidores.

donde:

$\mathrm{CM}=$ Conocimiento de la marca

\section{e.2. Implementar concursos con beneficios a la fuerza de ventas del distribuidor} para motivarlos e incrementar cobertura del producto: Con esta propuesta se busca la motivación del vendedor de las diferentes distribuidoras por vender los productos de Eterna, con un mínimo del $30 \%$ de vendedores premiados se asegura un adecuado desalojo de productos en el distribuidor. Los concursos no solo consideran volumen de ventas si no también cobertura es decir venta en mayores puntos de la cartera de clientes.Esto genera un mayor acercamiento del vendedor con la marca y una mayor efectividad en la cartera del distribuidor.El plan de acción se ejecutará bajo el mando de la gerencia de marketing y ventas. El indicador es:

Epre $>30 \%$

Epre $=$ Vpre $/$ NroVen

donde:

Epre $=$ Efectividad de premiación

Vpre $=$ Vendedores premiados

NroVen $=$ Número de vendedores 


\subsubsection{Actividades de apoyo}

\section{a. Infraestructura de la empresa}

Se identificó que la compañía en la actualidad viene tercerizando las áreas legales y contables; y maneja sus propias áreas que se mencionan a continuación:

Área de finanzas: Mirella Aguirre - Gerente de Finanzas

Tiene a su cargo las siguientes actividades:

- Elaboración del flujo de caja mensual, trimestral y anual.

- Elaborar y gestionar la cartera de cobranzas a los clientes.

- Adquisición de capital financiero.

- Emisión de cheques y pago a proveedores locales y extranjeros.

- Pago de planillas, beneficios, liquidaciones y los costos laborales.

- Representación financiera ante las entidades bancarias.

- Reportar mensualmente a la casa matriz las finanzas de la compañía.

Área de administración: Mirella Aguirre - Gerente de finanzas

Tiene a su cargo las siguientes actividades:

- Encargado de los recursos humanos

- Servicios generales

- Bienestar de los colaboradores. 
En la actualidad la empresa tiene un alto costo teniendo en sus instalaciones a un Gerente de finanzas, ya que las decisiones financieras se toman desde la casa matriz (Colombia).Por parte de Administración de personal el responsable tiene muchos temas que tratar dentro de su organización, trayendo como consecuencia la falta de generación de valor para la compañía en Perú. Recursos Humanos en la actualidad es manejado por el departamento de administración y finanzas. La empresa no tiene un procedimiento de contrataciones y desarrollo del personal.

Fuentes de generación de valor:

a.1.Prescindir de un gerente financiero, se considera necesario contratar un contralor de finanzas que coordinará el manejo financiero con la casa matriz en Colombia. Los reportes y manejo de decisiones deben ser coordinadas con la casa matriz. El indicador es el siguiente: Inf=Mca y Red Gast

donde:

Inf: Infraestructura

Mca:Menor carga administrativa

Red Gast:Reducción de gastos de planilla.

\section{a.2. Desarrollar el procedimiento y manual de contrataciones de personal y elaborar el plan de crecimiento profesional:se debe buscar desarrollar el talento, identificar las cualidades del personal de Eterna, mejorar y desarrollarlas mediante capacitación constante y motivación al personal. El indicador es el siguiente:}


Evaluación anual de personal.

\section{b. Adquisiciones}

Responsable: Juan Carlos Chirinos - Gerente de Logística

No existe un procedimiento de adquisiciones, compras a proveedores locales en la mayor parte contado o con cortos plazos de crédito.

Fuentes de generación de valor:

b.1. Creación de un procedimiento de adquisiciones: con este proceso se busca optimizar los tiempos de compras y buscar una efectividad adecuada en el proceso de la cadena de suministro, generar plan de adquisición anual de compras de cada área de la empresa para poder establecer prioridades en las compras que se ejecutaran el siguiente año. El indicador es:

$\mathrm{Cpc}=\mathrm{Ef}>\mathrm{Aa}$

donde:

$\mathrm{Cpc}=$ Creación de un procedimiento de adquisiciones

Ef: Efectividad

Aa: Año anterior

Con base en el análisis de las actividades de la cadena de valor genérica, se muestra la cadena de valor de la empresa Eterna Perú determinado a partir de las propuestas de generación de valor y los indicadores considerados para su medición. 


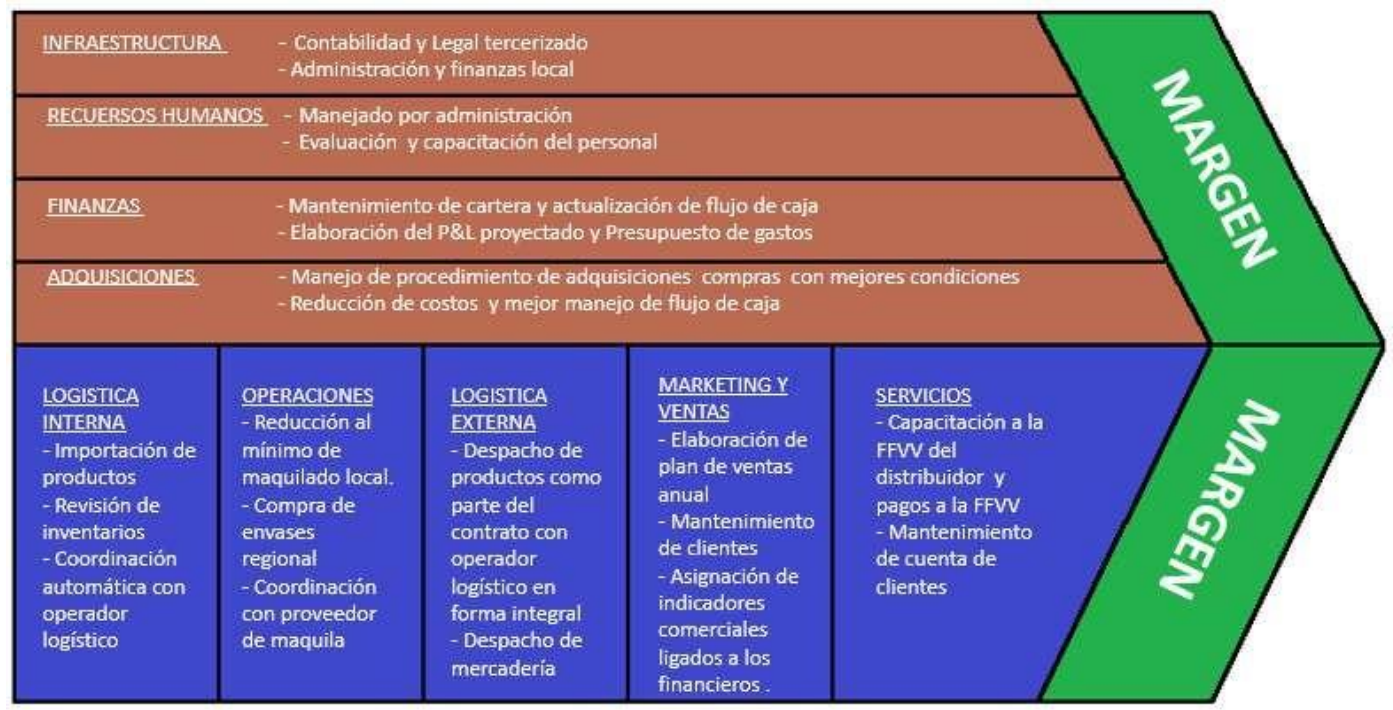

Figura 48.Nueva cadena de valor de Eterna Perú S.A.C.

\subsection{Indicadores de cada una de las actividades de la cadena de valor}

En la Tabla 36 se muestran los indicadores de gestión de cada una de las actividades de la cadena de valor de la empresa. Los indicadores permiten medir el desempeño de las actividades y posteriormente compararlo con los resultados de actividades similares de otras empresas de la industria. 
Tabla 36

Indicadores de cada una de las actividades

\begin{tabular}{|c|c|c|}
\hline Actividades & Indicador de Gestión & \\
\hline \multirow[t]{2}{*}{$\begin{array}{l}\text { Logística } \\
\text { Interna }\end{array}$} & $\begin{array}{l}\text { Reducir los costos logísticos en almacén de } \\
\text { productos descontinuados }\end{array}$ & Sbr= Ibj/Ivt \\
\hline & Manejar inventarios menores a 60 días & DInv=Inv.In / (ProV3/26) \\
\hline \multirow[t]{2}{*}{ Operaciones } & $\begin{array}{l}\text { Solicitar al proveedor de origen que brinden el } \\
\text { producto terminado para nuestros los clientes de } \\
\text { canal moderno }\end{array}$ & $\mathrm{MgG}=(\mathrm{Pv}-\mathrm{Cs}) / \mathrm{Pv}$ \\
\hline & $\begin{array}{l}\text { Implementar dentro del área de operaciones el } \\
\text { proceso de calidad }\end{array}$ & $\mathrm{Idm}=\mathrm{Ncdp} / \mathrm{Vt}$ \\
\hline $\begin{array}{l}\text { Logística } \\
\text { Externa }\end{array}$ & $\begin{array}{l}\text { Nro. máximo de atenciones a clientes del canal } \\
\text { tradicional, por cuota de ventas }\end{array}$ & $\mathrm{OpC}=\mathrm{Mcdm} / \mathrm{Vtm}$ \\
\hline \multirow[t]{3}{*}{$\begin{array}{l}\text { Marketing y } \\
\text { Ventas }\end{array}$} & $\begin{array}{l}\text { Eliminar la venta directa en minoristas y fortalecer } \\
\text { la red de ventas con los distribuidores }\end{array}$ & Red.Vt $=$ Vend $\min >1$ \\
\hline & Realizar un adecuado GotoMarket (G2M) & GtM $=$ Pvs $>$ Pvmin $>$ Pvmay $>$ Pvd \\
\hline & Crear un área de Trade Marketing & $\begin{array}{l}\text { IAP = Inversión en actividades } \\
\text { promocionales }\end{array}$ \\
\hline \multirow[t]{2}{*}{ Servicios } & $\begin{array}{l}\text { Capacitación a la fuerza de ventas del distribuidor } \\
\text { para una mayor efectividad en el desalojo del } \\
\text { producto }\end{array}$ & $\begin{array}{l}\mathrm{CM}>60 \% \text { la evaluación de da } \\
\text { en la FFVV de los } \\
\text { distribuidores. }\end{array}$ \\
\hline & $\begin{array}{l}\text { Implementar concursos con beneficios a la fuerza } \\
\text { de ventas del distribuidor para motivarlos e } \\
\text { incrementar cobertura del producto }\end{array}$ & $\begin{array}{l}\text { Epre }>30 \% \\
\text { Epre }=\text { Vpre / NroVen }\end{array}$ \\
\hline \multirow[t]{2}{*}{ Infraestructura } & $\begin{array}{l}\text { Controlador de finanzas que coordinará el manejo } \\
\text { financiero }\end{array}$ & Inf=Mca y Red Gast \\
\hline & $\begin{array}{l}\text { Reportes y manejo de decisiones coordinadas con } \\
\text { casa matriz }\end{array}$ & Inf=Mca y Red Gast \\
\hline $\begin{array}{l}\text { Recursos } \\
\text { Humanos }\end{array}$ & $\begin{array}{l}\text { Procedimiento y manual de contrataciones de } \\
\text { personal y elaborar el plan de crecimiento } \\
\text { profesional }\end{array}$ & Evaluación anual de personal \\
\hline Adquisiciones & Procedimiento de adquisiciones & $\mathrm{Cpc}=\mathrm{Ef}>\mathrm{Aa}$ \\
\hline
\end{tabular}




\subsection{Benchmarking y comparación con los líderes de la industria de cada una de lasactividades de la cadena de valor}

El Benchmarking es una herramienta de gestión, en la actualidad no hay una traducción literal, pero se considera que el mejor concepto de esta poderosa herramienta es la que nos brinda Robert C. Camp en su texto "Benchmarking":

"El benchamarking es la búsqueda de las mejores prácticas que realizan las empresas que conduzcan a un beneficio o desempeño superior". Actualmente la metodología del Benchmarking es listada perpetuamente en los puntos que han continuado las empresas ganadores de la recompensa de calidad.

A fin de conocer la actual posición competitiva de la empresa, se realizó la comparación de Eterna en relación con las actividades primarias y de soporte de la cadena de valor delas empresasIlko Perú y Colgate, dado que estos competidores tienen dentro de su portafolio de productos la marcaVirutex ylos diversos productos de la marca Colgate. Para efectuar esta comparación se llevaron a cabo algunas entrevistas a profundidad a empleados y ex empleados las compañías mencionadas líneas arriba. La finalidad de la comparación fue reconocer como se realizan y se pueden mejorar las principales actividades de valor de la compañía.

La Tabla 37 muestra cómoha sido construida el benchamarking en base a los anexos 1,2, 3 y 4 , estos anexos se elaboró a fin de conocer como se realizar los procesos de las compañías en la cual Eterna Perú ha sido comparada. 
Tabla 37

Benchmarking y comparación con el líder de la industria

\begin{tabular}{|c|c|c|c|c|c|}
\hline Actividades & Indicador de Gestión & & $\begin{array}{c}\text { Eterna } \\
\text { Peru }\end{array}$ & Virutex & Colgate \\
\hline \multirow[t]{2}{*}{$\begin{array}{l}\text { Logística } \\
\text { Interna }\end{array}$} & $\begin{array}{l}\text { Reducir los costos } \\
\text { logísticos en almacén de } \\
\text { productos } \\
\text { descontinuados }\end{array}$ & $\mathrm{Sbr}=\mathrm{Ibj} / \mathrm{Ivt}$ & Malo & Bueno & Bueno \\
\hline & $\begin{array}{l}\text { Manejar inventarios } \\
\text { menores a } 60 \text { días }\end{array}$ & $\begin{array}{l}\text { DInv=Inv.In / } \\
(\text { ProV3/26) }\end{array}$ & Malo & Malo & Bueno \\
\hline \multirow[t]{2}{*}{ Operaciones } & $\begin{array}{l}\text { Solicitar al proveedor de } \\
\text { origen que brinden el } \\
\text { producto terminado para } \\
\text { nuestros los clientes de } \\
\text { canal moderno }\end{array}$ & $\mathrm{MgG}=(\mathrm{Pv}-\mathrm{Cs}) / \mathrm{Pv}$ & Malo & Bueno & Bueno \\
\hline & $\begin{array}{l}\text { Implementar dentro del } \\
\text { área de operaciones el } \\
\text { proceso de calidad }\end{array}$ & $\mathrm{Idm}=\mathrm{Ncdp} / \mathrm{Vt}$ & Regular & Regular & $\begin{array}{l}\text { No } \\
\text { Detalla }\end{array}$ \\
\hline $\begin{array}{l}\text { Logística } \\
\text { Externa }\end{array}$ & $\begin{array}{l}\text { Nro. máximo de } \\
\text { atenciones a clientes del } \\
\text { canal tradicional, por } \\
\text { cuota de ventas }\end{array}$ & $\mathrm{OpC}=\mathrm{Mcdm} / \mathrm{Vtm}$ & Malo & Bueno & Bueno \\
\hline \multirow[t]{3}{*}{$\begin{array}{l}\text { Marketing y } \\
\text { Ventas }\end{array}$} & $\begin{array}{l}\text { Eliminar la venta directa } \\
\text { en minoristas y fortalecer } \\
\text { la red de ventas con los } \\
\text { distribuidores }\end{array}$ & Red. $\mathrm{Vt}=$ Vend $\min >1$ & Malo & Malo & Bueno \\
\hline & $\begin{array}{l}\text { Realizar un adecuado } \\
\text { GotoMarket (G2M) }\end{array}$ & $\begin{array}{l}\text { GtM }= \\
\text { Pvs }>\text { Pvmin }>\text { Pvmay }>\text { Pvd }\end{array}$ & Malo & Bueno & Bueno \\
\hline & $\begin{array}{l}\text { Crear un área de Trade } \\
\text { Marketing }\end{array}$ & $\begin{array}{l}\text { IAP = Inversión en } \\
\text { actividades } \\
\text { promocionales }\end{array}$ & Malo & Bueno & Bueno \\
\hline \multirow[t]{2}{*}{ Servicios } & $\begin{array}{l}\text { Capacitación a la fuerza } \\
\text { de ventas del distribuidor } \\
\text { para una mayor } \\
\text { efectividad en el desalojo } \\
\text { del producto }\end{array}$ & $\begin{array}{l}\text { CM > 60\% evaluación } \\
\text { en la FFVV de los } \\
\text { distribuidores. }\end{array}$ & Regular & Regular & Bueno \\
\hline & $\begin{array}{l}\text { Implementar concursos } \\
\text { con beneficios a la } \\
\text { fuerza de ventas del } \\
\text { distribuidor para } \\
\text { motivarlos e incrementar } \\
\text { cobertura del producto }\end{array}$ & $\begin{array}{l}\text { Epre > 30\% } \\
\text { Epre = Vpre / NroVen }\end{array}$ & Bueno & Malo & Bueno \\
\hline
\end{tabular}




\begin{tabular}{llllll}
\hline Infraestructura & $\begin{array}{l}\text { Controlador de finanzas } \\
\text { que coordinará el manejo } \\
\text { financiero }\end{array}$ & Inf=Mca y Red Gast & Malo & Regular & Bueno \\
& $\begin{array}{l}\text { Reportes y manejo de } \\
\text { decisiones coordinadas } \\
\text { con casa matriz }\end{array}$ & Inf=Mca y Red Gast & Bueno & Bueno & Bueno \\
\hline $\begin{array}{l}\text { Recursos } \\
\text { Humanos }\end{array}$ & $\begin{array}{l}\text { Procedimiento y manual } \\
\text { de contrataciones de } \\
\text { personal y elaborar el } \\
\text { plan de crecimiento } \\
\text { profesional }\end{array}$ & $\begin{array}{l}\text { Evaluación anual de } \\
\text { personal }\end{array}$ & Malo & Regular & Regular \\
& $\begin{array}{l}\text { Procedimiento de } \\
\text { adquisiciones }\end{array}$ & $\mathrm{Cpc}=\mathrm{Ef}>\mathrm{Aa}$ & Malo & Regular & Bueno \\
\hline Adquisiciones & & & & \\
\hline
\end{tabular}

\subsection{Competencias de la empresa}

Para poder determinar las competencias de la Empresa Eterna Perú S.A. se han tomado como base los factores críticos de éxito que se necesitan para lograr las ventajas competitivas, cuales son relevantes, cuales posee actualmente la empresa y cuales se podría desarrollar.

\section{Calidad de Producto}

Tal como se mencionó en los capítulos anteriores la empresa Eterna es especialista en la fabricación de productos a base de látex esto se debe a la experiencia de tener 60 años en el mercado Colombiano; cuenta con plantas altamente tecnificadas que aseguran la calidad de los productos, los productos de Eterna manejan certificaciones de calidad como el ISO 9001:2000 expedida por el ICONTEC, que respalda la calidad en todos los procesos de producción.En tal sentido los procesos y las certificaciones generan:

- Reconocimiento de producto

- Calidad (Guantes). 
- Competitividad (guantes).

- Portafolio diferenciado por canal en nivel de precio y uso de producto.

2. Llegada al Mercado

Eterna es líder de la categoría en el canal moderno o autoservicios debido al amplio portafolio de productos con el que cuenta, las marcas propias en guantes de las cadenas de autoservicios son fabricadas por Eterna, las marcas propias de las cadenas en general son fabricadas por el líder de la categoría.

También es importante destacar que la empresa cuenta con plantas propias en Colombia que le permiten una respuesta rápida al mercado en tiempo de entrega y flexibilidad en la producción, generando lo siguiente:

- Alta Participación de mercado en el canal moderno, líderes de mercado en cadenas de autoservicios quedando pendiente la codificación para Home Centers y Macro.

- Tiempo de repuesta (lead time) producción Colombia, los tiempos de abastecimiento desde las plantas de Eterna en Colombia son muy cortos, treinta días promedio desde la colocación de la Orden de compra a Colombia y llegada a los almacenes del operador logístico en Lima.

- Portafolio amplio de productos limpieza, Eterna también cuenta con plantas para la fabricación de paños, fibras y plásticos en Colombia. 


\section{Adaptabilidad}

La estructura horizontal de Eterna permite que muchos de los procesos de la casa matriz puedan ser replicados o adaptados en Perú, con lo que se aprovecha el conocimiento y experiencia colombiana para innovación en el mercado nacional permitiendo: facilidad para aplicar procesos ya desarrollados en la casa matriz, compras consolidadas desde, poder de negociación con proveedores y compras a escala, esto genera como beneficio la reducción de costos; estructura ligera con facilidad de tomar decisiones rápidas, la simplificación e identificación de los procesos permite reaccionar rápidamente al mercado.

La falta o deficiencias en algunas competencias traen como resultado que la empresa presente las siguientes debilidades susceptibles de poder mejorar:

- Poco reconocimiento de producto en otras líneas, esto debido al poder de los otros jugadores y líderes del mercado, Eterna está muy enfocado sólo en desarrollar la categoría de guantes.

- Desorden en la llegada al mercado (GotoMarket), administración muy enfocada en ventas sin un horizonte claro y sin un estrategia comercial definida por canal.

- Problemas de calidad en el almacenamiento, no existen procesos de control de calidad definidos y deficientes sistemas de almacenamientos de los productos que ocasionaban el deterioro de los mismos.

- Bajo nivel de servicios (procesos y procedimientos), deficiencias en los procesos financieros, control de cuentas de clientes, procesos logísticos de atención a clientes y controles de calidad en despacho. 
- Personal poco capacitado, no existen programas de capacitación definidas para los colaboradores y manejados por indicadores para medir su impacto en el negocio.

- Portafolio por canal errado, portafolio muy amplio para el canal tradicional que no permite un enfoque de parte del vendedor dela distribuidora al cliente minorista y este al cliente final.

\subsection{Identificación y determinación de las ventajas competitivas de la empresa}

Se ha identificado que la empresa Eterna es muy fuerte en la categoría de guantes, el consumidor identifica los guantes con la marca Eterna como un producto que tiene una calidad superior a las demás marcas que oferta en el mercado nacional la competencia. Sin embargo esta línea de productos que pertenecen a la industria de artículos de limpieza del hogar no tiene alta lealtad de marca, como lo puede tener un shampoo, jabón de piel, prestobarbas, detergentes o jabón de lavar ropa, lava vajilla, en ese sentido es clave la presencia física del producto en el mercado.

Otra de las ventajas competitivas de la empresa es que en la actualidad cuenta con su propia planta en Colombia lugar donde se ubica la empresa matriz; el contar con su propia infraestructura productiva permite que la empresa les brinde productos con valor agregado a los consumidores, generando así el posicionamiento de la marca, seguridad y garantía que solo Eterna puede brindarles a los clientes; la empresa puede atender las exigentes demandas de los principales clientes, ejemplo de ello sería un nuevo pedidoque puedan existir en el mercado 
(diseños personalizados por una empresa líder de limpieza de oficinas y hogar, colores propios de los usuarios, tamaños personalizados, guantes que tengan aromas, etc.)

Se identificó que en la comercialización de productos de consumo masivo los tiempos de reposición de los productos son de mucha importancia, un desabastecimiento de los guantes en los almacenes del cliente puede perjudicar al consumidor final, generando que el prestigio del vendedor y la imagen de la empresa comercializadora pierdan valor en el mercado. La ventaja que presenta Eterna en este factor es que el equipo logístico en coordinación con la matriz puede manejar tiempos de reposición o Lead Time de quince días promedio, esto permite controlar y reducir costos logísticos que involucre la llegada de la mercancía en destino.

Basado en lo expuesto, se puededeterminar las ventajas competitivas de Eterna en la industria donde se desarrolla (ver Tabla 38). Para ello se utiliza la matriz VRIO, en donde se evalúa las competencias y los recursos de la empresa para establecer si cumplen con el requisito de: valioso, raro, inimitable y organización.

Tabla 38

Ventajas competitivas de Eterna

\begin{tabular}{lllll}
\hline Competencia & Valioso & Raro & Inimitable & Organización \\
\hline & & & & \\
Calidad & $\mathrm{Si}$ & $\mathrm{si}$ & $\mathrm{Si}$ & $\mathrm{si}$ \\
Adaptabilidad al mercado & $\mathrm{Si}$ & $\mathrm{si}$ & $\mathrm{Si}$ & $\mathrm{si}$ \\
Lead time & $\mathrm{Si}$ & $\mathrm{si}$ & $\mathrm{Si}$ & $\mathrm{si}$ \\
Llegada al mercado & $\mathrm{Si}$ & $\mathrm{no}$ & $\mathrm{No}$ & no \\
Servicio & $\mathrm{Si}$ & no & $\mathrm{Si}$ & no \\
\hline
\end{tabular}


A partir de la matriz anterior se puede señalar que las ventajas competitivas de la empresa Eterna

Perú son:

Calidad superior: implementación de alta e insumos de calidad

Adaptabilidad al mercado: satisfacer la demanda del cliente

Lead Time: es muy corto dado que cuenta con un buen manejo logístico

Con las competencias identificadas, se debe definir las estrategias que permitan la mejor llegada al mercado con márgenes adecuados, costos controlados y generando una rentabilidad que permite el .buen desarrollo del negocio.

\subsection{Matriz de Evaluación de los Factores Internos EFI}

La matriz de evaluación de los factores internos (EFI) muestra la situación actual de la empresaconsiderando las fortalezas y debilidades que se ha obtenido durante el proceso de análisis y comparación con la competencia de cada una de las actividades estratégicas que realiza la empresa. (ver Tabla 39).

Tabla 39Matriz de Evaluación de los Factores Externos EFI

\begin{tabular}{lll}
\hline $\mathrm{N}^{\circ} \quad$ Factores Críticos de éxito & Peso Califi- & Total \\
& cación & Ponderado
\end{tabular}

\section{Fortaleza}

1 Reconocimiento de producto - calidad

$0.10 \quad 4 \quad 0.4$

2 Alta participación de mercado en canal moderno

$\begin{array}{lll}0.06 \quad 4 & 4 & 0.24\end{array}$

3 Tiempo de repuesta (lead time) apropiado

$\begin{array}{lll}0.09 & 4 & 0.36\end{array}$

4 Portafolio amplio de productos limpieza

0.083

0.24 
$\begin{array}{lllll}5 & \text { Facilidad para aplicar procesos ya desarrollados en casa matriz } & 0.08 & 3 & 0.24\end{array}$

6 Compras consolidadas desde casa matriz $\quad \begin{array}{llll}0.06 & 4 & 0.24\end{array}$

$\begin{array}{lllll}7 & \text { Estructura Ligera con facilidad de tomar decisiones rápidas } & 0.08 & 3 & 0.24\end{array}$ Debilidad

1 Desorden en la llegada de productos al mercado (GotoMarket) $\quad \begin{array}{lll}0.10 & 1 & 0.1\end{array}$

$\begin{array}{lllll}2 & \text { Servicio de distribución del producto costoso } & 0.09 & 1 & 0.09\end{array}$

$\begin{array}{lllll}3 & \text { Bajo nivel de servicios (Procesos y Procedimientos) } & 0.08 & 1 & 0.08\end{array}$

$\begin{array}{lllll}4 & \text { Personal de ventas poco capacitado } & 0.08 & 1 & 0.08\end{array}$

$\begin{array}{lllll}5 & \text { Falta claridad en el portafolio de productos por canal } & 0.10 & 1 & 0.1\end{array}$

$\begin{array}{lll}\text { Total } & 1.00 & 2.41\end{array}$

El proceso para elaborar la matriz de evaluación interna, consistió en establecer primero un peso o nivel de importancia a cada uno de los factores críticos de éxito. Esta ponderación se realizó mediante una entrevista a profundidad al gerente general de la empresa, quien a través de su experiencia se considera, puede establecer la importancia de cada uno de los factores.

Posteriormente se realizó una calificación de cada uno de los factores críticos de éxito en una escala de 3 (fortaleza menor) a 4 (fortaleza importante) para las fortalezas y de 1 (debilidad importante) a 2 (debilidad menor) para las debilidades según David (2013). Este proceso de calificación se realizó también mediante la consulta al gerente de la empresa y otras personas que laboran en el negocio.

El resultado alcanzado de 2.41 indica que la empresa con la estrategia actual no está en una buena posición para aprovechar las fortalezas con las que cuenta. Por tanto, se considera que esta posición debe mejorar en el futuro a fin de aumentar sus fortalezas y reducir sus debilidades. 


\section{Capítulo 7 Formulación de los objetivos y diseño de las estrategias}

En este capítulo se plantean en primer lugar los objetivos estratégicos tomando en cuenta las necesidades de la empresa y la información recogida a partir del análisis interno y externo. Posteriormente, se formulan las estrategias de negocios para la empresa tomando como base para el diseño las diferentes matrices que se usan para diseñar estrategias de este nivel.

\subsection{Alcance y planteamiento de los objetivos estratégicos}

El alcance y planeamiento de objetivos estratégicos tienen como base lo propuesto en la Misión y Visión de la empresa, que servirán como rumbo para la definición de los fines que espera alcanzar la empresa. Estos objetivos tienen como horizonte cinco años. Las acciones sugeridas posteriormente facilitarán el cumplimiento de los objetivos específicos de la organización.

\subsubsection{Objetivos Estratégicos}

Los objetivos Estratégicos son metas que se buscan alcanzar a fin de cumplir con lo propuesto en la Misión y Visión, están orientados en su cumplimiento en el mediano y largo plazo.

David (2013) considera que los objetivos a largo plazo deben ser el resultado del seguimiento de las estrategias planteadas. Los objetivos y estrategias normalmente tienen un horizonte de entre dos y cinco años. Para la empresa se propone un horizonte de evaluación de cinco años, los objetivos estratégicos propuestos son los siguientes: 
- Lograr una rentabilidad sobre ventas para la empresa de hasta un $10 \%$ para el año 2021

- Incrementar en un $10 \%$ anual las ventas totales de la empresas hasta el año 2021

- Brindar productos de calidad con estándares internacionales y buen servicio a nuestros clientes.

- Desarrollar un nuevo modelo comercial para la gestión del área en los próximos tres años que permita una correcta fijación de precios.

- Mantener un excelente clima laboral basado en el desarrollo profesional y personal de los colaboradores de la empresa.

Tabla 40

Objetivos estratégicos

$\mathrm{N}^{\circ}$ Objetivos estratégicos

1 Perspectiva Financiera: Generar y maximizar rentabilidad. Incrementar ventas.

2 Perspectiva Clientes: - Brindar excelentes productos y servicios a nuestros clientes

3 Perspectiva Procesos Internos: - Desarrollar un modelo comercial adecuado

4 Perspectiva Procesos Internos:- Controlar una correcta ejecución de precios

5 Perspectiva Aprendizaje y Crecimiento: - Mantener un excelente clima laboral basado en el desarrollo profesional y personal de nuestros colaboradores

\subsubsection{Análisis de los objetivos estratégicos}


En el análisis de los objetivos estratégicos se determina la relación entre estos y la nueva visión y misión. El logro de cada uno de estos objetivos permitirá alcanzar lo que se plantea en la visión y misión propuesta.

Posteriormente, los objetivos estratégicos se desglosan en varios objetivos operacionales, lo cuales deben cumplirse en su conjunto para lograr el éxito de cada objetivo estratégico.

\section{Tabla 41}

\section{Análisis de los objetivos}

\begin{tabular}{llll}
\hline $\mathrm{N}^{\circ}$ & Objetivos estratégico & Objetivo operacional & Área responsable
\end{tabular}

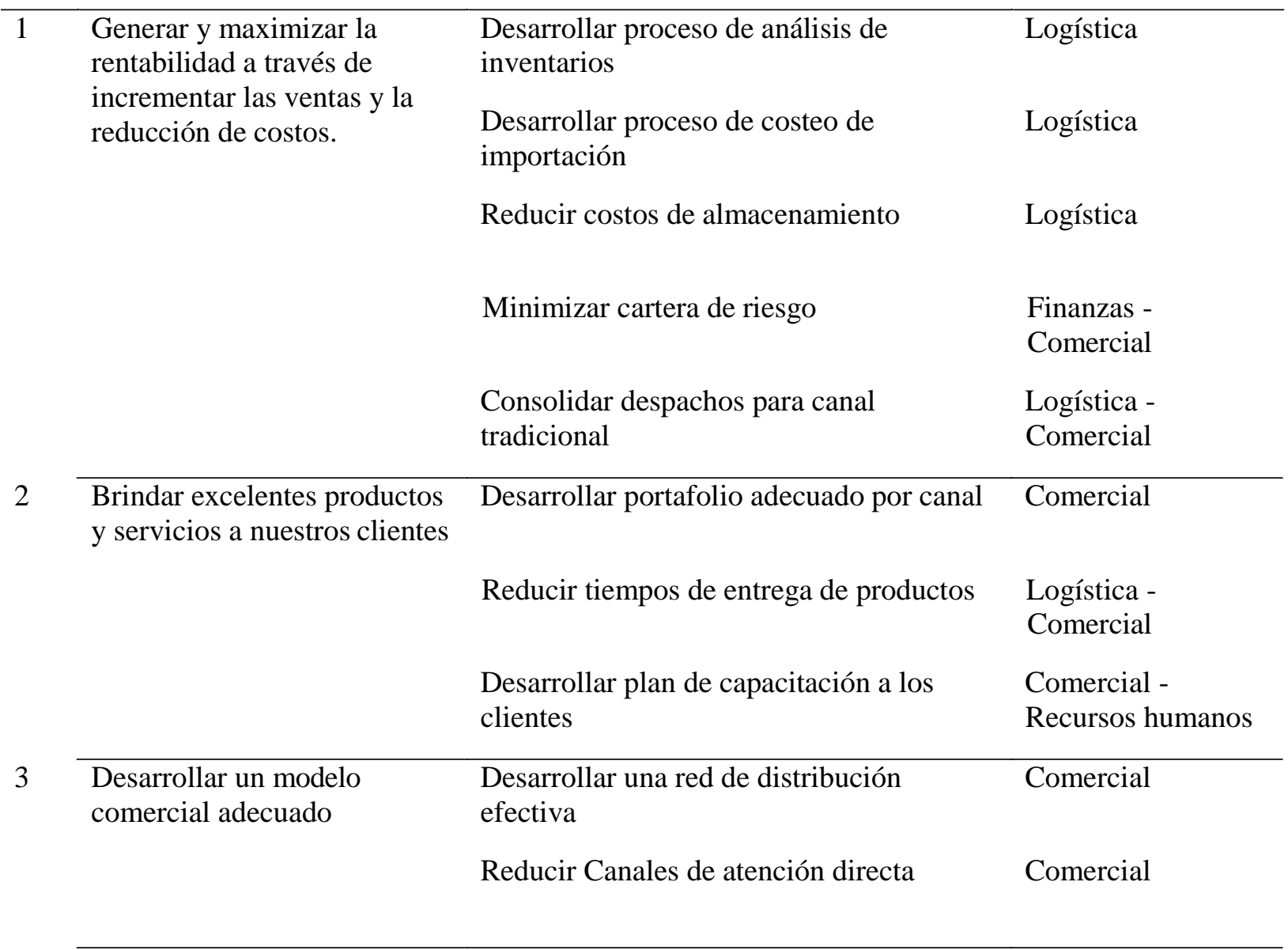




\begin{tabular}{|c|c|c|}
\hline $\begin{array}{l}\text { Controlar una correcta } \\
\text { ejecución de precios }\end{array}$ & $\begin{array}{l}\text { Desarrollar Lista de precios adecuada por } \\
\text { canal }\end{array}$ & Comercial \\
\hline & $\begin{array}{l}\text { Incentivar al cliente por una correcta } \\
\text { ejecución de precios }\end{array}$ & Comercial \\
\hline & $\begin{array}{l}\text { Imprentar equipo de mercaderismo para } \\
\text { exhibición de productos y colocación de } \\
\text { PVS }\end{array}$ & Comercial \\
\hline $\begin{array}{l}\text { Mantener un excelente clima } \\
\text { laboral basado en el } \\
\text { desarrollo profesional y } \\
\text { personal de nuestros } \\
\text { colaboradores. }\end{array}$ & $\begin{array}{l}\text { Desarrollar plan de reconocimiento al } \\
\text { personal }\end{array}$ & $\begin{array}{l}\text { Recursos humanos } \\
\text { - Comercial }\end{array}$ \\
\hline
\end{tabular}

\section{Alcanzar una rentabilidad}

Tal como se presenta en el capítulo de análisis de industria y del mercado, el uso de guantes de jebe en el hogar se ha incrementado en la frecuencia diaria, semanal y quincenal; sin embargo, las ventas de guantes de jebe para Eterna Perú no han acompañado este crecimiento. Por consiguiente, se considera que se debe obtener una rentabilidad promedio de $10 \%$ para los próximos años, dado que para generar y maximizar la rentabilidad no sólo es el resultado de incremento de las ventas sino de ser más eficientes, reduciendo costos, manteniendo márgenes sanos y cartera de cobranza efectiva.

2. Incrementar las ventas

Eterna ha perdido participación de mercado frente a sus principales competidores ScotchBrite, Virutex y Drokasa; sin embargo, el sector ha estado creciendo tal como se puede apreciar en la Tabla 42, donde se muestra el incremento significativo del 2011 al 2105 de la frecuencia de uso de los guantes. 
Tabla 42

Frecuencia de uso de artículos de guantes de limpieza

\begin{tabular}{lcccccc}
\hline $\begin{array}{l}\text { Frecuencia de } \\
\text { Uso }\end{array}$ & $\begin{array}{c}\text { Diario / Varias veces } \\
\text { por semana (\%) }\end{array}$ & \multicolumn{2}{c}{ Semanal (\%) } & \multicolumn{2}{c}{$\begin{array}{c}\text { Quincenal / Mensual } \\
(\%)\end{array}$} \\
\hline Año & 2011 & 2015 & 2011 & 2015 & 2011 & 2015 \\
$\begin{array}{l}\text { Guantes de jebe } \\
\text { para limpieza }\end{array}$ & 24 & 44 & 9 & 11 & 4 & 5 \\
Variación & \multicolumn{2}{c}{$83 \%$} & \multicolumn{2}{c}{$22 \%$} & & $25 \%$ \\
\hline
\end{tabular}

Nota: Ipsos

3. Brindar excelentes productos y servicios a nuestros clientes

El control de calidad es un factor clave a fin de brindar productos excelentes a nuestros clientes, bajo el esquema actual no se ha venido realizando un adecuado control de calidad por considerar que los productos eran de casa matriz; sin embargo existen productos que pudieran deteriorarse por el traslado en la exportación y un mal almacenamiento. Para corregir esta situación se podrían generar los siguientes procesos:

- Órdenes de compra (locales e internacionales)

- Recepción de mercaderías (Locales e Importación)

- Manejo de Almacén (inventarios, despachos, manejo de productos)

- Ventas ( facturación, notas de créditos, devoluciones, premios, planes comerciales)

- Mantenimiento de maestro de clientes y listas de precios

- Cuentas porcobrar y pagar

- $\quad$ Proveedores

- Recursos humanos

- Contabilidad 
- Seguridad laboral

Estos procesos se desarrollan con el fin de mejorar nuestra relación con nuestros clientes externos e internos.

4. Desarrollar un modelo comercial adecuado

Eterna Perú tiene en la actualidad un modelo de llegada al mercado poco eficiente, que genera altos costos operativos en despacho y almacenamiento, además de una estructura de venta directa que genera alejamiento de nuestros clientes con mejor potencial como es el caso de las distribuidoras multi-marca, un portafolio muy grande de productos la mayor parte de ellos que representan baja participación. Con este objetivo se busca una mejor llegada al mercado, en el canal moderno a fin de atenderlo en forma directa y en el canal tradicional sólo atenderlo a través de distribuidores que cumplan cierto perfil, como un portafolio complementario de otros proveedores, economía de escalas, eficiencias en distribución, una fuerza de ventas amplia y con gran cobertura geográfica.

5. Controlar una correcta ejecución de precios

Tal como hemos revisado en el capítulo dos existe un desorden en la fijación de precios al mercado, esto principalmente generado por la misma empresa Eterna. Al eliminar la venta directa se establecerán listas de precios únicas por canal y con márgenes adecuados a los segmentos que atienden, también con una correcta ejecución de exhibición en los diferentes mercados a través de un equipo de mercaderismo encargado de la comunicación y la colocación de precios de venta sugeridos (PVS). 
6. Mantener un excelente clima laboral basado en el desarrollo profesional y personal de nuestros colaboradores.

Bajo el nuevo modelo el colaborador es pieza clave para el logro de objetivos, en tal sentido empleados comprometidos buscaran los mejores resultados para la empresa, se busca capacitación constante, plan de desarrollo profesional, incentivos y promociones.

\subsection{Diseño y formulación de estrategias}

A partir del análisis estratégico realizado y de los objetivos estratégicos planteados se plantea el diseño y formulación de la estrategia tomando como guías el modelo de Océano azul y las matrices de PEYEA, FODA, Boston ConsultingGroup entre otros.

\subsubsection{Modelo Océano Azul}

Este modelo innovador busca desarrollar nuevos espacios de mercado a fin de salir de la competencia existente entre las empresas de la industria. Bajo este enfoque se busca no tratar de vencer a la competencia en los mercados conocidos (También llamados Océanos Rojos), sino enfocar los esfuerzos para crear nuevos espacios donde la competencia no existe (Océano azul).

Océano Rojo: Se encuentra todas las empresas del mercado actual con sus competencias y limitaciones definidas, el objetivo es tomar parte de este mercado venciendo al rival, en el caso de Eterna estaría constituido por las empresas de sector como Ilko (de la Marca Virutex), Drokasa (de la marca D'kasa), 3M (con los productos ScotchBrite) y las empresas y marcas que puedan ingresar al mercado lo que hace más difícil poder competir. 
Océano Azul. En esta estrategia se abandona el modelo tradicional de Océano Rojo donde se trata de vencer a la competencia en un mercado conocido, muchas veces saturado y con empresas con mayores capacidades económicas y estructuras más grandes - por un mercado o espacio de mercado donde no desgastemos energías en competir, este espacio poco explorado permite un crecimiento rentable a futuro.

Este modelo genera un lienzo estratégico donde se plasma el diagnóstico de la empresa y la industria. Permite también poder identificar los aspectos del mercado donde enfocarnos que pueden constituir los océanos azules.

\subsubsection{Lienzo de la estrategia actual de la empresa}

En este punto se han identificado las variables claves consideradas para este mercado considerando la situación actual de la empresa Eterna Perú, así como las características respecto a los principales competidores (ver Tabla 43).

Tabla 43Características del servicio de Eterna

\section{Características del servicio}

Características del servicio

- Calidad del producto

- Correcta ejecución de precios

- Distribución en mayoristas y mercados

\section{ETERNA}


- Lead time cortos de abastecimiento 5

- Surtido de productos 5

- Posicionamiento de la empresa 2

- Eficiencia en costos logísticos / 2 distribución

2

- Atractivita / márgenes a clientes 2

- Fidelización de FFVV de clientes 2

Elaboración propia

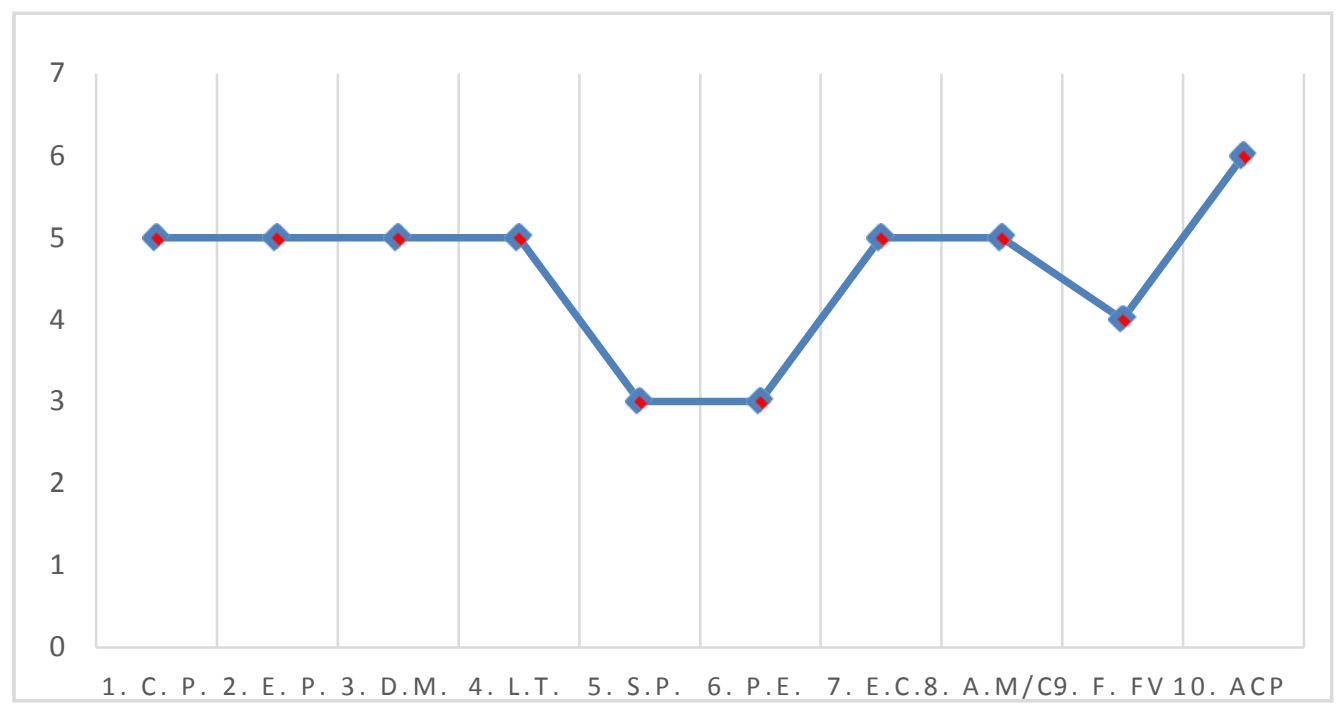

\begin{tabular}{cll}
\hline Item & Características del servicio & \\
\hline 1 & Calidad del producto & 1. C. P. \\
2 & Correcta ejecución de precios & 2. E. P. \\
3 & Distribución en mayoristas y mercados & 3. D.M.M. \\
4 & Lead time cortos de abastecimiento & 4. L.T. \\
5 & Surtido de productos & 5. S.P. \\
6 & Posicionamiento de la empresa & 6. P.E. \\
7 & Eficiencia en costos logísticos / distribución & 7. E.C. \\
8 & Atractivita / márgenes a clientes & 8. A.M/C. \\
9 & Fidelización de FFVV de clientes & 9. F. FV \\
\hline
\end{tabular}

Figura 49. Lienzo de la estrategia de Eterna Perú 
En la figura 49, se muestra la situación de la empresa, de acuerdo a lo a la entrevista realizado al Gerente General de Eterna, estos son los factores más relevantes en la industria de la limpieza del hogar.

\subsubsection{Lienzo de la estrategia de la industria}

En la actualidad, el lienzo de las empresas que participan en la industria de artículos de limpieza del hogar, tienen similitud con la empresa Eterna Perú. En los ítems donde se refleja las característica del producto (ver Figura 47), podemos ver que 3M tienen un mayor nivel de ofrecimiento según el valor en el cuadro, Virutex queda como segundo y Eterna tiene una oferta de los atributos que se ofrecen al cliente, que debería ser modificada con base en estrategias que se trata de implementar en el siguiente plan estratégico. 
Tabla 44

Características del servicio de la industria

\begin{tabular}{lcccc}
\hline Características del servicio & ETERNA & VIRUTEX & DKASA & $3 \mathrm{M}$ \\
\hline Calidad del producto & 5 & 4 & 3 & 2 \\
Correcta ejecución de precios & 3 & 5 & 4 & 4 \\
Distribución en mayoristas y mercados & 2 & 4 & 4 & 5 \\
Lead time cortos de abastecimiento & 5 & 3 & 3 & 3 \\
Surtido de productos & 5 & 4 & 3 & 2 \\
Posicionamiento de la empresa & 2 & 4 & 2 & 6 \\
Eticiencia en costos logisticos / & 2 & 4 & 3 & 4 \\
distribución & 2 & 4 & 4 & 3 \\
Atractivita / márgenes a clientes & 2 & 4 & 2 & 3 \\
Fidelización de FFVV de clientes & &
\end{tabular}

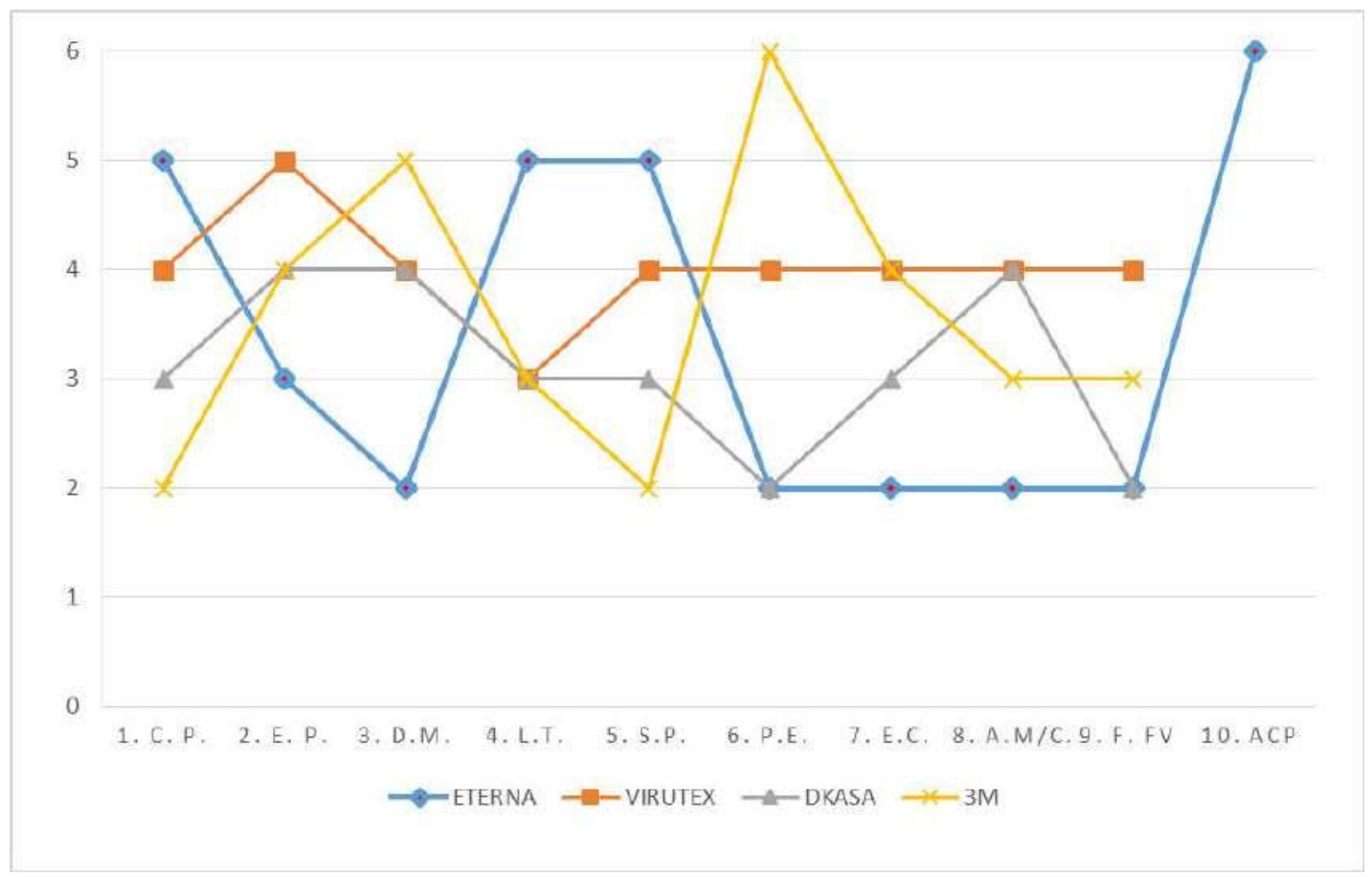

Figura 50.Lienzo de la estrategia de la industria 


\subsubsection{Matriz (eliminar, reducir, incrementar, crear)}

En la matriz de eliminar, reducir, incrementar, crear se identificó las características del servicio relacionada con el cliente que deberán ser reducidas, aumentadas, eliminadas y creadas. El propósito es buscar elementos relacionados con los clientes que permita que la empresa Eterna esté diferenciada y genere un nuevo valor en el mercado en comparación con sus competidores.

Las características relacionadas con el cliente que se deben incrementar son: la mejora en la atención al cliente, una entrega oportuna del producto, margen de beneficio al cliente y una política de precios acorde a la compra del cliente. Por otro lado, un elemento que se debe crear es el servicio de asesoría a los clientes que buscan nuevos mercados para los productos de ETERNA Perú, así como la atención en línea a los requerimientos de los clientes. En la Tabla 45 se muestra la matriz de eliminar, reducir, incrementar, crear.

Tabla 45

Matriz eliminar, reducir, incrementar, crear

\begin{tabular}{cl}
\hline Eliminar & Incrementar \\
\hline Correcta política de precios \\
Entregaoportuna del producto \\
Margen al cliente a través de eliminación \\
de intermediarios \\
Atención a clientes \\
\hline Reducir & Crear \\
\hline Número de SKUs de baja rotación & Servicio de asesoría para ampliar el \\
& mercado de nuestros clientes \\
& Atención on line \\
\hline
\end{tabular}

\section{Lienzo de la nueva estrategia considerada}


El nuevo lienzo de la estrategia para la empresa Eterna muestra que la empresa tiene elementos de diferenciación relacionados con el servicio de asesoría a los clientes y la atención en línea que las demás empresas competidoras no lo brindan hasta el momento. Por tanto, la estrategia de la empresa es la diferenciación en el servicio de asesoría personalizada que se brinda al cliente para brindarle los productos necesarios y el apoyo para lograr ofertar el producto al cliente. En la Figura 48 se muestra el lienzo de la estrategia que se plantea bajo el enfoque del océano azul.

Tabla 46

Lienzo de la nueva estrategia de la industria

\begin{tabular}{lcccc}
\hline \multicolumn{1}{c}{ Características del servicio } & ETERNA & VIRUTEX & DKASA & $3 \mathrm{M}$ \\
\hline Calidad del producto & 5 & 4 & 3 & 2 \\
Correcta política de precios & 5 & 5 & 4 & 4 \\
Disponibilidaddel producto en & 5 & 4 & 4 & 3 \\
mayoristas y mercados & 5 & 3 & 3 & 2 \\
Lead time de abastecimiento & 3 & 4 & 3 & 6 \\
Surtido de productos & 6 & 4 & 2 & 4 \\
Atención a clientes & 6 & 4 & 3 & 3 \\
Entrega oportuna al cliente & 6 & 4 & 4 & 0 \\
Márgenes a clientes & & & 0 & 0 \\
Asesoría gratuita para ampliar & 6 & 0 & 0 & \\
mercado & 6 & 0 & & \\
Atención on line & & & & \\
\hline
\end{tabular}




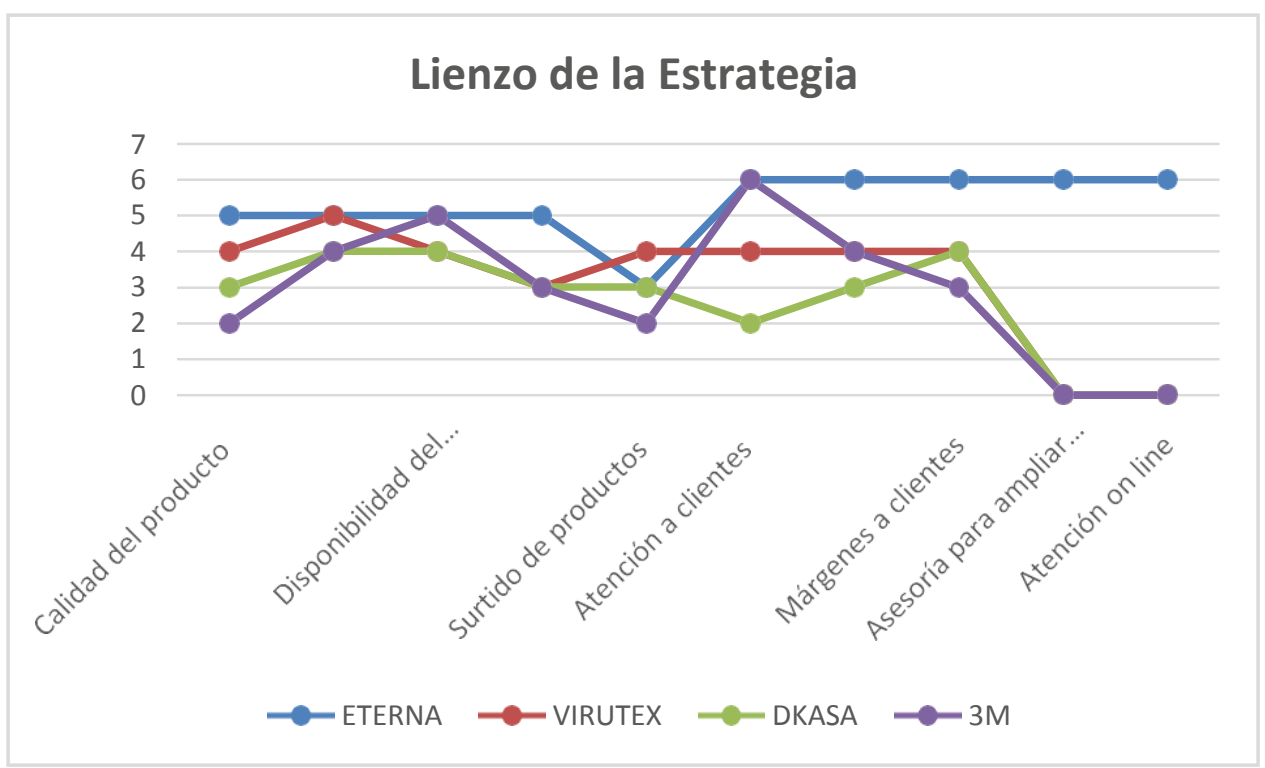

Figura 51.Lienzo de la estrategia de la industria

Figura 48Lienzo de la nueva estrategia de la industria

Con estas nuevas características, Eterna Perú está creando un océano azul, ya que actualmente los competidores no brindan un servicio que se denomina "Asesoramiento en procesos de compras con el estado”. Lo que se espera con esta estrategia es fidelizar más al cliente proporcionándole un asesor que los acompañe y brinde su conocimiento a los clientes, invitando a los distribuidores a un centro de exposición y ofrecerles el servicio sin costo alguno, las pautas para ser un proveedor del Estado.

Esta oportunidad nace debido a que actualmente el estado es un cliente potencial, representa más del $80 \%$ de las compras que se hacen en el país y los montos que adquieren pueden ser muy atractivo (ver anexo 14), donde se hace una reseña de las principales entidades públicas y sus requerimientos en artículos de limpieza. 


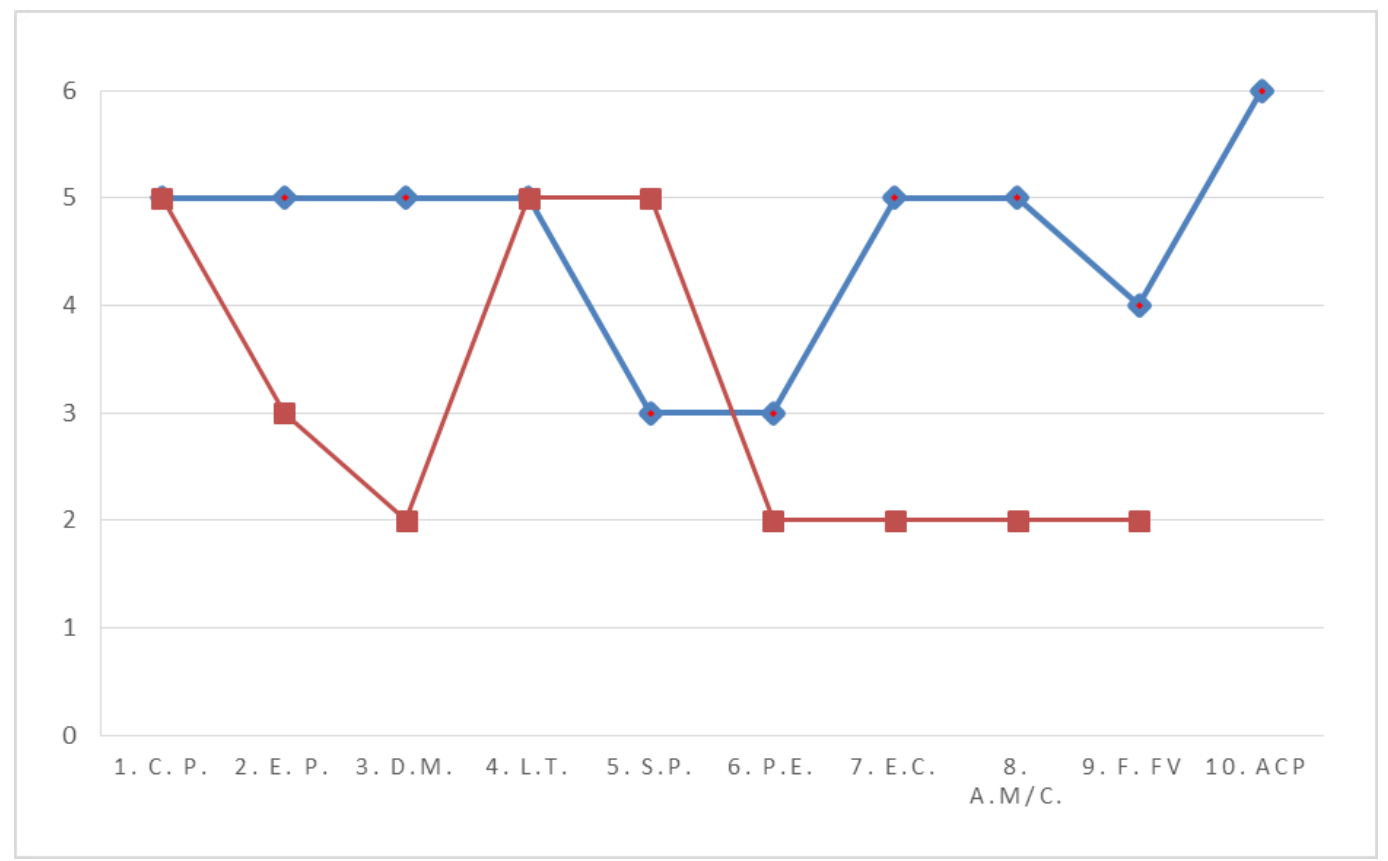

Figura 52.Comparativo Océano Azul - Océano Rojo

\subsubsection{Matrices de formulación de estrategias}

\subsubsection{Matriz FODA}

Esta matriz se elabora luego de identificar en primer lugar las fortalezas, las oportunidades, las debilidades y las amenazas para Eterna Perú. Luego, se lleva a cabo el cruce entre las variables de cada una de ellas con la finalidad de formular estrategias que se ajusten a la coyuntura de la situación actual y del mercado nacional.

Tabla 47

Matriz FODA de Eterna 


\begin{tabular}{|c|c|c|c|}
\hline & FORTALEZAS & & DEBILIDADES \\
\hline $\mathrm{F} 1$ & $\begin{array}{l}\text { Reconocimiento de producto - } \\
\text { calidad }\end{array}$ & D1 & $\begin{array}{l}\text { Desorden en la llegada de } \\
\text { productos al mercado } \\
\text { (GotoMarket) }\end{array}$ \\
\hline $\mathrm{F} 2$ & $\begin{array}{l}\text { Alta participación de mercado en } \\
\text { canal moderno }\end{array}$ & D2 & $\begin{array}{l}\text { Servicio de distribución del } \\
\text { producto costoso }\end{array}$ \\
\hline F3 & $\begin{array}{l}\text { Tiempo de repuesta (lead time) } \\
\text { apropiado }\end{array}$ & D3 & $\begin{array}{l}\text { Bajo nivel de servicios (Procesos } \\
\text { y Procedimientos) }\end{array}$ \\
\hline $\mathrm{F} 4$ & $\begin{array}{l}\text { Portafolio amplio de productos } \\
\text { limpieza }\end{array}$ & D4 & $\begin{array}{l}\text { Personal de ventas poco } \\
\text { capacitado }\end{array}$ \\
\hline F5 & $\begin{array}{l}\text { Facilidad para aplicar procesos ya } \\
\text { desarrollados en casa matriz }\end{array}$ & D5 & $\begin{array}{l}\text { Falta claridad en el portafolio de } \\
\text { productos por canal }\end{array}$ \\
\hline F6 & $\begin{array}{l}\text { Compras consolidadas desde casa } \\
\text { matriz }\end{array}$ & & \\
\hline F7 & $\begin{array}{l}\text { Estructura Ligera con facilidad de } \\
\text { tomar decisiones rápidas }\end{array}$ & & \\
\hline
\end{tabular}

\section{Oportunidades}

Estabilidad política

O1

Comercio minorista al alza

$\mathrm{O} 2$

Retail moderno: Las ventas O3 totales crecerán $6 \%$

Búsqueda de productos de calidad $\mathrm{O} 4$ por los clientes

O5

Crecimiento del PBI

Tipo de cambio estable O6

\section{Amenazas}

Crecimiento acelerado del canal A1 online

Menor evolución del empleo y A2 salario

Familias que pasaron a la clases A3 media

A4 País con mayor rigidez laboral

A5 Políticas de reciclaje

A6

Producción local a bajo costo

Importaciones de bajo costo y

A7

menor calidad

A8 Inseguridad ciudadana
Ampliar distribución en canales

O1 F1 estratégicos como: Bodegas, Home Centers, Mayoristas, Farmacias

O2 F3 Incrementar participación de mercado

O3 F4 Evaluar la importación de líneas complementarias

Aprovechar el conocimiento del

$\mathrm{O} 4 \mathrm{Fl}$ producto para generar reconocimiento de marca

O5 F5 Ampliar distribución en canales donde ya se tiene una presencia Fortalecer la importación y O6 F6 distribución de productoscon ventaja diferencial de Colombia
Desarrollar nuevos canales de

O2 D1 venta

Elevar el nivel de servicios que

O2 D3 brinda el personal de la empresa

Formular plan para una mejora

O3 D1 llegada al mercado

Formular nuevas actividades para

O4 D1 la llegada al mercado

Capacitar al personal sobre todo

O5 D4 al personal de ventas 
Con base en las acciones propuestas a través de la matriz FODA, se seleccionaron las estrategias que le permitirá a la empresa alcanzar la ventaja competitiva dentro del periodo que alberga el presente plan estratégico.

1. Penetración de mercado,al aumentar los canales de ventas. Esta estrategia tiene como finalidad elevar el porcentaje de volumen de ventas de los guantes para la limpieza del hogar al aumentar la frecuencia de compras de los usuarios con relación a la competencia.

2. Desarrollo de mercado: al desarrollar el canal de venta institucional permitirá crear un nuevo mercado para la participación de los distribuidores en licitaciones de compras del Estado.

3. Reducción de costos, al producir productos de marca propia, lo permite generar rentabilidad para la empresa al usar la capacidad de planta ociosa.

4. Desarrollo de producto: permitirá introducir nuevos servicios a los clientes, así como nuevos productos con características que permitan consolidar la empresa en el mercado.

5. Desinvertir, reducción de portafolio para potenciar productos demayor rotación en el mercado peruano.

\subsubsection{Matriz PEYEA}

Para David (2013), la matriz PEYEA es una herramienta poderosa, dado que permite formular estrategias para una compañía determinada. Los ejes de esta matriz representan dos factores internos: (FF) fuerza financiera y (VC) ventaja competitiva; y también muestras dos 
factores externos: (EE) estabilidad del entorno y (FI) fuerza de la industria. A partir de estos

factores se generan las estrategias para la empresa.

Tabla 48

Matriz PEYEA de Eterna

\begin{tabular}{|c|c|c|c|}
\hline Análisis interno & & Análisis externo & \\
\hline Fuerza Financiera $(\mathrm{FF})$ & & Estabilidad del entorno (EE) & \\
\hline Flujo de efectivo negativo 2015 & 1 & Gobierno abierto a la inversión & -2 \\
\hline Respaldo financiero de casa matriz & 2 & PBI en recuperación & -3 \\
\hline \multirow[t]{3}{*}{ Riesgo implícito del negocio } & \multirow[t]{3}{*}{2} & Facilidad de ingreso al mercado & -3 \\
\hline & & $\begin{array}{l}\text { Mayor acceso a información (Acceso a Internet y } \\
\text { redes sociales) }\end{array}$ & -2 \\
\hline & & Mayor cuidado personal (Cuidado de la piel) & -3 \\
\hline Fuerza Financiera (FF) Promedio & 1.67 & Estabilidad del entorno (EE) Promedio & -2.60 \\
\hline \multicolumn{2}{|l|}{ Análisis interno } & \multicolumn{2}{|l|}{ Análisis externo } \\
\hline \multicolumn{2}{|l|}{ Ventaja Competitiva (VC) } & \multicolumn{2}{|l|}{ Fuerza de la industria (FI) } \\
\hline Calidad de Producto & -1 & Potencial de crecimiento consumo & 4 \\
\hline Liderazgo en Canal Moderno & -1 & $\begin{array}{l}\text { Potencial de crecimiento en la participación de } \\
\text { mercado }\end{array}$ & 5 \\
\hline \multicolumn{2}{|l|}{$\begin{array}{l}\text { Estructura empresarial Ligera y con agilidad para } \\
\text { ejecución }\end{array}$} & Estabilidad financiera de la industria & 3 \\
\hline fabricación directa de casa matriz & -1 & $\begin{array}{l}\text { Reducidos número de empresas con fabricación } \\
\text { directa }\end{array}$ & 1 \\
\hline Ventaja Competitiva (VC) Promedio & -1.25 & Fuerza de la industria (FI) Promedio & 3.25 \\
\hline Eje $X:-1.25+(+3.25)=$ & \multicolumn{2}{|c|}{2.00} & \\
\hline Eje Y: $-2.60+(+1.67)=$ & \multicolumn{2}{|l|}{-0.93} & \\
\hline Cordenada & \multicolumn{2}{|l|}{$(2.00,-0.93)$} & \\
\hline \multicolumn{3}{|l|}{ Conclusión: el sector se ubica en el cuadrante competitivo } & \\
\hline
\end{tabular}

Con base en el análisis de la matriz PEYEA, se pudo identificar que Eterna tiene 2.00 en el eje X (estabilidad del ambiente) y -0.93 en el eje Y (Fuerza de la industria), dando como resultado la coordenada $(2.00,-0.93)$. Si trazamos un vector que una el punto inicial $(0.00,0.00)$, 
a la coordenada calculada, su orientación nos lleva a la conclusión de que la empresa se encuentra en el cuadrante competitivo con importantes ventajas competitivas en una industria que experimenta un alto crecimiento. (ver Tabla 48).

La orientación del eje en la matriz permite establecerlas siguientes estrategias claves: (ver Figura 53):

1. Penetración de mercado

2. Desarrollo de mercado

3. Desarrollo de producto

4. Integración hacia atrás / adelante.

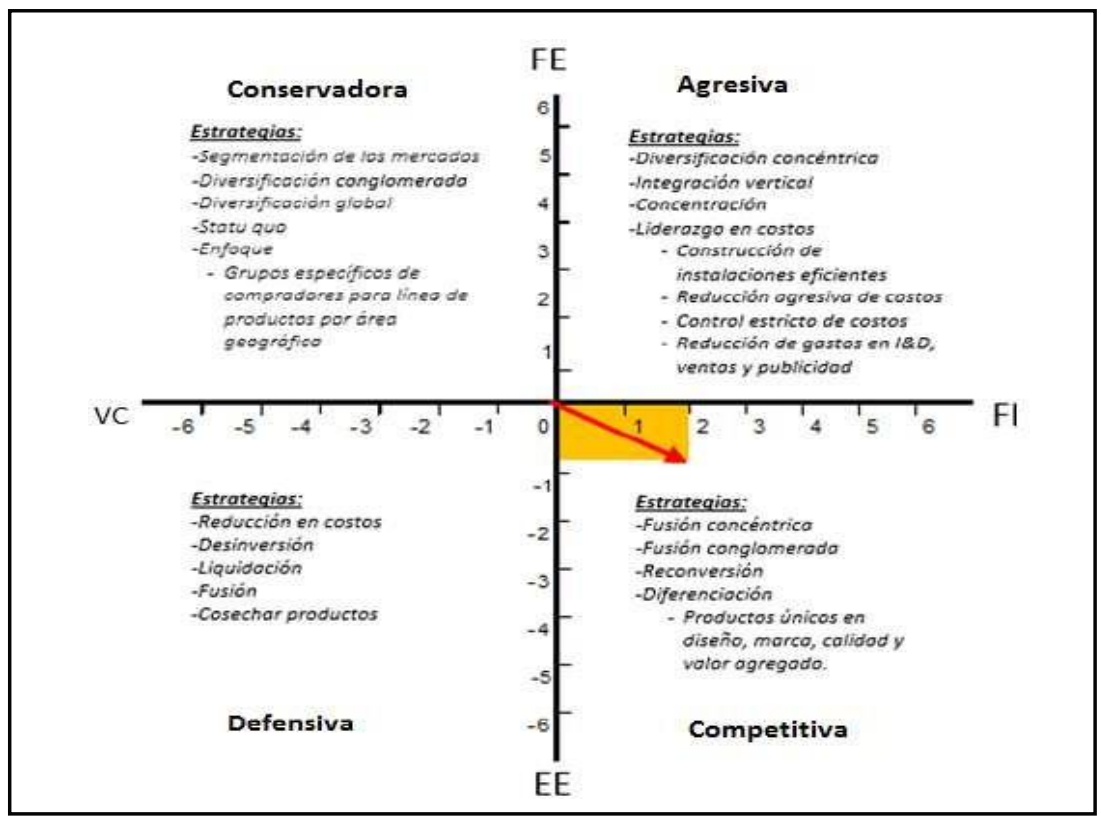

Figura 53.Matriz PEYEA 


\subsubsection{Matriz Interna Externa}

Para David (2013), la presente matrizmuestralas diversas funciones de una compañía en un modelo de nueve cuadros, esta es similar a la matriz BCG debido a la esquematización de ambas; aquí cada circulo representa el porcentaje de las ventas que brinda cada área, y las partes que existen en el interior revelando el porcentaje de utilidad que genera cada división. La diferencia en ambas matrices es que en la presente matriz se necesita mayor información acerca de los valores de las matrices EFE y EFI en su ponderación.

Con base a lo analizado se llega a una definición para ampliar el entendimiento del lector, el concepto es el siguiente: La matriz Interna Externa nos representa otra poderosa herramientapara evaluar a una compañía,considerando sus Factores Internos (Fortalezas y Debilidades) y también sus Factores Externos (Oportunidades y Amenazas), esto es cuantificando un índice que puede ser graficado y situarlo en uno de los 9 cuadrantes de dicha matriz.

La matriz se elabora con base a los puntajes totales ponderados del EFE (2.35) y EFI (3.28); esta nos brinda las siguientes estrategias claves:

1. Penetración de mercado

2. Desarrollo de mercado

3. Desarrollo de producto 


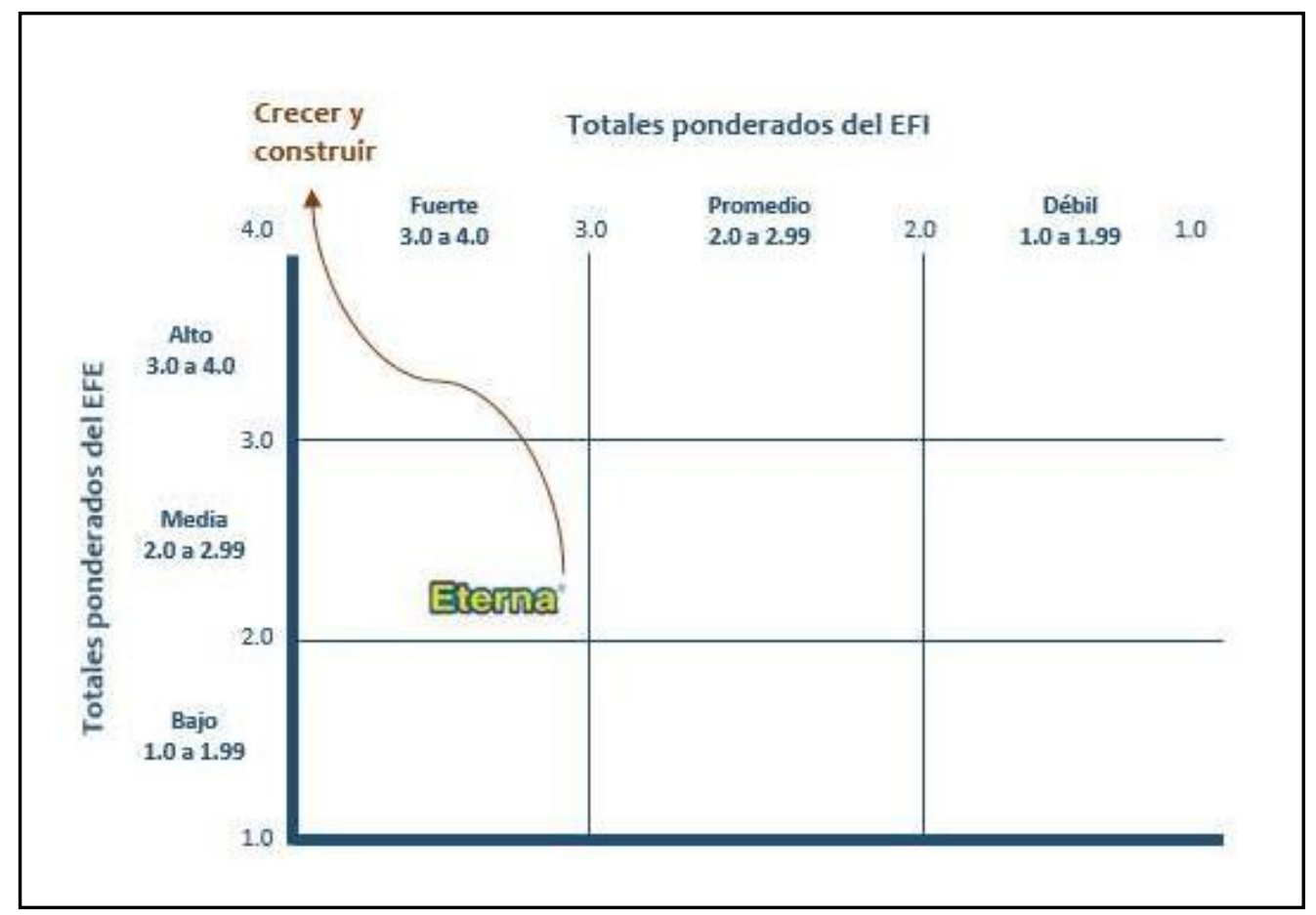

Figura 54. Matriz Interna Externa

\subsubsection{Matriz, Boston ConsultingGroup}

Para David (2013), La Matriz de BCG (o Matriz Crecimiento-Participación) es otra herramienta de forma gráfica que permite analizar la cartera de productos de una organización. Presenta un método de análisis estratégico, principalmente diseñado para poder planificar las estrategias corporativas. En el caso de las estrategias corporativas, se evalúa la cartera de negocios que tiene la empresa.

Esta herramienta está muy vinculada y es de continuo uso en el área de marketing. Su metodología de trabajo es analíticay ayuda a la empresa a decidir las direcciones para las diferentes carteras de productos o negocios, para penetrar dónde es necesario desinvertir, invertir, o si fuese necesario abandonar. 
La presente matriz se estructura con base en la información que se pudo obtener de participación por importación de los principales competidores del mercado, donde se muestra que la empresa se ubica en un entorno de alta participación, presenta bajo crecimiento.

Según la posición de la empresa Eterna Perú, la matriz BSG nos brinda las siguientes estrategias claves:

1. Recorte de gastos

2. Desarrollo de producto

3. Desarrollo de mercado

Tabla49

Matriz Boston ConsultingGroup

\begin{tabular}{lcc}
\hline Importadores & Total US\$ & Participación \\
\hline Virutex & $6,240,000$ & $39 \%$ \\
Eterna & $3,200,000$ & $20 \%$ \\
Drokasa & $2,880,000$ & $18 \%$ \\
$3 \mathrm{M}$ & $1,600,000$ & $10 \%$ \\
Otros & $2,080,000$ & $13 \%$ \\
\hline
\end{tabular}




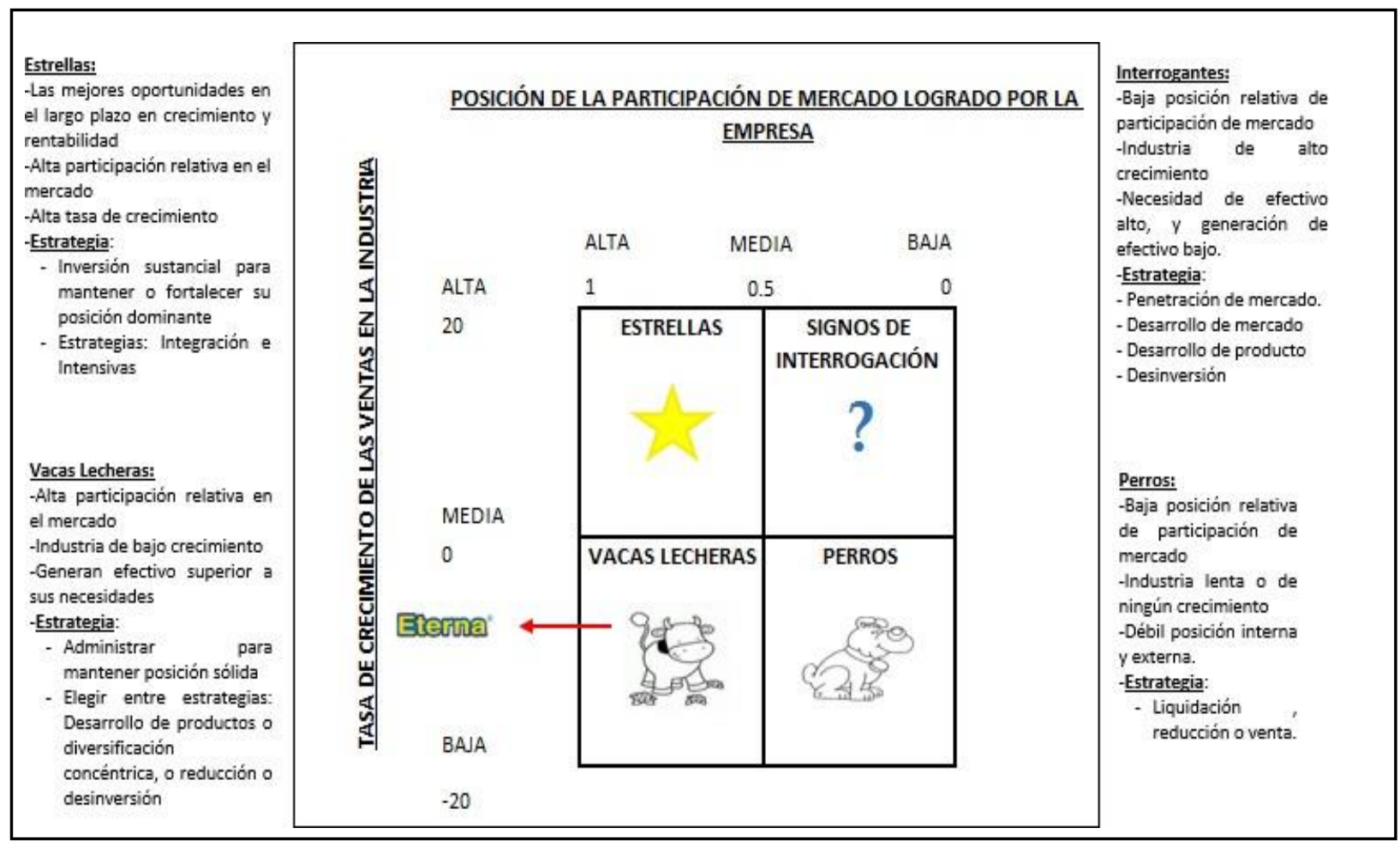

Figura 55.Matriz Boston ConsultingGroup

\subsubsection{Matriz de la Gran Estrategia}

La matriz de la Gran Estrategia, es una herramienta que sirve para formular estrategias que son alternativas a las antes expuestas. En esta etapa todas las compañías se pueden asignar en uno de los cuadrantes estratégicos de la presente matriz, aquí también puede colocarse cada división de la compañía. Se precisa que la matriz de la gran estrategia es una herramienta que es utilizada para afinar y evaluar la estrategia adecuada para la compañía.

Con base a las entrevistas realizadas a los expertos de la industria y a la investigación independiente de reportes económicos, estadísticas información de las sociedades que conforman la industrias etc., que el mercado crece un 3.5\% a $4 \%$, también existe una competencia agresiva 
que busca ganar posición de mercado y precio, se considera el efecto del cuadrante I, debido a que Eterna a partir de los análisis vistos anteriormente se encuentra dentro de un mercado con crecimiento rápido y posición competitiva fuerte; la presente matriz nos brinda las siguientes estrategias claves:

1. Desarrollo de mercado

2. Desarrollo de producto

3. Penetración de mercado

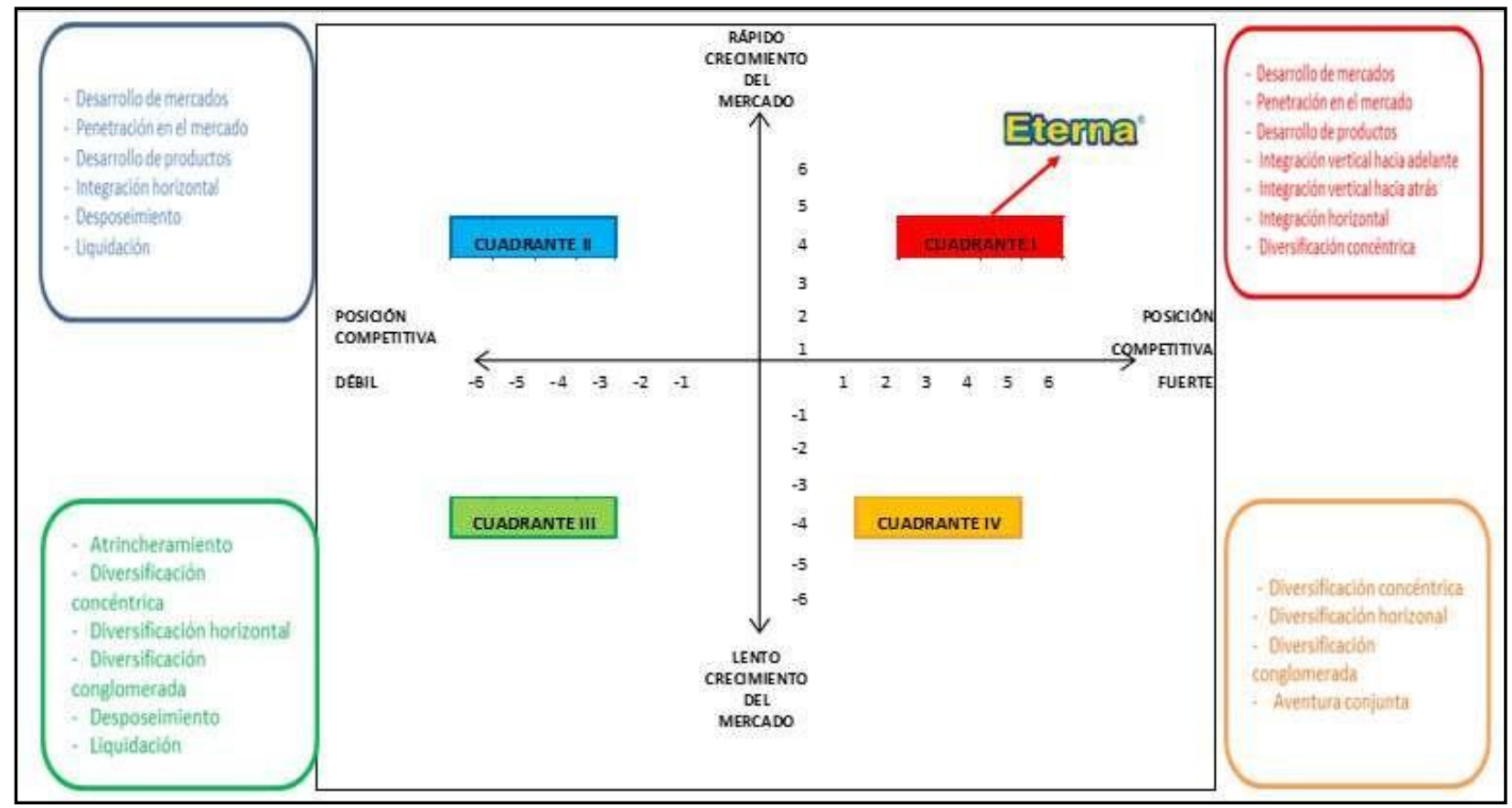

Figura 56.Matriz de la Gran Estrategia 


\subsection{Resumen de las Estrategias Formuladas}

Las estrategias a nivel de negocio propuestas para la empresa Eterna Perú, se han formulado sobre la base de los análisis realizados en capítulos anteriores y teniendo en cuenta la lectura del mercado, de los canales de distribución, del consumidor final y de la dirección de la empresa, estas son:

1. Penetración de mercado, tiene como finalidadelevar el porcentaje de volumen de ventas de los guantes para la limpieza del hogar con relación a la competencia.

2. Reducción de costos, generando rentabilidad para la empresa.

3. Desinvertir, reducción de portafolio para potenciar productos de mayor rotación en el mercado peruano.

4. Desarrollo de producto: se busca dirigir las operaciones de la empresa para ofrecer nuevos productos al mercado.

5. Desarrollo de mercado: permite orientar los esfuerzos de la empresa para hallar otros mercados para los productos de la empresa.

6. Reducción de costos

7. Desinversión 


\section{Capítulo 8 Selección de la estrategia}

En el presente capitulo, se desarrolla un análisis de las estrategias propuestas a fin de seleccionar las más adecuada y que se deberá implementar en la compañía. Las estrategias propuestas nacen a partir de las siguientes matrices:

- FODA (Fortalezas, oportunidades, debilidades y amenazas)

- PEYEA ( Posición estratégicas y evaluación)

- IE (Interno - externo)

- $\quad$ BCG (Boston ConsultingGroup)

- GE (Matriz de la gran estrategia)

\subsection{Método Factores Estratégicos Claves}

A fin de determinar efectos de determinar cuáles es la estrategia a implementar, se utilizó la matriz de Método Factores Estratégicos Claves. Esta matriz permite evaluar cada de las estrategias resultantes a fin de determinarla estrategia que debe implementar en la empresa Eterna Perú.

Las estrategias que obtuvieron de manera más frecuente a partir de los modelos usados son las siguientes:

- Penetración de mercado, es una alternativa estratégica orientada a reforzar y/o incrementar la participación de mercado de Eterna Perú, ya que no cuentas con el liderazgo en ventas, la recordación de marca está por debajo de la competencia. 
- Desarrollo de mercados (diversificación de canales), se propone mitigar el riesgo que supone una alta concentración en las cadenas de supermercados, El desarrollo se quiere dar en las bodegas de Lima y provincias.

- Reducción de costos: operaciones logísticas, se busca reducir estos temas para generar rentabilidad, se busca reorganizar la empresa y hacerla distintiva actualmente la compañía viene generando altos costos estos en temas de personal y.

\subsubsection{Criterios de selección}

Los criterios son los siguientes:

- Participación de mercado

- Rentabilidad en el negocio

- Fidelización de clientes en el mercado

- Disminución de riesgo de concentración

- Disponibilidad de recursos financieros

- Facilidad en implementar

\subsubsection{Matriz de selección}

La matriz del Método Factores Estratégicos Claves es una herramienta que permite evaluar las alternativas de estrategias con objetividad, con base en los componentes de éxito, tanto externos como internos, identificados anteriormente.

La escala de medición es de uno a diez donde: 1 es muy débil, 5 es regular y 10 es muy fuerte. La matriz se muestra en la Tabla 50. 
Tabla 50

Matriz del Método Factores Estratégicos Claves

\begin{tabular}{|c|c|c|c|c|c|c|c|}
\hline & Peso & $\begin{array}{l}\mathrm{E}-1 \\
\text { Penetración } \\
\text { de mercado }\end{array}$ & & $\begin{array}{l}\mathrm{E}-2 \\
\text { Desarrollo } \\
\text { de mercado }\end{array}$ & & $\begin{array}{l}E-3 \\
\text { Reducción } \\
\text { de costos }\end{array}$ & \\
\hline $\begin{array}{l}\text { Participación de } \\
\text { mercado }\end{array}$ & $25 \%$ & 10 & 2.5 & 10 & 2.5 & 5 & 1.25 \\
\hline $\begin{array}{l}\text { Rentabilidad en el } \\
\text { negocio }\end{array}$ & $20 \%$ & 6 & 1.2 & 10 & 2 & 8 & 1.6 \\
\hline $\begin{array}{l}\text { Fidelización de } \\
\text { clientes en el } \\
\text { mercado }\end{array}$ & $15 \%$ & 5 & 0.75 & 10 & 1.5 & 5 & 0.75 \\
\hline $\begin{array}{l}\text { Disminución de } \\
\text { riesgo de } \\
\text { concentración }\end{array}$ & $10 \%$ & 10 & 1.0 & 7 & 0.7 & 10 & 1.0 \\
\hline $\begin{array}{l}\text { Disponibilidad de } \\
\text { recursos financieros }\end{array}$ & $15 \%$ & 8 & 1.2 & 5 & 0.75 & 10 & 1.5 \\
\hline $\begin{array}{l}\text { Facilidad en } \\
\text { implementar }\end{array}$ & $25 \%$ & 8 & 2 & 8 & 2 & 6 & 1.5 \\
\hline Total & $100 \%$ & & 8.65 & & 9.45 & & 7.6 \\
\hline
\end{tabular}

En primer lugar se asignan los pesos a cada uno de los factores estratégicos claves, luego se realiza la calificación de las estrategias según el criterio seleccionado considerando la escala indicada. Posteriormente se multiplican los valores y finalmente se suman.

La estrategia seleccionada con este método es desarrollo de mercado al obtener el mayor valor en la sumatoria final. En este caso el valor promedio es de 9.45. La segunda mejor estrategia según este método es la estrategia de penetración de mercado que obtiene un valor promedio de 8.65 . 


\subsection{Método de Escenarios}

El método de escenarios plantea diseñar futuros posibles basados en tendencias o en la aplicación de la prospectiva. En este contexto se plantean las siguientes interrogantes:

- ¿Qué puede suceder?

- ¿Qué podemos hacer?

- ¿Qué haremos?

- ¿Cómo lo haremos?

\subsubsection{Descripción de escenarios considerados}

A fin de plantear un contexto con respecto a los eventos o situaciones futuras, se puso énfasis en el programa de planificación estratégica para el 2021, elaborado por el CEPLAN. Las proyecciones son las siguientes:

- Una Población de 33 millones de peruanos sin pobreza extrema, desempleo, desnutrición, analfabetismo ni mortalidad infantil.

- Un ingreso per cápita entre US\$ 8000 y US\$10 000.

- Un producto bruto interno duplicado entre 2010 y 2021.

- Un volumen de exportaciones cuadruplicado entre 2010 y 2021.

- Una tasa de crecimiento anual promedio cercana al $6 \%$ anual.

- Una tasa de inversión anual promedio cercana al 25\%.

- Una reducción de la pobreza a menos del $10 \%$ de la población total. 
Sobre estos objetivos y con base en las últimas tendencias, se está planteando tres posibles escenarios (ver Tabla 51), para cada una de las variables analizadas, agrupadas en:

- Demografía

- Economía

- Político y social

Tabla 51

Escenarios considerados

\begin{tabular}{|c|c|c|c|}
\hline \multicolumn{4}{|c|}{ Escenarios (2017 - 2021) } \\
\hline Demografía & 1 & 2 & 3 \\
\hline $\begin{array}{l}\text { Tasa de crecimiento } \\
\text { poblacional }\end{array}$ & $\begin{array}{l}\text { Tendencia a } \\
\text { disminuir }<1 \%\end{array}$ & Permanente $+/-1.1 \%$ & $\begin{array}{l}\text { Tendencia a } \\
\text { incrementar }>1.1 \%\end{array}$ \\
\hline $\begin{array}{l}\text { Crecimiento de la } \\
\text { población urbana }\end{array}$ & $\begin{array}{l}\text { Menor crecimiento } \\
\text { comparado al ámbito } \\
\text { rural }\end{array}$ & $\begin{array}{l}\text { Sin tendencia a subir o } \\
\text { bajar comparado con } \\
\text { rural }\end{array}$ & $\begin{array}{l}\text { Mayor crecimiento } \\
\text { comparado al ámbito } \\
\text { rural }\end{array}$ \\
\hline $\begin{array}{l}\text { Estructura } \\
\text { poblacional según } \\
\text { NSE }\end{array}$ & $\begin{array}{l}\text { Mayor población } \\
\text { NSE A-B }\end{array}$ & $\begin{array}{l}\text { Mayor población } \\
\text { NSE C }\end{array}$ & $\begin{array}{l}\text { Mayor población } \\
\text { NSE D-E }\end{array}$ \\
\hline Economía & 1 & 2 & 3 \\
\hline Crecimiento del PBI & Menor 3\% & Entre $3 \%$ a $5 \%$ & Mayor a 5\% \\
\hline $\begin{array}{l}\text { Política de } \\
\text { importaciones }\end{array}$ & Estable sin mayor TLC & $\begin{array}{l}\text { Estado protector de la } \\
\text { industria }\end{array}$ & $\begin{array}{l}\text { Incremento de acuerdos } \\
\text { internacionales }\end{array}$ \\
\hline Ingreso per cápita & Presenta caída & Se mantiene & Crecimiento \\
\hline \multicolumn{4}{|l|}{ Político y social } \\
\hline Estabilidad política & Democrática & Democrática & Dictadura \\
\hline Mercado laboral & $\begin{array}{l}\text { Se mantiene la tasa de } \\
\text { trabajo }\end{array}$ & $\begin{array}{l}\text { Crece la demanda } \\
\text { laboral }\end{array}$ & $\begin{array}{l}\text { Desaceleración de la } \\
\text { demanda laboral }\end{array}$ \\
\hline Estabilidad jurídica & Se mantiene & Se fortalece & Corrupta y debilitada \\
\hline
\end{tabular}


Con las alternativas detalladas líneas arriba, se procederá a seleccionar y establecer dos escenarios coherentes y posibles; a juicio de los expertos, así como uno con mayor probabilidad de ocurrencia que el otro, las cuales se detallan en la Tabla 52.

\section{Tabla 52}

Escenarios probables y menos probables

\begin{tabular}{lcl}
\hline Demografía & I (más probable) & II (menos probable) \\
\hline $\begin{array}{l}\text { Tasa de crecimiento } \\
\text { poblacional }\end{array}$ & Permanente +/- 1.1\% & Tendencia a incrementar >1.1\% \\
$\begin{array}{l}\text { Crecimiento de la población } \\
\text { urbana }\end{array}$ & $\begin{array}{l}\text { Mayor crecimiento } \\
\text { comparado al ámbito rural }\end{array}$ & $\begin{array}{l}\text { Sin tendencia a subir o bajar comparado } \\
\text { con rural }\end{array}$ \\
$\begin{array}{l}\text { Estructura poblacional } \\
\text { según NSE }\end{array}$ & Mayor población NSE C & Mayor población NSE A-B \\
\hline Economía & I (más probable) & II (menos probable) \\
\hline Crecimiento del PBI & Entre 3\% a 5\% & Mayor a 5\% \\
Política de importaciones & Estable sin mayor TLC & Incremento de acuerdos internacionales \\
Ingreso per cápita & Se mantiene & Crecimiento \\
Político y social & I (más probable) & II (menos probable) \\
Estabilidad política & Democrática & Democrática \\
Mercado laboral & Crece la demanda laboral & Se mantiene la tasa de trabajo \\
Estabilidad jurídica & Se mantiene & Se fortalece \\
\hline
\end{tabular}




\subsubsection{Comparación de Estrategias con escenarios}

Teniendo en cuenta los efectos que podrían tener en el negocio de Eterna Perú y en sus resultados, se identificaron cuáles son los impactos que cada escenario causaría en términos de:

a) El mercado de artículos de limpieza

b) La competencia de Eterna en el mercado

En la Tabla 53 se muestra la comparación de las estrategias con los escenarios el más probable y el menos probable.

Tabla 53

Comparación de Estrategias con escenarios

\begin{tabular}{|c|c|c|}
\hline Impacto en el mercado & I (más probable) & II (menos probable) \\
\hline $\begin{array}{l}\text { Mayor demanda de los guantes } \\
\text { de limpieza }\end{array}$ & Continuo crecimiento & Mayor crecimiento \\
\hline Evolución en el canal modernos & Continuo crecimiento & Mayor crecimiento \\
\hline Evolución en el canal tradicional & Continuo crecimiento & Mayor crecimiento \\
\hline \multicolumn{3}{|l|}{ Impacto en la competencia } \\
\hline Nuevos competidores & Poco probable & Altamente probable \\
\hline $\begin{array}{l}\text { Mayor agresividad en el } \\
\text { mercado de guantes }\end{array}$ & Probable & Altamente probable \\
\hline $\begin{array}{l}\text { Nuevos productos con valor } \\
\text { agregado en el mercado }\end{array}$ & Probable & Altamente probable \\
\hline
\end{tabular}

En función de estos impactos, determinamos en qué grado afectan a cada una de las alternativas estratégicas (ver tabla 54). 
Tabla 54

Grado que afectan a cada una de las alternativas estratégicas

\begin{tabular}{llll}
\hline & $\begin{array}{l}\text { Estrategias (2017 - } \\
\text { 2021) }\end{array}$ & I (más probable) & II (menos probable) \\
\hline $\mathrm{E}-1$ & $\begin{array}{l}\text { Penetración de } \\
\text { mercado }\end{array}$ & Favorable & Favorable \\
$\mathrm{E}-2$ & $\begin{array}{l}\text { Desarrollo de } \\
\text { mercado }\end{array}$ & Muy favorable & Muy favorable \\
$\mathrm{E}-3$ & Recorte de gastos & Muy favorable & Favorable \\
\hline
\end{tabular}

Se identificóque en el escenario I (más probable), la implementación de la estrategia de desarrollo de mercado planteadaes altamente favorable para la consecución de los objetivos estratégicos de Eterna.

\subsection{Matriz de Planeación Estratégica Cuantitativa MPEC}

La matriz MPEC utiliza la información de la matriz FODAdesarrollada en los capítulos anteriores. Esta matriz evalúa las estrategias con las fortalezas, debilidades de la empresa y con las oportunidades que ofrece el entorno. 
Tabla 55

Matriz de Planeación Estratégica Cuantitativa MPEC

\begin{tabular}{|c|c|c|c|c|c|c|c|c|}
\hline OPORTUNIDADES & & $\begin{array}{l}\text { ESTRATEGIA } 1 \\
\text { Penetración de } \\
\text { mercado }\end{array}$ & & & $\begin{array}{l}\text { ESTRATEGIA } \\
\mathbf{2} \\
\text { Desarrollo de merc }\end{array}$ & ado & $\begin{array}{l}\text { ESTRATEGIA } \\
\mathbf{3} \\
\text { Reducción de costos }\end{array}$ & \\
\hline Estabilidad política & 0.06 & & 5 & 0.3 & 5 & 0.3 & 5 & 0.3 \\
\hline $\begin{array}{l}\text { Comercio minorista al } \\
\text { alza }\end{array}$ & 0.08 & & 5 & 0.4 & 5 & 0.4 & 4 & 0.32 \\
\hline $\begin{array}{l}\text { Retail moderno: Las } \\
\text { ventas totales crecerán } \\
6 \%\end{array}$ & 0.07 & & 5 & 0.35 & 5 & 0.35 & 4 & 0.28 \\
\hline $\begin{array}{l}\text { Búsqueda de productos } \\
\text { de calidad por los } \\
\text { clientes }\end{array}$ & 0.09 & & 4 & 0.36 & 5 & 0.45 & 3 & 0.27 \\
\hline Crecimiento del PBI & 0.08 & & 4 & 0.32 & 5 & 0.4 & 4 & 0.32 \\
\hline Tipo de cambio estable & 0.09 & & 5 & 0.45 & 4 & 0.36 & 4 & 0.36 \\
\hline \multicolumn{9}{|l|}{ AMENAZAS } \\
\hline $\begin{array}{l}\text { Crecimiento acelerado } \\
\text { del canal online }\end{array}$ & 0.05 & & 3 & 0.15 & 5 & 0.25 & 3 & 0.15 \\
\hline $\begin{array}{l}\text { Menor evolución del } \\
\text { empleo y salario } \\
\text { Familias que pasaron a }\end{array}$ & 0.07 & & 3 & 0.21 & 3 & 0.21 & 5 & 0.35 \\
\hline $\begin{array}{l}\text { la clases media } \\
\text { País con mayor rigidez }\end{array}$ & 0.08 & & 5 & 0.4 & 5 & 0.4 & 4 & 0.32 \\
\hline laboral & 0.07 & & 4 & 0.28 & 4 & 0.28 & 5 & 0.35 \\
\hline Políticas de reciclaje & 0.03 & & 4 & 0.12 & 4 & 0.12 & 5 & 0.15 \\
\hline
\end{tabular}


Producción local a bajo

costo

0.09

$3 \quad 0.27$

$\begin{array}{ll}3 & 0.27\end{array}$

$5 \quad 0.45$

Importaciones de bajo costo y menor calidad

\section{FORTALEZAS}

Reconocimiento de producto - calidad

Alta participación de mercado en canal

moderno

Tiempo de repuesta (lead time) apropiado Portafolio amplio de

productos limpieza

Facilidad para aplicar procesos ya

desarrollados en casa

matriz

0.08

$5 \quad 0.4$

$4 \quad 0.32$

Compras consolidadas desde casa matriz

Estructura Ligera con

facilidad de tomar decisiones rápidas

0.08

$4 \quad 0.32$

$\begin{array}{ll}5 & 0.4\end{array}$

DEBILIDADES

Desorden en la llegada de productos al mercado (GotoMarket)

Servicio de distribución del producto costos 
Bajo nivel de servicios

(Procesos y

Procedimientos)

0.08

$\begin{array}{ll}4 & 0.32\end{array}$

$4 \quad 0.32$

$5 \quad 0.4$

Personal de ventas poco

capacitado

0.08

$3 \quad 0.24$

$3 \quad 0.24$

$\begin{array}{ll}4 & 0.32\end{array}$

Falta claridad en el

portafolio de productos

por canal

0.10

$\begin{array}{ll}4 & 0.4\end{array}$

$3 \quad 0.3$

8.31




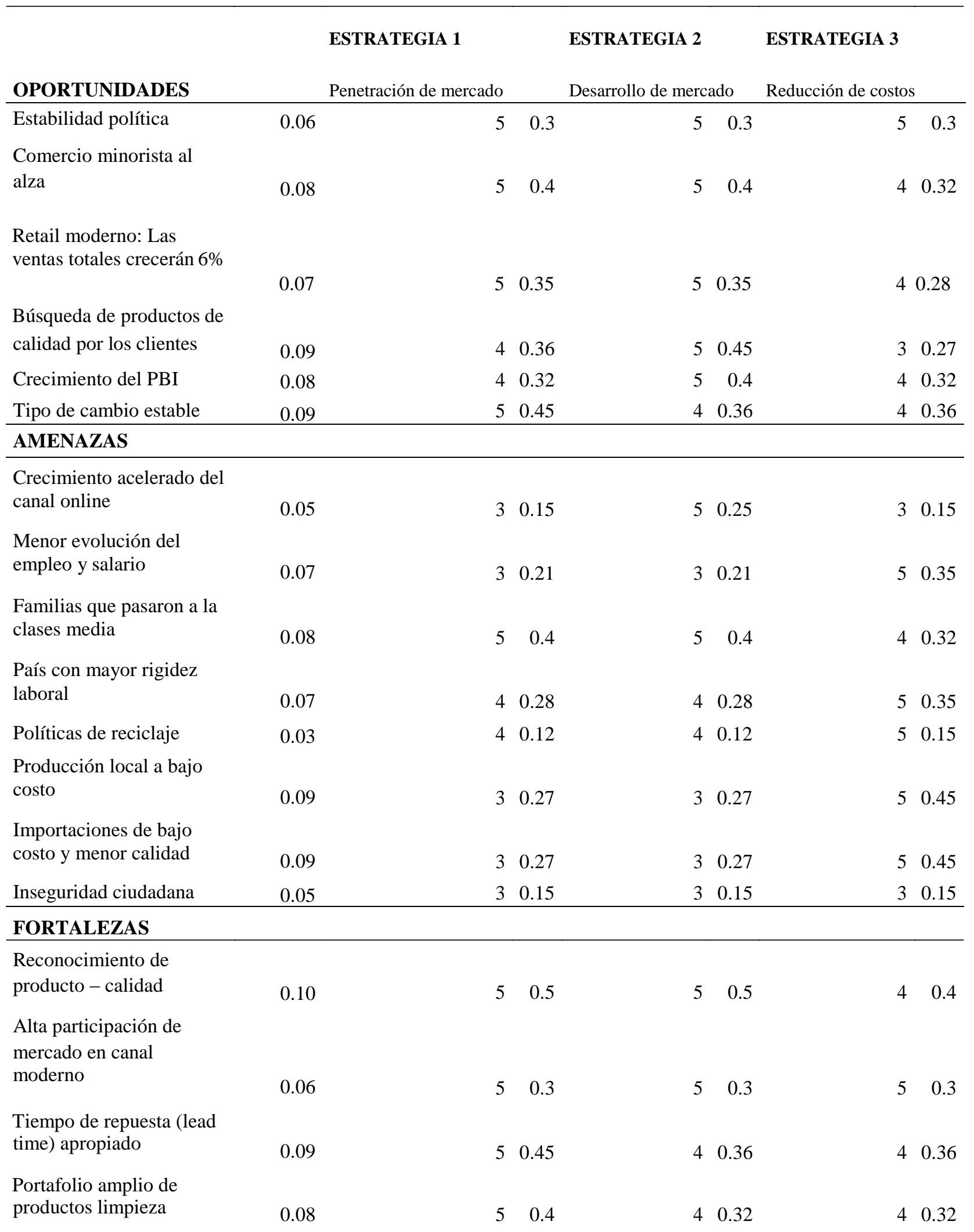


Facilidad para aplicar procesos ya desarrollados en casa matriz
0.08
$\begin{array}{ll}4 & 0.32\end{array}$
$5 \quad 0.4$
$\begin{array}{ll}4 & 0.32\end{array}$

Compras consolidadas desde casa matriz

$\begin{array}{ll}4 & 0.24\end{array}$

$\begin{array}{ll}5 & 0.3\end{array}$

$\begin{array}{ll}5 & 0.3\end{array}$

Estructura Ligera con

facilidad de tomar

decisiones rápidas

0.08

$\begin{array}{ll}4 & 0.32\end{array}$

$5 \quad 0.4$

$\begin{array}{ll}4 & 0.32\end{array}$

\section{DEBILIDADES}

Desorden en la llegada de

productos al mercado

(GotoMarket)

0.10

$4 \quad 0.4$

$\begin{array}{ll}4 & 0.4\end{array}$

$\begin{array}{ll}3 & 0.3\end{array}$

Servicio de distribución

del producto costos

0.09

$\begin{array}{ll}3 & 0.27\end{array}$

$3 \quad 0.27$

$\begin{array}{ll}5 & 0.45\end{array}$

Bajo nivel de servicios

(Procesos y

Procedimientos)

0.08

$4 \quad 0.32$

$4 \quad 0.32$

$5 \quad 0.4$

Personal de ventas poco capacitado

Falta claridad en el portafolio de productos por canal 0.10 $\begin{array}{ll}4 & 0.4\end{array}$ $4 \quad 0.4$ 30.3

\subsection{Descripción de estrategia seleccionada}

Las estrategias evaluadas con los métodos anteriores para seleccionar las estrategias son las siguientes:

E - 1 Penetración de mercado

E - 2 Desarrollo de mercado

E - 3 Recorte de gastos 
A partir de los resultados alcanzados en los tres métodos se selecciona la estrategia E 2"Desarrollo de mercado". (Ver Tabla 56)

Tabla 56

Selección de la estrategia principal

\begin{tabular}{lccc}
\hline & $\begin{array}{l}\text { E-1 } \\
\text { Penetración de } \\
\text { mercado }\end{array}$ & $\begin{array}{l}\text { E - 2 } \\
\text { Desarrollo de mercado }\end{array}$ & $\begin{array}{l}\text { E - 3 } \\
\text { Reducción de costos }\end{array}$ \\
\hline $\begin{array}{l}\text { Método Factores Estratégicos } \\
\text { Claves }\end{array}$ & 2 & 1 & 3 \\
$\begin{array}{l}\text { Método de escenarios } \\
\text { Matriz de Planeación }\end{array}$ & 3 & 1 & 2 \\
Estratégica Cuantitativa & 3 & 1 & 2 \\
\hline & $\mathbf{3}$ & $\mathbf{1}$ & $\mathbf{2}$ \\
\hline
\end{tabular}

El desarrollo de mercado, a veces es referido como buscar un mayor porcentaje de mercado. Esta estrategia está enfocada para generar una nueva alternativa para conseguir clientes que permita generar volumen de ventas de los guantesen relación con la competencia. Para aumentar el desarrollo de mercado, Eterna Perú puede emplear una serie de acciones con el fin de tomar las ventas de nuestros principales competidores.

\subsection{Descripción de estrategia contingente}

Según las matrices usadas para la selección de la estrategia, tenemos a partir de los resultados alcanzados en los tres métodos se selecciona la estrategia E - 3“'Reducción de Costos"

La reducción de costosocurriría porque Eterna podría replantearalgunas actividades que se llevan a cabo en la empresa y luego enfocarlas para revertir la desaceleración de las ventas y 
los márgenes de utilidad.Durante esta reducción de costos, las actividadesque realiza la compañía podrían ser afectadascon pocos recursos y enfrentar la influencia de los accionistas, y stakeholders. A continuación se presentan algunas acciones a llevar a cabo para consolidar la estrategia:

- La reducción de la línea y diversidad

- Renegociación con los proveedores

- La disminución del número de empleados

- La institución de sistemas de control de gastos. 


\section{Capítulo 9 Implantación de la estrategia}

Este capítulo describe la ejecución de la estrategia de desarrollo de mercado seleccionada para Eterna Perú. El modelo utilizado para realizar el proceso de implementación es el Balance Scorecard propuesto por Kaplan y Norton.

\subsection{Mapa de la Estrategia}

El mapa de la estrategia describe la implementación de la estrategia seleccionada para Eterna Perú en función de cuatro perspectivas: finanzas, cliente, procesos internos y aprendizaje y crecimiento.

Para la implementación de la estrategia de desarrollo de mercado se debe tomar en cuenta los aspectos culturales de la empresa que afectan al talento humano, dado que se considera que la gestión del capital humano es el que genera el compromiso requerido para realizar las actividades que se requiere para implementar de manera exitosa la estrategia del negocio. Este aspecto es importante ya que el éxito para lograr los objetivos trazados depende en gran mesura de la cultura organizacional, dado que si no existe la disposición para el logro de los objetivos, la estrategia será poco efectiva, llegando a ser incluso negativa en la gestión de la empresa.

La Figura 57 presenta el mapa de la estrategia de la empresa bajo cuatro perspectivas: financiero, clientes, procesos internos y aprendizaje. En la gráfica, se puede apreciar la relación 
causa y efecto que existe entre los objetivos planteados por Eterna Perú S.A. para implementar la estrategia seleccionada.

- Aprendizaje y Crecimiento: Se identificaron los elementos más trascendentales para la estrategia que requiere aprender la empresa a fin de consolidar la estrategia. Los aspectos considerados en esta perspectiva son: conocimiento de los productos de la empresa, conocimiento de mercado y clientes, desarrollar competencias para atender a los nuevos clientes

- Procesos internos: Se identificaron los procesos más críticos que sirven de soporte para llevar a cabo los objetivos relacionados con los aspectos financieros y del cliente. Los procesos estratégicos considerados son: almacenamiento, atención al cliente y control de calidad. Las actividades a realizar en estos procesos permitirán estandarizar y gestionar procedimientos del área, establecer las coordinaciones en las actividades que impactan en el cliente interno, así como mejorar el servicio de atención al cliente, asegurar la calidad del producto ofrecida al cliente, entre otros.

- Cliente: Se identificaron los objetivos considerando la proposición de valor para los clientes existentes y potenciales de Eterna. La perspectiva del clienteestará en función de tres condiciones: disponibilidad de productos, capacitación de la fuerza de ventas del cliente y asesoría para nuevos clientes.

- Financiera: Los objetivos de esta perspectiva están vinculados a los objetivos inferiores de las otras perspectivas, y deben alineados a la estrategia y visión de la empresa. Se considera como elementos de esta perspectiva: la rentabilidad, mayor número de clientes las mayores ventas. 


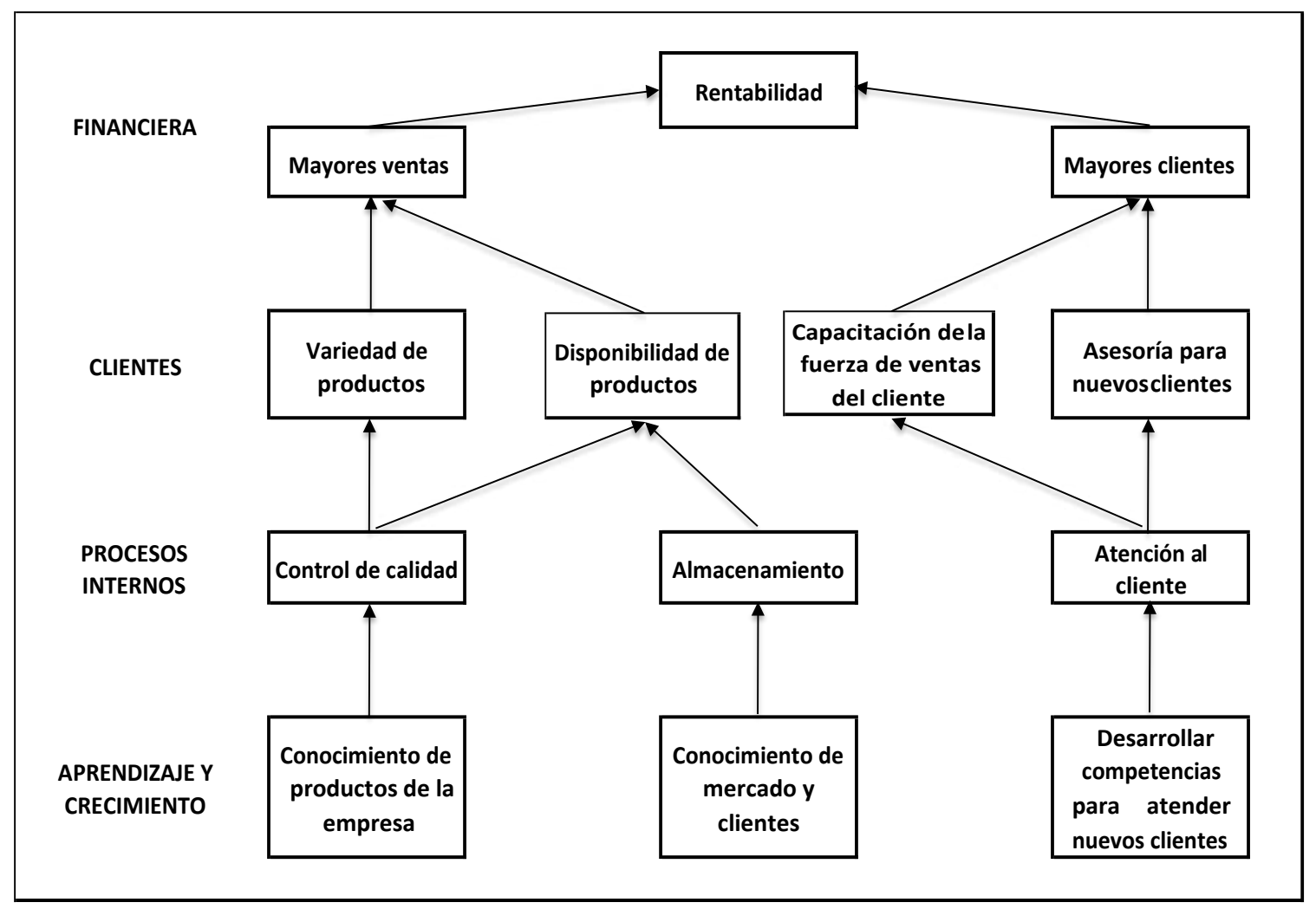

Figura 57.Mapa de laestrategia 


\subsection{Objetivos específicos según el mapa de la estrategia}

S consideran los objetivos específicos que se requieren, con cada perspectiva a trabajar, Eterna lograra llegar a la meta trazada en el año 2021, esto requiere mucho compromiso por las personas responsables de cada objetivo.

\begin{tabular}{|c|c|c|}
\hline & & OBJETIVO \\
\hline \multirow{3}{*}{ Finanzas } & Rentabilidad & Alcanzar una rentabilidad sobre las ventas del $20 \%$ en el año 2021 \\
\hline & Mayores Clientes & Incrementaren $100 \%$ el nủmero de clientes \\
\hline & Mayores ventas & Aumentar el portafolio de productos mandatarios en clientes nuevos \\
\hline \multirow{4}{*}{ Clientes } & Variedad de productos & Ofrecer al diente el 100\% de la gama de productos según tipo de diente al 2021 \\
\hline & Disponibilidad de productos & Lograr un nivel de cumplimiento de las ordenes a clientes en un $90 \%$ \\
\hline & \begin{tabular}{|c|}
$\begin{array}{c}\text { Capacitación de la fuerza de ventas del } \\
\text { cliente }\end{array}$ \\
\end{tabular} & $\begin{array}{l}\text { Lograr el } 100 \% \text { de la fuerza de ventas de dientes capacitados en portafolio de productos } \\
\text { de Eterna en un (01) año }\end{array}$ \\
\hline & Asesoría para nuevos clientes & Ofrecer asesoría sobre ventas al estado al $100 \%$ de los clientes claves 2018 \\
\hline \multirow{2}{*}{ Procsos Intemos } & Almacenamiento & Garantizar la existencia de un $95 \%$ de productos ofrecidos al mercado \\
\hline & Control de cal idad & Garantizar que el $100 \%$ de los productos cumplan con las especificaciones técnicas \\
\hline \multirow{3}{*}{ Formación y Crecirniento } & $\begin{array}{l}\text { Conocimiento de productos de la } \\
\text { empresa }\end{array}$ & Capacitar al $100 \%$ de la fuerza de ventas sobre los productos de la empresa \\
\hline & Conodimiento de mercado y clientes & Capacitar al $100 \%$ de la fuerza de ventas sobre el mercado y clientes de la empresa \\
\hline & $\begin{array}{c}\text { Desarrollar competencias para atender } \\
\text { a los nuevos clientes }\end{array}$ & $\begin{array}{l}\text { Lograr competencias de atención al cliente en el } 100 \% \text { de la fuerza de ventas de la } \\
\qquad \text { empresa }\end{array}$ \\
\hline
\end{tabular}

Figura 58. Objetivos específicos 


\subsection{Indicadores para cada uno de los objetivos específicos}

Se establecen los indicadores que medirán, de manera cuantitativa, el cumplimiento de los objetivos trazados.

\begin{tabular}{|c|c|c|c|}
\hline & & OBJETIVO & INDICADOR \\
\hline \multirow{3}{*}{ Finanzas } & Rentabilidad & $\begin{array}{l}\text { Alcanzar una rentabilidad sobre las } \\
\text { ventas del } 20 \% \text { en el año } 2021\end{array}$ & ROS \\
\hline & Mayores Clientes & $\begin{array}{c}\text { Incrementar en } 100 \% \text { el número de } \\
\text { clientes }\end{array}$ & $\begin{array}{l}\text { Nuevos Clientes } \\
\text { Total clientes }\end{array}$ \\
\hline & Mayores ventas & $\begin{array}{l}\text { Aumentar el portafolio de productos } \\
\text { mandatarios en clientes nuevos }\end{array}$ & $\begin{array}{c}\begin{array}{c}\text { No. de productos codificados por } \\
\text { nuevo cliente }\end{array} \\
\text { Total de productos demandados por } \\
\text { cliente }\end{array}$ \\
\hline
\end{tabular}

\begin{tabular}{|c|c|c|c|}
\hline \multirow{4}{*}{ Clientes } & Variedad de productos & $\begin{array}{l}\text { Ofrecer al cliente el } 100 \% \text { de la gama de } \\
\text { productos según tipo de cliente al } 2021\end{array}$ & $\begin{array}{c}\text { Portafolio de productos ofrecidos } \\
\text { Total de portafolio de productos }\end{array}$ \\
\hline & $\begin{array}{l}\text { Disponibilidad de } \\
\text { productos }\end{array}$ & $\begin{array}{l}\text { Lograr un nivel de cumplimiento de las } \\
\text { ordenes a clientes en un } 90 \%\end{array}$ & $\begin{array}{c}\text { Ordenes de clientes atendidos } \\
\text { Ordenes recibidas de los clientes }\end{array}$ \\
\hline & $\begin{array}{l}\text { Capacitación de la } \\
\text { fuerza de ventas del } \\
\text { cliente }\end{array}$ & $\begin{array}{c}\text { Lograr el } 100 \% \text { de la fuerza de ventas de } \\
\text { clientes capacitados en portafolio de } \\
\text { productos de Eterna en un (01) año }\end{array}$ & $\begin{array}{l}\begin{array}{c}\text { Fuerza de ventas de clientes } \\
\text { capacitados }\end{array} \\
-0-0 \text { Total fuerza de venta de clientes }\end{array}$ \\
\hline & $\begin{array}{l}\text { Asesoría para nuevos } \\
\text { clientes }\end{array}$ & $\begin{array}{l}\text { Ofrecer asesoria sobre ventas al estado } \\
\text { al } 100 \% \text { de los clientes claves } 2018\end{array}$ & $\begin{array}{c}\mathrm{N}^{\circ} \text { de clientes claves Asesorados } \\
\text { Total de clientes clave }\end{array}$ \\
\hline
\end{tabular}




\begin{tabular}{|c|c|c|c|}
\hline & Almacenamiento & $\begin{array}{l}\text { Garantizar la existencia de un } 95 \% \text { de } \\
\text { productos ofrecidos al mercado }\end{array}$ & $\begin{array}{l}\text { Productos surtidos a los clientes } \\
\text { Productos ofrecidos a los clientes }\end{array}$ \\
\hline $\begin{array}{l}\text { Procesos } \\
\text { Internos }\end{array}$ & Control de calidad & $\begin{array}{l}\text { Garaantizar que el } 100 \% \text { de los } \\
\text { productos cumplan con las } \\
\text { especificaciones técnicas }\end{array}$ & $\begin{array}{l}\text { Productos vendidos que cumplen } \\
\text { especificaciones técnicas }\end{array}$ \\
\hline
\end{tabular}

\begin{tabular}{|c|c|c|c|}
\hline \multirow{3}{*}{$\begin{array}{l}\text { Formación y } \\
\text { Crecimiento }\end{array}$} & $\begin{array}{c}\text { Conocimiento de } \\
\text { productos de la empresa }\end{array}$ & $\begin{array}{c}\text { Capacitar al } 100 \% \text { de la fuerza de ventas } \\
\text { sobre los productos de la empresa }\end{array}$ & $\begin{array}{l}\text { Fuerza de ventas capacitada en } \\
\text { productos de la empresa } \\
\text { Total de fuerza de ventas }\end{array}$ \\
\hline & $\begin{array}{l}\text { Conocimiento de } \\
\text { mercado y clientes }\end{array}$ & $\begin{array}{c}\text { Capacitar al } 100 \% \text { de la fuerza de ventas } \\
\text { sobre el mercado y clientes de la } \\
\text { empresa }\end{array}$ & $\begin{array}{c}\text { Fuerza de ventas capacitada en } \\
\text { mercado y clientes / total de fuerza de } \\
\text { ventas }\end{array}$ \\
\hline & $\begin{array}{c}\text { Desarrollar } \\
\text { competencias para } \\
\text { atender a los nuevos } \\
\text { clientes }\end{array}$ & $\begin{array}{l}\text { Lograr competencias de atención al } \\
\text { cliente en el } 100 \% \text { de la fuerza de } \\
\text { ventas de la empresa }\end{array}$ & $\begin{array}{c}\text { Fuerza de ventas con competencias de } \\
\text { atención al cliente } \\
\text { Total de fuerza de ventas }\end{array}$ \\
\hline
\end{tabular}

Figura 59. Indicadores para los objetivos

\subsection{Metas para cada uno de los objetivos específicos}

A partir de los objetivos planteados en el mapa de la estrategia, se establecen las metas que a partir del año 2017 tiene que ser ejecutados hasta el año 2021. 


\begin{tabular}{|c|c|c|c|c|}
\hline & & OBJETIVO & INDICADOR & METAS \\
\hline \multirow{3}{*}{ Finanzas } & Rentabilidad & $\begin{array}{l}\text { Alcanzar una rentabilidad sobre las } \\
\text { ventas del } 20 \% \text { en el año } 2021\end{array}$ & ROS & \begin{tabular}{ll} 
& \multicolumn{1}{c}{ ROS } \\
2017 & $: 5.00 \%$ \\
2018 & $: 5.00 \%$ \\
2019 & $: \quad 7.00 \%$ \\
2020 & $: \quad 9.00 \%$ \\
2021 & $: 10.00 \%$
\end{tabular} \\
\hline & Mayores Clientes & $\begin{array}{c}\text { Incrementar en } 100 \% \text { el número de } \\
\text { clientes }\end{array}$ & $\begin{array}{c}\text { Nuevos Clientes } \\
--{ }^{\text {Total clientes }}\end{array}$ & \begin{tabular}{cl}
$\%$ & \multicolumn{1}{c}{ Estado } \\
$100 \%$ & $:$ Bueno \\
$90 \%$ & $:$ Regular \\
$80 \%$ & $:$ Malo
\end{tabular} \\
\hline & Mayores ventas & $\begin{array}{l}\text { Aumentar el portafolio de productos } \\
\text { mandatarios en clientes nuevos }\end{array}$ & $\begin{array}{c}\begin{array}{c}\text { No. de productos codificados por } \\
\text { nuevo cliente }\end{array} \\
-\begin{array}{c}\text { Total de productos demandados por } \\
\text { cliente }\end{array}\end{array}$ & \begin{tabular}{ccc}
\multicolumn{2}{c}{ Participación } \\
$2017 \quad:$ & $50 \%$ \\
2018 & $:$ & $80 \%$ \\
2019 & $:$ & $85 \%$ \\
2020 & $:$ & $90 \%$ \\
2021 & $:$ & $100 \%$
\end{tabular} \\
\hline
\end{tabular}

\begin{tabular}{|c|c|c|c|c|}
\hline \multirow{4}{*}{ Clientes } & Variedad de productos & $\begin{array}{l}\text { Ofrecer al cliente el } 100 \% \text { de la gama de } \\
\text { productos según tipo de cliente al } 2021\end{array}$ & $\begin{array}{c}\text { Portafolio de productos ofrecidos } \\
\text { Total de portafolio de productos }\end{array}$ & $\begin{array}{ll}2 \text { Trimestre : } & 70 \% \\
4 \text { Trimestre : } & 80 \% \\
6 \text { Trimestre : } & 90 \% \\
8 \text { Trimestre : } & 100 \%\end{array}$ \\
\hline & $\begin{array}{l}\text { Disponibilidad de } \\
\text { productos }\end{array}$ & $\begin{array}{l}\text { Lograr un nivel de cumplimiento de las } \\
\text { ordenes a clientes en un } 90 \%\end{array}$ & $\begin{array}{l}\text { Ordenes de clientes atendidos } \\
\text { Ordenes recibidas de los clientes }\end{array}$ & $\begin{array}{cl}\text { Nivel de atención } & \text { Estado } \\
>=90 \%: & \text { Bueno } \\
85 \%-89 \%: & \text { Regular } \\
<=84 \%: & \text { Malo }\end{array}$ \\
\hline & $\begin{array}{l}\text { Capacitación de la } \\
\text { fuerza de ventas del } \\
\text { cliente }\end{array}$ & $\begin{array}{l}\text { Lograr el } 100 \% \text { de la fuerza de ventas de } \\
\text { clientes capacitados en portafolio de } \\
\text { productos de Eterna en un (01) año }\end{array}$ & $\begin{array}{l}\begin{array}{l}\text { Fuerza de ventas de clientes } \\
\text { capacitados }\end{array} \\
-0-0 \text { Total fuerza de venta de clientes }\end{array}$ & 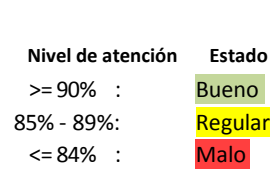 \\
\hline & $\begin{array}{l}\text { Asesoría para nuevos } \\
\text { clientes }\end{array}$ & $\begin{array}{l}\text { Ofrecer asesoría sobre ventas al estado } \\
\text { al 100\% de los clientes claves } 2018\end{array}$ & $\begin{array}{c}\mathrm{N}^{\circ} \text { de clientes claves Asesorados } \\
-\mathrm{y}^{-} \text {Total de clientes clave }\end{array}$ & $\begin{array}{ll}1 \text { Semestre }: & 40 \% \\
2 \text { Semestre }: & 70 \% \\
\text { 3 Semestre }: & 100 \%\end{array}$ \\
\hline
\end{tabular}




\begin{tabular}{|c|c|c|c|c|c|}
\hline & Almacenamiento & $\begin{array}{l}\text { Garantizar la existencia de un } 95 \% \text { de } \\
\text { productos ofrecidos al mercado }\end{array}$ & Productos surtidos a los clientes & $\begin{array}{c}\text { Costo Logistico } \\
\quad<6 \% \\
6 \%-8 \% \\
>8 \%\end{array}$ & $\begin{array}{l}\text { Estado } \\
\text { : Bueno } \\
\text { : Regular } \\
\text { : Malo }\end{array}$ \\
\hline $\begin{array}{l}\text { Procesos } \\
\text { Internos }\end{array}$ & Control de calidad & $\begin{array}{c}\text { Garaantizar que el } 100 \% \text { de los } \\
\text { productos cumplan con las } \\
\text { especificaciones técnicas }\end{array}$ & $\begin{array}{l}\text { Productos vendidos que cumplen } \\
\text { especificaciones técnicas }\end{array}$ & $\begin{array}{c}\text { \% de mal estado } \\
\begin{array}{cl}0 \% & : \\
1 \% & : \\
2 \% & :\end{array}\end{array}$ & $\begin{array}{l}\text { Estado } \\
\text { : Bueno } \\
\text { : Regular } \\
\text { : Malo }\end{array}$ \\
\hline
\end{tabular}

\begin{tabular}{|c|c|c|c|c|}
\hline \multirow{3}{*}{$\begin{array}{l}\text { Formación y } \\
\text { Crecimiento }\end{array}$} & $\begin{array}{l}\text { Conocimiento de } \\
\text { productos de la empresa }\end{array}$ & $\begin{array}{c}\text { Capacitar al } 100 \% \text { de la fuerza de ventas } \\
\text { sobre los productos de la empresa }\end{array}$ & $\begin{array}{c}\begin{array}{c}\text { Fuerza de ventas capacitada en } \\
\text { productos de la empresa }\end{array} \\
\text { Total de fuerza de ventas }\end{array}$ & $100 \%$ : 1er semestre \\
\hline & $\begin{array}{l}\text { Conocimiento de } \\
\text { mercado y clientes }\end{array}$ & $\begin{array}{c}\text { Capacitar al } 100 \% \text { de la fuerza de ventas } \\
\text { sobre el mercado y clientes de la } \\
\text { empresa }\end{array}$ & $\begin{array}{c}\text { Fuerza de ventas capacitada en } \\
\text { mercado y clientes / total de fuerza de } \\
\text { ventas }\end{array}$ & $100 \%: 1$ er semestre \\
\hline & $\begin{array}{c}\text { Desarrollar } \\
\text { competencias para } \\
\text { atender a los nuevos } \\
\text { clientes }\end{array}$ & $\begin{array}{l}\text { Lograr competencias de atención al } \\
\text { cliente en el } 100 \% \text { de la fuerza de } \\
\text { ventas de la empresa }\end{array}$ & $\begin{array}{c}\text { Fuerza de ventas con competencias de } \\
\text { atención al cliente } \\
\text { Total de fuerza de ventas }\end{array}$ & $100 \%: 1$ er semestre \\
\hline
\end{tabular}

Figura 60.Metas para cada uno de los objetivos

\subsection{Iniciativas (acciones a llevar a cabo para cada uno de los objetivos específicos)}

Se definen que iniciativas se deben realizar para cada punto trazado. Las actividades propuestas fueron coordinadas con el equipo gerencial de Eterna Perú. 


\begin{tabular}{|c|c|c|c|c|c|}
\hline & & OBJETIVO & INDICADOR & METAS & ACTIVIDADES \\
\hline \multirow{3}{*}{ Finanzas } & Rentabilidad & $\begin{array}{l}\text { Alcanzar una rentabilidad sobre las } \\
\text { ventas del } 20 \% \text { en el año } 2021\end{array}$ & ROS & 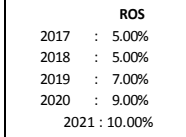 & $\begin{array}{l}\text { A1. Importar productos de mayor margen. } \\
\text { A2. Desarrollo de procedimiento de operaciones (optimizar } \\
\text { costos logísticos) y ventas. }\end{array}$ \\
\hline & Mayores Clientes & $\begin{array}{l}\text { Incrementar en } 100 \% \text { el número de } \\
\text { clientes }\end{array}$ & $\begin{array}{c}\text { Nuevos Clientes } \\
\text { Total clientes }\end{array}$ & $\begin{array}{l}\% \text { Estado } \\
100 \%: \text { : Bueno } \\
90 \%: \text { Regular } \\
80 \%: \text { Malo }\end{array}$ & $\begin{array}{l}\text { A1. Incrementar clientes por zonas geográficas en Lima y } \\
\text { provincias. } \\
\text { A2. Asistira eventosque realiza la Cámara de Comerciode Lima } \\
\text { y provincias. } \\
\text { A3. Adquisición de bases de datos de futuros clientes } \\
\text { potenciales. }\end{array}$ \\
\hline & Mayores ventas & $\begin{array}{l}\text { Aumentar el portafolio de productos } \\
\text { mandatarios en clientes nuevos }\end{array}$ & $\begin{array}{l}\text { No. de productos codificados por } \\
\text { nuevo cliente } \\
----------------------- \\
\text { Total de productos demandados por } \\
\text { cliente }\end{array}$ & \begin{tabular}{ll}
\multicolumn{2}{l}{ Participación } \\
$2017 \quad: \quad 50 \%$ \\
$2018 \quad: \quad 80 \%$ \\
$2019 \quad: \quad 85 \%$ \\
$2020 \quad: \quad 90 \%$ \\
$2021 \quad: \quad 100 \%$
\end{tabular} & $\begin{array}{l}\text { A1. Ampliación de portafolio especializado por canal. } \\
\text { A2. Promocionar los portafolios en ferias y eventos que se } \\
\text { realicen en Lima y provincias. } \\
\text { A3. Comunicar los atributos de del producto a los clientes. }\end{array}$ \\
\hline
\end{tabular}

\begin{tabular}{|c|c|c|c|c|c|}
\hline \multirow{4}{*}{ Clientes } & Variedaddeproductos & $\begin{array}{l}\text { Ofreceral cliente el } 100 \% \text { de lagamade } \\
\text { productossegúntipodeclienteal } 2021\end{array}$ & $\begin{array}{l}\text { Portafolio de productos ofrecidos } \\
\text { Total de portafolio de productos }\end{array}$ & $\begin{array}{ll}2 \text { Trimestre : } & 70 \% \\
4 \text { Trimestre : } & 80 \% \\
6 \text { Trimestre : } & 90 \% \\
8 \text { Trimestre : } & 100 \%\end{array}$ & $\begin{array}{l}\text { A1. Desarrollar matriz de productos mandatorio por cliente. } \\
\text { A2. Desarrollo y entrega de material publicitario. } \\
\text { A3. Presentación de beneficios del producto al cliente. }\end{array}$ \\
\hline & $\begin{array}{l}\text { Disponibilidad de } \\
\text { productos }\end{array}$ & $\begin{array}{l}\text { Lograrunnivel de cumplimientode las } \\
\text { ordenes a clientes en un } 90 \%\end{array}$ & $\begin{array}{c}\text { Ordenes de clientes atendidos } \\
\text { Ordenes recibidas de los clientes }\end{array}$ & 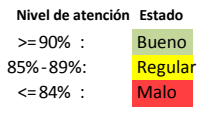 & $\begin{array}{l}\text { A1. Desarrollode software para apoyoalageneraciónde } \\
\text { Pronóstico de ventas. } \\
\text { A2. Desarrollo de proceso de revisión de pronóstico de ventas } \\
\text { por canal. }\end{array}$ \\
\hline & $\begin{array}{l}\text { Capacitacióndela } \\
\text { fuerza de ventas del } \\
\text { cliente }\end{array}$ & $\begin{array}{c}\text { Lograrel } 100 \% \text { de lafuerza de ventas de } \\
\text { clientescapacitadosen portafoliode } \\
\text { productos de Eterna en un (01) año }\end{array}$ & $\begin{array}{l}\text { Fuerza de ventas de clientes } \\
\text { capacitados } \\
-0-0 \text { Total fuerza de venta de clientes }\end{array}$ & 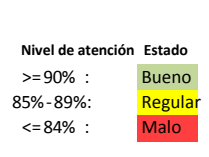 & $\begin{array}{l}\text { A1. Programar plan de capacitación bimestral a clientes. } \\
\text { A2. Elaborar material informativo que se brindaran a los } \\
\text { asistentes. } \\
\text { A3. Brindar asesoría continua luego de la capacitación. } \\
\text { A4. Visitar al personal postclases paraconocer suexperienciay } \\
\text { brindar oportunidades demejoras. }\end{array}$ \\
\hline & $\begin{array}{c}\text { Asesoría para nuevos } \\
\text { clientes }\end{array}$ & $\begin{array}{r}\text { Ofrecer asesoría sobre ventas al estado } \\
\text { al } 100 \% \text { de los clientes claves } 2018\end{array}$ & \begin{tabular}{c}
$\mathrm{N}^{\circ}$ de clientes claves Asesorados \\
\hdashline- Total de clientes clave $^{----}$
\end{tabular} & $\begin{array}{l}1 \text { Semestre : } 40 \% \\
2 \text { Semestre : } 70 \% \\
\text { 3 Semestre : } 100 \%\end{array}$ & $\begin{array}{l}\text { A1. Contratar los servicios de una consultoría especializada en } \\
\text { contrataciones del estado. } \\
\text { A2. Seguimiento continuo al cliente post consultoría. } \\
\text { A3. Comunicar al clientemodificaciones enla ley de } \\
\text { contrataciones delestado. } \\
\text { A4. Comunicar a otros clientes las experiencias de distribuidores } \\
\text { que llevaron la consultoría. }\end{array}$ \\
\hline
\end{tabular}




\begin{tabular}{|c|c|c|c|c|c|}
\hline \multirow[b]{2}{*}{$\begin{array}{l}\text { Procesos } \\
\text { Internos }\end{array}$} & Almacenamiento & $\begin{array}{l}\text { Garantizar la existencia de un } 95 \% \text { de } \\
\text { productos ofrecidos al mercado }\end{array}$ & $\begin{array}{c}\text { Productos surtidos a los clientes } \\
\text { Productos ofrecidos a los clientes }\end{array}$ & $\begin{array}{l}\text { Costo Logistico Estado } \\
<6 \% \text { : Bueno } \\
6 \%-8 \%: \text { Regular } \\
>8 \%: \text { Malo }\end{array}$ & $\begin{array}{l}\text { A1. Elaborar un proceso óptimo en almacenajes de los productos } \\
\text { de la compañía. } \\
\text { A2. Alertar al área de compraslos productos que esténcercaal } \\
\text { quiebre. }\end{array}$ \\
\hline & Control de calidad & $\begin{array}{l}\text { Garaantizar que el } 100 \% \text { de los } \\
\text { productos cumplan con las } \\
\text { especificaciones técnicas }\end{array}$ & $\begin{array}{l}\text { Productos vendidos que cumplen } \\
\text { especificaciones técnicas } \\
\text { Total de productos vendidos }\end{array}$ & 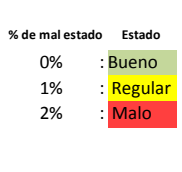 & $\begin{array}{l}\text { A1. Elaborar un proceso óptimo en control de calidad de los } \\
\text { productos importados. } \\
\text { A2. Revisión aleatoria de productos puestos en destino. } \\
\text { A3. Generar reportes quincenales de los productos que } \\
\text { muestran fallastécnicas. } \\
\text { A4. Coordinar las notas de créditos que segeneran araíz de los } \\
\text { productos que llegan en mal estado. }\end{array}$ \\
\hline
\end{tabular}

\begin{tabular}{|c|c|c|c|c|c|}
\hline \multirow{3}{*}{$\begin{array}{l}\text { Formación y } \\
\text { Crecimiento }\end{array}$} & $\begin{array}{c}\text { Conocimiento de } \\
\text { productos de la empresa }\end{array}$ & $\begin{array}{c}\text { Capacitar al } 100 \% \text { de la fuerza de ventas } \\
\text { sobre los productos de la empresa }\end{array}$ & $\begin{array}{l}\text { Fuerza de ventas capacitada en } \\
\text { productos de la empresa } \\
\text { Total de fuerza de ventas }\end{array}$ & $100 \%$ : 1er semestre & $\begin{array}{l}\text { A1. Contratar los servicios de los mejores vendedores de la } \\
\text { empresa matriz (Eterna Colombia) para capacitar. } \\
\text { A2. Adquisición de información de estudios de mercado de } \\
\text { empresa confiables en el mercado. } \\
\text { A3. Evaluar el desempeño del personal capacitado. }\end{array}$ \\
\hline & $\begin{array}{l}\text { Conocimiento de } \\
\text { mercado y clientes }\end{array}$ & $\begin{array}{c}\text { Capacitar al } 100 \% \text { de la fuerza de ventas } \\
\text { sobre el mercado y clientes de la } \\
\text { empresa }\end{array}$ & $\begin{array}{c}\text { Fuerza de ventas capacitada en } \\
\text { mercadoyclientes/totaldefuerzade } \\
\text { ventas }\end{array}$ & $100 \%: 1$ er semestre & $\begin{array}{l}\text { A1. Contratar los servicios de una empresa consultora } \\
\text { especialista en gestión comercial. } \\
\text { A2. Adquisición de información de estudios de mercado de } \\
\text { empresa confiables en el mercado. } \\
\text { A3. Evaluar el desempeño del personal capacitado. } \\
\text { A4. Premiar al personal que obtuvo buenos resultados en } \\
\text { base a la capacitación brindada. }\end{array}$ \\
\hline & $\begin{array}{l}\text { Desarrollar } \\
\text { competencias para } \\
\text { atender a los nuevos } \\
\text { clientes }\end{array}$ & $\begin{array}{l}\text { Lograr competencias de atención al } \\
\text { cliente en el } 100 \% \text { de la fuerza de } \\
\text { ventas de la empresa }\end{array}$ & $\begin{array}{c}\text { Fuerza de ventas con competencias de } \\
\text { atención al cliente }\end{array}$ & $100 \%: 1$ er semestre & $\begin{array}{l}\text { A1. Capacitar al personal tanto en pre ventay postventa. } \\
\text { A2. Armar un equipo que se encargue de evaluar al personal } \\
\text { de ventas a través de entrevistas a los clientes. } \\
\text { A3. Premiar al personal que obtuvo buenos resultados en } \\
\text { base a la entrevista con los clientes. }\end{array}$ \\
\hline
\end{tabular}

Figura 61. Iniciativas para los objetivos 


\subsection{Responsable de cada una de las iniciativas}

\section{Se considera que la persona responsable por cada iniciativa a ejecutarse debe tener el}

apoyo de la Gerencia General y sus directores.Implementar el BalancedScorecardserá de útil

ayuda para llegar a las metas planteadas para el 2021, por ende la persona debe tener un entero

compromiso y el apoyo continuo de sus colaboradores.

\section{Tabla 57}

Responsable de cada iniciativa

\begin{tabular}{|c|c|c|}
\hline ACTIVIDADES & NOMBRE & RESPONSABLE \\
\hline $\begin{array}{l}\text { A1. Importar productos de mayor margen. } \\
\text { A2. Desarrollo de procedimiento de operaciones (optimizar costos logísticos) y ventas. }\end{array}$ & $\begin{array}{l}\text { Ivan Peña Delgado } \\
\text { Mirella Aguirre Salas }\end{array}$ & $\begin{array}{l}\text { Jefe Comercial } \\
\text { Adminstración y Finanzas }\end{array}$ \\
\hline $\begin{array}{l}\text { A1. Incrementar clientes por zonas geográficas en Lima y provincias. } \\
\text { A2. Asistir a eventos que realiza la Cámara de Comercio de Lima y provincias. } \\
\text { A3. Adquisición de bases de datos de futuros clientes potenciales. }\end{array}$ & Ivan Peña Delgado & Jefe Comercial \\
\hline $\begin{array}{l}\text { A1. Ampliación de portafolio especializado por canal. } \\
\text { A2. Promocionar los portafolios en ferias y eventos que se realicen en Lima y provincias. } \\
\text { A3. Comunicar los atributos de del producto a los clientes. }\end{array}$ & Ivan Peña Delgado & Jefe Comercial \\
\hline $\begin{array}{l}\text { A1. Desarrollar matriz de productos mandatorio por cliente. } \\
\text { A2. Desarrollo y entrega de material publicitario. } \\
\text { A3. Presentación de beneficios del producto al cliente. }\end{array}$ & Ivan Peña Delgado & Jefe Comercial \\
\hline $\begin{array}{l}\text { A1. Desarrollo de software para apoyo a la generación de Pronóstico de ventas. } \\
\text { A2. Desarrollo de proceso de revisión de pronóstico de ventas por canal. }\end{array}$ & Juan Chirinos & Jefe de Logística \\
\hline $\begin{array}{l}\text { A1. Programar plan de capacitación bimestral a clientes. } \\
\text { A2. Elaborar material informativo que se brindaran a los asistentes. } \\
\text { A3. Brindar asesoría continua luego de la capacitación. } \\
\text { A4. Visitar al personal post clases para conocer su experiencia y brindar oportunidades de mejoras. }\end{array}$ & Ivan Peña Delgado & Jefe Comercial \\
\hline $\begin{array}{l}\text { A1. Contratar los servicios de una consultoría especializada en contrataciones del estado. } \\
\text { A2. Seguimiento continuo al cliente post consultoría. } \\
\text { A3. Comunicar al cliente modificaciones en la ley de contrataciones del estado. } \\
\text { A4. Comunicar a otros clientes las experiencias de distribuidores que llevaron la consultoría. }\end{array}$ & $\begin{array}{l}\text { Ivan Peña Delgado } \\
\text { Mirella Aguirre Salas }\end{array}$ & $\begin{array}{l}\text { Jefe Comercial } \\
\text { Adminstración y finanzas }\end{array}$ \\
\hline $\begin{array}{l}\text { A1. Elaborar un proceso óptimo en almacenajes de los productos de la compañía. } \\
\text { A2. Alertar al área de compras los productos que estén cerca al quiebre. }\end{array}$ & $\begin{array}{l}\text { Mirella Aguirre Salas } \\
\text { Juan Chirinos }\end{array}$ & $\begin{array}{l}\text { Administración y finanzas } \\
\text { Logística }\end{array}$ \\
\hline $\begin{array}{l}\text { A1. Elaborar un proceso óptimo en control de calidad de los productos importados. } \\
\text { A2. Revisión aleatoria de productos puestos endestino. } \\
\text { A3. Generar reportes quincenales de los productos que muestran fallas técnicas. } \\
\text { A4. Coordinar las notas de créditos que se generan a raíz de los productos que llegan en mal estado. }\end{array}$ & $\begin{array}{l}\text { Mirella Aguirre Salas } \\
\text { Juan Chirinos }\end{array}$ & $\begin{array}{l}\text { Administración y finanzas } \\
\text { Logística }\end{array}$ \\
\hline $\begin{array}{l}\text { A1. Contratar los servicios de los mejores vendedores de la empresa matriz (Eterna Colombia) para capacitar. } \\
\text { A2. Adquisición de información de estudios de mercado de empresa confiables en el mercado. } \\
\text { A3. Evaluar el desempeño del personal capacitado. }\end{array}$ & $\begin{array}{l}\text { Ivan Peña Delgado } \\
\text { Mirella Aguirre Salas }\end{array}$ & $\begin{array}{l}\text { Jefe Comercial } \\
\text { Administración y finanzas }\end{array}$ \\
\hline $\begin{array}{l}\text { A1. Contratar los servicios de una empresa consultora especialista en gestión comercial. } \\
\text { A2. Adquisición de información de estudios de mercado de empresa confiables en el mercado. } \\
\text { A3. Evaluar el desempeño del personal capacitado. } \\
\text { A4. Premiar al personal que obtuvo buenos resultados en base a la capacitación brindada. }\end{array}$ & $\begin{array}{l}\text { Ivan Peña Delgado } \\
\text { Mirella Aguirre Salas }\end{array}$ & $\begin{array}{l}\text { Jefe Comercial } \\
\text { Administración y finanzas }\end{array}$ \\
\hline $\begin{array}{l}\text { A1. Capacitar al personal tanto en pre venta y post venta. } \\
\text { A2. Armar un equipo que se encargue de evaluar al personal de ventas a través de entrevistas a los clientes. } \\
\text { A3. Premiar al personal que obtuvo buenos resultados en base a la entrevista con los clientes. }\end{array}$ & $\begin{array}{l}\text { Ivan Peña Delgado } \\
\text { Mirella Aguirre Salas }\end{array}$ & $\begin{array}{l}\text { Jefe Comercial } \\
\text { Administración y finanzas }\end{array}$ \\
\hline
\end{tabular}




\title{
9.7 Presupuesto de cada una de las iniciativas
}

\author{
Tabla 58
}

Presupuesto de cada una de las iniciativas

\begin{tabular}{|c|c|c|}
\hline ACTIVIDADES & RESPONSABLE & PRESUPUESTO \\
\hline $\begin{array}{l}\text { A1. Importar productos de mayor margen. } \\
\text { A2. Desarrollo de procedimiento de operaciones (optimizar costos logísticos) y ventas. }\end{array}$ & $\begin{array}{c}\text { Jefe Comercial } \\
\text { Administración y Finanzas }\end{array}$ & $-/-$ \\
\hline $\begin{array}{l}\text { A1. Incrementar clientes por zonas geográficas en Lima y provincias. } \\
\text { A2. Asistir a eventos que realiza la Cámara de Comercio de Lima y provincias. } \\
\text { A3. Adquisición de bases de datos de futuros clientes potenciales. }\end{array}$ & Jefe Comercial & $\begin{array}{l}\% \text { de inversión del } \\
\text { presupuesto }\end{array}$ \\
\hline $\begin{array}{l}\text { A1. Ampliación de portafolio especializado por canal. } \\
\text { A2. Promocionar los portafolios en ferias y eventos que se realicen en Lima y provincias. } \\
\text { A3. Comunicar los atributos de del producto a los clientes. }\end{array}$ & Jefe Comercial & $\begin{array}{l}\% \text { de inversión del } \\
\text { presupuesto }\end{array}$ \\
\hline $\begin{array}{l}\text { A1. Desarrollar matriz de productos mandatorio por cliente. } \\
\text { A2. Desarrollo y entrega de material publicitario. } \\
\text { A3. Presentación de beneficios del producto al cliente. }\end{array}$ & Jefe Comercial & S/. $10,000.00$ \\
\hline $\begin{array}{l}\text { A1. Desarrollo de software para apoyo a la generación de Pronóstico de ventas. } \\
\text { A2. Desarrollo de proceso de revisión de pronóstico de ventas por canal. }\end{array}$ & Jefe de Logística & $-/-$ \\
\hline $\begin{array}{l}\text { A1. Programar plan de capacitación bimestral a clientes. } \\
\text { A2. Elaborar material informativo que se brindaran a los asistentes. } \\
\text { A3. Brindar asesoría continua luego de la capacitación. } \\
\text { A4. Visitar al personal post clases para conocer su experiencia y brindar oportunidades de mejoras. }\end{array}$ & Jefe Comercial & S/. 5,000.00 \\
\hline $\begin{array}{l}\text { A1. Contratar los servicios de una consultoría especializada en contrataciones del estado. } \\
\text { A2. Seguimiento continuo al cliente post consultoría. } \\
\text { A3. Comunicar al cliente modificaciones en la ley de contrataciones del estado. } \\
\text { A4. Comunicar a otros clientes las experiencias de distribuidores que llevaron la consultoría. }\end{array}$ & $\begin{array}{l}\text { Jefe Comercial } \\
\text { Adminstración y finanzas }\end{array}$ & S/. 36,000.00 \\
\hline $\begin{array}{l}\text { A1. Elaborar un proceso óptimo en almacenajes de los productos de la compañía. } \\
\text { A2. Alertar alárea de compras los productos queesténcerca al quiebre. }\end{array}$ & $\begin{array}{l}\text { Administración y finanzas } \\
\text { Logística }\end{array}$ & $-/-$ \\
\hline $\begin{array}{l}\text { A1. Elaborar un proceso óptimo en control de calidad de los productos importados. } \\
\text { A2. Revisión aleatoria de productos puestos en destino. } \\
\text { A3. Generar reportes quincenales de los productos que muestran fallas técnicas. } \\
\text { A4. Coordinar las notas de créditos que se generan a raíz de los productos que llegan en mal estado. }\end{array}$ & $\begin{array}{l}\text { Administración y finanzas } \\
\text { Logística }\end{array}$ & $S / .3,000.00$ \\
\hline $\begin{array}{l}\text { A1. Contratar los servicios de los mejores vendedores de la empresa matriz (Eterna Colombia) para capacitar. } \\
\text { A2. Adquisición de información de estudios de mercado de empresa confiables en el mercado. } \\
\text { A3. Evaluar el desempeño del personal capacitado. }\end{array}$ & $\begin{array}{l}\text { Jefe Comercial } \\
\text { Administración y finanzas }\end{array}$ & $S / .5,000.00$ \\
\hline $\begin{array}{l}\text { A1. Contratar los servicios de una empresa consultora especialista en gestión comercial. } \\
\text { A2. Adquisición de información deestudios de mercado deempresaconfiablesenelmercado. } \\
\text { A3. Evaluar el desempeño del personal capacitado. } \\
\text { A4. Premiar al personal que obtuvo buenos resultados en base a la capacitación brindada. }\end{array}$ & $\begin{array}{l}\text { Jefe Comercial } \\
\text { Administración y finanzas }\end{array}$ & S/. $36,000.00$ \\
\hline $\begin{array}{l}\text { A1. Capacitar al personal tanto en pre venta y post venta. } \\
\text { A2. Armarun equipo que se encargue de evaluaral personal de ventas a través de entrevistas a los clientes. } \\
\text { A3. Premiaral personal que obtuvo buenos resultados en base a la entrevista con los clientes. }\end{array}$ & $\begin{array}{l}\text { Jefe Comercial } \\
\text { Administración y finanzas }\end{array}$ & S/. 36,000.00 \\
\hline
\end{tabular}




\subsection{Cronograma de cada una de las iniciativas}

\section{Tabla 59}

Cronograma de cada una de las iniciativas

\begin{tabular}{|c|c|c|c|c|c|c|c|}
\hline ACTIVIDADES & PRESUPUESTO & \multicolumn{6}{|c|}{ CRONOGRAMA } \\
\hline $\begin{array}{l}\text { A1. Importar productos de mayor margen. } \\
\text { A2. Desarrollo de procedimiento de operaciones (optimizar } \\
\text { costos logísticos) y ventas. }\end{array}$ & $-/-$ & \begin{tabular}{|l|}
$A 1$ \\
$A 2$ \\
\end{tabular} & 2017 & 2018 & 2019 & 2020 & 2021 \\
\hline $\begin{array}{l}\text { A1. Incrementar clientes por zonas geográficas en Lima y } \\
\text { provincias. } \\
\text { A2. Asistir a eventos que realiza la Cámara de Comercio de Lima } \\
\text { y provincias. } \\
\text { A3. Adquisición de bases de datos de futuros clientes } \\
\text { potenciales. }\end{array}$ & $\%$ de inversión del presupuesto & \begin{tabular}{|l|} 
A1 \\
A2 \\
A3 \\
\end{tabular} & 2017 & 2018 & 2019 & 2020 & 2021 \\
\hline $\begin{array}{l}\text { A1. Ampliación de portafolio especializado por canal. } \\
\text { A2. Promocionar los portafolios en ferias y eventos que se } \\
\text { realicen en Lima y provincias. } \\
\text { A3. Comunicar los atributos de del producto a los clientes. }\end{array}$ & $\%$ de inversión del presupuesto & \begin{tabular}{|l|} 
A1 \\
A2 \\
A3 \\
\end{tabular} & 2017 & 2018 & \begin{tabular}{|l|l|}
2019 \\
\end{tabular} & \begin{tabular}{|l|l}
2020 \\
\end{tabular} & 2021 \\
\hline
\end{tabular}

A1. Desarrollar matriz de productos mandatorio por cliente.

A2. Desarrollo y entrega de material publicitario.

A3. Presentación de beneficios del producto al cliente.

S/ $10,000.00$

A1. Desarrollo de software para apoyo a la generación de Pronóstico de ventas.

A2. Desarrollo de proceso de revisión de pronóstico de ventas por canal.

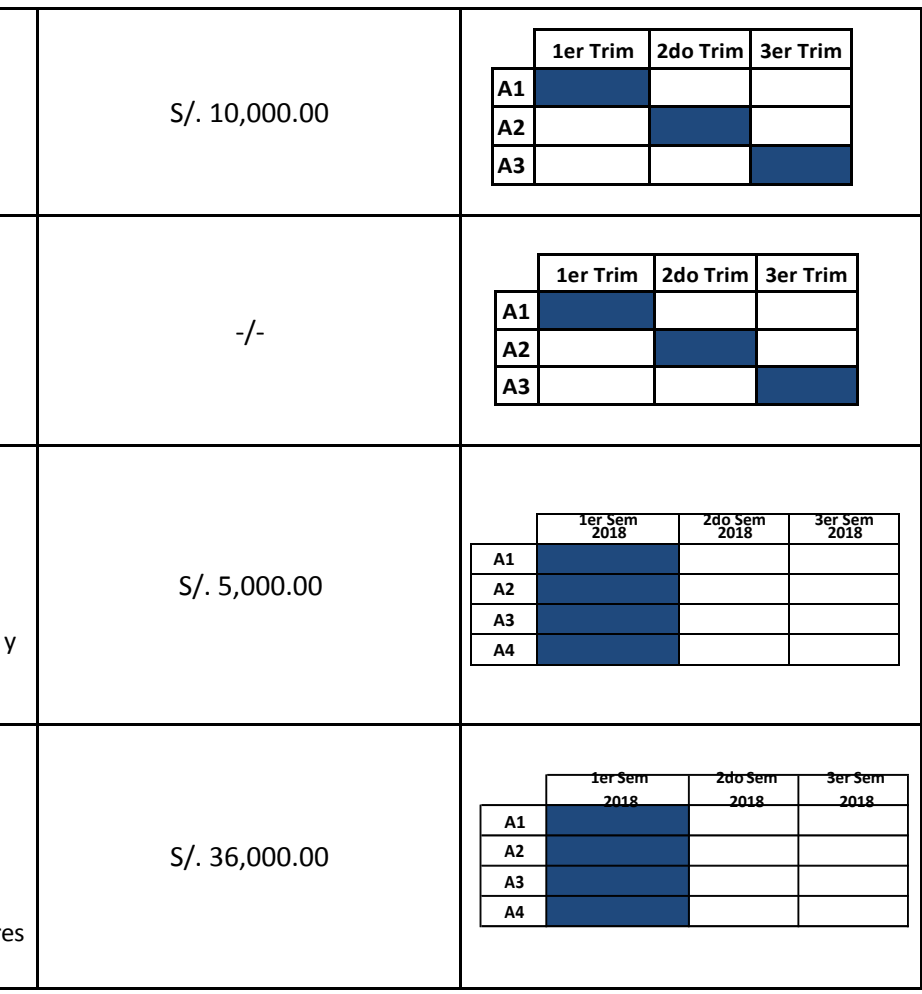

A1. Programar plan de capacitación bimestral a clientes. A2. Elaborar material informativo que se brindaran a los asistentes.

A3. Brindar asesoría continua luego de la capacitación.

A4. Visitar al personal post clases para conocer su experiencia y brindar oportunidades de mejoras.

A1. Contratar los servicios de una consultoría especializada en contrataciones del estado.

A2. Seguimiento continuo al cliente post consultoría.

A3. Comunicar al cliente modificaciones en la ley de contrataciones del estado.

A4. Comunicar a otros clientes las experiencias de distribuidores que llevaron la consultoría. 


\begin{tabular}{|c|c|c|c|c|c|c|c|}
\hline A1. Elaborar un proceso óptimo en almacenajes de los productos & \multirow[b]{2}{*}{$-/-$} & & 2017 & 2018 & & 2020 & 2021 \\
\hline $\begin{array}{l}\text { de la compañía. } \\
\text { A2. Alertar al área de compras los productos que estén cerca al } \\
\text { quiebre. }\end{array}$ & & $\begin{array}{ll}\text { A1 } \\
\text { A2 }\end{array}$ & 2017 & 2018 & 2019 & 2020 & 2021 \\
\hline \multirow{5}{*}{$\begin{array}{l}\text { A1. Elaborar un proceso óptimo en control de calidad de los } \\
\text { productos importados. } \\
\text { A2. Revisión aleatoria de productos puestos en destino. } \\
\text { A3. Generar reportes quincenales de los productos que } \\
\text { muestran fallas técnicas. } \\
\text { A4. Coordinar las notas de créditos que se generan a raíz de los } \\
\text { productos que llegan en malestado }\end{array}$} & \multirow{5}{*}{ S/. 3,000.00 } & & & & & & \\
\hline & & A1 & 2017 & 2018 & 2019 & 2020 & 2021 \\
\hline & & A2 & & & & & \\
\hline & & \begin{tabular}{l|l}
$\mathrm{A} 4$ \\
\end{tabular} & & & & & \\
\hline & & & & & & & \\
\hline
\end{tabular}

A1. Contratar los servicios de los mejores vendedores de la empresa matriz (Eterna Colombia) para capacitar.

A2. Adquisición de información de estudios de mercado de empresa confiables en el mercado.

A3. Evaluar el desempeño del personal capacitado.

A1. Contratar los servicios de una empresa consultora especialista en gestión comercial.

A2. Adquisición de información de estudios de mercado de empresa confiables en el mercado.

A3. Evaluar el desempeño del personal capacitado.

A4. Premiar al personal que obtuvo buenos resultados en base a la capacitación brindada.

A1. Capacitar al personal tanto en pre venta y post venta.

A2. Armar un equipo que se encargue de evaluar al personal de ventas a través de entrevistas a los clientes.

S/. $36,000.00$

A3. Premiar al personal que obtuvo buenos resultados en base a la entrevista con los clientes.

S/. 5,000.00
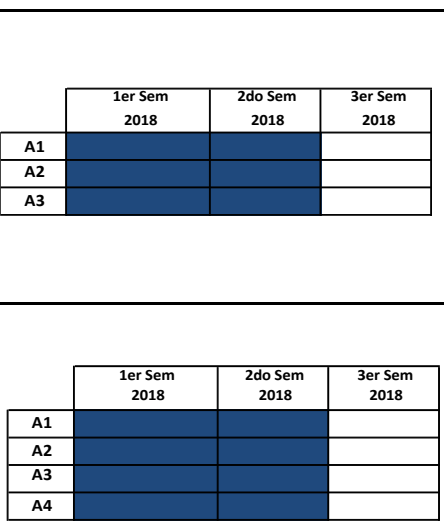


\section{Capítulo 10 Evaluación}

En este capítulo sepresenta la evaluación financiera, cualitativa y cuantitativa de la estrategia seleccionada considerando el proceso de implementación propuesto.

En la evaluación cualitativa, se toma como base los elementos propuestos por Rumelt que indica que una estrategia debe presentar congruencia, consonancia, factibilidad y ventaja. Mientras que la evaluación cuantitativa se realiza a través del método del valor presente neto y la tasa interna de retorno.

\subsection{Evaluación Cualitativa}

Una evaluación cualitativa de la estrategia es importante, considerando que existen algunos aspectos durante la implantación que tienen gran predominio subjetivo, por lo que se debe de evaluar los resultados esperados de la estrategia con evaluaciones críticas. En ese sentido, se hamejorado la información sobre el proceso de implementación, con planteamientos que de alguna manera obliguen lo más objetivamente posible examinar laestrategia.

Fred (2013), menciona lo siguiente: “La evaluación de la estrategia incluye tres actividades básicas: (a) examinar las bases subyacentes a la estrategia de una empresa, (b) comparar los resultados esperados con los resultados reales; y (c) tomar acciones correctivas para asegurarse de que el desempeño va de acuerdo con los planes". 
Del mismo modo, realizar una evaluación minuciosa de la estrategia es vital, más aún para una empresa como Eterna que ha venido reportando resultados negativos, ya que las dificultadespueden surgir con rapidez y el escenario puede cambiar drásticamente por los factores externos e internos.

\subsubsection{Criterios de Evaluación}

Para llevar a cabo el presente análisis, los autores han tomado en cuenta los criterios de Richard (2013) que menciona cuatro criterios que resultan útiles para evaluar una estrategia: "congruencia, consonancia, factibilidad y ventaja".

(a) Congruencia: la estrategia debe ser congruente con las políticas de la organización e integrar a las áreas.

- Los productos de Eterna están dirigidos a un segmento de mercado dispuesto a pagar más por un producto de calidad y diferenciado

- Eterna no busca entrar en una guerra de precios con productos de menor calidad que dejara márgenes muy pequeños o pérdidas.

- Eterna busca aumentar su participación de mercado con productos innovadores.

- Los productos de Eterna deben dejar un margen adecuado a la compañía con una adecuada política de control de gastos y costos. 
(b) Consonancia: la estrategia debe considerar una rápida respuesta a los factores internos y externos.

- Eterna debe adecuarse a las exigencias del mercado presentando una oferta innovadora y diferenciada

- Eterna debe de tener en cuanta las tendencias del mercado, buscando también el desarrollo de la categoría, nuevas oportunidades de usos de los productos y contribuir al cuidado personal de nuestros consumidores.

- La estrategia busca hacer crecer el mercado y su participación en este.

(c) Viabilidad: La estrategia debe ser objetiva y factible, la estrategia debe ser viable en términos de los recursos físicos, humanos y financieros de la empresa. La estrategia no debe acapara todos los recursos de la empresa.

- El ser fabricantes directos desde casa matriz en Colombia permite a la empresa la innovación de productos.

- La empresa puede manejar estándares apropiados de calidad y poder manejar los costos de los productos.

- Manejar con una línea de crédito amplia con casa matriz permite contar con el capital de trabajo adecuado.

(d) Ventaja: la estrategia debe fomentar y mantener las ventajas competitivas de la organización en el mercado nacional.

- La empresa tendrá un buen posicionamiento en el mercado que le permitirá ampliar sus ventas a nivel nacional

- Se fortalecerá la calidad de los productos y se deberá mejorar el proceso de atención a los clientes 


\subsubsection{Comparación de la estrategia con los criterios}

Tomando en cuenta los criterios expuestos, analizamos la estrategia para Eterna siguiendo la propuesta del presente plan:

- Congruencia: tanto la estrategia seleccionada "desarrollo de mercados", como la estrategia contingente "Reducción de gastos" están acordes a la visión de la empresa y también alinean a la misión. Por otro lado la empresa debe impartir una política de orden gerencial a partir de la puesta en inicio los objetivos estratégicos, tomando en cuenta que el cumplimiento de los objetivos es el resultado del trabajo de todas las áreas de la empresa.

- Consonancia: Asumiendo que las tendencias externas y supuestos que ya han sido examinados en el capítulo $\mathrm{V}$, pueden afectar a la estrategia de la empresa, se ha verificado que la propuesta adapta una asertividad al ambiente externo y los probables cambios que se presenten; toda esta información responde al análisis de las matrices evaluadas en los capítulos previos, que finalmente se resume en la matriz de selección de la estratégica.

- Viabilidad: si bien la estrategia plantea diversas iniciativas, todas estas son posibles para la implementación del plan estratégico. Debido al crecimiento actual y la proyección que tiene la empresa, la inversión y gastos generados por estas iniciativas son totalmente viables, tomando en cuenta además que por la etapa de crecimiento en que se encuentra Eterna.

- Ventaja: la estrategia propuesta reforzará la confianza en los colaboradores de la empresa, lo que generará también un clima laboral propicio que cambiará el escenario 
actual. Cabe mencionar que para la estrategia seleccionada, se establecen algunas iniciativas que reforzarán aspectos que maneja Eterna en relación a los competidores, así como variables que generan ventajas competitivas sostenibles para la industria de artículos de limpieza.

Tabla 60

Matriz de Rumelt

\begin{tabular}{llllll}
\hline & $\begin{array}{l}\text { Estrategias } \\
\text { Comerciales }\end{array}$ & Congruencia & Consonancia & Viabilidad & Ventaja \\
\hline $\mathrm{E}-1$ & $\begin{array}{l}\text { Penetración de } \\
\text { mercado }\end{array}$ & $\mathrm{Si}$ & $\mathrm{Si}$ & $\mathrm{Si}$ & $\mathrm{Si}$ \\
\hline $\mathrm{E}-2$ & $\begin{array}{l}\text { Desarrollo de } \\
\text { mercado }\end{array}$ & $\mathrm{Si}$ & $\mathrm{Si}$ & $\mathrm{Si}$ & $\mathrm{Si}$ \\
\hline $\mathrm{E}-3$ & $\begin{array}{l}\text { Reducción de } \\
\text { costos }\end{array}$ & $\mathrm{Si}$ & $\mathrm{Si}$ & $\mathrm{Si}$ & $\mathrm{Si}$ \\
\hline
\end{tabular}

\subsection{Evaluación Financiera de la Estrategia}

Para Aguirre (2014), la evaluación financiera de proyectos (EFP),se realiza con la finalidad de saber si la inversión en el proyecto deseado,genere en un futuro valor a los accionistas y estas cumplan sus expectativas.

La EFP incluye la evaluación financiera en sí misma, la formulación del proyecto y el análisis de riesgo de proyectos de inversión. Cada vez es más generalizada la EFP en las compañías; sin embargo,algunos pocos directivos no pueden visualizar los beneficios de 
realizarlas, brevemente se detallaran los beneficios de una evaluación financiera cuando una compañía quiere realizar un proyecto de inversión:

- Medir el potencial de creación de valor para los accionistas, la finalidad primaria de una compañía es generar el máximo valor para los accionistas y la EFP proyecta el valor esperado cuando se inicie la implementación de la estrategia, este valor es medido por el VAN.

- Incentiva la discusión de la estrategia y su modelo de negocio, Las diferentes áreas de una empresa propondrán sus estrategias el año en curso o próximo, estas serán evaluadas para saber si generan valor, contribuyen al medio ambiente y aumenta las ventas.

- Exigen a la empresa en esforzarse en analizar los potenciales beneficios y riesgos, se necesita ser evaluado financieramente, con esta acción se sabrá los beneficios, ventajas competitivas y riesgos que asume la empresa al implementar la estrategia.

La evaluación financiera de proyectos permitirá ver dos coas:

i) tomar la decisión de seguir o no con el proyecto ejecutado después de tener mayor conocimiento de los riesgos del proyecto

ii) Obliga a los involucrados en ser precavidos y creativos al manejar los riesgos que se presenten cuando el proyecto entre en ejecución. 


\subsubsection{Histórico de los estados financieros (situación actual y con la nueva estrategia)}

Los estados financieros históricos proporcionan información financiera referente a las operaciones, activos, pasivos y capital (patrimonio) de ejercicios terminados. Este tipo de informes nos muestra el resultado de las decisiones que tomaron los principales ejecutivos de la compañía hasta el último día del ejercicio y que se determina en el propio informe.

La información financiera fue proporcionado por el contador general de la empresa Ilko Perú S.A.C. bajo la autorización del Gerente general protagonista principal y colaborador eficaz del presente plan estratégico. A continuación e realiza un breve análisis de los estados financieros históricos (periodo 2014 y 215).

- En caja y bancos existe una variación de S/. - 396,048.37, lo que equivale en porcentaje al -76 \% respecto al año 2015 comparado con el 2014., debido a un manejo más eficiente de pago a proveedores extranjeros.

- Otras cuentas por cobrar muestra otro escenario hay una variación de S/.251,202.08, esto refleja un aumento de $14 \%$ comparando ambos años.

- En maquinarias y equipos se muestra un aumento de $\mathrm{S} / .83,192.00$, mostrando un crecimiento $156 \%$, esto se debe a compra de automóviles y equipos de cómputo.

- El total de activos aumento el 2015 reflejando en soles S/.355,919.19, aumentado un $6 \%$.

- Los pasivos sufrieron un aumento de S/.1,759,556.84, en porcentajes es $26 \%$,

- La utilidad fue negativa disminuyendo un 10\% (- S/.166,474.30), en el 2015.

- El capital se mantuvo igual que el año 2014, no experimentando cambio alguno. 
Tabla 61

Estados de resultados 2014, 2015

ETERNA PERU SA:

PROFIT AND LOSS STATEMENT FOR PERIOD FROM Jan ist UP TO Dicember 31 st, 2014

NET SALES

Net sales paños

Net sales Service

Others wert Sales

TOTAL Ner SALES

cost of SALES

Cost of sales

TOTAL COST OF SAEES

GROSS PROFIT

Gress proti

TOTAL GROSS PROFIT (LOSS)

OPERATNG EXPENSES

Operating expensel

TOTAL OPERATING EXPENSES

OPERATING PROFH (LOSS)

Financial incomeieverense:

Net Sates Properti, mashinery and equipment

cost Property, machinery and equipment

PROFT (LOSS) BEFORE TAX

Empliayees share in profics

Insometain

PROFIT (LOSS) FOR TNE RNANCIAI YEAR

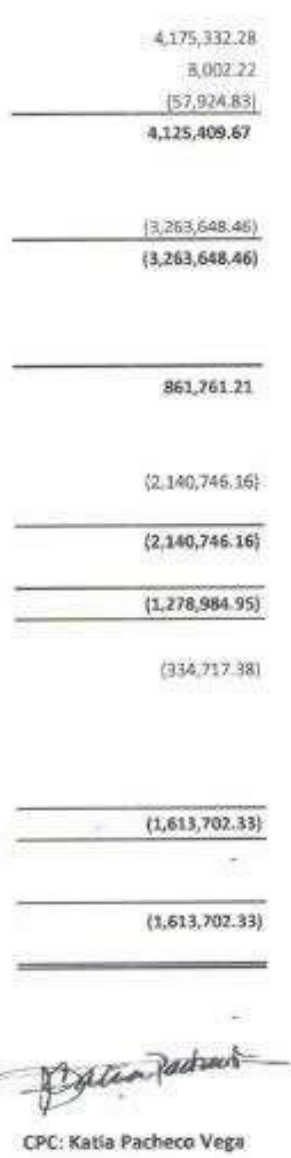

\section{ETERNA PERU SA}

PROFIT AND LOSS STATEMENT

FOR PERIOD FROM Jan 1st UP TO Dicember 31 st, 2015

nTo

NET SALES

Net sales Partios

Nat sales Service

Others Net Sains

TOTAL NET SALES

COST OF SALES

Cost of sates TOTAL Cost OF SALES

GROSS PROFIT

Gross profit

TOTAL GROSS PROFI LLOSS

OPERATING EXPENSES

Operating expentses

TOTALOPERATING EXPENSES

OPERATING PROFI (LOSS)

Financial incomejexperses

Net Salas Property, machinery and equiloment

Cost Property, machinery and equipment

PROFT (LOSS) BEFOAE TAX

Employees' stare in profies

tincome tax

PROFT (LOSS) FOR TME PNANCIAL YEAR

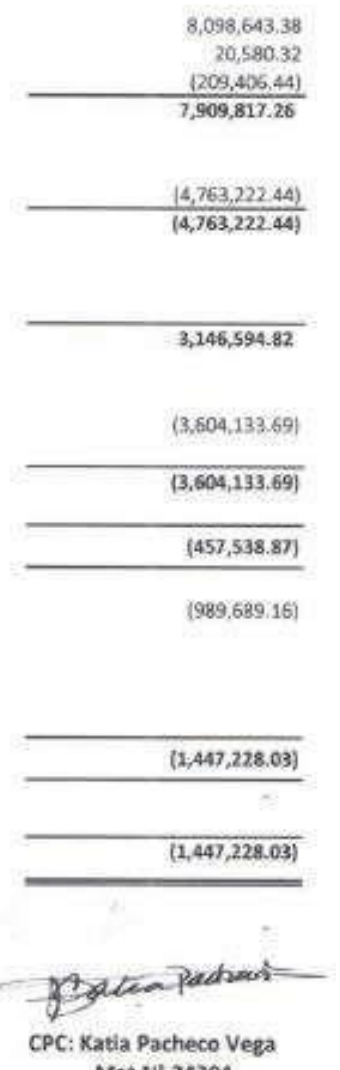


Tabla 62

Balance general 2014, 2015
BALANCE SHEET

UP TO Dicember 31 st, 2014 s/.

UABUITIES

\section{CURRENT LLABIUMIES}

CURRENT ASSETS

Exhibit

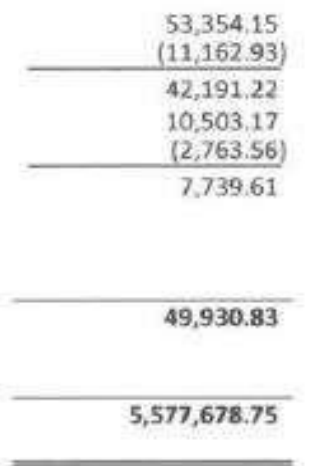

Cash and banks

Trade accounts receivable

Other accounts receivable

Miscellaneous Supplies

Deferred Changes

Prepaid expenses

Other assets

TOTAL CURRENT ASSETS

\section{NON CURRENT ASSEIS}

Property, machinery and equipment (less accumulated depreciation)

Intangible assets

(iess accumulated amortization)

$523,705.01$

$1,796,839.47$

$23,689.68$

$2,438,306.82$ 8.773 .96 $736,432.98$ $5,527,747.92$

No. 1

No. 2

No, 3

No. 4

No. 9

No. 5

TOTAL NON CURRENT ASSETS

TOTAL ASSETS

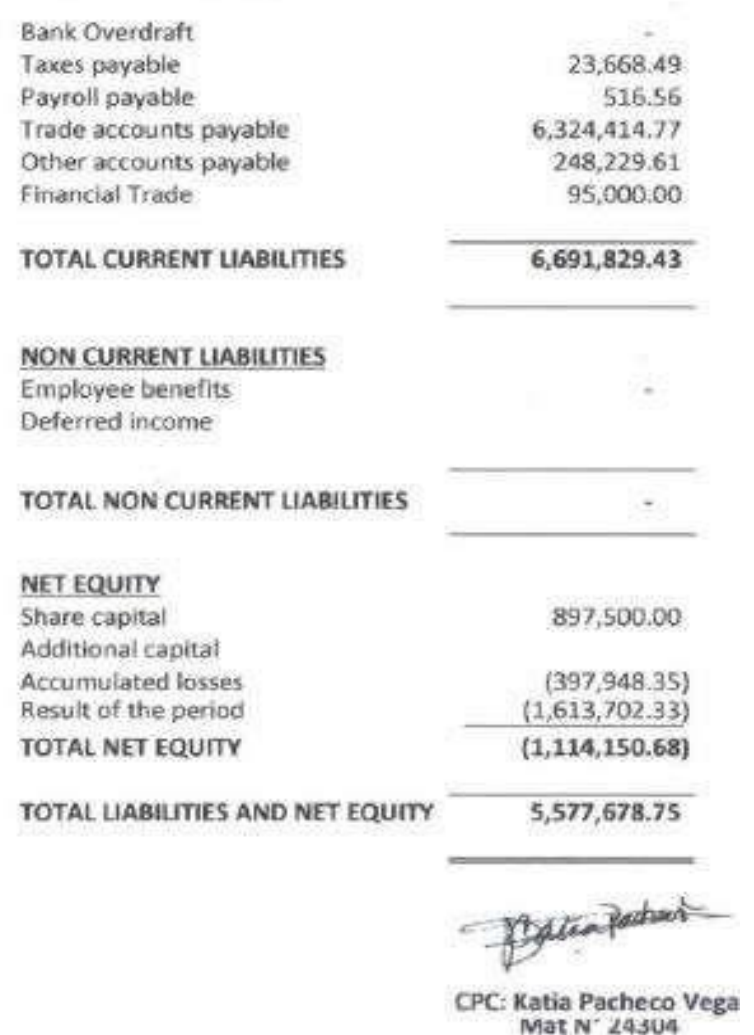

Katia Pacheco Vegat
Mat N' 24304 
BALANCE SHEET

UP TO Dicember 31 st, 2015

s/.

\section{ASSETS}

\section{CURRENT ASSETS}

Cash and banks

Trade accounts receivable

Other accounts receivable

Miscellaneous Supplies

Deferred Changes

Prepaid expenses

Other assets

TOTAL CURRENT ASSETS

\section{NON CURRENT ASSETS}

Property, machinery and equipment

(less accumulated depreciation)

Intangible assets

(less accumulated amortization)

TOTAL NON CURRENT ASSETS

TOTAL ASSETS
Exhibit

LABIIITIES

\section{CURRENT LIABILTIES}

Bank Overdraft

Taxes payable

Payroll payable

Trade accounts payable

Other accounts payable

$2,048,041.55$

No. 2

No. 4

$2,915,476.50$

170.597 .09

No. 9

$539,092.00 \quad$ No. 5

$5,813,605.27$

Financial Trade

Other accounts payable

TOTAL CURRENT LIABIUTIES

5).

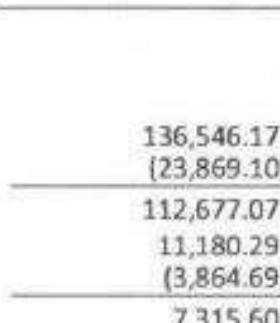

No. 6
$119,992.67$

$5,933,597.94$

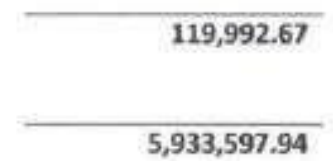

\section{NOALILITIES}

Employee benefits

Deferred income

\section{TOTAL NON CURRENT LIABILITIES}

\section{NFT EQUITY}

Share capital

Additional capital

Accumulated losses

Result of the period

TOTAL NET EQUITY

TOTAL. LIABILTIES AND NET EQUITY<smiles>CC(Cl)(Cl)C(C)(Cl)Cl</smiles>

CPC: Katia Pacheco-Ves mat N L4sud

$(1,968,060.30)$

$(1,447,228.03)$

$(2,517,788.33)$ 94

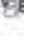

$4,933,135.01$

$82,990.51$

$3,394,843.38$

$8,451,386.27$ 


\subsubsection{Estado de resultados (situación actual y con la nueva estrategia)}

Para obtener el flujo de efectivo de la empresa considerando que continúa sin implementar la estrategia, las ventas se proyectan a partir de las ventas históricas de la empresa, así como los costos y gastos que se incurren en dicho periodo. La tasa de crecimiento esperada en las ventas anuales es de $2 \%$.

En la tabla 63, se muestra el estado de resultados proyectado sin la estrategia para los siguientes cinco (05) años, también se puede observar que el ritmo de crecimiento se mantiene en un nivel bajo generando perdida para la empresa en el primer año y mínimas utilidades en el siguiente; a continuación se explican los siguientes puntos:

- Las ventas en el periodo 2016 se mantienen, es a partir del año 2017 donde la compañía empieza a crecer levemente en un $2 \%$, este crecimiento se mantiene de manera constante para los ejercicios 2018, 2019, 2020 y 2021. El resultado de este crecimiento fue analizado, estructurado y argumentado por el Gerente General de Eterna Perú S.A., Jorge Gagliardo, el sustento se basa en sus treinta años que viene desempeñando como ejecutivo en las principales empresas de limpieza en el mercado nacional.

- Los costos de ventas, gastos administrativos y gastos de ventas se obtienen del promedio de los años 2014, 2015 y 2016. También los autores detallan que los costos de ventas equivaldrían en $60 \%$ de las ventas anuales de la compañía. 
- Los gastos administrativos se mantienen en un $15 \%$, luego se disminuye $3 \%$ debido a una breve reducción de personal, luego se procede a aumentar para los últimos dos (02) años.

Tabla 63

Estados de Resultados sin estrategia

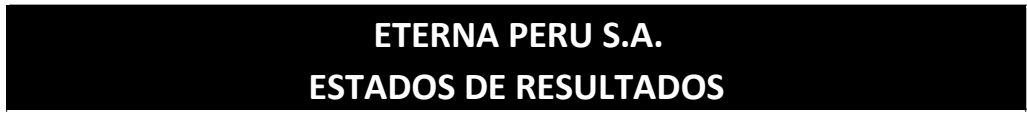

\begin{tabular}{lccccc} 
& \multicolumn{5}{c|}{ SIN ESTRATEGIA } \\
\cline { 2 - 6 } & $\mathbf{2 0 1 7}$ & $\mathbf{2 0 1 8}$ & $\mathbf{2 0 1 9}$ & $\mathbf{2 0 2 0}$ & $\mathbf{2 0 2 1}$ \\
Ventas Netas & $7,588,552$ & $7,740,323$ & $7,895,129$ & $8,053,032$ & $8,214,093$ \\
Costo de ventas & $4,553,131$ & $4,644,194$ & $4,737,078$ & $4,831,819$ & $4,928,456$ \\
\hline Utilidad bruta & $\mathbf{3 , 0 3 5 , 4 2 1}$ & $\mathbf{3 , 0 9 6 , 1 2 9}$ & $\mathbf{3 , 1 5 8 , 0 5 2}$ & $\mathbf{3 , 2 2 1 , 2 1 3}$ & $\mathbf{3 , 2 8 5 , 6 3 7}$ \\
\hline
\end{tabular}

Gastos Operacionales:

Gastos administrativos

$1,138,283 \quad 1,161,048 \quad 1,184,269 \quad 1,207,955 \quad 1,232,114$

Gastos de ventas

$2,276,566 \quad 1,548,065 \quad 1,579,026 \quad 1,610,606 \quad 1,642,819$

\begin{tabular}{lrrrrr}
\hline Amortizaciones & 46,621 & 46,621 & 46,621 & 46,621 & 46,621 \\
\hline Utilidad operativa & $-426,049$ & 340,395 & 348,135 & 356,030 & 364,083
\end{tabular}

Otros Ingresos y Egresos:

\begin{tabular}{lrrrrr} 
Ingresos Financieros & 18,000 & 18,000 & 18,000 & 18,000 & 18,000 \\
Gastos flnancieros & 200,000 & 200,000 & 200,000 & 200,000 & 200,000 \\
Diferencia en Cambio, Neta & 15,177 & 15,481 & 15,790 & 16,106 & 16,428 \\
\hline Uilidad antes de Impuestos & $-623,226$ & $\mathbf{1 4 2 , 9 1 4}$ & $\mathbf{1 5 0 , 3 4 5}$ & $\mathbf{1 5 7 , 9 2 4}$ & $\mathbf{1 6 5 , 6 5 5}$ \\
\hline Impuesto 28\% & - & 40,016 & 42,097 & 44,219 & 46,383 \\
\hline Utilidad (Pérdida) Neta & $\mathbf{- 6 2 3 , 2 2 6}$ & $\mathbf{1 0 2 , 8 9 8}$ & $\mathbf{1 0 8 , 2 4 8}$ & $\mathbf{1 1 3 , 7 0 5}$ & $\mathbf{1 1 9 , 2 7 2}$ \\
\hline
\end{tabular}


- La utilidad neta de la compañía muestra utilidad a excepción del primer año donde se puede ver una pérdida de 623,226.00 soles.

- Los ingresos financieros son consecuencia de una inyección de capital por parte de la matriz Eterna Colombia, la cual es el principal financista de la compañía en Perú; los bancos representan un poco protagonismo en los temas financieros de la empresa.

Para la proyección de los estados financieros para la empresa considerando la implantación de la estrategia se toma en cuenta los siguientes supuestos

- Crecimiento anual de las ventas: $10 \%$ que es consistente con los objetivos estratégicos de la empresa y con el crecimiento esperado del mercado.

- Rentabilidad esperada para los próximos 5 años: $15 \%$ que ésta basado en los objetivos estratégicos de la empresa.

- Costos de implementación de la estrategia: 131,000 soles que resultan de la ejecución de la estrategia.

En la Tabla 64, se muestra el estado de resultados proyectado con la nueva estrategia para los siguientes cinco (05) años, también detallan los siguientes se puede ver que el ritmo de crecimiento para el año 2017 considerado es de 10\% comparado con los resultados negativo que presenta el 2016. Los cinco años siguientes semantiene un crecimiento promedio de $10 \%$, este sería el escenario optimista según el análisis realizado. A continuación se explican los siguientes puntos: 
- Las ventas en el periodo 2016 se mantienen, es a partir del año 2017 donde la compañía empieza a crecer en un $10 \%$, este crecimiento se da debido a la mayor demanda y al plan agresivo de ventas, generadas gracias al plan estratégico de la compañía. El resultado de este crecimiento fue analizado, estructurado y argumentado por el Gerente General de Eterna Perú S.A., Jorge Gagliardo, el sustento se basa en sus treinta años que desempeña como ejecutivo en las principales empresas de limpieza en el mercado nacional.

- Los costos de ventas, gastos administrativos y gastos de ventas se obtienen del promedio de los años 2014, 2015 y 2016. También los autores detallan que los costos de ventas con el escenario optimo viene disminuyendo en $1 \%$ a partir del periodo 2018; estas disminuciones de debe a las estrategias de reducción de costos que se pueden visualizar en el BSG de la compañía.

- Los gastos administrativos se mantienen en un $15 \%$, luego se disminuye $3 \%$ debido a una breve reducción de personal y otros gastos, luego se procede a aumentar para los últimos dos (02) años.

- La utilidad neta de la compañía viene en aumento en los últimos años (en promedio un $10 \%$ ) cerrando el año 2021 con un monto positivo de S/. 526,269 soles de utilidad.

- El EBITDA de la empresa viene en aumento, esto vuelve más atractiva a la empresa ante las principales entidades financieras, grandes clientes instituciones y accionistas. 
Tabla 64

Estados de Resultados con estrategia

\begin{tabular}{|c|c|c|c|c|}
\hline \multicolumn{5}{|c|}{$\begin{array}{l}\text { ETERNA PERU S.A. } \\
\text { STADOS DE RESULTADOS }\end{array}$} \\
\hline \multicolumn{5}{|c|}{ CON ESTRATEGIA } \\
\hline 2017 & 2018 & 2019 & 2020 & 2021 \\
\hline $8,183,733$ & $9,002,106$ & $9,902,316$ & $10,892,548$ & $11,981,803$ \\
\hline $4,910,240$ & $5,401,263$ & $5,941,390$ & $6,535,529$ & $7,189,082$ \\
\hline $3,273,493$ & $3,600,842$ & $3,960,927$ & $4,357,019$ & $4,792,721$ \\
\hline
\end{tabular}

Gastos Operacionales:

$\begin{array}{llllll}\text { Gastos administrativos } & 1,227,560 & 1,350,316 & 1,485,347 & 1,633,882 & 1,797,270 \\ \text { Gastos de ventas } & 1,636,747 & 1,800,421 & 1,980,463 & 2,178,510 & 2,396,361\end{array}$

\begin{tabular}{lrrrrr}
\hline Amortizaciones & $\mathbf{7 2 , 8 2 1}$ & $\mathbf{7 2 , 8 2 1}$ & $\mathbf{7 2 , 8 2 1}$ & $\mathbf{7 2 , 8 2 1}$ & $\mathbf{7 2 , 8 2 1}$ \\
\hline Utilidad operativa & $\mathbf{3 3 6 , 3 6 5}$ & $\mathbf{3 7 7 , 2 8 4}$ & $\mathbf{4 2 2 , 2 9 5}$ & $\mathbf{4 7 1 , 8 0 6}$ & $\mathbf{5 2 6 , 2 6 9}$
\end{tabular}

Otros Ingresos y Egresos:

\begin{tabular}{|c|c|c|c|c|c|}
\hline Ingresos Financieros & 18,000 & 18,000 & 18,000 & 18,000 & 18,000 \\
\hline Gastos fInancieros & 300,000 & 300,000 & 300,000 & 300,000 & 300,000 \\
\hline Diferencia en Cambio, & 16,367 & 18,004 & 19,805 & 21,785 & 23,964 \\
\hline $\begin{array}{l}\text { Uilidad antes de } \\
\text { Impuestos }\end{array}$ & 37,998 & 77,280 & 120,490 & 168,021 & 220,305 \\
\hline Impuesto $28 \%$ & 10,639 & 21,638 & 33,737 & 47,046 & 61,685 \\
\hline Utilidad (Pérdida) Neta & 27,358 & 55,641 & 86,753 & 120,975 & 158,620 \\
\hline
\end{tabular}

\subsubsection{Balance general (situación actual y con la nueva estrategia)}

En la Tabla 65,se muestra el balance general sin estrategia proyectado al año 2021, aquí se aporecia los siguiente: 
- El capital social de la compañía (Capital que los socios de una empresa aportan a esta para ejecutar su actividad comercial), no muestra aumento y disminución en los proximos cinco (05) años, S/. 4,243,291.00 soles.

- El pasivo (todaslas deudas que la empresa posee frente a terceros como bancos, proveedores u otros acreedores), viene en incremento conforme van ejecutandose los ejercicios anuales, mientras que los activos (los bienes, derechos y otros recursos controlados económicamente por la empresa) se mantienen constante sin un incremente que genere un beneficios económico para la compañía.

- No cuenta con reservas patrimoniales (parte del capital contable o de la participación total de los accionistas en una empresa, consistente en partidas que no se encuentran utilizables para su recogimiento por parte de los propietarios), ya que es una filial de la sede principal Eterna Colombia; ellos son los principales dueños.

- Los resultados del ejercicio es la utilidad neta de la estados de resultados de Eterna Colombia sin estrategia. 
Tabla 65

Balance General sin estrategia

ETERNA PERU S.A.

ESTADOS DE RESULTADOS

Sin Estrategia

\begin{tabular}{|l|r|r|r|r|r|r|}
\hline & $\mathbf{2 0 1 7}$ & $\mathbf{2 0 1 8}$ & $\mathbf{2 0 1 9}$ & $\mathbf{2 0 2 0}$ & $\mathbf{2 0 2 1}$ \\
ACTIVO & 38,654 & 41,244 & 39,546 & 39,774 & 42,455 \\
\hline Caja y Bancos & $1,849,972$ & $2,582,047$ & $3,352,645$ & $3,781,671$ & $4,023,723$ \\
\hline Cuentas Cobrar Comerciales & 15,000 & 16,500 & 18,150 & 19,965 & 21,962 \\
\hline Otras Cuentas por Cobrar & $2,513,497$ & $2,262,147$ & $1,868,529$ & $1,859,799$ & $2,078,741$ \\
\hline Existencias & 862,600 & 580,354 & 522,318 & 470,086 & 423,078 \\
\hline Gastos Pagados por Anticipado & $\mathbf{5 , 2 7 9 , 7 2 3}$ & $\mathbf{5 , 4 8 2 , 2 9 2}$ & $\mathbf{5 , 8 0 1 , \mathbf { 1 8 9 }}$ & $\mathbf{6 , 1 7 1 , 2 9 5}$ & $\mathbf{6 , 5 8 9 , 9 5 8}$ \\
\hline
\end{tabular}

ACTINO NO CORRIENTE

\begin{tabular}{|c|c|c|c|c|c|}
\hline Inmuebles, maq. y equipo & 154,493 & 154,493 & 154,493 & 154,493 & 154,493 \\
\hline Depreciación acumulada & $-51,178$ & $-64,832$ & $-78,487$ & $-92,142$ & $-105,797$ \\
\hline Intangibles & 21,674 & 21,674 & 21,674 & 21,674 & 21,674 \\
\hline Amortización Acumulada & $-6,100$ & $-7,218$ & $-8,336$ & $-9,454$ & $-10,572$ \\
\hline Activo No Corriente & 118,889 & 104,117 & 89,344 & 74,571 & 59,798 \\
\hline TOTAL ACTIVOS & $5,398,612$ & $5,586,409$ & $5,890,533$ & $6,245,866$ & $6,649,756$ \\
\hline
\end{tabular}

PASIVO Y PATRIMONIO

PASIVO CORRIENTE

\begin{tabular}{|c|c|c|c|c|c|}
\hline Sobregiro Bancario & - & - & - & - & - \\
\hline Tributos por Pagar & 24,828 & 27,310 & 30,041 & 33,046 & 36,350 \\
\hline Remuneraciones por Pagar & 40,924 & 45,017 & 49,518 & 54,470 & 59,917 \\
\hline Cuentas por Pagar Comerciales & $3,167,172$ & $3,325,531$ & $3,591,807$ & $3,950,988$ & $4,346,087$ \\
\hline Obligaciones Financieras & $2,667,835$ & $2,587,800$ & $2,510,166$ & $2,384,657$ & $2,265,424$ \\
\hline TOTAL PASIVO & $5,900,759$ & $5,985,657$ & $6,181,533$ & $6,423,161$ & $6,707,779$ \\
\hline
\end{tabular}

\section{PATRIMONIO}

\begin{tabular}{|c|c|c|c|c|c|}
\hline Capital Social & $4,243,291$ & $4,243,291$ & $4,243,291$ & $4,243,291$ & $4,243,291$ \\
\hline \multicolumn{6}{|l|}{ Reserva Legal } \\
\hline Resultados Acumulados & $-4,122,211$ & $-4,745,437$ & $-4,642,539$ & $-4,534,291$ & $-4,420,585$ \\
\hline Resultados del Ejercicios & $-623,226$ & 102,898 & 108,248 & 113,705 & 119,272 \\
\hline TOTAL PATRIMONIO & $-502,146$ & $-399,248$ & $-291,000$ & $-177,294$ & $-58,022$ \\
\hline \multicolumn{6}{|c|}{-} \\
\hline TOTAL PASIVO Y PATRIMONIO & $5,398,612$ & $5,586,409$ & $5,890,533$ & $6,245,867$ & $6,649,756$ \\
\hline
\end{tabular}


En la tabla 66,se muestra el balance general con estrategia proyectado al año 2021, aquí se aporecia los siguiente:

- El capital social de la compañía, no muestra aumento y disminución en los proximos cinco (05) años, S/. 4,243,291.00 soles, se mantiene igual que el balance sin estrategia.

- El pasivo viene disminuyendo conforme van ejecutandose los ejercicios anuales al final del 2021 disminye en un 50\% comparado con el periodo 2017, mientras que los activos se mantienen en incremento ya que se esta aplicando la estrategia, generando beneficios económicos para la compañía.

- No cuenta con reservas patrimoniales ya que es una filial de la sede principal Eterna Colombia; ellos son los principales dueños.

- Los resultados del ejercicio es la utilidad neta de la estados de resultados de Eterna Colombia con estrategia. 
Tabla 66

Balance General con estrategia

ETERNA PERU S.A.

ESTADOS DE RESULTADOS

Con Estrategia

\begin{tabular}{|c|c|c|c|c|c|}
\hline & 2017 & 2018 & 2019 & 2020 & 2021 \\
\hline \multicolumn{6}{|l|}{ ACTIVO } \\
\hline Caja y Bancos & 250,000 & 475,000 & 502,500 & 532,750 & 366,025 \\
\hline Cuentas Cobrar Comerciales & $1,987,256$ & $2,022,756$ & $2,261,806$ & $1,889,848$ & $2,483,725$ \\
\hline Otras Cuentas por Cobrar & 11,946 & 12,543 & 13,170 & 14,487 & 13,895 \\
\hline Existencias & $1,538,794$ & 43,377 & 342,481 & 624,094 & 185,842 \\
\hline Gastos Pagados por Anticipado & 195,362 & 197,316 & 201,262 & 204,300 & 275,690 \\
\hline Activo Corriente & $3,983,358$ & $2,750,992$ & $3,321,218$ & $3,265,478$ & $3,325,177$ \\
\hline
\end{tabular}

ACTINO NOCORRIENTE

\begin{tabular}{|c|c|c|c|c|c|}
\hline Inmuebles, maq. y equipo & 154,493 & 154,493 & 154,493 & 154,493 & 154,493 \\
\hline Depreciación acumulada & $-51,178$ & $-64,832$ & $-78,487$ & $-92,142$ & $-105,797$ \\
\hline Intangibles & 21,674 & 21,674 & 21,674 & 21,674 & 21,674 \\
\hline Amortización Acumulada & $-6,100$ & $-7,218$ & $-8,336$ & $-9,454$ & $-10,572$ \\
\hline Activo No Corriente & 118,889 & 104,117 & 89,344 & 74,571 & 59,798 \\
\hline TOTAL ACTIVOS & $4,102,246$ & $2,855,109$ & $3,410,562$ & $3,340,049$ & $3,384,975$ \\
\hline
\end{tabular}

\section{PASIVO Y PATRIMONIO}

PASIVO CORRIENTE

\begin{tabular}{|c|c|c|c|c|c|}
\hline Sobregiro Bancario & - & - & - & - & - \\
\hline Tributos por Pagar & 27,571 & 24,571 & 21,571 & 20,296 & 19,893 \\
\hline Remuneraciones por Pagar & 60,283 & 23,000 & 21,000 & 16,000 & 13,000 \\
\hline Cuentas por Pagar Comerciales & $2,365,954$ & $1,559,645$ & $1,842,159$ & $1,733,446$ & $1,657,304$ \\
\hline Obligaciones Financieras & $1,500,000$ & $1,043,813$ & $1,235,000$ & $1,158,500$ & $1,124,350$ \\
\hline TOTAL PASIVO & $3,953,808$ & $2,651,029$ & $3,119,730$ & $2,928,241$ & $2,814,547$ \\
\hline
\end{tabular}

PATRIMONIO

\begin{tabular}{|c|c|c|c|c|c|}
\hline Capital Social & $4,243,291$ & $4,243,291$ & $4,243,291$ & $4,243,291$ & $4,243,291$ \\
\hline \multicolumn{6}{|l|}{ Reserva Legal } \\
\hline Resultados Acumulados & $-4,122,212$ & $-4,094,853$ & $-4,039,212$ & $-3,952,459$ & $-3,831,484$ \\
\hline Resultados del Ejercicios & 27,358 & 55,641 & 86,753 & 120,975 & 158,620 \\
\hline TOTAL PATRIMONIO & 148,438 & 204,079 & 290,832 & 411,807 & 570,427 \\
\hline TOTAL PASIVO Y PATRIMONIO & $4,102,246$ & $2,855,108$ & $3,410,562$ & $3,340,048$ & $3,384,974$ \\
\hline
\end{tabular}




\subsubsection{Flujo de efectivo}

La Tabla 67, nos presenta el flujo de efectivo de la compañía sin estrategia, los autores muestran los siguientes detalles:

- Las Actividades de Operación los dos primeros años tuvo un crecimiento elevado tanto remuneraciones, pagos a proveedores, pago de tributos y gastos administrativos y de ventas. Sin las mejoras administrativas a partir del año 2017 estos gastos operacionales continúan en aumento generando altos costos desfavorables para la compañía.

- Las Actividades de Inversión se muestran en los dos primeros de años, y a partir del año 2017 no tuvieron ningún tipo de inversión.

- Las Actividades de Financiamiento se mantienen los años siguientes con financiamiento bancarios. 
Tabla 67

Flujo sin estrategia

INVERSIÓN INICIAL

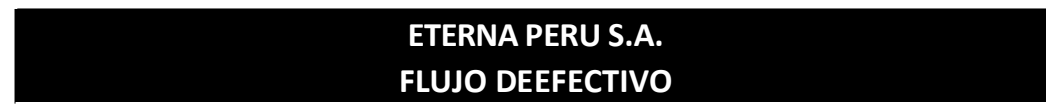

VENTAS
COSTOS VARIABLES
MARGEN DE CONTRIBUCIÓN

GASTOS FIJOS

DEPRECIACION

INTERESES

UTILIDAD DE OPERACIÓN (EBIT)

IMPUESTO A LA RENTA 28\%

UTILIDAD NETA

(+) DEPRECIACIÓN

FLUJO DE CAJA

\begin{tabular}{|c|c|c|c|c|}
\hline \multicolumn{5}{|c|}{ SIN ESTRATEGIA } \\
\hline 2017 & 2018 & 2019 & 2020 & 2021 \\
\hline $7,588,552$ & $7,740,323$ & $7,895,129$ & $8,053,032$ & $8,214,093$ \\
\hline$=\underline{4}, \underline{553}, \underline{13} 1$ & $\underline{4,644}, 194$ & $\underline{4}, \underline{737}, \underline{078}$ & $\underline{4}, \underline{831}, \underline{819}$ & $\underline{4}, 928,456$ \\
\hline$=3,035, \overline{421}$ & $\underline{3}, 096, \underline{129}$ & $\underline{3}, \underline{158}, \overline{052}$ & $\underline{3}, 221,213$ & $\underline{\mathbf{3}}, \mathbf{2 8 5}, \underline{637}$ \\
\hline $3,414,848$ & $2,709,113$ & $2,763,295$ & $2,818,561$ & $2,874,932$ \\
\hline 46,621 & 46,621 & 46,621 & 46,621 & 46,621 \\
\hline$=200,000$ & $\underline{200}, \underline{000}$ & $\underline{200}, \underline{000}$ & $\underline{200}, \underline{000}$ & $\underline{200}, \underline{000}$ \\
\hline$-626,049$ & $\underline{140}, \underline{395}$ & $\underline{148, \underline{135}}$ & $\underline{156}, \underline{030}$ & $\underline{164}, \underline{083}$ \\
\hline- & $=40,016$ & $\underline{42,}, \underline{097}$ & $\underline{44, \underline{219}}$ & $\underline{46}, \underline{38} 3$ \\
\hline$-626,049$ & $100, \underline{379}$ & $\underline{106}, \underline{039}$ & $\underline{111}, \underline{812}$ & $\underline{117}, \overline{700}$ \\
\hline 46,621 & 46,621 & 46,621 & 46,621 & 46,621 \\
\hline$-579, \underline{428}$ & $\underline{147,000}$ & $\underline{152,660}$ & 158,433 & $\underline{164,321}$ \\
\hline
\end{tabular}




\subsubsection{Proyección de flujos con la nueva estrategia}

Se muestra los nuevos flujos de efectivo, esto representa las entradas de efectivo y los desembolsos de dinero por parte de la empresa y nos muestra la estimación de la capacidad de generación de caja que la empresa poseerá en el futuro.

La Tabla 68, nos presenta el flujo de efectivo de la compañía, los autores muestran los siguientes detalles:

- Las Actividades de Operación los dos primeros años tuvo un crecimiento elevado tanto remuneraciones, pagos a proveedores, pago de tributos y gastos administrativos y de ventas. Gracias a las mejoras administrativas a partir del año 2017 estos gastos operacionales tuvieron una disminución considerable y favorable para la empresa.

- Las Actividades de Inversión se muestran en los dos primeros de años, y a partir del año 2017 no tuvieron ningún tipo de inversión gracias a las mejoras administrativas.

- Las Actividades de Financiamiento se mantienen los años siguientes con financiamiento bancarios. 
Tabla 68

Flujo con estrategia

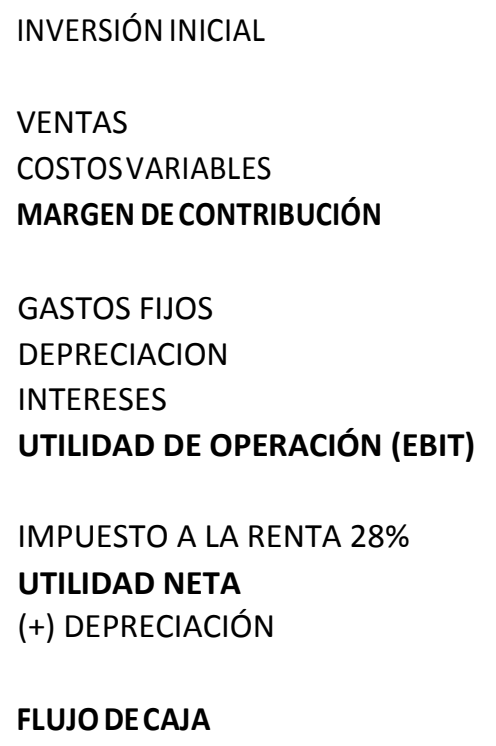

\begin{tabular}{|c|c|c|c|c|c|}
\hline & & & $\begin{array}{l}\text { NAPERUS. } \\
\text { DEEEFCTII }\end{array}$ & & \\
\hline & & & ESTRATEG & & \\
\hline & 2017 & 2018 & 2019 & 2020 & 2021 \\
\hline 131,000 & & & & & \\
\hline & $8,183,733$ & $9,002,106$ & $9,902,316$ & $10,892,548$ & $11,981,803$ \\
\hline & $=\underline{4}, \underline{910}, \underline{240}$ & $\underline{5}, \underline{401}, \underline{26} 3$ & $\underline{5}, \underline{941}, \underline{390}$ & $\underline{6}, \underline{535}, \underline{529}$ & $\underline{7}, \underline{189}, \underline{082}$ \\
\hline & $=\underline{3}, 273, \underline{493}$ & $\underline{3}, \underline{600}, \underline{842}$ & $\underline{3}, \underline{960}, \underline{927}$ & $4, \underline{357}, 019$ & $\underline{4}, \underline{792}, \underline{721}$ \\
\hline & $2,864,306$ & $3,150,737$ & $3,465,811$ & $3,812,392$ & $4,193,631$ \\
\hline & 72,821 & 72,821 & 72,821 & 72,821 & 72,821 \\
\hline & $\underline{300}, 000$ & $\underline{300}, \underline{000}$ & $\underline{300}, \underline{000}$ & $\underline{300}, 000$ & $\underline{300}, \underline{000}$ \\
\hline & $=\underline{36}, \underline{365}$ & $\underline{77}, \underline{284}$ & $\underline{122}, \underline{295}$ & $\underline{171}, \underline{806}$ & $\underline{226}, \underline{269}$ \\
\hline & $=\underline{10}, \underline{639}$ & $\underline{21}, \underline{638} 8$ & $\underline{33}, \underline{737}$ & $\underline{47}, \underline{046}$ & $\underline{61}, \underline{68} 5$ \\
\hline & $=\underline{25}, \underline{726}$ & $\underline{55}, \underline{646}$ & $\underline{88}, \underline{557}$ & $\underline{124, \underline{760}}$ & $\underline{164, \underline{583}}$ \\
\hline & 72,821 & 72,821 & 72,821 & 72,821 & 72,821 \\
\hline$-131,000=$ & $98, \underline{547}$ & $\underline{128,467}$ & $161, \underline{379}$ & $197, \underline{582}$ & $\underline{237,405}$ \\
\hline
\end{tabular}




\subsubsection{Evaluación Financiera (VAN, TIR y ratios financieros)}

\section{Flujos sin estrategia}

Se proyectan a partir de las ventas históricas de la empresa, así como los costos y gastos que se incurren en dicho periodo. La tasa de crecimiento esperada en las ventas anuales es de $2 \%$.

\section{Flujo con estrategia}

Para la proyección de los estados financieros se consideran los siguientes supuestos:

- Crecimiento anual de las ventas: $10 \%$ que es consistente con los objetivos estratégicos de la empresa y con el crecimiento esperado del mercado.

- Rentabilidad esperada para los próximos 5 años: $15 \%$ que ésta basado en los objetivos estratégicos de la empresa.

- Costos de implementación de la estrategia: 167,000 soles que resultan de la ejecución de la estrategia.

Para el cálculo del VAN se consideró los siguientes valores:

IR:

TEA anual:

(Rf) Tasa libre de riesgo:

(Rm) Prima de mercado:

(R país) Riesgo país:

Beta (productos domésticos):

Beta desapalancado:
$28.00 \%$

$25.00 \%$

$2.34 \%$

$7.08 \%$

$1.33 \%$

0.85 (promedio de los tres últimos años)

0.69 (http://www.betasdamodaran.com/betas-

damodaran-2017/) 


\section{Cálculo del VAN}

$\begin{array}{cc}\begin{array}{c}\text { FCE } \\ 0131,000\end{array} & \begin{array}{c}\text { Valor Actual } \\ 131,000\end{array} \\ 198,547 & 87,226 \\ 2128,467 & 100,646 \\ 3161,379 & 111,906 \\ 4197,582 & 121,271 \\ 5237,405 & 128,974 \\ \text { VAN } & \mathbf{4 1 9 , 0 2 3}\end{array}$

El valor mayor que cero obtenido nos indica que es conveniente implementar la estrategia de desarrollo de mercado en la empresa ETERNA Perú SAC. 
Tabla 69

Ratios financieros de Eterna con la nueva estrategia

ETERNA PERU S.A.

RATIOS FINANCIEROS

\begin{tabular}{|c|c|c|c|c|c|}
\hline & \multicolumn{5}{|c|}{ Con Estrategia } \\
\hline & 2017 & 2018 & 2019 & 2020 & 2021 \\
\hline \multicolumn{6}{|l|}{ RATIOS DE LIQUIDEZ } \\
\hline Capital de Trabajo & 29,550 & 99,963 & 201,488 & 337,237 & 510,630 \\
\hline Liquidez Corriente & 1.01 & 1.04 & 1.06 & 1.12 & 1.18 \\
\hline Liquidez Ácida & 0.57 & 0.95 & 0.89 & 0.83 & 1.02 \\
\hline Liquidez de Tesorería & 0.06 & 0.18 & 0.16 & 0.18 & 0.13 \\
\hline \multicolumn{6}{|l|}{ RATIOS DE GESTIÓN } \\
\hline Rotación de Existencias (Veces) & -2.27 & -6.83 & -30.80 & -13.52 & -17.75 \\
\hline Rotación de Existencias (Días) & -159 & -53 & -12 & -27 & -20 \\
\hline Rotación del Activo & 0.85 & 1.29 & 1.58 & 1.61 & 1.78 \\
\hline Periodo de Cobranza & 74 & 69 & 70 & 53 & 63 \\
\hline Periodo de Pago & -197 & -122 & -90 & -78 & -113 \\
\hline \multicolumn{6}{|l|}{ RATIOS DE SOLVENCIA } \\
\hline Endeudamiento del Activo & $96 \%$ & $93 \%$ & $91 \%$ & $88 \%$ & $83 \%$ \\
\hline Solvencia Patrimonial & 26.64 & 12.99 & 10.73 & 7.11 & 4.93 \\
\hline Apalancamiento Financiero & 35.86 & 19.74 & 12.66 & 9.61 & 6.85 \\
\hline Cobertura de Gastos Financieros & - & - & - & - & - \\
\hline \multicolumn{6}{|l|}{ RATIOS DE RENTABILIDAD } \\
\hline Rentabilidad Patrimonial (ROE) & $10 \%$ & $16 \%$ & $18 \%$ & $17 \%$ & $16 \%$ \\
\hline Rentabilidad de la Invensión (ROA) & $5.90 \%$ & $9.51 \%$ & $8.92 \%$ & $10.17 \%$ & $11.19 \%$ \\
\hline Rentabilidad de las Ventas & $0.33 \%$ & $0.62 \%$ & $0.88 \%$ & $1.11 \%$ & $1.32 \%$ \\
\hline Margen Bruto & $40 \%$ & $40 \%$ & $40 \%$ & $40 \%$ & $40 \%$ \\
\hline Rentabilidad de la EBITDA & $0.00 \%$ & $0.00 \%$ & $0.00 \%$ & $0.00 \%$ & $0.00 \%$ \\
\hline
\end{tabular}




\section{Ratios de liquidez}

Capital de Trabajo: Una vez que la empresa cancele el total de sus obligaciones corrientes, le quedara S/. 510,630 y cómo podemos seguir observando los siguientes años va mejorando el Capital de Trabajo en relación a un año anterior, lo que le permite afrontar sus obligaciones a corto plazo.

Liquidez corriente: Para el año 2017 la Empresa Eterna Perú S.A-C.por cada S/. 1.00 de la obligación vigente contaba con S/. 1.01 para respaldarla, es decir que por cada S/. 100.00 de sus ingresos el $99 \%$ son para pagos de sus obligaciones y el 1\% le queda como disponible. En el año 2018 podemos ver que su liquidez aumento, vale decir, si antes destinaba el 99\% para sus deudas financieras, ahora solo destinara el $82 \%$ para el respaldo de las mismas.

Liquides acida: Podemos observar si la empresa tuviera la necesidad de atender todas sus obligaciones corrientes sin necesidad de liquidar o vender sus inventarios, en el año 2017 la empresa no alcanzaría a atender sus obligaciones y tendría que liquidar parte de sus inventarios para poder cumplir, pero si observamos en el año 2018 este indicador va aumenta pero no lo suficiente para poder atender todas sus obligaciones corrientes sin necesidad de vender sus inventarios. La empresa va a depender directamente de la venta de sus inventarios para poder atender sus obligaciones corrientes.

Liquidez de Tesorería: Podemos observar que en el año 2018 mejora el ratio respecto al año 2017. 
Ratios de gestión

Rotación de Existencias (Veces): Significa que las existencias en el año 2017 rotaron 2.29 veces versus 2.07 veces, quiere decir que la rotación es un poco lenta, los siguientes años va disminuyendo de manera favorable gracias a las estrategias y mejoras que la empresa tuvo a inicios del año 2017.

Rotación de Existencias (Días): El término de los días de la empresa tiene en promedio de existencias en el año 2017158 días, mientras que en el año 2017 tuvo 173días.

Rotación del Activo: Significa que el año 2017 por cada S/. 1.00 de activo total promedio se generó S/. 0.98 vale decir que se mantiene sus inversiones.

Periodo de Cobranza: Significa el promedio de las cuentas por cobrar se convierten el efectivo en un promedio de 55días.

Periodo de Pago: Significa que el promedio de las cuentas por pagar se cancelan en un promedio de 112días versus 102días al año anterior, lo cual es muy favorable para la generación de liquidez.

Ratios de solvencia

Endeudamiento del Activo: Significa que por cada S/. 1.00 de activo total en el año 2017 este ha sido financiado por el $70 \%$ de pasivo total y va disminuyendo cada año.

Solvencia Patrimonial: Significa que por cada sol de patrimonio neto en el año 2017 hay 2.34 de pasivo total lo que demuestra que la estructura financiera es casi el $50 \%$.

Apalancamiento Financiero: Significa que por cada S/. 1.00 de patrimonio neto promedio hay 6.19 de activo total promedio. 
Cobertura de Gastos Financieros: Significa la capacidad que tiene la empresa para cubrir con su EBITDA los gastos financieros del periodo, el año 2017 puede cubrir con su EBITDA hasta 9.21 veces de sus gastos financieros del periodo.

\section{Ratios de rentabilidad}

Rentabilidad Patrimonial (ROE): Es la rentabilidad de los accionistas y en año 2018 disminuye un poco con la con relación al año 2017 debido a que aumento el patrimonio por los resultados acumulados, se considera un ratio apropiado cuando es mayor al $15 \%$ vale decir que el año 2017 tenemos $16.71 \%$ y va creciendo favorablemente.

Rentabilidad de la Inversión (ROA): es la rentabilidad de la calidad de las inversiones y en el año 2017 disminuye un poco con relación al año 2018.

Rentabilidad de las Ventas: Refleja el margen neto de las ventas para ser distribuido a los accionistas o reinvertirlo en el capital de trabajo de la empresa.

Margen Bruto: El margen bruto como indicador de la rentabilidad es muy importante pues a través de este se puede recuperar los gastos de operación necesaria para garantizar la operatividad del negocio, si observamos nuestro margen bruto tiene un crecimiento favorable.

Rentabilidad de la EBITDA: Es un indicador de rentabilidad, es muy importante que nos dice los flujos que puede generar la empresa para enfrentar el endeudamiento en caso enfrentar una etapa, si observamos el EBITDA de la empresa tiene un crecimiento favorable.

AC-PC: Una vez que la empresa cancele el total de sus obligaciones corrientes, le quedara S/. 1139533, y como podemos seguir observando los siguientes años va mejorando el 
Capital de Trabajo en relación a un año anterior lo que le permite afrontar sus obligaciones a corto plazo.

AC/PC: Para el año 2017 la empresa por cada S/1.00 de la obligación vigente contaba con S/. 1.26 para respaldarla, es decir que el 100 de sus ingresos el $85 \%$ son para pagos de sus obligaciones y el $15 \%$ le queda como disponible. En el año 2018 podemos ver que su liquidez aumento, vale decir, si antes destinaba el $85 \%$ para sus deudas financieras, ahora solo destinara el $80 \%$ para el respaldo de las mismas.

AC-INV/PC: Podemos observar si la empresa tuviera la necesidad de atender todas sus obligaciones corrientes sin necesidad de liquidar o vender sus inventarios, en el año 2017 la empresa no alcanzaría a atender sus obligaciones y tendría que liquidar parte de sus inventarios para poder cumplir, pero si observamos en el año 2018 este indicador va aumenta pero no lo suficiente para poder atender todas sus obligaciones corrientes sin necesidad de vender sus inventarios, la empresa dependerá directamente de la venta de sus inventarios para poder atender sus obligaciones corrientes. 


\section{CONCLUSIONES Y RECOMENDACIONES}

\section{Conclusiones}

1. El consumidor peruano está cada vez más preocupado por el cuidado personal, por tal motivo existe una gran oportunidad de incrementar el uso de guantes de látex en el hogar para el cuidado de las manos. La belleza de las manos es una de las principales preocupaciones de las personas en especial de las damas.

2. Es de vital importancia el uso de guantes en servicios médicos para la prevención en salud, los guantes de látex son utilizados en los servicios de salud como una berrera física para proteger tanto a los trabajadores de los diversos servicios médicos como a los usuarios de estos servicios. Los guantes en la salud previenen que los trabajadores entren en contacto con los fluidos, sangre, secreciones, piel expuesta, líquidos corporales, etc. También evitan que los microorganismos presentes en la piel de las manos de los trabajadores de salud se trasmitan a los usuarios y puedan empeorar su condición de salud.

El uso correcto de guantes en los servicio médicos pueden reducir infecciones y es vital para preservar la salud no sólo del usuario del servicio sino también de los trabajadores de los servicios de salud. El uso adecuado de los guantes de látex descartables previene que los microrganismos de las manos de los trabajadores puedan transmitir enfermedades a otros usuarios y así evitar las infecciones cruzadas. 
La oportunidad está en ingresar a instituciones de salud con un producto de calidad a un precio adecuado y el respaldo técnico y sanitario adecuado.

Los guantes de látex para examen en la actualidad no solo son usados en la industria médica sino cada vez más en nuestra vida cotidiana, como en peluquerías, manipulación de alimentos, veterinarias y uso de tintes entre otros.

Las ejecutivas modernas no sólo deben de contar con una gran capacidad intelectual y talento sino también de una presentación impecable y las manos son muy importantes en este aspecto. Es de vital importancia de guantes en servicios médicos para la prevención en salud, los guantes de látex son utilizados en los servicios de salud como una berrera física para proteger tanto a los trabajadores de los diversos servicios médicos como a los usuarios de estos servicios.

Los guantes en la salud previenen que los trabajadores entren en contacto con los fluidos, sangre, secreciones, piel expuesta, líquidos corporales, etc.

También evitan que los microorganismos presentes en la piel de las manos de los trabajadores de salud se trasmitan a los usuarios y puedan empeorar su condición de salud.El uso correcto de guantes en los servicio médicos pueden reducir infecciones y es vital para preservar la salud no sólo del usuario del servicio sino también de los trabajadores de los servicios de salud.

El uso adecuado de los guantes de látex descartables previene que los microrganismos de las manos de los trabajadores puedan transmitir enfermedades a otros usuarios y así evitar las infecciones cruzadas.

La oportunidad está en ingresar a instituciones de salud con un producto de calidad a un precio adecuado y el respaldo técnico y sanitario adecuado. 
Los guantes de látex para examen en la actualidad no solo son usados en la industria médica sino cada vez más en nuestra vida cotidiana, como en peluquerías, manipulación de alimentos, veterinarias y uso de tintes entre otros.

3. Los guantes de látex no generan lealtad de marca, si bien es cierto existen preferencias de parte del consumidor por el uso de determinadas marcas lo más importante es estar en la mayor parte de puntos de venta.

Los guantes de látex son productos de venta generalmente en canal moderno es decir autoservicios y en puestos de mercado del canal tradicional, la oportunidad es introducir la categoría en bodegas del canal tradicional. A lo largo del presente proyecto hemos visto el incremento del uso del guante en el hogar y la bodegas de barrio siguen siendo el punto de venta más visitado por el consumidor peruano.

4. Los guantes en la actualidad son fabricados para diferentes usos, aunque el común de las personas crean que dos pares de guantes puedan ser idénticos, estos tienen diferentes usos, estos son fabricados con diferente grosor, textura, incluso el color de estos denota un uso diferente.

5. Los guantes son productos que rayan con el cuidado personal de las personas, son casi de uso personal, por poner un ejemplo el ama de casa usa un guante para ella y si tuviera personal de servicio lo más probable es que este utilice uno diferente y en el hogar no se 
utiliza el mismo guante para lavar los servicios de cocina y lavar la ropa o los baños. La utilización de guantes por cada actividad evita la contaminación cruzada.

Como vimos a lo largo del presente proyecto la utilización de guantes se ha incrementado notablemente en los hogares con respecto a años anteriores pero existe un potencial importante de desarrollo de la categoría básicamente al lograr penetración de mercado.

6. La empresa Eterna es reconocida como una empresa comercializadora de guantes de buena calidad, no se ha desarrollado los otros productos del portafolio. La percepción de calidad de los guantes Eterna por parte del consumidor no ha sido aprovechada con los demás productos como paños, fibras y esponjas. 


\section{Recomendaciones}

1. Se recomienda aprovechar el posicionamiento de calidad delos guantes Eterna para la introducción de los otros productos del portafolio como son las fibras, paños y esponjas. Debido al poder de la marca ScotchBrite en el mercado peruano es muy difícil realizar acciones para competir de igual a igual con los paños, fibras y esponjas, es necesario ingresar a bodegas en conjunto y con el paraguas de los guantes.

2. Recuperar los niveles de facturación y ventas en productos de la marca Eterna cuando la marca era manejada por Drokasa.

3. Desarrollar una estructura de distribución eficiente en el canal tradicional a través de distribuidores especializados y evitar la venta directa.

4. Desarrollar una arquitectura de precios adecuada por canal que permita la adecuada llegada al mercado y elimine la especulación de precios en el mercado.

5. Ampliar la base de distribuidores regionales espacialmente en el norte del Perú y el sur chico.

6. Desarrollar las otras unidades de negocio como guantes industriales, productos para la industria de la construcción y automovilismo e industria médica a través de distribuidores especializados que sean atendidos directamente desde casa matriz sólo bajo pedido y pagado por adelantado parcial o totalmente. 


\section{Anexos \\ Anexo 1: Entrevista al Gerente General de Eterna Perú}

\section{Dirección:}

- Los investigadores han definido que el entrevistador será Ivan Peña Delgado, su compañero Joseph Mongrut Principe lo asistirá en esta oportunidad con lo que ambas personas necesiten.

- Se citara al Gerente General esto de acuerdo a su agenda.

Técnica:

- Elaborar las preguntas por parte de los investigadores.

- Definir el objetivo de la entrevista.

- Grabar la reunión bajo consentimiento del Gerente General.

- Emitir un resumen de la entrevista formulada.

Tiempo:

- Las entrevistas oscilan entre una hora o dos horas, esto varía de acuerdo a la expansión en el tema del colaborador.

Ubicación:

- Las entrevistas se pactaran en la oficina del Gerente general en las instalaciones de Eterna Perú, distrito de Ate Vitarte, provincia de Lima.

Fechas de entrevistas:

- Las fecha se pactó de acuerdo a la agenda del colaborador

Objetivo:

- Mayor conocimiento de la visión empresarial y ver las perspectivas del colaborador en la industria de la limpieza para el hogar.

Participantes:

- Joseph Mongrut Principe

- Ivan Peña Delgado 
Escogidos:

- Gagliardo Hidalgo Jorge Andrés: Gerente General

Guion:

Buenas noches,

Quien lo saludas es Ivan Peña Delgado. y mi colega es Joseph Mongrut Principe, el día de hoy queremos realizarle algunas preguntas con la finalidad de conocer su opinión respecto a las ventajas competitivas de las compañías de la industria de la limpieza del hogar comparada con Eterna Perú.

La confidencialidad será estrictamente respetada, siéntase seguro que no será divulgado bajo ningún medio así que con confianza siéntase libre de responder con toda la libertad del mundo.

De antemano valoramos su sinceridad y estamos agradecidos por su participación.

Cuestionario:

1. ¿Háblenos un poco de su persona, quien es usted?

2. ¿Coméntanos sobre tu experiencia a lo largo de su trayectoria profesional?

3. ¿Cuánto tiempo usted labora en la industria de la limpieza del hogar?

4. ¿Cuál es su situación actual en el mercado de limpieza del hogar?

5. ¿Qué factores son los que está afectando actualmente el mercado?

6. ¿La empresa está cumpliendo con sus objetivos trazados? ¿Por qué no?

7. ¿Su personal es el adecuado?

8. ¿Ventas está cumpliendo con los objetivos?

9. ¿Se cuenta con los recursos necesarios para que el negocio vaya bien?

10. ¿La compañía cuenta con un presupuesto óptimo?

11. ¿Actualmente los procesos son los adecuados o necesitan una redefinición?

12. ¿Considera que la empresa es eficiente?

13. ¿La compañía está generando ganancia o pérdida? ¿Por qué?

14. ¿Cuál es el negocio de la compañía?

15. ¿Qué productos ofrece? ¿A quién ofrece el bien?

16. ¿Actualmente qué posición tiene la empresa en estos bienes?

17. ¿Qué lugares ofrece estos bienes a nivel capital o nacional?

18. ¿Se puede medir el grado de satisfacción de sus clientes?

19. ¿Detálleme los recursos físicos con los que cuenta la empresa para generar el bien? 
20. ¿Bríndeme detalles de la estructura organizacional? ¿Cueles son sus aspectos positivos y negativos de esta estructura?

21. ¿La empresa ha crecido en estos últimos años? ¿Cómo lo ha hecho?

22. ¿Cuál es el clima laboral de la empresa y porque es así?

23. ¿Su opinión respecto a los niveles de rentabilidad de la compañía?

24. ¿Podría decirme que servicios la empresa subcontrata?

25. ¿Realiza la empresa investigación de mercados?

26. ¿Los precios son competitivos?

27. Se conoce la información de la empresa competidora respecto a:

Utilidad, precios, condiciones de venta, canales de mercado

28. ¿Cuál es la competencia de la empresa?

29. ¿La empresa ofrece un producto diferenciado?

30. ¿Cuenta la empresa con catálogos, manuales, especificaciones, etc.?

31. ¿Mencione los puntos fuertes de la empresa?

32. ¿Mencione las debilidades de la empresa?

33. ¿Mencióneme cual es el área estratégica de la cual surge el éxito de la compañía?

Se agradece le tiempo prestado. 
Anexo 2: Análisis de la entrevista al gerente general de Eterna Perú

1. ¿Háblenos un poco de su persona, quien es usted?

Mi nombre es Jorge Gagliardoy soy Gerente General de Eterna Perú S.A.C. desde julio del 2016, soy de Origen Ecuatoriano y resido en Perú ya 12 años, llegué al Perú trasladado por la empresa en la que trabajaba y como muchos expatriados (es como se les conoce a las personas trasladadas de un país a otro en las corporaciones) me quedé enamorado de este país, soy casado y tengo 2 hijas las cuales estudian acá, mi familia al igual que yo se han adaptado muy bien a la cultura y sociedad peruana, tal es así que en muchas veces he tenido oportunidad de migrar a otro país por trabajo o regresar a Ecuador, pero no lo he aceptado ya que tenemos una vida ya asentada en Perú.

2. ¿Coméntanos sobre tu experiencia a lo largo de su trayectoria profesional? Soy egresado de la Pontificia Universidad Católica de Ecuador en la carrera de Administración, Empecé en el mundo de la ventas muy joven trabajando en Clorox Ecuador, al principio como vendedor luego ejecutivo de ventas, supervisor y posteriormente legando a tener jefatura en el área comercial, luego pasé a trabajar a Shick\&Energizer Ecuador llegando a la posición de Gerente de Ventas. En el año 2003 soy trasladado a Perú como director de ventas para iniciar las operaciones de Shick\&Energizer en Perú y en el año 2007 soy ascendido a la posición de Gerente General.

El balance de mis resultados afortunadamente a lo largo de mi trayectoria profesional ha sido positivo, llegando a incrementar ventas y sobre todo a que la compañía sea rentable.

Me considero una persona que me gusta enseñar y compartir mi experiencia, esto es la clave de potenciar los resultados, cuanto mejor capacitados y motivados estén nuestros colaboradores nos será más fácil poder cumplir nuestros objetivos. 
3. ¿Cuánto tiempo usted labora en la industria de la limpieza del hogar?

Específicamente limpieza del hogar no es la palabra, toda mi trayectoria profesional la he desarrollado en consumo masivo y en las empresas en las que he laborado siempre hemos manejado la categoría de limpieza del hogar.

4. ¿Cuál es su situación actual en el mercado de limpieza del hogar?

Está presente en todos los canales de venta,

- canal moderno como autoservicios y home centers como Sodimac, Ace, o Promart

- Canal Tradicional como mayoristas, mercados y bodegas.

Especialmente en el caso de Guantes para aseo doméstico, que es el principal producto de comercialización de Eterna está muy enfocado en autoservicios, mayoristas y mercados, pero la oportunidad está básicamente en bodegas ya que sólo en Lima existen unas ochenta mil.

La categoría de limpieza ya existe en bodegas en ella se venden detergentes para ropa y platos, lejía, paños, fibras, desinfectantes, etc. Porque no a esta categoría existente dentro de las bodegas agregar guantes domésticos, no con un portafolio muy grande pero si con los SKUs por tipo y talla más comunes.

5. ¿Qué factores son los que está afectando actualmente el mercado?

Yo creo que el mercado ha sido afectado en forma positiva por diferentes factores como:

- Mayor demanda de productos especializados.

- Mayor gasto per cápita en el Perú

- Mayor acceso a la información y exposición de productos en los diferentes mercados

- En el caso femenino mayor preocupación de por el cuidado personal especialmente de la piel.

- Mayor oferta de productos en las categorías en las que participamos.

- Incremento en la búsqueda de productos de mayor calidad y funcionalidad.

6. ¿La empresa está cumpliendo con sus objetivos trazados? ¿Por qué no? 
Desde su ingreso al Perú en el 2014 hasta el 2016 Eterna no ha reportado utilidades, es más la pérdida acumulada de la compañía ha sido asumida por casa matriz (eterna Colombia) esto debido a procesos ineficientes y una forma errada de llegada al mercado. Costos elevados de distribución y logística, márgenes no adecuados, llegada poco clara al mercado (GotoMarket), pasar de un modelo de distribución manejado por Drokasa a venta directa por la propia marca.

En la actualidad estamos trabajando para llegar a nuestros objetivos, casi hemos llegado a nuestro punto de equilibrio, estamos en un proceso de restructuración que nos permita ser más eficientes.

En el canal moderno, hemos llegado a ser los proveedores de los autoservicios con sus marcas propias, cabe destacar que los autoservicios generalmente mandan a fabricar sus marcas propias con los líderes de la categoría.

En el caso del canal tradicional hemos conseguido armar una red de distribución más estable y retomar la confianza con nuestros distribuidores, fortalecer a nuestros mayoristas y estamos trabajando muy duro con la fuerza de ventas de los distribuidores para hacer la mayor distribución posible.

Estamos seguros que los resultados serán positivos a muy corto plazo.

7. ¿Su personal es el adecuado?

Es algo duro lo que te voy a decir para hemos tenido que hacer una reestructuración total de los colaboradores dentro de la compañía, personal poco comprometido, con poca capacidad de gestión, personal poco capacitado y sin iniciativa. En la actualidad estamos brindando capacitación constante a nuestros colaboradores y haciéndolos participe en forma activa de las reuniones de planeamiento. 
8. ¿Ventas está cumpliendo con los objetivos?

Como te comente estamos alcanzando nuestro punto de equilibrio, luego de haber desarrollado el plan para Lima estamos empezando con el desarrollo de las principales ciudades en provincia. Nos falta todavía por desarrollar el norte del Perú y la sierra. La región oriente o selva ya se revisará para una posterior.

9. ¿Se cuenta con los recursos necesarios para que el negocio vaya bien?

Tenemos la confianza de casa matriz para ejecutar los planes que nos permitan alcanzar los objetivos, hemos reducido considerablemente nuestros costos operativos esto nos permite contar con mayores recursos para reinvertir.

10. ¿La compañía cuenta con un presupuesto óptimo?

Los presupuestos están en función a la venta y al margen, debemos ser muy cautelosos en ejecutar bien los presupuestos alcanzando los volúmenes de venta adecuados y siendo eficientes en los manejos de costos y gastos.

11. ¿Actualmente los procesos son los adecuados o necesitan una redefinición?

Estamos desarrollado manuales de procesos para cada área de la empresa y seguimos mejorándolos, la mayoría de estos se han implementado desde cero ya que no existían.

12. ¿Considera que la empresa es eficiente?

La empresa está siendo cada vez más eficiente, como te comente en un principio nos está costando este proceso hacer cambios importantes dentro de la organización. 
13. ¿La compañía está generando ganancia o pérdida? ¿Por qué?

A la fecha tenemos todavía pérdida acumulada, pero como te comente estamos muy cerca de nuestro punto de equilibrio y posterior mente recuperar la perdida.

14. ¿Cuál es el negocio de la compañía?

La empresa es una empresa de consumo masivo enfocada en productos de aseo del hogar y cuidado personal. Nuestro principal producto es el guante doméstico. El guante represente el 90\% de las ventas de la compañía.

15. ¿Qué productos ofrece? ¿A quién ofrece el bien?

Productos de cuidado y limpieza del hogar, especialmente guantes a base de látex. Eterna es el líder en la categoría de guantes en el Perú, esto debido a la calidad de sus productos, cabe resaltar que es la una marca que produce sus guantes en sus propias plantas en Colombia a diferencia de los marcas competidoras que generalmente son importadores de guantes desde el Asia.

Nosotros ofrecemos nuestros productos al consumidor final, generalmente ama de casa a través de autoservicios (canal moderno) y distribuidores (canal tradicional). También nuestros productos son muy requeridos en la industria como pesca, agricultura, manufactura, institucionales, etc.

16. ¿Actualmente qué posición tiene la empresa en estos bienes?

Eterna como te comente s es la empresa líder en la comercialización de guantes en el Perú, para que tengas una idea los autoservicios sólo mandan a fabricar sus productos de marca propia con los líderes de las respectivas categorías, en el caso de esta categoría Eterna le fabrica 
los guantes marca propia a Supermercados Peruanos, Cencosud (para Wong y Metro), Tottus, y en la actualidad Eterna Colombia empezará a producir los guantes marca propia a Sodimac para todo Sudamérica. Esto denota la calida de nuestros productos.

17. ¿Qué lugares ofrece estos bienes a nivel capital o nacional?

Estamos principalmente en Lima ya que la deficiencia en la red de distribución ha permitido el crecimiento de otras marcas en provincia. Como te comente tenemos que fortalecer la red de distribución en provincia bajo un esquema logístico eficiente, con costos adecuados y con una supervisión eficiente.

18. ¿Se puede medir el grado de satisfacción de sus clientes?

En la actualidad no tenemos medición de grado de satisfacción del consumidor final para sí podemos afirmar que para nuestros clientes directos del canal moderno o tradicional somos una de las compañías que brinda mejores márgenes para el cliente.

Pero como te comente tenemos todavía deficiencias en atención al cliente por plazos y tiempos de entrega, desviaciones en los inventarios, lo que lleva a incumplimientos en los pedidos.

19. ¿Detálleme los recursos físicos con los que cuenta la empresa para generar el bien? Eterna es una empresa Colombiana con 70 años en el mercado, cuenta con plantas propias para la fabricación de sus productos. Esto permite poder garantizar una calidad de productos estandarizada y reducir los Lead time (Plazos de abastecimiento) menores y garantizados. 
El reto para Eterna Perú es entregar a Eterna Colombia los presupuestos (Forecast) de Ventas por productos proyectados y adecuados para optimizar nuestra logística y garantizar el $100 \%$ de atención a nuestros clientes.

20. ¿Bríndeme detalles de la estructura organizacional? ¿Cueles son sus aspectos positivos y negativos de esta estructura?

Somos un estructura bastante plana y relativamente pequeña que nos permite ser muy agiles para la toma de decisiones esto nos ha permitido hacer los cambios que te he comentado con un impacto positivo.

Yo no lo diría como aspecto negativo sino como oportunidad de mejora básicamente es terminar con definir y poner en uso los procesos de la compañía.

La estructura es bastante amigable lo que estaba faltando es un rumbo establecido para Eterna Perú, que brinde utilidades adecuadas es decir que sea una empresa rentable y no como solo un cliente de Eterna Colombia.

21. ¿La empresa ha crecido en estos últimos años? ¿Cómo lo ha hecho?

Desde su nacimiento como empresa en el 2014 la empresa viene creciendo sin embargo no presenta rentabilidad como compañía.

Te preguntaras porque una empresa que no es rentable se sigue manteniendo, pero la respuesta es mucho más profunda, Eterna Perú representa un volumen de venta importante para Eterna Colombia, es por eso que decía que para Eterna Colombia Eterna Perú es un cliente. Pero Eterna Perú también debe ser rentable. 
22. ¿Cuál es el clima laboral de la empresa y porque es así?

Considero que existe un buen clima laboral. Eterna Perú es una empresa relativamente pequeña, actualmente somos casi 40 personas, pero para el tamaño de negocio y con la nueva estructura deberíamos ser menos, considero que dentro del nuevo esquema de llegada al mercado debemos ser unas 30 personas trabajando directamente en la empresa, además contamos con colaboradores de otras empresas que nos brindan servicios, como mercaderismo y promoción en los puntos de venta.

El ser una empresa de este tamaño facilita el clima laboral, acá todos nos conocemos, la organización es bastante plana, bastante comunicación,

23. ¿Su opinión respecto a los niveles de rentabilidad de la compañía?

La empresa ha incurrido en gastos excesivos de comercialización y logística que han hecho de la empresa una empresa poco rentable, pese a que somos prácticamente fabricantes de nuestros productos por las plantas de Eterna en Colombia y manejamos buenos márgenes brutos, los costos de comercialización y logísticos son demasiado altos, con la nueva estructura debemos optimizar nuestros gastos y hacer de esta compañía una empresa rentable.

24. ¿Podría decirme que servicios la empresa subcontrata?

Eterna Perú subcontrata servicios de:

- Mercaderismo, que son los servicios de colocación y exhibición de nuestros productos en puntos de venta, esto generalmente en autoservicios.

- Promotoría, son el personal de apoyo a las ventas y acompañamiento a la fuerza de ventas de los distribuidores.

- Servicios de Distribución y logísticos.

- Estudio Contable. 
25. ¿Realiza la empresa investigación de mercados?

En la actualidad no estamos contratando servicios de investigación de mercados, esto es un plan a mediano plazo tan pronto terminemos de consolidar nuestra red de distribución.

26. ¿Los precios son competitivos?

Los precios son muy competitivos, sin embargo el plan es poder ordenar el mercado con una llegada adecuada en escala de precios por canal, cada canal debe manejar un margen diferenciado.

27. Se conoce la información de la empresa competidora respecto a: Utilidad, precios, condiciones de venta, canales de mercado Sólo la información que es pública, como sebes este tema es delicado, nosotros manejamos nuestros precios y márgenes en función de las necesidades de nuestra empresa y no en función de los precio de la competencia. Nuestros productos manejan una ventaja diferencial en cuanto a calidad del producto.

28. ¿Cuál es la competencia de la empresa?

Existen empresas grandes en el mercado que fabrican y comercializan productos similares a los nuestros como es el caso de Ilko con los productos Virutex, 3m y Drokasa, estos son los principales.

29. ¿La empresa ofrece un producto diferenciado?

Nuestra fortaleza esta en los guantes de látex, por la calidad de los productos y el portafolio que manejamos. 
30. ¿Cuenta la empresa con catálogos, manuales, especificaciones, etc.?

Por supuesto, para una empresa de comercialización y consumo masivo es muy importante el trabajo con material de este tipo, aunque es algo en que tenemos oportunidad de mejora, la mayor parte dela publicidad y artes para esta son de origen de casa matriz en Colombia y no estamos realizando la tropicalización para adaptarlo a la realidad Peruana.

31. ¿Mencione los puntos fuertes de la empresa?

Los principales puntos fuertes son:

- Contar con marcas propias para la marca, esto garantiza una calidad de producto estándar, acorta los plazos de entrega y flexibilidad para manejar y producir tipos especiales de productos.

- Una estructura ligera que nos permite realizar toma de decisiones rápidas.

- Reconocimiento en guantes como un producto de calidad y que nos servirá como paraguas para lograr el desarrollo de otros productos del portafolio.

32. ¿Mencione las debilidades de la empresa?

Las principales debilidades son:

- Llegada al mercado poco clara. Canales que se sobreponen y generan desorden de precios y desabastecimiento del mercado.

- Altos costos de comercialización y logísticos.

- Procesos ineficientes que generan reprocesos.

- Débil estructura de distribución de los productos

- $\quad$ Niveles de control logísticos y financieros deficientes. 
33. ¿Mencióneme cual es el área estratégica de la cual surge el éxito de la compañía? Cada área de la compañía es estratégica desde su punto de vista, la clave es que se manejen en forma integradas para que no se creen cuellos de botella y evitar los reprocesos los cuales generan costos excesivos.

Se agradece le tiempo prestado. 
Anexo 3: Análisis de la entrevista al gerente de ventas Colgate Palmolive Perú

\section{Dirección:}

- Los investigadores realizaran la entrevista, en esta etapa se tuvo el apoyo logístico de personal externo y la consultoría de profesionales en la materia, que por motivos de confidencialidad no brindaremos sus nombres.

- Las entrevistas se darán de manera individual a los colaboradores de las siguientes compañías: Colgate, en la industria de la limpieza el nivel de rotación es bajo debido a ello se llegó a estas personas mediante recomendaciones y otro medio fue por el grado de amistas que los autores tienen con estas personas.

Técnica:

- Los autores elaboraron las preguntas críticas y claves para la elaboración de la herramienta del benchmarking, con la finalidad de cumplir con los objetivos deseados.

- Después de haber elaborado las entrevistas se estará emitiendo un resumen de nivel ejecutivo para mayor conocimiento de los autores y el lector.

Tiempo:

- Las entrevistas oscilan entre 30 y 45, esto varía de acuerdo a la expansión en el tema del colaborador.

Ubicación:

- Las entrevistas se pactaron en un punto medio, estos fueron realizados en su mayoría en establecimientos como Starbucks, USIL, etc.

Fechas de entrevistas:

- Las fechas fueron variando de acuerdo a las agendas de nuestros informantes, se tuvo que pactar fechas y horas distintas con cada colaborador.

Objetivo:

- Ver las ventajas y comparar a Eterna con los líderes y los principales competidores de la industria de la limpieza del hogar.

Participantes:

- Joseph Mongrut Principe

- Ivan Peña Nieto

- Otros (soporte logístico y consultores mencionados líneas arriba en Dirección). 
Escogidos:

- Empleados y ex trabajadores de las compañías: Colgate.

Guion:

Buenas noches,

Quien lo saludas es Joseph Anthony Mongrut Principe y mi colega es Ivan Peña

Delgado, el día de hoy queremos realizarle algunas preguntas con la finalidad de conocer su opinión respecto a las ventajas competitivas de las compañías de la industria de la limpieza del hogar comparada con Eterna Perú.

La confidencialidad será estrictamente respetada, siéntase seguro que no será divulgado bajo ningún medio, así que, con plena confianza siéntase libre de responder con toda la libertad del mundo.

De antemano valoramos su sinceridad y estamos agradecidos por su participación. 
Cuestionario:

1. ¿Cuánto tiempo usted labora en empresas de consumo masivo?

Mi experiencia es de 10 años en empresas del sector

2. ¿En qué compañía Ud. Labora?

Actualmente me encuentro laborando en Colgate Palmolive Perú.

3. ¿La empresa en la que Ud. Labora manejan productos de cuidado del hogar?

Específicamente cuidado del hogar no, Colgate es una empresa americana especializada

en 3 categorías:

- Cuidado Oral, en esta categoría se manejan las cremas dentales Colgate y Kolinos, Cepillos dentales, Enjuagues bucales y productos especializados.

- Cuidado Personal, Jabones Palmolive y Protex, desodorantes SpeedStick para hombre y mujer y Shampoo.

- Cuidado del hogar, es esta categoría manejamos suavizantes de ropa, detergentes para platos, etc.

4. ¿La entrega de productos a sus clientes se ejecuta a tiempo?

Tenemos plazo de entrega que son respetados al pie de la letra, el nivel de satisfacción de nuestros clientes en cuanto al servicio es muy alto.

5. ¿Se presentan fallas de entrega o existe la devolución de los productos actualmente en la empresa donde labora o laboro?

Tratamos de minimizar las fallas, Colgate es una empresa transnacional que exige estándares altos de calidad, para ellos contratamos a empresas líderes en mercado que nos brindan sus servicios, específicamente para el tema logístico lo trabajamos con Yobel.

La estructura de Colgate nos permite manejar un modelo de negocio rentable que optimiza sus procesos y reduce los costos logísticos. 
6. ¿Las compras son las mismas con los clientes potenciales o existe alguna diferencia? Depende del tipo de canal, por ejemplo en el canal moderno cada cadena maneja sus propias exigencias de atención esta es muy diferente a farma, en el canal tradicional la atención es más homogénea.

Para el canal tradicional en Colgate trabamos con clientes especializados en distribución multi-marca es decir empresas que se dedican a la comercialización de productos de diferentes proveedores, que pueden entrar a los diferentes mercados con marcas líderes y le dan cliente bodega o mercado una oferta atractiva.

7. ¿La empresa es innovadora en sacar nuevos productos al mercado? Por ser una empresa transnacional contamos con productos innovadores adecuados al mercado y somos líderes en las categorías en las que participamos.

8. ¿Los procesos en la compañía actualmente son los más adecuados o estos podrían mejorar?

Pienso que siempre hay oportunidades de mejora, pero actualmente el modelo que manejamos nos ha funcionado, el contar con una cartera de cliente optimizada, clientes de una buena presencia en el mercado.

9. ¿Existe un buen clima laboral? ¿Las evaluaciones al colaborador eran correctas? El clima laboral es excelente, el área de recursos humanos está muy pendiente de cada uno de los colaboradores de la familia Colgate. 
10. ¿Qué tan alta es la rotación del personal en la empresa incluido los puestos de confianza? Colgate es una empresa transnacional que cuida a su gente, brinda capacitación constante y los prepara manejar cualquier tipo de organización. La rotación de personal es muy baja, es más los puestos de confianza generalmente son promovidos a especializarse o trasladarse a otros países.

Se agradece le tiempo prestado. 
Anexo 4: Análisis de la entrevista al ejecutivo de planeamiento de Ilko Perú

Dirección:

- Los investigadores realizaran la entrevista, en esta etapa se tuvo el apoyo logístico de personal externo y la consultoría de profesionales en la materia, que por motivos de confidencialidad no brindaremos sus nombres.

- Las entrevistas se darán de manera individual a los colaboradores de las siguientes compañías: ILKO, en la industria de la limpieza el nivel de rotación es bajo debido a ello se llegó a estas personas mediante recomendaciones y otro medio fue por el grado de amistad que los autores tienen con estas personas.

Técnica:

- Los autores elaboraron las preguntas críticas y claves para la elaboración de la herramienta del benchmarking, con la finalidad de cumplir con los objetivos deseados.

- Después de haber elaborado las entrevistas se estará emitiendo un resumen de nivel ejecutivo para mayor conocimiento de los autores y el lector.

Tiempo:

- Las entrevistas oscilan entre 30 y 45, esto varía de acuerdo a la expansión en el tema del colaborador.

Ubicación:

- Las entrevistas se pactaron en un punto medio, estos fueron realizados en su mayoría en establecimientos como Starbucks, USIL, etc.

Fechas de entrevistas:

- Las fechas fueron variando de acuerdo a las agendas de nuestros informantes, se tuvo que pactar fechas y horas distintas con cada colaborador.

Objetivo:

- Ver las ventajas y comparar a Eterna con los líderes y los principales competidores de la industria de la limpieza del hogar.

Participantes:

- Joseph Mongrut Principe

- Ivan Peña Delgado

- Otros (soporte logísticoy consultores mencionados líneas arriba en Dirección). 
Escogidos:

- Empleados y ex trabajadores de las compañías: ILKO,

Guion:

Buenas noches,

Quien lo saludas es Joseph Anthony Mongrut Principe y mi colega es Ivan Peña

Delgado, el día de hoy queremos realizarle algunas preguntas con la finalidad de conocer su opinión respecto a las ventajas competitivas de las compañías de la industria de la limpieza del hogar comparada con Eterna Perú.

La confidencialidad será estrictamente respetada, siéntase seguro que no será divulgado bajo ningún medio, así que, con plena confianza siéntase libre de responder con toda la libertad del mundo.

De antemano valoramos su sinceridad y estamos agradecidos por su participación. 
Cuestionario:

1. ¿Cuánto tiempo usted labora en la industria de la limpieza del hogar?

Vengo laborando 5 años aproximadamente.

2. ¿En qué compañía usted labora o ha laborado?

Laboro en Ilko Perú SA.

3. ¿La entrega a los clientes se ejecutaban a tiempo?

En su mayoría sí, nuestro nivel de servicio supera el 97\%. La atención de las órdenes de venta se dan en 24 horas incluso a los clientes en provincia salvo los autoservicios que se manejan con citas fijas. Los cortes son al mediodía y salen a despacho al día siguiente a primera hora, nuestro nuevo centro de distribución con sistema WMS hace que la labor de picking y despacho sea efectiva así mismo trabajamos con proveedores estratégicos que nos permiten llegar a tiempo con las entregas.

4. ¿Se presentan fallas de entrega o existe la devolución de los productos actualmente en la empresa donde labora o laboro?

Por tema de confidencialidad no puedo detallar nuestras fallas, pero tenemos ciertas dificultades con atención al cliente post venta, eso incluyen fallas de entrega y devoluciones.

5. ¿Las ventas son las mismas con los clientes potenciales o existe alguna diferencia? Nuestros clientes potenciales son autoservicios (Canal Moderno) en cuanto a volumen y monto, con ellos se tienen acuerdos comerciales los cuales incluyen cobros de rebates, fillrate, servicio logístico entre otros. 
6. ¿La empresa es innovadora en sacar nuevos productos al mercado?

Sí estamos con varios proyectos para diversificar nuestras categorías de productos, y a la vez estamos descontinuando productos menos rentables y de poca rotación. 
Anexo 5: Ficha técnica investigación cualitativa: entrevista clima organizacional

\section{La empresa}

ETERNA S.A. es una empresa colombiana con una sede en Lima, Perú desde el año 2014. En Colombia fue fundada hace más 60 años.

\section{Productos que ofrece la empresa}

La empresa se enfoca en atender las necesidades del consumidor con productos de limpieza del hogar en sus diferentes categorías.

\section{Objetivo de la investigación}

- Se busca conocer el clima laboral que existe en la empresa y las variables de comportamiento que influyen en crear un clima adecuado para los empleados y trabajadores de ETERNA S.A.

- Reconocer el ambiente organizacional que existe en la empresa en relación al personal que labora en la empresa.

\section{Perfil del participante}

Los participantes del estudio son personas que laboran al menos un año en la empresa ETERNA Perú S.A.

\section{Guía de preguntas}

\section{Frase de presentación}

Estimado Señor(a), somos un grupo de alumnos del Programa de Maestría de la Universidad San Ignacio de Loyola. Como parte del proceso de graduación estamos elaborando un proyecto sobre un plan estratégico para la empresa Eterna Perú S.A. del sector de productos de limpieza del hogar. En este marco, nos gustaría conocer su opinión sobre el nivel de clima laboral que existe en la empresa Eterna Perú S.A. La información que nos proporcionen en esta entrevista será usada de manera confidencial para la elaboración del proyecto. 


\section{Diseño de fase de calentamiento:}

Cuánto tiempo labora en Eterna Perú S.A.

Un año y medio

Cuál es el trabajo que realiza en la empresa Eterna Perú S.A.

Ejecutivo comercial

\section{Listado de preguntas}

1. ¿Cómo se desarrollan las relaciones sociales e interpersonales con sus compañeros de trabajo?

Creo que normales pero no interactuamos mucho, cada uno anda en sus cosas y en las reuniones solo vemos temas de trabajo y además son muy pocas, una al mes y nuestro jefe se reúne en forma individual, cuando estamos en reuniones son cordiales pero no se confraterniza mucho .

2. Cómo se desarrollan las relaciones sociales e interpersonales con el personal directivo de la empresa?

Con respeto básicamente con temas de trabajo nada personal, las personas de recursos humanos no se involucran mucho con nosotros o nuestra vida personal como si lo veo en otras compañías.

3. ¿Cuál es su opinión sobre las condiciones ambientales de trabajo?

Bueno te refieres al ambiente en la oficina, 
4. Sí y digamos comodidades ambiente de trabajo

Creo que son buenas pero en mi caso particular no me siento muy augusto porque me siento un poco discriminada al no poder ingresar por donde ingresa el personal de oficinas y tengo que ingresar por donde ingresan los promotores y el personal de despacho del operador que alquila el local a la empresa.

Por otro lado creo que las oficinas son cómodas.

5. Cuál es el grado de control en las actividades que tienen sobre el trabajo que realiza?

Bueno todas las actividades son supervisadas por mi jefe inmediato y entiendo que son reportadas por el a su jefe el gerente general.

A nosotros nos controlan mediante nuestros formatos de planificación semanal.

6. Cuál es el grado de control en la toma de decisiones relacionadas con el trabajo que realiza?

Cualquier tipo de decisión concerniente al trabajo debe de ser consultada con el gerente comercial ya que él es el encargado del canal.

7. Considera que el desarrollo de su trabajo cuenta con autonomía?

Yo creo que si ya que el cronograma de actividades lo desarrollo yo y solo se las presento a mi jefe, claro si hubiera algún tipo de observación o cambio sugerido por mi jefe lo tenemos que cumplir y si no es posible de hacer se lo explicamos, por ejemplo que tenga que hacer un cambio en las visitas para cerrar una venta o porque un cliente necesita una 
reunión de última hora. También pueda darse el caso que el cliente nos cancele una reunión y tengamos que reprogramar. Al final debemos rendir a la gerencia por el cumplimiento de los objetivos mensuales.

8. Considera que recibe el apoyo de su jefe inmediato en el trabajo que realiza?

Creo que sí, cuando necesito de algún apoyo mi jefe inmediato me ha apoyado incluso ha sacado cara por más de uno en la oficina cuando algo a pasado.

9. Ha participado de programas de desarrollo personal, motivación laboral y formación realizados por la empresa?

La empresa nunca ha desarrollado ningún tipo de programa de ese tipo, en algún momento creo que el gerente general lo mencionó en una reunión pero nunca se concretó. Pero sería muy importante para el personal.

10. Existe un sistema de recompensas económicas adecuado en la empresa?

El incentivo de ventas del mes, creo que está dentro de lo que paga el mercado para el tamaño de la empresa.

11. Existen programas de desarrollo y crecimiento profesional en la empresa?

Eso si no existe.

12. Existe en la empresa un sistema de comunicación organizacional? 
No, la comunicación es directa con mi jefe inmediato, es más recursos humanos solo nos llama para la entrega de boletas o algún documento como ese.

13. Considera que en la empresa se toman de decisiones con conocimiento de los objetivos de trabajo y los resultados obtenidos?

Los objetivos de la empresa nos lo transmite la gerencia pero creo que a veces son objetivos que no van de acuerdo con la realidad de la empresa.

14. En la empresa se llevan a cabo programas para favorecer la innovación y la creatividad en el trabajo

No, todo lo que se hace generalmente viene de lo que se implementa en Colombia o iniciativas de los gerentes pero a los ejecutivos no nos dan la oportunidad de poner en práctica iniciativas

Datos de cada participante: Liliana Ames

Posición en la empresa: Ejecutiva de Ventas

Labora en la empresa por un año 6 meses.

15. ¿Los procesos en la compañía actualmente son los más adecuados o estos podrían mejorar? Estamos en proceso de mejora, con nuevas políticas internas y cambios.

16. ¿Existe un buen clima laboral? ¿Las evaluaciones al colaborador eran correctas?

El clima laboral es regular, no muchos cargos son por "confianza" o grado de amistad y no por grado de instrucción, conocimiento o calificación para el puesto. 
17. ¿Qué tan alta es la rotación del personal en la empresa incluido los puestos de confianza?

La rotación del personal es alta en cuanto al personal operativo, mandos medio y puestos de confianza.

Se agradece le tiempo prestado. 
Anexo 6: Ficha técnica investigación cualitativa: entrevista clima organizacional

\section{La empresa}

ETERNA S.A. es una empresa colombiana con una sede en Lima, Perú desde el año 2014. En Colombia fue fundada hace más 60 años.

\section{Productos que ofrece la empresa}

La empresa se enfoca en atender las necesidades del consumidor con productos de limpieza del hogar en sus diferentes categorías.

\section{Objetivo de la investigación}

- Se busca conocer el clima laboral que existe en la empresa y las variables de comportamiento que influyen en crear un clima adecuado para los empleados y trabajadores de ETERNA S.A.

- Reconocer el ambiente organizacional que existe en la empresa en relación al personal que labora en la empresa.

\section{Perfil del participante}

Los participantes del estudio son personas que laboran al menos un año en la empresa ETERNA Perú S.A.

\section{Guía de preguntas}

\section{Frase de presentación}

Estimado Señor(a), somos un grupo de alumnos del Programa de Maestría de la Universidad San Ignacio de Loyola. Como parte del proceso de graduación estamos elaborando un proyecto sobre un plan estratégico para la empresa Eterna Perú S.A. del sector de productos de limpieza del hogar. En este marco, nos gustaría conocer su opinión sobre el nivel de clima 
laboral que existe en la empresa Eterna Perú S.A. La información que nos proporcionen en esta entrevista será usada de manera confidencial para la elaboración del proyecto.

\section{Diseño de fase de calentamiento:}

Cuánto tiempo labora en Eterna Perú S.A.

Un año y medio

Cuál es el trabajo que realiza en la empresa Eterna Perú S.A.

Ejecutivo comercial

Ejecutivo de ventas del canal Tradicional, Institucional e industrial

\section{Listado de preguntas}

1. ¿Cómo se desarrollan las relaciones sociales e interpersonales con su compañerosde trabajo?

En realidad ha sido un trabajo más personalizado, no había mucho trabajo en equipo, eso le faltaba a la empresa generar un trabajo en equipo

2. ¿Cómo se desarrollan las relaciones sociales e interpersonales con el personal directivo de la empresa?

Los directivos no gestionaba el trabajo en equipo cada directivo se preocupaba por sus propios asuntos, se enfocaba en solo las responsabilidades de su cargo en mi caso la exigencia de la cuota de ventas.

3. ¿Cuáles su opinión sobre las condiciones ambientales de trabajo? 
En mi opinión un poco escasa en realidad no contábamos con las herramientas para poder realizar nuestro trabajo como lo necesita un ejecutivo, computadora, laptop o Tablet, a veces nos daba un celular, pero los equipos que necesitábamos para presentar la línea de nuestros productos o cerrar una venta no las teníamos.

Se desarrollábamos la actividades de sistemas o de computo en la misma empresa o en alguna cabina de internet en la calle, después de un tiempo quisieron darnos a cada uno una laptop pero el mayor tiempo lo hacíamos en cabinas o en la casa enviando los correos o nuestros proyectados y el CallValue (Agenda de trabajo) mensualmente.

4. ¿Cuál es el grado de control en las actividades que tienen sobre el trabajo que realiza?

El control era principalmente a través de nuestra agenda que enviábamos mensualmente a nuestro jefe directo que era el gerente comercial en la que se mostraba las reuniones con los clientes, distribuidores y aumentar la cartera de clientes en mi caso del sector que manejaba, era un control ciclo que se hacia la primera semana del mes y se enviaba al gerente comercial y no teníamos un control propiamente ya que para eso estaba la agenda que enviábamos pero si ahabia algún cambio teníamos que comunicarlo.

5. ¿En este caso Ud. manejaba su propia agenda?

En esta caso igual que todos enviábamos nuestra agenda mensual como le digo al gerente comercial y ellos sabían que si íbamos a la oficina estábamos en reuniones o saliendo 
con la fuerza de ventas o clientes o si había algún cambio imprevisto se comunicaba al gerente comercial para que tenga conocimiento de ello.

6. ¿Cuál es el grado de control en la toma de decisiones relacionadas con el trabajo que realiza?

En mi caso y creo que en el de todos teníamos el apoyo del gerente comercial y del gerente general, si pensábamos sacar alguna promoción extra o algunos incentivos extras para la fuerza de ventas de alguna distribuidora que requería en ese momento que lo apoyemos con el desalojo de la mercadería que había comprado para esa parte teníamos el apoyo más del gerente general que del gerente comercial, en esa parte si puedo decir que nos apoyaban, no ocurría siempre pero las pocas veces que se hizo sí.

7. ¿Pero digamos tu tenías decisión sobre eso?

Si porque era al fin yo quien planteaba lo que a esa distribuidora le convenía los incentivos o alguna promoción extra para poder desalojar lo que nosotros pesábamos desalojar en ese mes para que haya una compra terminando esa promoción.

8. ¿Cada promoción tenía que ser supervisada por su jefe, cada decisión que Ud. tomaba?

No necesariamente la supervisión la realizaba yo, presentaba lo que se podía hacer, ellos me lo aprobaban y tenía que hacer el seguimiento y tenía que concordar con lo que había presentado en la venta. 
9. ¿Digamos que la decisión final era autorizada o aprobada por su jefe?

Si la decisión final era aprobada por el gerente comercial y el gerente general Bueno mi jefe inmediato si apoyaba, si había que hacer algún cambio en las propuestas que se presentaban a los clientes.

10. ¿Ha participado de programas de desarrollo personal, motivación laboral y formación realizados por la empresa?

No en los 3 años nunca hubo ese tipo de actividades es más los sugerí yo en su momento pero por ser una empresa nueva nunca se realizó.

11. Existe un sistema de recompensas económicas adecuado en la empresa?

No

12. Existen programas de desarrollo y crecimiento profesional en la empresa?

No

13. Existe en la empresa un sistema de comunicación organizacional?

En la empresa netamente con el jefe directo, por allí con el gerente general cuando era un caso espacial pero mayormente era con el jefe directo, le reportábamos a el y el presentaba al gerente general. La comunicación era directamente con el jefe inmediato en esta caso el gerente comercial. 
14. ¿Existía algún sistema en el cual le enviaban a ustedes algún feedback de acuerdo a su desarrollo profesional o un formato formal donde Ud. Enviaba algún tipo de información a la empresa?

Bueno el aspecto de ventas era enviar el seguimiento que le hacíamos a los clientes a la fuerza de ventas.

15. Pero digamos ya no en el aspecto de ventas porque eso lo ve directamente con su jefe sino en el tema del clima organizacional de ¿cómo se sentía Ud. En el trabajo su grado de tranquilidad en el trabajo?

Bueno era bastante presión, netamente las ventas al ser una empresa nueva en Perú que teníamos del gerente general y del gerente comercial eran llegar a hacer la cuota eso también afectaba el clima laboral porque no era la forma quizás de exigir una cuota que a las finales estaba bien pero las formas en como la hacían no eran las correctas, no era un clima laboral adecuado para poder seguir trabajando en una empresa que quizás trataba a sus empleados en una forma no sana y eso motivó a que mucha gente se retirara incluso en mi caso también llegar a un punto de renunciar a a empresa. Eso sería un poco lo que respiraba dentro de la empresa Eterna Perú.

16. Considera que en la empresa se toman de decisiones con conocimiento de los objetivos de trabajo y los resultados obtenidos?

Si los objetivos los anunciaba el gerente general en una reunión que el hacía casi trimestral dentro de la empresa pero eran objetivos para ser una empresa nueva objetivos inalcanzables por que no eran productos de consumo masivo no eran productos un desplazamiento rápido, eran productos que podías usarlos bastante tiempo, no era un desplazamiento rápido por ende las cuotas que nos ponían o se comprometía la empresa en 
darle a Colombia eran inalcanzables porque no había tampoco una parte de inversión de parte de ellos en el tema de publicidad en el tema de promociones no había, eso también nos generaba a nosotros malestar porque la misma empresa no te apoyaba, entonces creo que allí el gerente general cometió errores que está bien uno pude poner cifras altas pero no tanto, por ejemplo si duplicaste la venta en un año para el siguiente debes pedir un crecimiento de 5\%, 10\% o 15\% máximo, no ponerle un 100\%, ese es quizás un poco el error que cometieron los directivos de la empresa.

17. En la empresa se llevan a cabo programas para favorecer la innovación y la creatividad en el trabajo

Las ideas sí las teníamos los ejecutivos de la empresa para que se pongan en práctica pero al parecer Eterna Colombia no es política de ellos creo que en ningún país donde trabajan hacer ese tipo de actividades, creo que ellos tienen un chip en la cabeza que viene un producto aquí a Perú y que simplemente de va a vender porque es Eterna cuando la realidad de los mercados es diferente, Colombia con Perú es diferente, en cultura, modo de pensar e incluso en las ventas, siempre se les propuso a ellos hacer un cambio al menos en Perú para que sus productos puedan ser reconocidos y obviamente para sus productos los puedan consumir pero no era política de Colombia hacer ese tipo de actividades y obviamente nunca se hizo.

18. Sr. ¿Cómo considera el clima Laboral en una escala del 1 al 10 ?

En una escala del 1 al 10 yo creo que 3, la empresa Eterna Perú no tenía un clima laboral favorable bueno, es más hay trabajadores en otras empresas que les da gusto de ir a 
las oficinas, compartir con los compañeros, estar allí con ellos departiendo pero en Eterna Perú no se daba ese tipo de clima laboral, no te despertaba las ganas de ir a la oficina conversar con el gerente comercial, no había ese tipo de clima laboral favorable, cada quien trabajaba por su cuenta, hacían sus cosas, no había trabajo en equipo, el equipo creo que es lo esencial en una empresa, si no hay trabajo en equipo de todos, desde la persona que ve finanzas, el gerente general, los ejecutivos de venta, no crecen y es por eso que muchas empresas caen.

Entrevistado: Sr. Richard Jara Palacios

Posición en la empresa: Ejecutivo de ventas Canal

Tradicional Trabajó en Eterna Perú S.A. por 3 años 
Anexo 7: Escala de clasificación terminología estándar y procedimientos

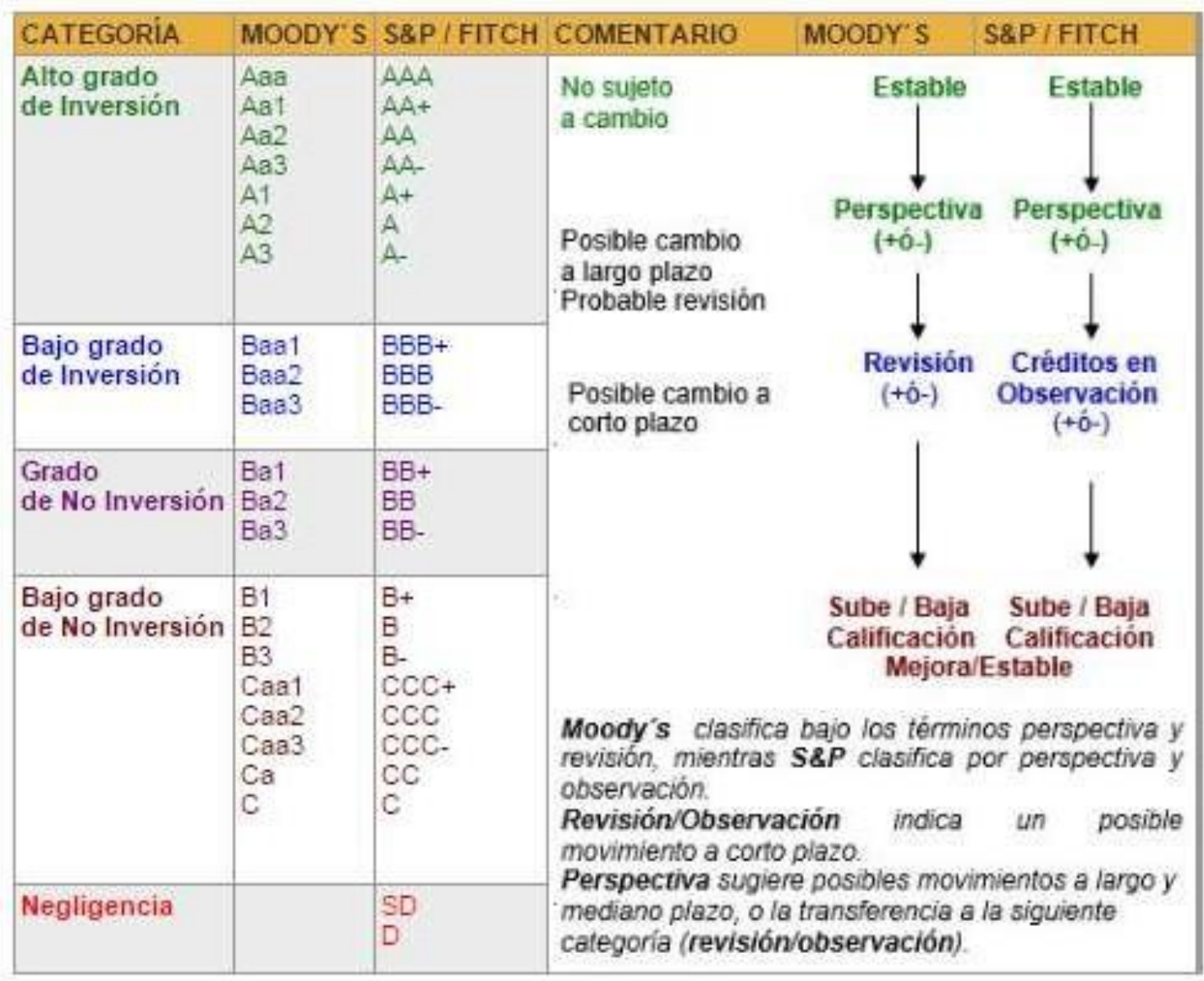


Anexo 8: Índices Económicos

\section{GfK ICC y actitudes hacia la economia}

\section{Encuesta Nacional Urbano Rural}

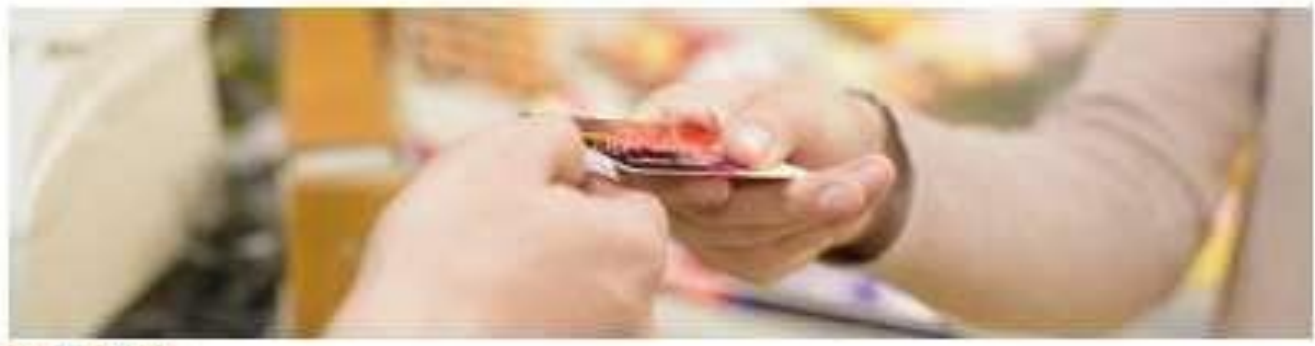

Contenido

1 Resumen del mes

Principales conclusiones.

Panorama económico

Situación del pais y economia personal.

Indice de confianza del consumidor (ICC)

Resitados a nivel nacional, por región y segün niveles socioeconomicos

Uso de gratificación de flestas Patrias

Uso y destino del ingreso adicional. 
¿Cómo es su situación económica personal en relación a un ano atrás: diria que mejoró, se mantiene igual o empeoró?

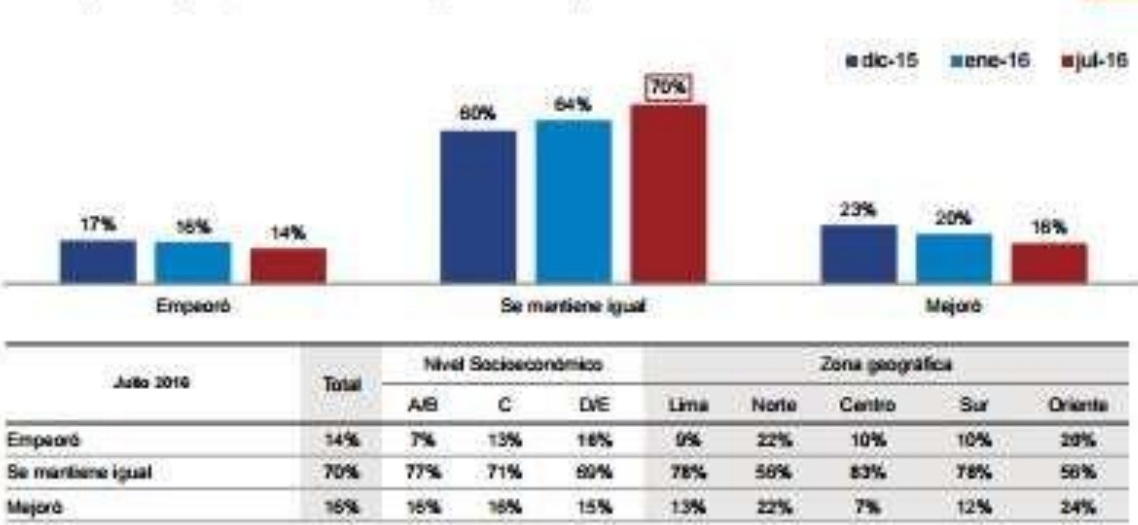

\section{Índice de Confianza del Consumidor (ICC)}

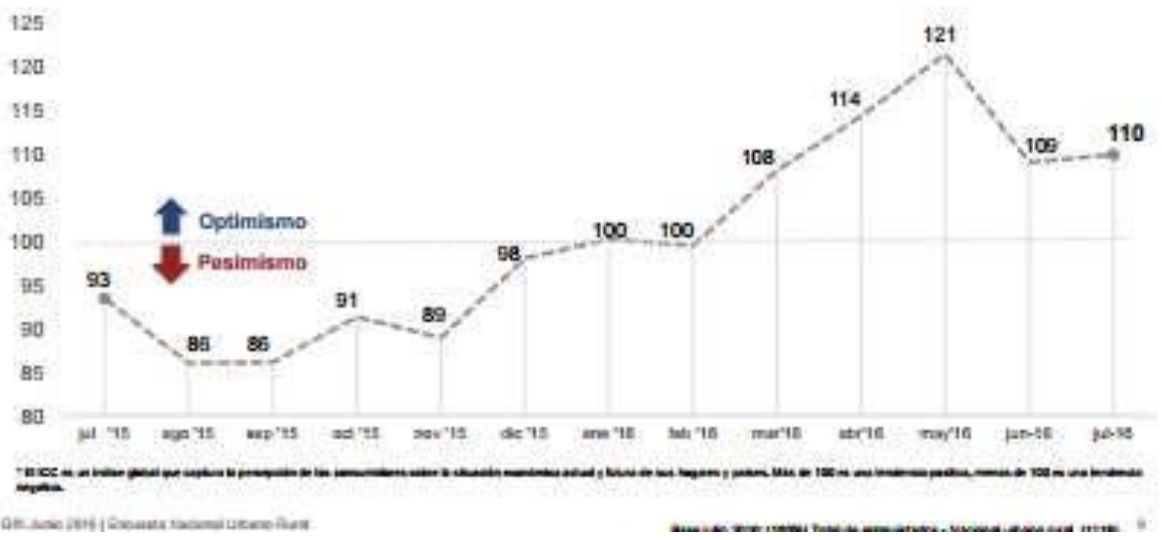


El Indice de Confianza del Consumidor (ICC)- Lima e interior

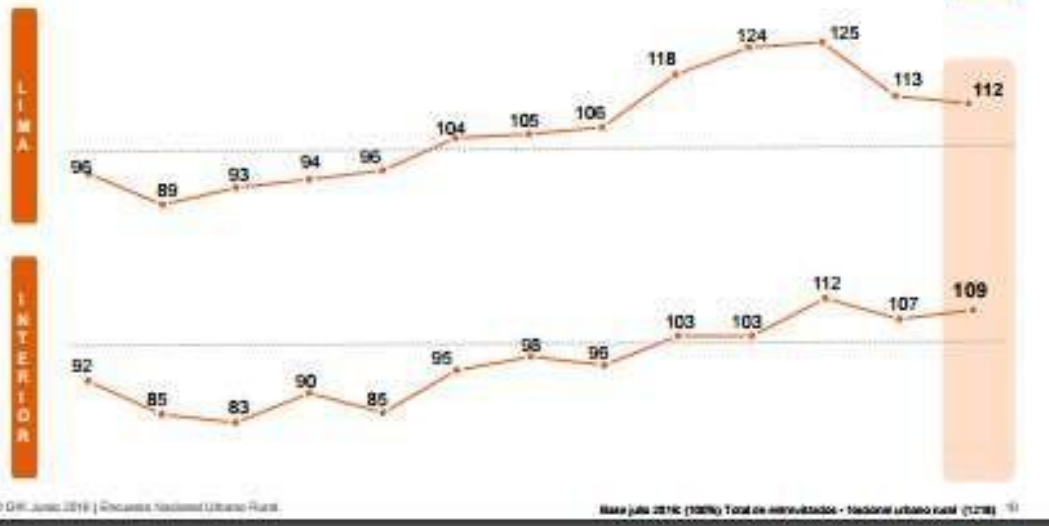

El Indice de Confianza del Consumidor (ICC)- Por zonas geográficas Crecimientos en las zonas Sur y Oriente.

\section{Norte}

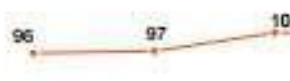
115. $104 \quad 105$ 195

\section{Centro}

97.<smiles>C[AlH2]</smiles>

102 $105 \quad 104$ 101

Sur

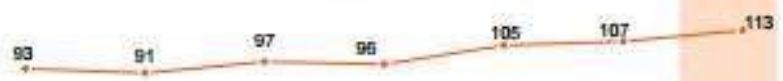

Orlante

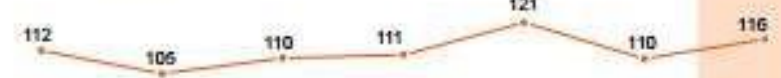

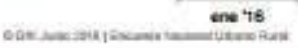
tob 7 mat 78 ati' 18

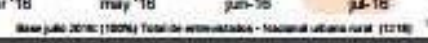

El Indice de Confianza del Consumidor (ICC)- Por nivel socioeconómico $100 \quad 290 \quad 98 \quad 104 \quad 108 \quad 105 \quad 111,119 \quad 120,126 \quad 125 \quad 119$

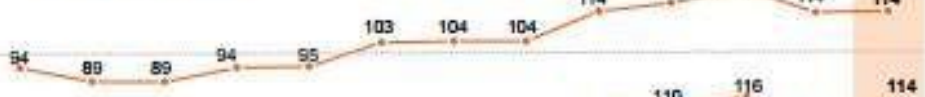

a. 9

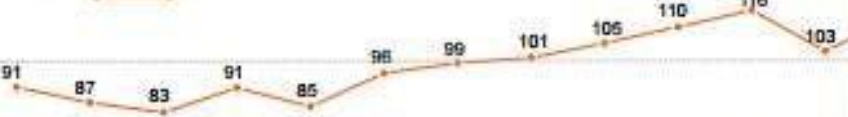

e 20

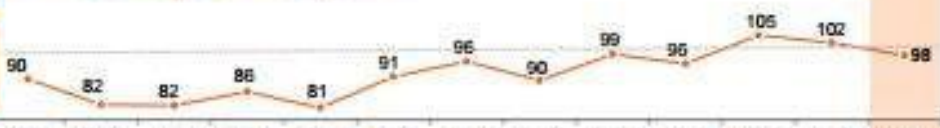

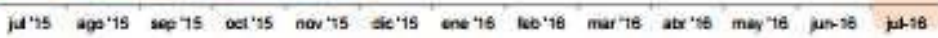

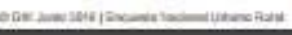


Anexo09: Señales de alerta "artículo de diario Gestión"

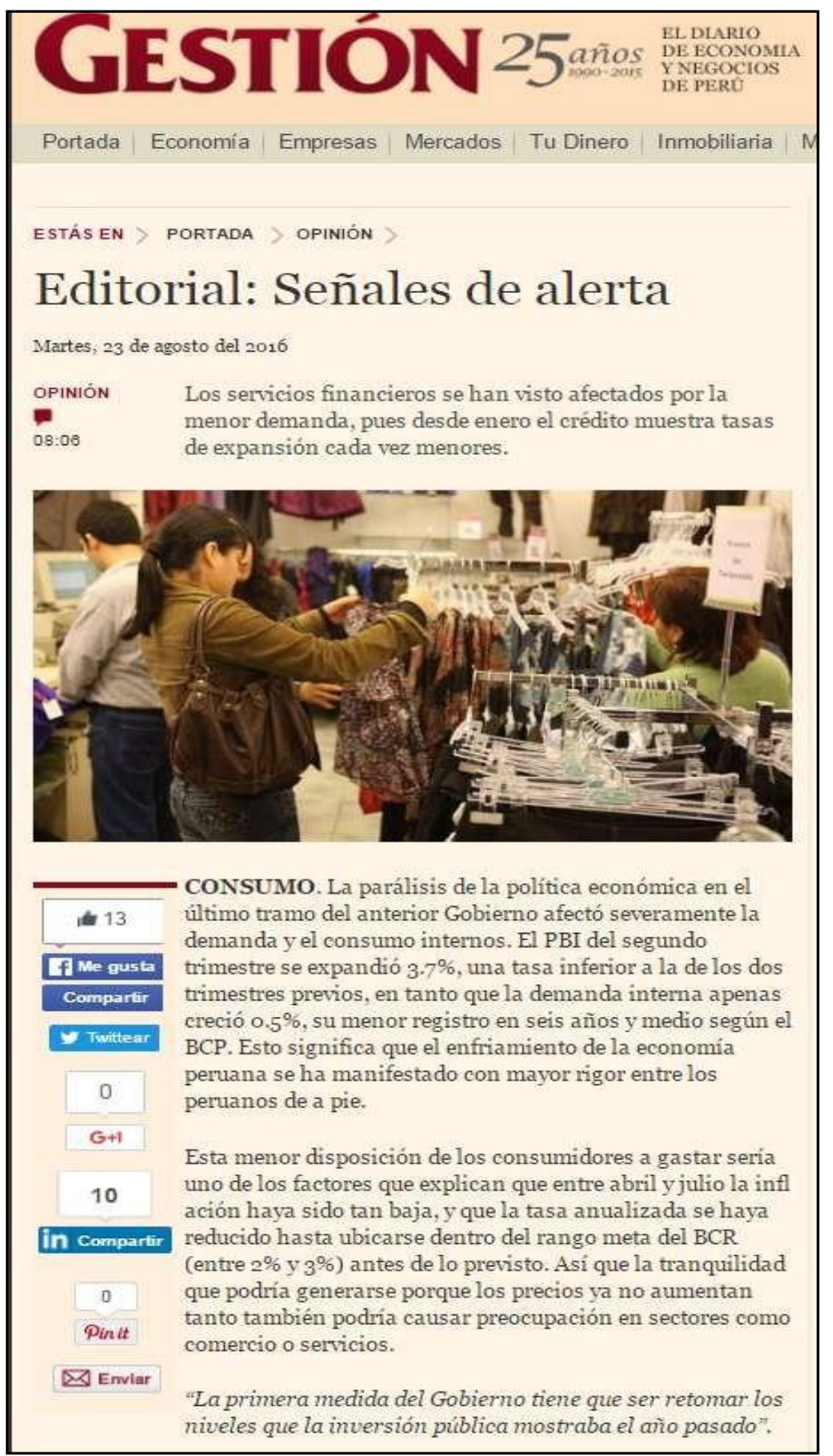


Anexo 10: Beneficios arancelarios de los productos de caucho con Colombia

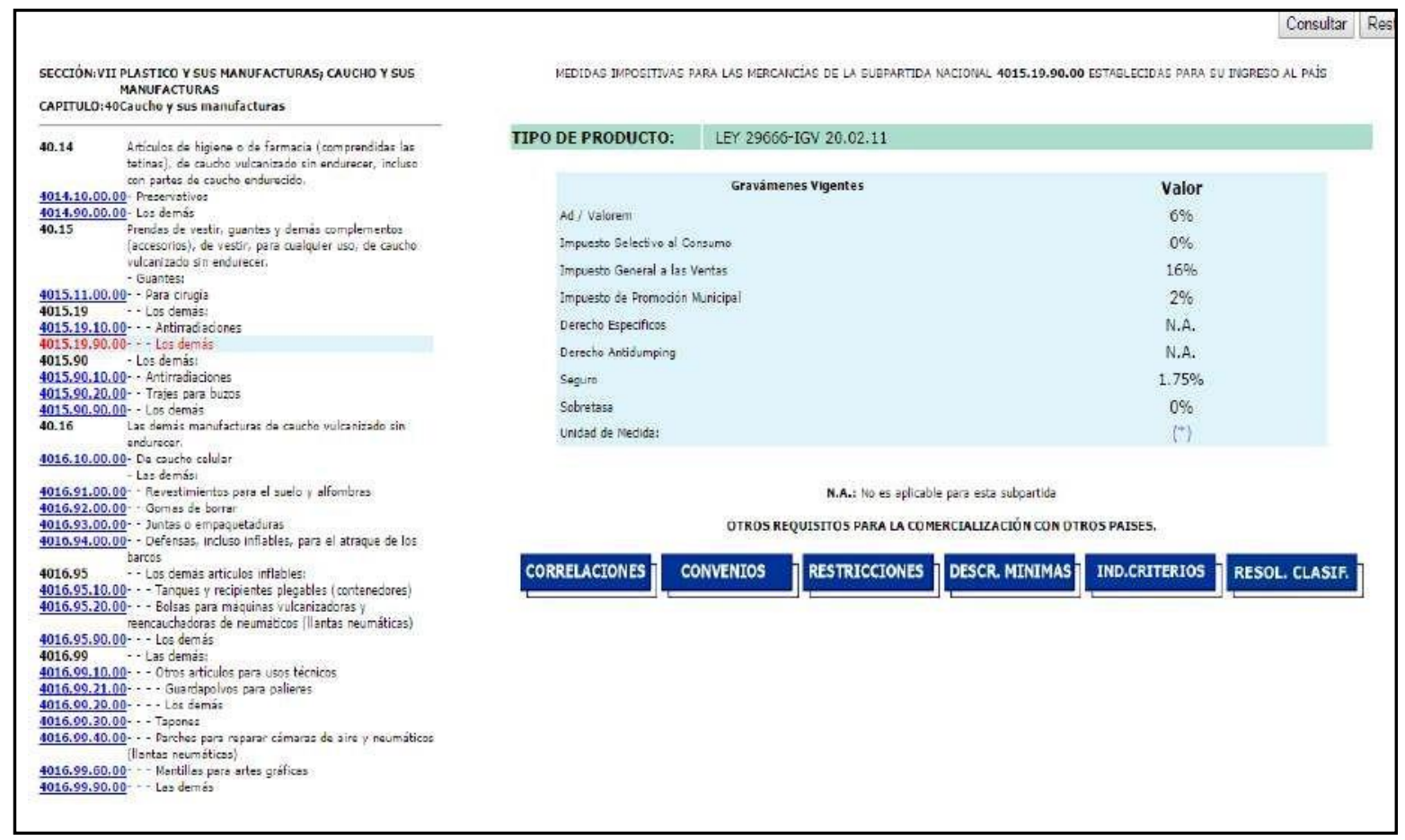


Anexo 11: Industria de Fabricación de Productos de Tocador y Limpieza Setiembre 2014

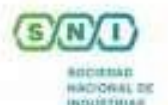

\section{Industria de Fabricación de Productos de Tocador y Limpieza \\ Setiembre 2014}

\section{REPORTE SECTORIAL}

La industria de fabricación de productos de tocador y limpieza, ubicada en la clase CIIU 2023 (Clasificación Industrial Internacional Uniforme Rev. 4), experimentó en el mes de junio del 2014, una disminución productiva de $-6,7 \%$.

Con este resultado acumula un crecimiento de $7,4 \%$ en el primer semestre del año 2014, ligeramente menor af registrado en similar periodo del año anterior cuando creció en $9,5 \%$.

Esta clase industrial comprende las actividades de fabricación de jabon, detergentes para lavar en polvo 0 liquidas, lavavajillas, productos para limpiar y pulir, preparados para perfumar $y$ desadorizar ambientes, $y$, perfumes $y$ preparados de tocador, entre otros productos.

De acuerdo a la infarmación de los productos que marcan la tendencia de este sector industrial, son las detergentes los que tienen un mayor peso en la estructura sectorial, ademós de los jabones para ropa, jabones de tocador, limpiadores y lavavajillas, entre atros.

En los últimos años, la mayor fobricación de productos de tocador y articulos de limpieza, ha estado relacionado a la mejora en los ingresos de la población, que ha impulsado una mayor aferta $y$ renovación de productos, nuevas marcas y formatos de presentocion, requiriendo una mayor inversión de los empresas.

En este sentido, la capacidad instalada de las industrias de este sector, se ha venido incrementando los útimos años, cerrando el año 2013 con una tasa de utilización del $81,4 \%$ (BCRP).
Producción industrial

Variación porcentual mensual, año 2014
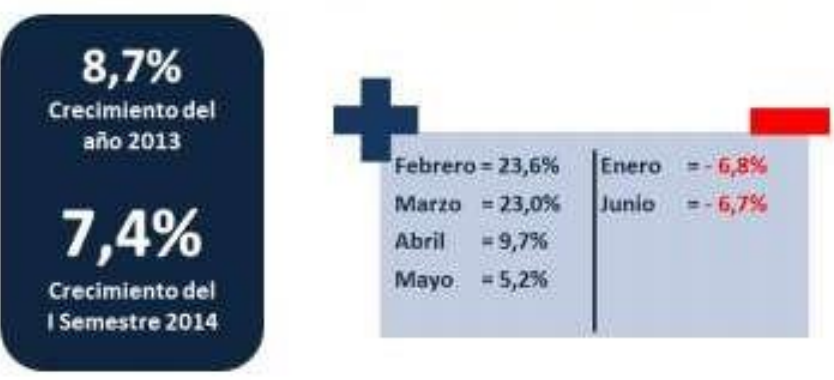

Variación \% mensual de la industria de fabricación de productos de tocador y limpieza, Enero 2013 - Junio 2014

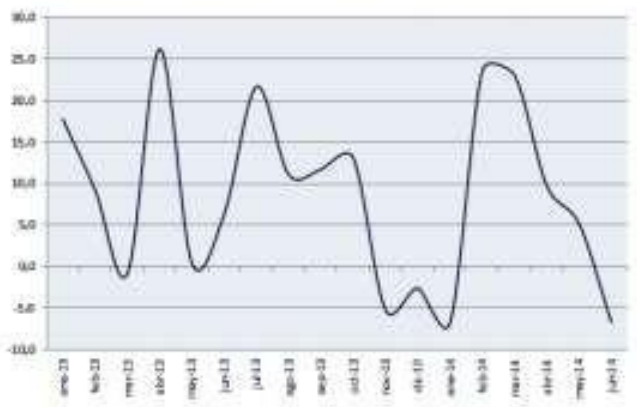

Relación de productos de las principales empresas que participan en la muestra del índice del volumen fisico de la producción manufacturera

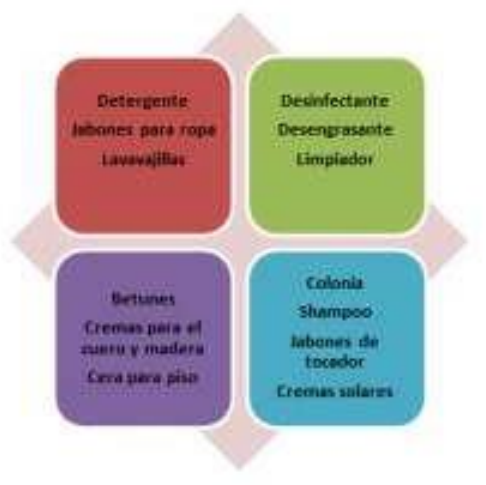


Anexo 12: Perfil del Bodeguero 2014

\section{Perfil de la Bodega y el Bodeguero 2014 \\ Lima Metropolitana- Arequipa - Trujillo}

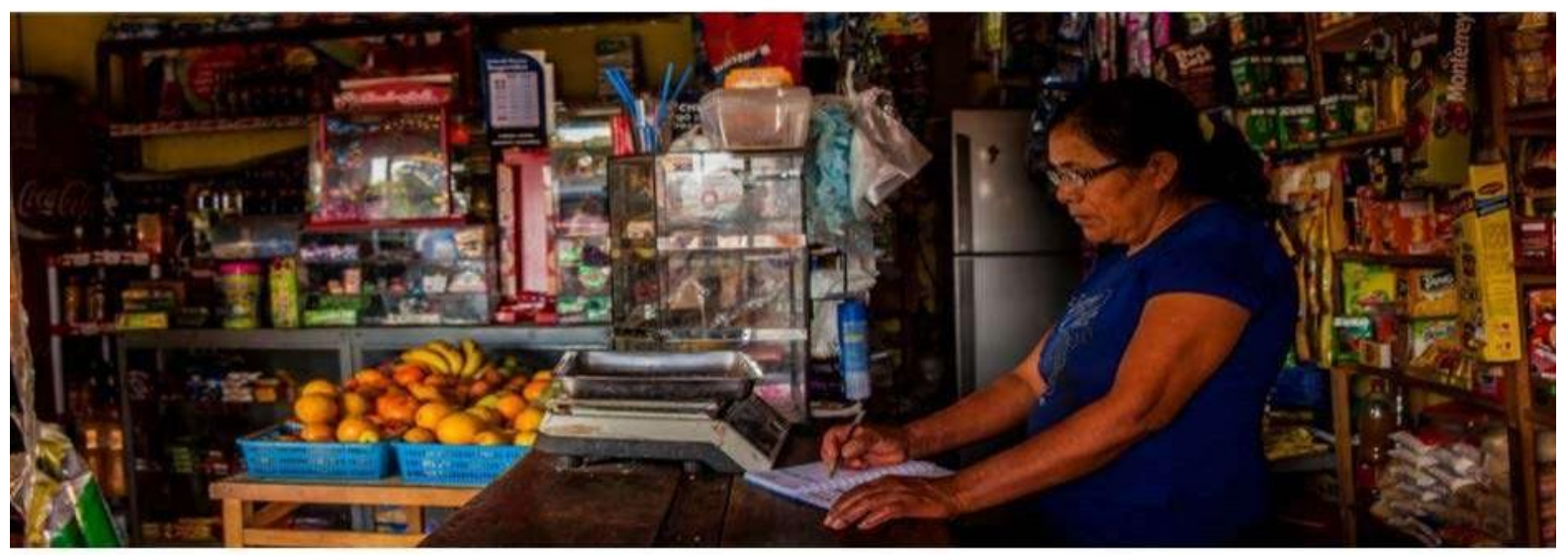

Mayo 2014

(a) 2014 lpsos. All rights reserved. Contains Ipsos' Confidential and Proprietary information and may not be disclosed or reproduced without the prior written consent of Ipsos.

Ipsos

\section{El informe Perfil de la bodega y el bodeguero 2014, es una publicación de Ipsos Perú}

Dirección del estudio Asistente de Investigación Ventas: Giuliana Nuñez (Giuliana.Nunez@ipsos.com) : Kelly Cayhuatla (Kelly_Cayhualla@ipsos.com) : Johans Tang (johans.tang@ipsos.com)

Av. Reducto 1363 Lima 18 - Perú

Telf. $(51-1) 610-0100$

Fax: $(51-1) 610-0191$

www.ipsos.pe

Hecho depósito legal $N^{\circ} 2014-11450$

Búscanos como losos Perú en:

f] $[$ in Youtute 


\section{Las bodegas se consolidan y especializan como canal minorista, constituyéndose en una fuente cada vez más importante y estable de ingresos para el hogar.}

- Los ingresos del punto de venta son el principal sustento de más del $40 \%$ de hogares de los bodegueros en Lima y Trujillo y cerca del $50 \%$ en Arequipa. Alrededor del $70 \%$ cuenta también con recursos provenientes de trabajos, sobre todo dependientes, de otros miembros del hogar.

- En Lima se observa un incremento notable de los jefes de hogar entre los bodegueros, quiénes alcanzan ahora a ser casi la mitad en este segmento (47\%). Así, el negocio es cada vez más una fuente esencial de ingresos para el hogar.

- La antigüedad de las bodegas ha aumentando en los últimos años. Actualmente oscila entre 10 a 12 años, lo que denota una menor rotación y mayor estabilidad del canal.

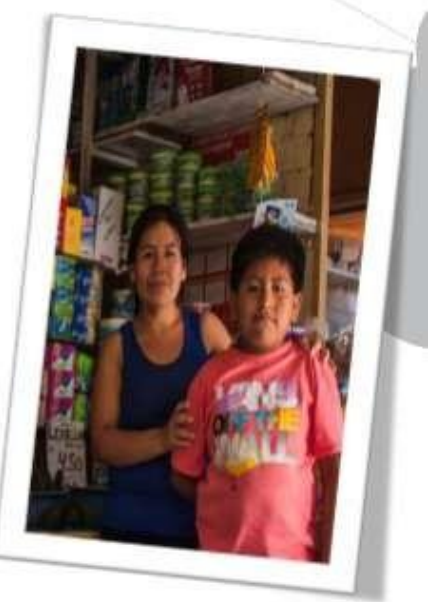

- La venta promedio creció en más del 10\% en Lima y Arequipa entre el 2012 y el 2014. Aumenta la permanencia del cliente, la concurrencia en días de semana y el ticket de compra.

- La mayor parte de bodegueros percibe que el negocio en el último año ha sido mejor o igual que antes, y una amplia mayoría (95\% a $96 \%$ ) piensa continuar en la actividad.

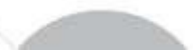

Ipsos Marketing

\section{¿Qué consideramos bodegas?}

Las bodegas son locales independientes donde se venden principalmente abarrotes (productos envasados: alimentos, artículos de aseo personal, limpieza, menestras, gaseosas, golosinas, etc. $)^{*}$

Para el presente informe, se tomó en cuenta como uno de los filtros principales, que la bodega venda al menos 4 de los siguientes productos: aceite, arroz, azúcar, fideos, gaseosas, leche o menestras.
Adicionalmente, se consideró el tamaño de la bodega como una variable de segmentación, el cual fue clasificado en chico $(<=18 \mathrm{~m} 2$ ), mediano (De 19 a $34 \mathrm{~m} 2$ ) y grande $(>=35 \mathrm{~m} 2)$ de acuerdo con el área del local.

Cabe resaltar que en el caso de las bodegas- ventana, éstas fueron clasificadas como chicas, con excepción de las que tenían más de dos tenderos, que fueron consideradas como medianas.

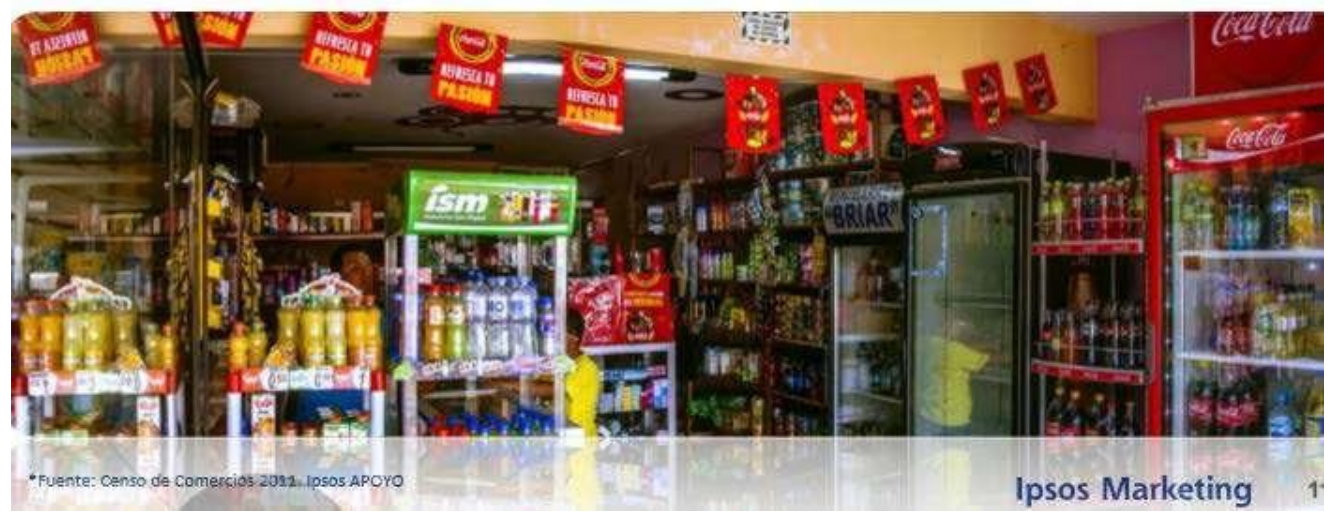




\section{¿Por qué son tan importantes las bodegas?}

- El canal tradicional, especialmente el conformado por bodegas, es visitado con mayor frecuencia por el ama de casa para realizar las compras de productos para el hogar, siendo esta periodicidad de visita mayor en los niveles socioeconómicos más bajos.

Asistencia a bodegas

$54^{65} 61$

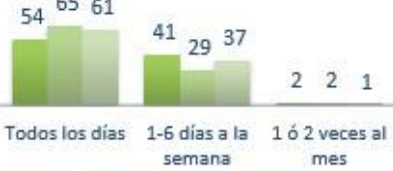

$\pm 2011=2012 \equiv 2013$

Asiste todos los dias Según Nivel Socioeconómico (\%)

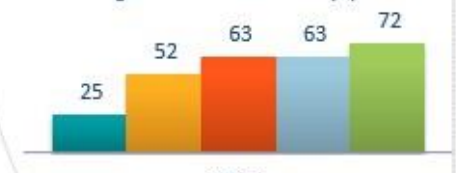

2013

- NSE A $\approx$ NSE B $\approx$ NSE C $\equiv$ NSE D $=$ NSEE

Base: Total de amas de casa entrevistadas 609

•Fuente: IGM Perfil del Ama de Casa 2013. Ipsos Perú
Asistencia a mercado

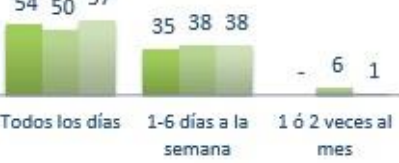

= $2011=2012=2013$

Asiste todos los días Según Nivel Socioeconómico \%)

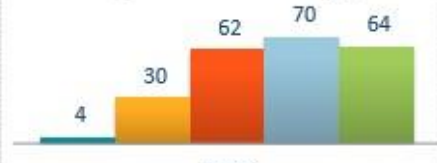

2013

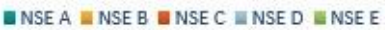

\section{con mayor frecuencia por el ama de
dicidad de visita mayor en los niveles} Asistencia a supermercados

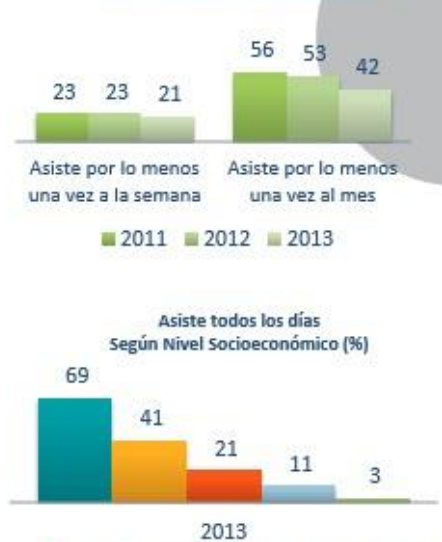

a NSEA $=$ NSE B $\approx$ NSE C $=$ NSED $=$ NSEE

Ipsos Marketing

\section{¿Por qué son tan importantes las bodegas?}

- La mayor proporción del gasto mensual del ama de casa en compra de productos para el hogar se efectúa a través del canal tradicional (77\%), en el que las bodegas concentran el $21 \%$ de dicho presupuesto.

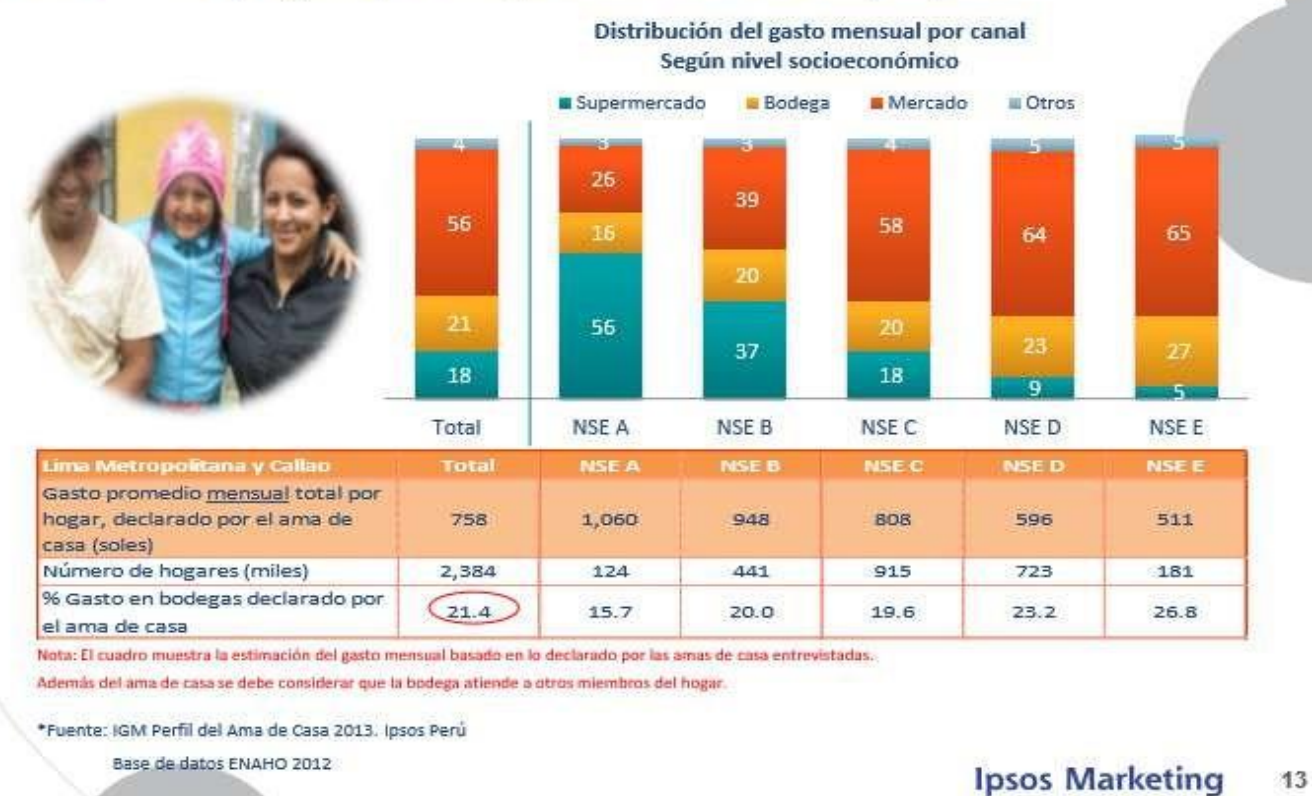




\section{Lima Metropolitana}

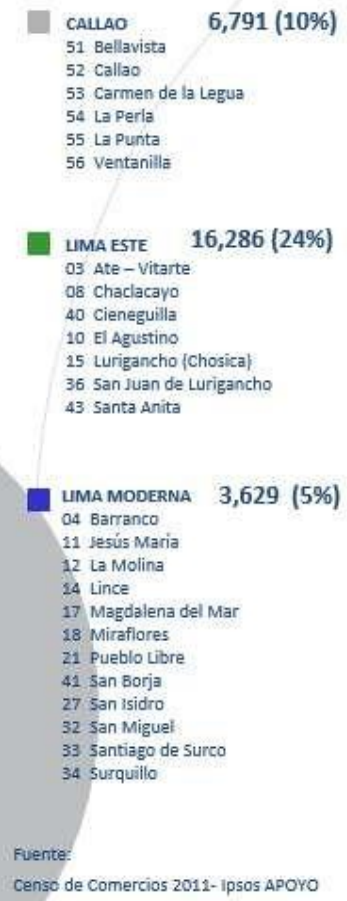

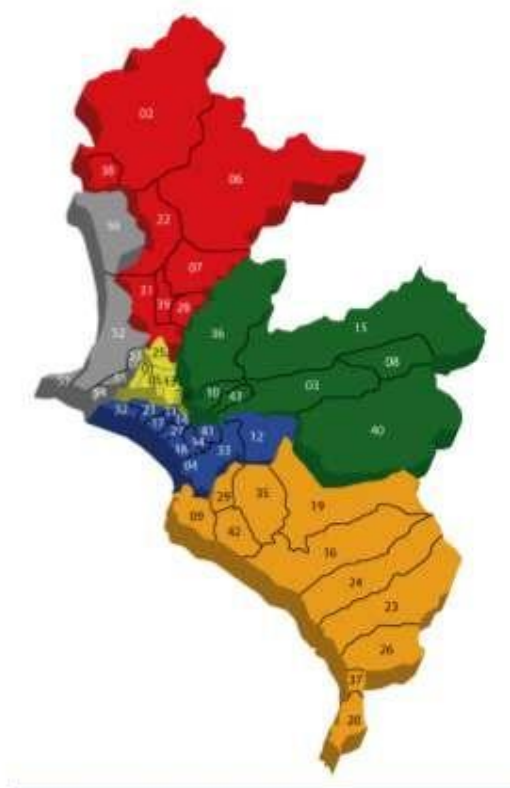

Universo Total de Bodegas 2011= 66,734

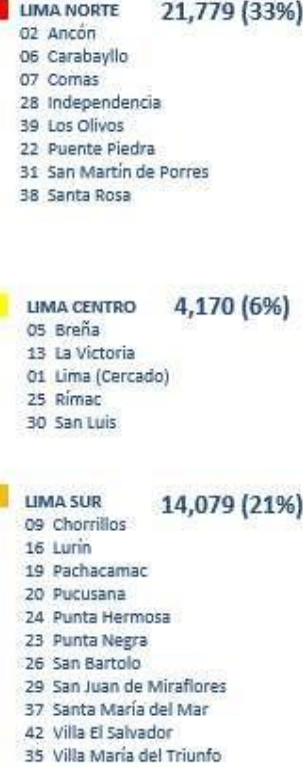

Ipsos Marketing

Universo Lima Metropolitana - Año 2011

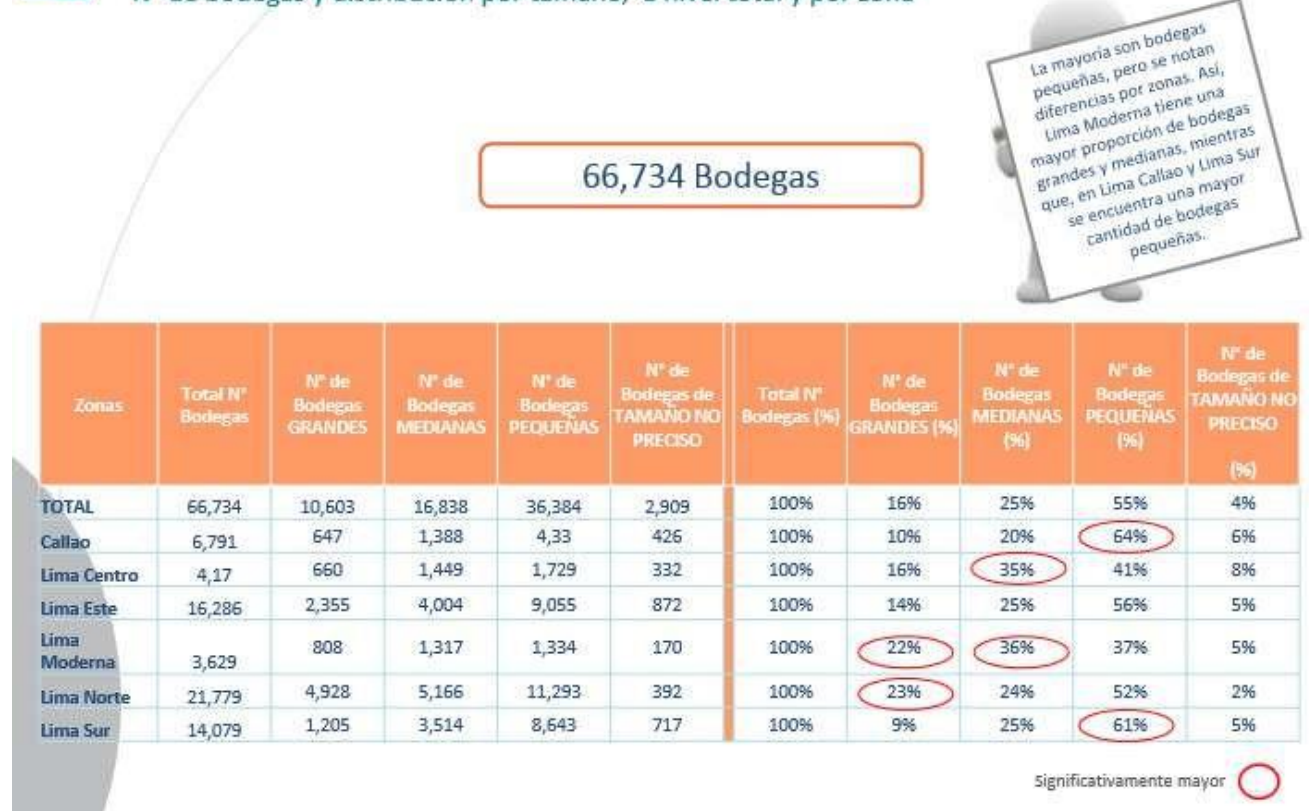


Universo Arequipa- Año 2011

$N^{\circ}$ de bodegas y distribución por tamaño

\begin{tabular}{|c|c|c|c|c|c|c|c|c|c|c|}
\hline & $\begin{array}{l}\text { Tot in } \\
\text { Bosdegas }\end{array}$ & 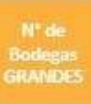 & $\begin{array}{l}\text { Prde } \\
\text { Boderas } \\
\text { Misoyanias }\end{array}$ & 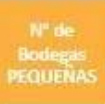 & $\begin{array}{l}\text { Wrode } \\
\text { Bodecra de } \\
\text { TAMAvio No } \\
\text { PRícoso }\end{array}$ & $\begin{array}{l}\text { Total N } \\
\text { Bodiges } \\
\text { (6) }\end{array}$ & 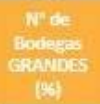 & $\begin{array}{l}\text { Mode } \\
\text { Bodegras } \\
\text { MEDIANAS: } \\
\text { (S) }\end{array}$ & $\begin{array}{l}\text { Node } \\
\text { Bodeles } \\
\text { pequinis } \\
\text { (b) }\end{array}$ & 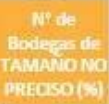 \\
\hline TOTAL & 8,752 & 2,316 & 1,951 & 4,323 & 162 & $100 \%$ & $26 \%$ & $22 \%$ & $49 \%$ & $2 \%$ \\
\hline
\end{tabular}

$\mathrm{N}^{\circ}$ de bodegas por manzana y $\mathrm{N}^{\circ}$ de personas por bodega

\begin{tabular}{|c|c|c|c|c|c|}
\hline & $\begin{array}{l}\text { Totalle: } \\
\text { Bodegas } 2011 \\
\text { (b) }\end{array}$ & $\begin{array}{l}\text { Node Mamanias } \\
\frac{2012}{\text { (b) }}\end{array}$ & $\begin{array}{l}\text { Pobleción estimada } \\
2012 \text { [c] }\end{array}$ & $\begin{array}{l}\text { Bodegas (a)// } \\
\text { Manzinas (b) }\end{array}$ & $\begin{array}{l}\text { Población (c) } \\
\text { Bodegas (a) }\end{array}$ \\
\hline TOTAL & 8,752 & 12,382 & 843,126 & 0.71 & 96 \\
\hline
\end{tabular}

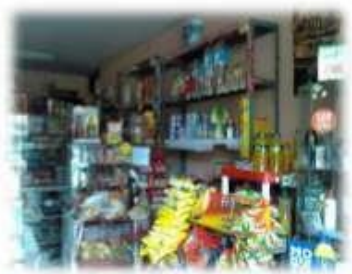

En Arequipa hay una mayor proporción de bodegas grandes que en Lima.

Ademós, existe un poco menos de 1 bodego por cada manzana y una

población promedio de 94 habitontes por establecimiento, valares cercanos aunque menores a los observodos en Lima Metropolitano.

Fuentes:

(a) Censo de Comercios 2011. Ipsos APOYO

(byc) Estadistica Poblacional 2012- INEI

Universo Trujillo- Año 2011

$\mathrm{N}^{\circ}$ de bodegas y distribución por tamaño

\begin{tabular}{|c|c|c|c|c|c|c|c|c|c|c|}
\hline & $\begin{array}{l}\text { Tatal N" } \\
\text { Bodegas }\end{array}$ & $\begin{array}{l}N^{N} \text { de } \\
\text { Bodegas } \\
\text { GRANCES }\end{array}$ & $\begin{array}{l}N^{*} \text { de } \\
\text { Bodegas } \\
\text { MECHANAS }\end{array}$ & $\begin{array}{l}N^{*} \text { de } \\
\text { Bodegas } \\
\text { PEQUEÑAS }\end{array}$ & $\begin{array}{l}N^{*} \text { de } \\
\text { Bodegas de } \\
\text { TAMAÑO } \\
\text { NO PRECISO }\end{array}$ & $\begin{array}{l}\text { Total No } \\
\text { Bodegas } \\
(96)\end{array}$ & $\begin{array}{c}N^{*} \text { de } \\
\text { Bodegas } \\
\text { GRANDES } \\
\text { (\%) }\end{array}$ & $\begin{array}{c}\text { No de } \\
\text { Bodegas } \\
\text { MEDIANAS } \\
\text { (96) }\end{array}$ & $\begin{array}{l}\text { No de } \\
\text { Bodegas } \\
\text { PEQUEÑAS } \\
\text { (96) }\end{array}$ & $\begin{array}{l}N^{\circ} \text { de } \\
\text { Bodegas de } \\
\text { TAMAÑNO } \\
\text { NO PRECISO } \\
\text { (95) }\end{array}$ \\
\hline TOTAL & 7,311 & 349 & 1,499 & 5,211 & 252 & $100 \%$ & $5 \%$ & $21 \%$ & $71 \%$ & $3 \%$ \\
\hline
\end{tabular}

$\mathrm{N}^{\circ}$ de bodegas por manzana y $\mathrm{N}^{\circ}$ de personas por bodega

\begin{tabular}{|c|c|c|c|c|c|}
\hline & $\begin{array}{c}\text { Total N" } \\
\text { Bodegas } 2011 \\
\text { (a) }\end{array}$ & $\begin{array}{l}\text { Node } \\
\text { Mamanas } \\
2012(b)\end{array}$ & $\begin{array}{l}\text { Poblacion } \\
\text { estimada } 2012 \\
\text { (c) }\end{array}$ & $\begin{array}{l}\text { Bodegas (a) } \\
\text { Manzanas (b) }\end{array}$ & $\begin{array}{c}\text { Poblacioin (C)/ } \\
\text { Bodegas (a) }\end{array}$ \\
\hline TTAL & 7,311 & 5,436 & 762,25 & 1.34 & 104 \\
\hline
\end{tabular}

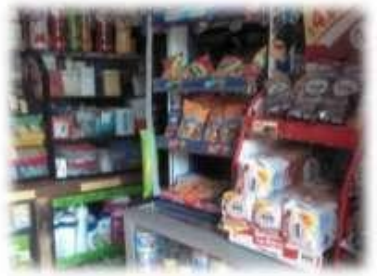

En Trujillo se nota una mayor concentración de bodegos que en Lima y Arequipo, existiendo más de 1 bodega por manzana, y atienden a una población promedio por establecimiento de 104 personas - contidod similar a la de Arequipa-

Además, hay una proporción notoblemente mayor de bodegas pequeños que la que se observa en Lima o Arequipo.

Fuentes:

(a) Censo de Comercios 2011. ipsos APOYO

(b y c) Estadística Poblacional 2012-INEI 
Gestión de la bodega

Ipsos Un día normal en la vida del bodeguero

De Lunes a Viernes (Hora promedio de actividades)
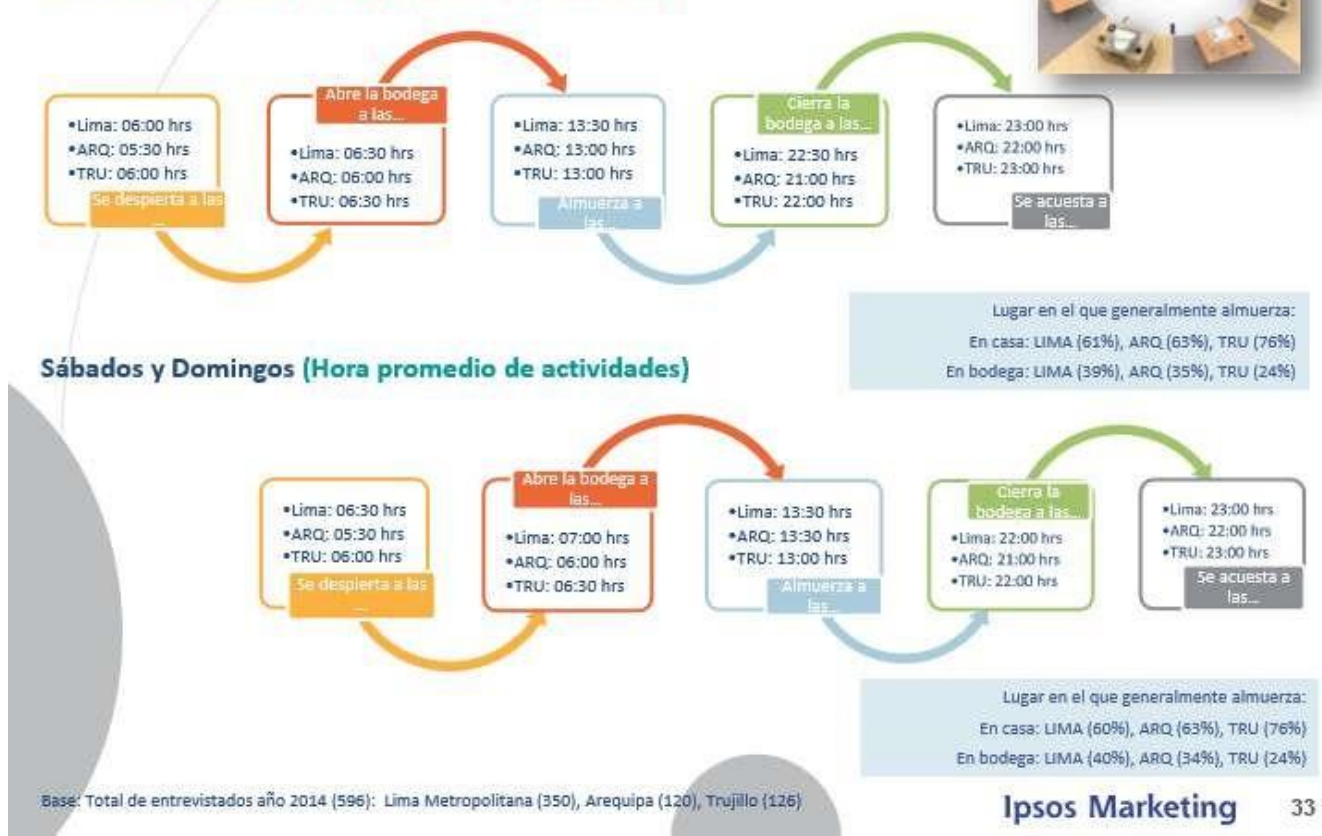

En bodega: UMA (3996), ARQ (35\%), TRU (2496)

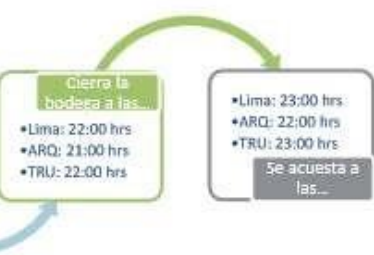

Lugar en el que generalmente almuerza: En casa: UMA (60\%6), ARQ \{63\%6), TRU (7696\} En bodega: LIMA \{4096), ARQ (3496), TRU (2436\}

Ipsos Marketing 33

\section{Gestión de la bodega}

Ipsos Horario de atención y trabajo

De Lunes a Viernes (Hora promedio de actividades)
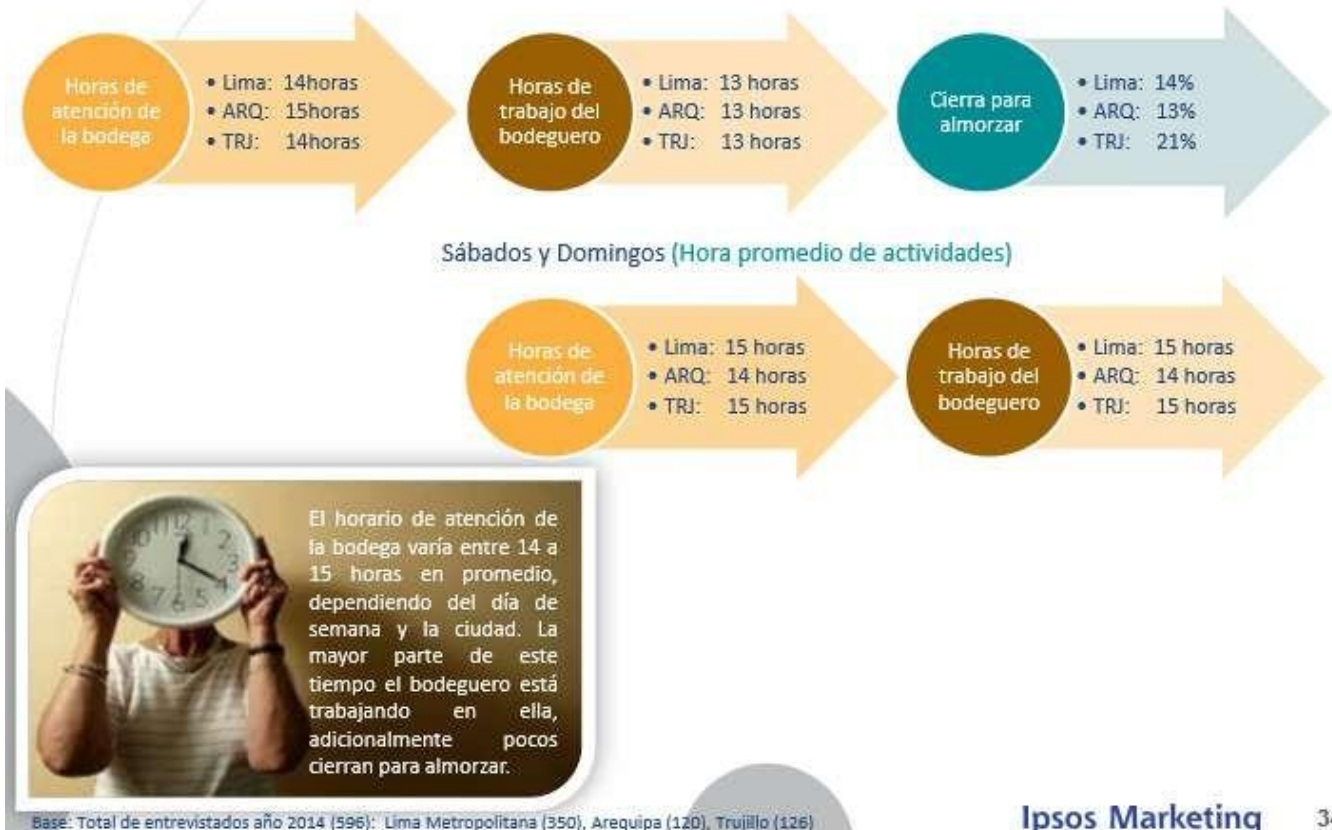

Sábados y Domingos (Hora promedio de actividades) 


\section{Gestión de la bodega}

Ipsos Orden en la exhibición de los productos: Motivo por el cual da preferencia a alguna marca o categoría Comparativo Por ciudades (\%)

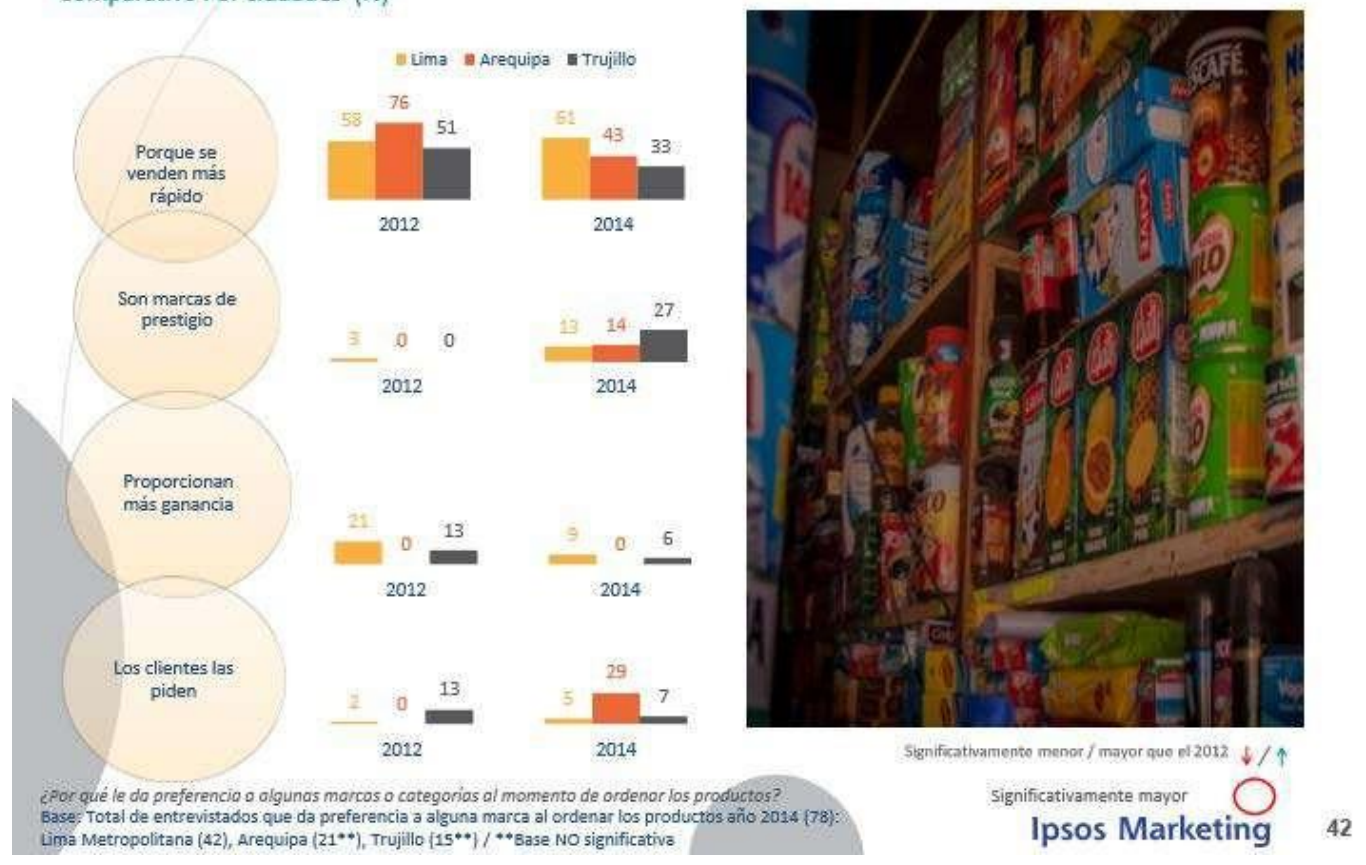


Anexo 13: Liderazgo en productos de cuidado personal y limpieza del hogar 2011

Ipsos

Ipsos Marketing

Liderazgo en productos de cuidado personal y limpieza del hogar 2011

Informe Gerencial de Marketing

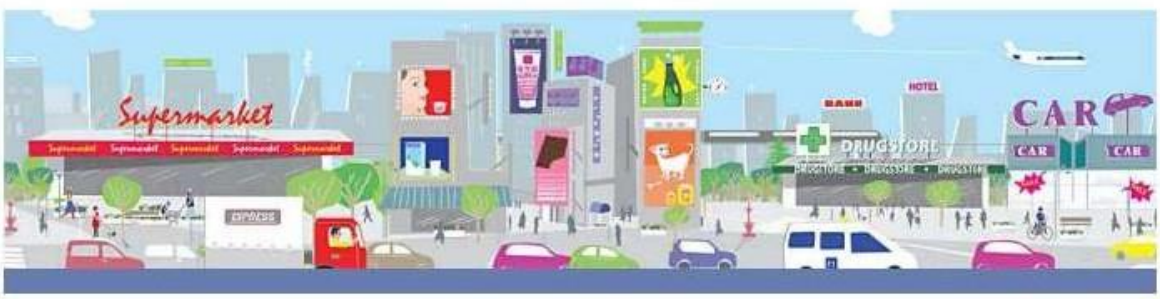

\section{Q. Ipos Aporo Penetración de productos de limpieza del \\ Ipsos hogar}

Uso habitual: Por lo menos una vez al mes

\begin{tabular}{|c|c|c|c|c|c|c|c|c|c|c|c|}
\hline \multirow{3}{*}{ Principalas respuestas } & \multicolumn{11}{|c|}{$\begin{array}{c}\text { Productos usados habitualmente por mas del } 60 \% \text { de hogares } \\
\text { Productos de alta penetración }\end{array}$} \\
\hline & \multirow{2}{*}{ TorAL } & \multirow{2}{*}{$\frac{\text { rotal }}{2010}$} & \multirow{2}{*}{$\frac{\text { Torac }}{2011}$} & \multicolumn{5}{|c|}{ NSE } & \multicolumn{3}{|c|}{ EDAD } \\
\hline & & & & A & $\begin{array}{l}8 \\
\%\end{array}$ & $\frac{c}{4}$ & $\%$ & $E$ & $\begin{array}{c}12 \text { a } 17 \\
\%\end{array}$ & $\frac{18 a 24}{\%}$ & $\begin{array}{c}25 \text { a } 35 \\
\%\end{array}$ \\
\hline Detergente para ropa & 99 & 100 & 100 & 98 & 100 & 100 & 100 & 100 & 100 & 100 & 100 \\
\hline Papel higienico & 100 & 100 & 100 & 100 & 100 & 100 & 100 & 100 & 100 & 100 & 100 \\
\hline Jabón de tocador & 98 & 98 & 95 & 87 & 97 & 94 & 95 & 98 & 93 & 97 & 96 \\
\hline Lejia & 94 & 95 & 90 & 86 & 85 & 91 & 92 & 90 & 87 & 91 & 94 \\
\hline Jabón para ropa & 89 & 85 & 88 & $\pi$ & 80 & 89 & 92 & 91 & 87 & 86 & 94 \\
\hline Betùn & 95 & 91 & 87 & 70 & 84 & 89 & 90 & 93 & 93 & 86 & 83 \\
\hline Desinfectante & 78 & 75 & 74 & 95 & 92 & 83 & 69 & 33 & 73 & 73 & 76 \\
\hline Lavavajilla en detergente & 90 & 92 & 73 & 81 & 68 & 76 & 70 & 78 & 70 & 72 & 80 \\
\hline Esponjas de limpieza & 80 & 85 & 71 & 89 & 80 & 79 & 64 & 52 & 72 & 71 & 72 \\
\hline
\end{tabular}




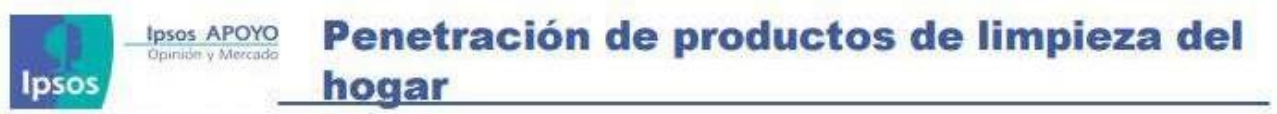

Uso habitual: Por lo menos una vez al mes

\begin{tabular}{|c|c|c|c|c|c|c|c|c|c|c|c|}
\hline \multirow{3}{*}{ Princlpales respuestas } & \multicolumn{11}{|c|}{$\begin{array}{c}\text { Productos usados habitualmente por más del } 30 \% \text { de hogares } \\
\text { Productos de mediana penetracion }\end{array}$} \\
\hline & \multirow{2}{*}{$\begin{array}{l}\text { TOTAL } \\
\frac{2009}{\%}\end{array}$} & \multirow{2}{*}{$\begin{array}{l}\text { TOTAL: } \\
\frac{2010}{\%}\end{array}$} & \multirow{2}{*}{$\frac{\text { TOTAL }}{2011}$} & \multicolumn{5}{|c|}{ NSE } & \multicolumn{3}{|c|}{ EDAD } \\
\hline & & & & A & B & $\%$ & $\begin{array}{l}0 \\
\%\end{array}$ & $E^{6}$ & $\frac{12 a 47}{4}$ & $18 a 24$ & 25 a 39 \\
\hline Servilietas de papel & 58 & 57 & 55 & 89 & 73 & 62 & 43 & 25 & 47 & 55 & 72 \\
\hline Cera para pisos & 61 & 54 & 49 & 69 & 78 & 60 & 35 & 7 & 45 & 53 & 50 \\
\hline $\begin{array}{l}\text { Desengrasantes I } \\
\text { Quilagrasa }\end{array}$ & 44 & 37 & 48 & 85 & 65 & 62 & 29 & 17 & 45 & 51 & 47 \\
\hline $\begin{array}{l}\text { Suavizante de ropa ! } \\
\text { enjuague }\end{array}$ & 49 & 52 & 47 & 67 & 60 & 43 & 50 & 30 & 45 & 51 & 45 \\
\hline $\begin{array}{l}\text { Guantes de jebe para } \\
\text { limpleza }\end{array}$ & 44 & 36 & 37 & 73 & 34 & 45 & 32 & 22 & 31 & 39 & 47 \\
\hline Shampoo para betes & 48 & 40 & 37 & 33 & 43 & 37 & 35 & 40 & 54 & 28 & 22 \\
\hline Algodón & 38 & 29 & 35 & 58 & 39 & 33 & 40 & 15 & 35 & 38 & 28 \\
\hline Papel toalla & 39 & 30 & 33 & 82 & 62 & 33 & 13 & 14 & 31 & 39 & 26 \\
\hline
\end{tabular}

Base: Total de amas de casa entrevistadas (308)

Insos Marketina sid

\begin{tabular}{l} 
Ipsos Ipsos Aporo $\begin{array}{l}\text { Frecuencia de uso de productos de } \\
\text { limpieza del hogar }\end{array}$ \\
\hline
\end{tabular}

\begin{tabular}{|c|c|c|c|c|c|}
\hline Productos: & $\begin{array}{c}\text { Diario } 1 \\
\text { Yarias } \\
\text { veces por } \\
\text { semana } \\
\text { (ख) }\end{array}$ & Samanal & $\begin{array}{l}\text { Quincenal } \\
\text { Mensual } \\
\text { (ex) }\end{array}$ & $\mid \begin{array}{c}\text { peasional } \\
\left(\psi^{\prime}\right)\end{array}$ & $\begin{array}{l}\text { Yunce } \\
(\%)\end{array}$ \\
\hline Detergente para ropa & 71 & 29 & 0 & 0 & 0 \\
\hline Papel higienico & 100 & 0 & 0 & 0 & 0 \\
\hline Jabón de tocador & 93 & 1 & 1 & 1 & 4 \\
\hline Lejia & 60 & 21 & 9 & 4 & 6 \\
\hline Jabón para ropa & 53. & 30 & 5 & 5 & 7 \\
\hline Betùn & 80 & 5 & 2 & 6 & 7 \\
\hline Desinfectante & 54 & 14 & 6 & 3 & 23 \\
\hline $\begin{array}{l}\text { Lavavajilla en } \\
\text { detergente }\end{array}$ & 72 & 0 & 1 & 1 & 26 \\
\hline Esponjas de limpieza & 67 & 3 & 1 & 7 & 22 \\
\hline Servilletas de papet & 43 & 9 & 3 & 17 & 28 \\
\hline Cera para pisos & 8 & 25 & 16 & 6 & 45 \\
\hline $\begin{array}{l}\text { Desengrasantes / } \\
\text { Quitagrasa }\end{array}$ & 36 & 7 & 5 & 6 & 46 \\
\hline $\begin{array}{l}\text { Suavizante de ropa I } \\
\text { enjuague }\end{array}$ & 27 & 18 & 2 & 11 & 41 \\
\hline $\begin{array}{l}\text { Guantes de jebe para } \\
\text { limpieza }\end{array}$ & 24 & 9 & 4 & 18 & 45 \\
\hline Shampoo para bebes & 36 & 1 & 0 & 2 & 61 \\
\hline
\end{tabular}

\begin{tabular}{|c|c|c|c|c|c|}
\hline Productos: & $\begin{array}{c}\text { Diariol } \\
\text { Varias } \\
\text { Veces por } \\
\text { semana } \\
\text { (7) }\end{array}$ & $\frac{\text { Semanal }}{(x)}$ & $\begin{array}{c}\text { Quincenal| } \\
\mid \begin{array}{c}\text { Mensual } \\
(8)\end{array}\end{array}$ & $\frac{\text { Pcasional }}{\text { (V) }}$ & $\begin{array}{l}\text { Nonca } \\
(\%)\end{array}$ \\
\hline Algodón & 13 & 10 & 12 & 52 & 13 \\
\hline Papel toalla & 31 & 1 & 1 & 13 & 54 \\
\hline $\begin{array}{l}\text { Desodorante } \\
\text { ambiental }\end{array}$ & 21 & 5 & 3 & 6 & 65 \\
\hline Talco para bebés & 26 & 0 & 0 & 2 & 72 \\
\hline Pañales de bebé & 25 & 0 & 0 & 1 & 74 \\
\hline $\begin{array}{l}\text { Panîtos hùmedos de } \\
\text { bebé }\end{array}$ & 24 & 1 & 0 & 4 & 71 \\
\hline Jabón liquido & 24 & 0 & 0 & 7 & 69 \\
\hline $\begin{array}{l}\text { Detergente para ropa } \\
\text { delicada }\end{array}$ & 12 & 6 & 1 & 6 & 75 \\
\hline Quitamanchas & 5 & 5 & 5 & 10 & 75 \\
\hline Insecticidas & 4 & 4 & 7 & 30 & 55 \\
\hline Papel Tissue & 11 & 2 & 1 & 9 & 77 \\
\hline $\begin{array}{l}\text { Pañuelos húmedos. } \\
\text { (no de bebé) }\end{array}$ & 11 & 1 & 0 & 7 & 81 \\
\hline Lavavaifilla liquida & 9 & 2 & 0 & 5 & 84 \\
\hline Desatorader & 2 & 2 & 4 & 8 & 84 \\
\hline $\begin{array}{l}\text { Productos para } \\
\text { limpiar metales }\end{array}$ & 0 & 1 & 3 & 6 & 89 \\
\hline
\end{tabular}

Base: Total de amas de casa entrevistadas (308) 


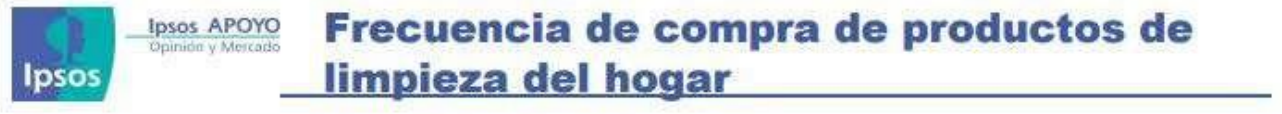

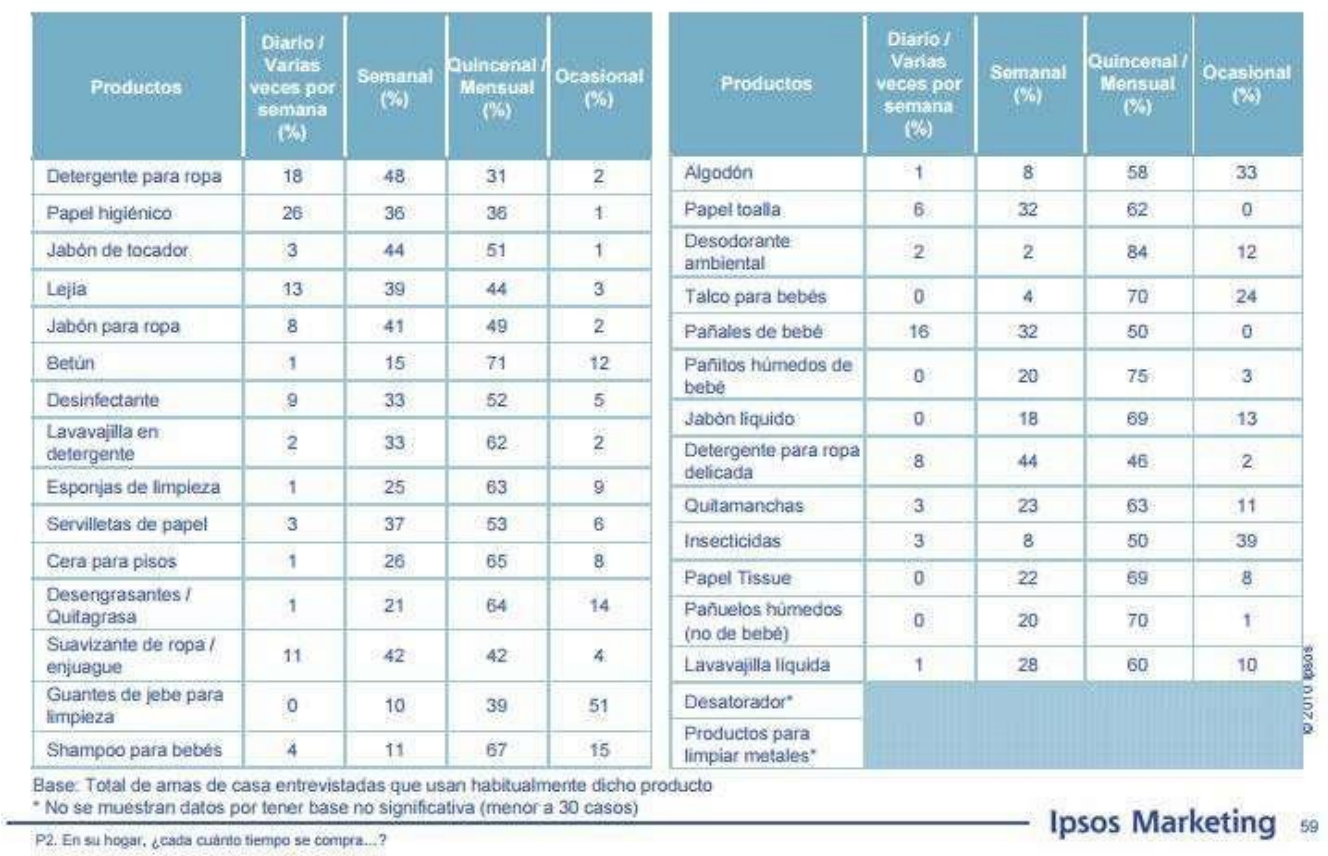

\section{Ipsos
Ipsos APoro Lealtad a la marca de productos de
limpieza del hogar}

Lealtad a la marca = Va a otro lugar a buscar la marca si no la encuentra $/$ No compra nada

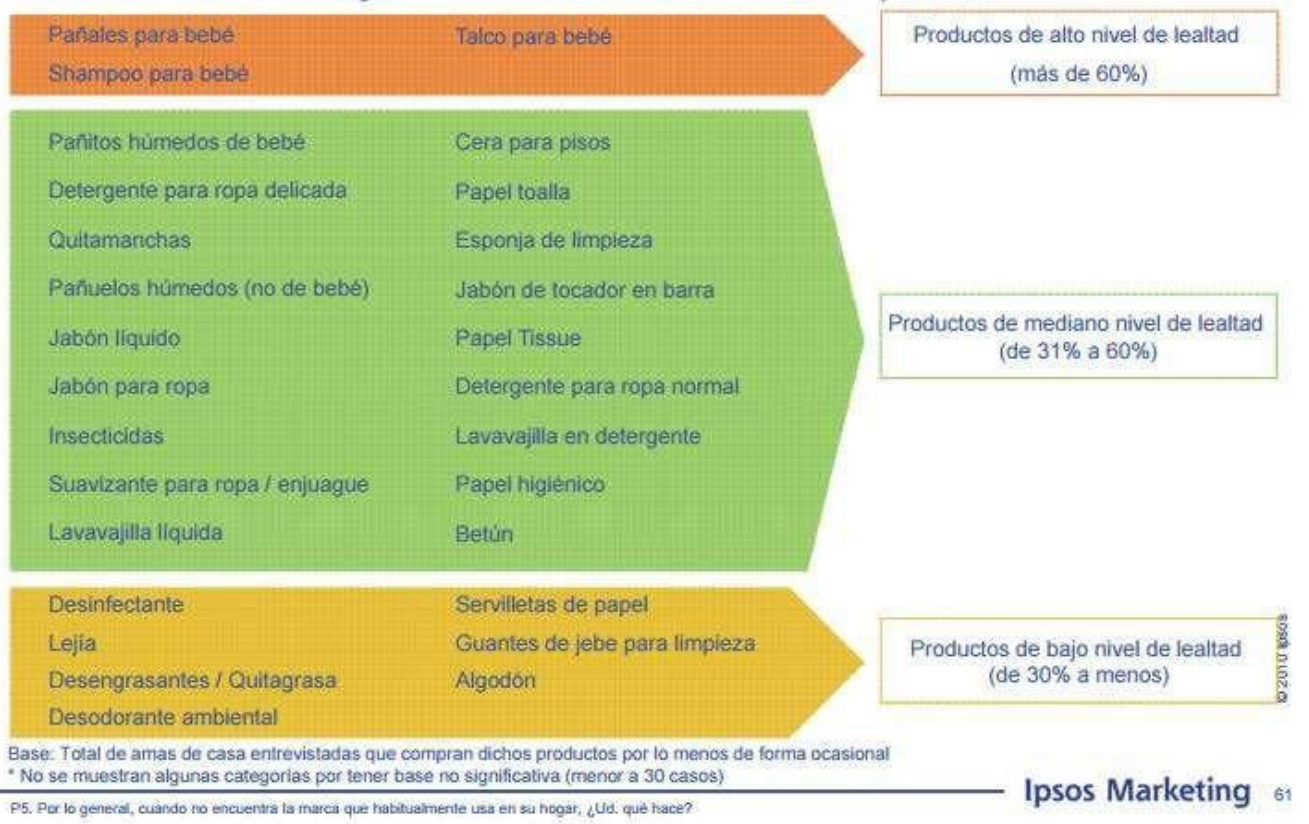




\begin{tabular}{|c|c|c|c|c|c|c|c|c|c|c|c|c|c|c|c|c|}
\hline Mar & más utiliza & ada en & los últi & nos & res & mese & & & & & & & & & & \\
\hline & Princip & pales re & spuest: & s $6 \%$ & & & & & Lugar de comp & TOTAL & TOTAL & & & NSE & & \\
\hline & & & & & & & & & $\begin{array}{l}\text { freciente (Principales } \\
\text { respuestas) }\end{array}$ & 2010 & $\begin{array}{c}2011 \\
\%\end{array}$ & A & $\begin{array}{l}8 \\
\%\end{array}$ & \begin{tabular}{|l|l} 
& 1 \\
$\%$
\end{tabular} & $\stackrel{D}{*}$ & E \\
\hline 52 & 48 & 50 & 39 & & 47 & 4 & & & Mercado/ puestos. & 44 & 36 & 6 & 17 & \begin{tabular}{l|l}
36 & 3 \\
\end{tabular} & 38 & 68 \\
\hline & & & & & & & & & Bodega & 29 & 35 & 4 & 20 & 325 & 57 & 30 \\
\hline & $\begin{array}{l}\text { Sapolio } \\
=200\end{array}$ & 9 & 2010 & $\begin{aligned} & A y \\
= & 20\end{aligned}$ & udin & & & & $\begin{array}{l}\text { Supermercado/ } \\
\text { auloservicios }\end{array}$ & 23 & 28 & 90 & 63 & $30=$ & 5 & 2 \\
\hline Marca más 4 & lzada en los & TOTAL & TOTAL & & & NSE & & & & TOTAL & |TOTAL | & & & NSE & & \\
\hline $\begin{array}{l}\text { oftimos! } \\
\text { II }\end{array}$ & smeses & $\begin{array}{c}2010 \\
\%\end{array}$ & $\frac{2011}{4}$ & $\stackrel{A}{\%}$ & $\%$ & $\begin{array}{c}c \\
*\end{array}$ & $\frac{D}{8}$ & E & $\begin{array}{l}\text { Leallada a ta } \\
\text { Marea: }\end{array}$ & 8010 & 2011 & A & $\begin{array}{l}B \\
8\end{array}$ & $\begin{array}{l}c \\
\dot{\gamma}\end{array}$ & $\%$ & $\frac{\mathrm{E}}{\mathrm{\gamma}}$ \\
\hline Sapolio & & 48 & 50 & 46 & 60 & 50 & 46 & 49 & Lealtad a la marca & 23 & 33 & 28 & 42 & 22 & 46 & 26 \\
\hline Ayudin & & 47 & 43 & $\Delta 0$ & 35 & 44 & 45 & 49 & Compra otra marca & 78 & 65 & 68 & 58 & 76 & 52 & 74 \\
\hline Lava & & 3 & 4 & 12 & 2 & 2 & 7 & 0 & No rrecisa & 1 & 3 & ${ }_{0}$ & 0 & 2 & $=$ & \\
\hline Metro & & 0 & 1 & 0 & 0 & 2 & 0 & 0 & & 1 & 2 & 0 & 0 & 2 & 2 & 0 \\
\hline Otros & & 1 & 0 & 2 & 3 & 0 & 0 & 0 & "I eattad a la marca = Va a & buscarta & a otrolug & gar si & nola & iencue & jentra! & हूँ \\
\hline No precisa & & 1 & 2 & 0 & 0 & 2 & 2 & 2 & & & & & & & & \\
\hline
\end{tabular}

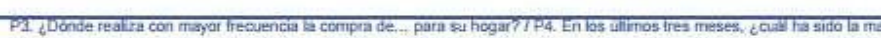

usado en su hogan? IP5. Por lo petrerat, cuando no encuenira a marca que habihisimente usa en su hoqas, iUd, que hace?

\section{Ipsos $\underbrace{\text { Ipsos APOYO }}$ Guantes de jebe}

Marca más utilizada en los últimos tres meses

Principales respuestas $(\%)$

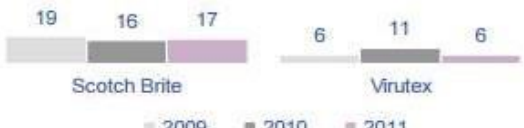

$=2009 \quad \approx 2010=2011$

\begin{tabular}{|c|c|c|c|c|}
\hline \multirow{2}{*}{$\begin{array}{l}\text { Marca mits utilizada en } \\
\text { los ütumos tres meses } \\
\text { (Total) }\end{array}$} & \multirow{2}{*}{$\begin{array}{l}\text { TOTAL } \\
2010 \\
\%\end{array}$} & \multirow{2}{*}{$\frac{\text { TOTAL }}{2011}$} & \multicolumn{2}{|c|}{ NSE } \\
\hline & & & A & $\begin{array}{l}c \\
\%\end{array}$ \\
\hline Scotch Brite & 16 & 17 & 15 & 20 \\
\hline Virutex & 11 & 6 & 0 & 10 \\
\hline Task & 9 & 4 & 0 & 7 \\
\hline Eterna & 0 & 4 & 2 & 3 \\
\hline Vleda & 3 & 3 & 2 & 7 \\
\hline Otros & 10 & 2 & 14 & 0 \\
\hline No precisa & 51 & 64 & 67 & 53 \\
\hline
\end{tabular}

Base: Total de amas de casa que compran dicho producto por lo menos de forma ocasional (128)

- No se muestra información de NSE B, D y E por tener base no significativa (menor a 30 casos)

\begin{tabular}{|l|c|c|c|c|}
\hline \multirow{2}{*}{$\begin{array}{c}\text { Lugar de compra } \\
\text { más frecuente } \\
\text { (Principales } \\
\text { respuestas) }\end{array}$} & $\begin{array}{c}\text { TOTAL } \\
2010\end{array}$ & \begin{tabular}{c} 
TOTAL \\
2011 \\
\cline { 4 - 5 }
\end{tabular} & \multicolumn{3}{|c|}{ NSE } \\
\hline Mercado/ puestos & 41 & 44 & 2 & 47 \\
\hline $\begin{array}{l}\text { Supermercado/ } \\
\text { autoservicios }\end{array}$ & 29 & 35 & 98 & 30 \\
\hline Bodega & 12 & 12 & 0 & 13 \\
\hline Ambulante & 3 & 1 & 0 & 3 \\
\hline
\end{tabular}

\begin{tabular}{|c|c|c|c|c|}
\hline \multirow{2}{*}{$\begin{array}{l}\text { Lealtad a la } \\
\text { Marca: }\end{array}$} & \multirow{2}{*}{$\begin{array}{l}\text { TOTAL } \\
2010 \\
\%\end{array}$} & \multirow{2}{*}{$\begin{array}{c}\text { TOTAL } \\
\frac{2011}{\%}\end{array}$} & \multicolumn{2}{|c|}{ NSE } \\
\hline & & & A & $\stackrel{c}{*}$ \\
\hline Lealtad a la marca & 13 & 24 & 27 & 20 \\
\hline Compra otra marca & 70 & 64 & 69 & 77 \\
\hline No precisa & 17 & 12 & 4 & 3 \\
\hline
\end{tabular}

Ipsos Marketina 


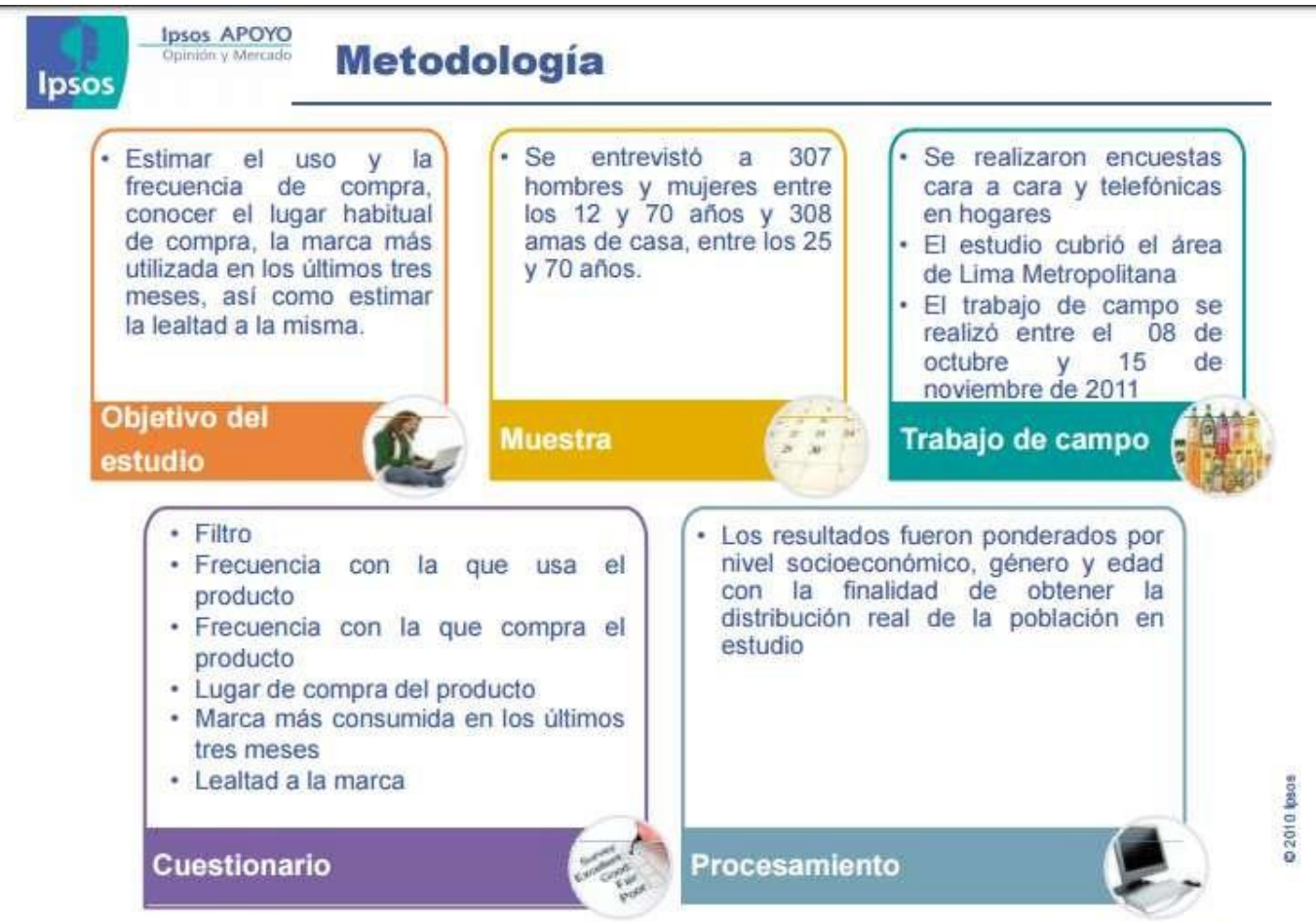


Anexo 14: Oportunidades de negocio con el estado
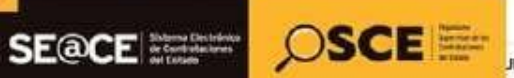

At Volver I ${ }_{\text {Contactenos I }}$ iो Preguntas Fi

JeN SERVICIO AL CIUDAdANO

Sabodo, 8 de Julto del 2017 13:05:22

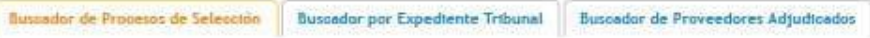

\begin{tabular}{|c|c|c|c|}
\hline $\begin{array}{l}\text { Código } \\
\text { osptoha (") }\end{array}$ & & $\begin{array}{l}\text { (") Campo } \\
\text { oblizatorio }\end{array}$ & \\
\hline $\begin{array}{l}\text { Nombreo } \\
\text { Stsyla de } \\
\text { Entidad }\end{array}$ & & $\begin{array}{l}\text { Tipo de } \\
\text { Selecoction }\end{array}$ & [Seleocione] \\
\hline $\begin{array}{l}\text { Objeto de } \\
\text { Contratactón }\end{array}$ & Bien & Nro. Selecootón & \\
\hline $\begin{array}{l}\text { Dessorpotión } \\
\text { del Objeto }\end{array}$ & materiales de LWMPIEZA & $\begin{array}{l}\text { Año de le } \\
\text { Convooatoria } \\
\text { (") }\end{array}$ & 2017 \\
\hline Version SEACE & Seroe 3 & & \\
\hline
\end{tabular}

Si desea realizar büequendas mas Exhaustivas y Precisas, le recomendemos seleccionar la opoción de Büsqueda teranzoda

Busquede Avertzadin

Butes Limphar

Exportar a Excel

\begin{tabular}{|c|c|c|c|c|c|c|c|c|c|c|}
\hline \multicolumn{11}{|c|}{ Lista de Proceson } \\
\hline $\mathrm{N}^{*}$ & $\begin{array}{l}\text { Mombre o 5tgia } \\
\text { de la Entridad }\end{array}$ & $\begin{array}{l}\text { Fechan y } \\
\text { Hora de } \\
\text { Publtcacton }\end{array}$ & Nomenoloture & $\begin{array}{l}\text { Reinieledo } \\
\text { Desde }\end{array}$ & $\begin{array}{l}\text { Objeto de } \\
\text { Cantrataclón }\end{array}$ & Desaripoión de Objeto & $\begin{array}{r}\text { Valor } \\
\text { Referencial } \\
\text { / Valor } \\
\text { Estrmado }\end{array}$ & Moneda & $\begin{array}{l}\text { Versión } \\
\text { SEACE }\end{array}$ & Acotones \\
\hline 1 & $\begin{array}{l}\text { INSTITUTO } \\
\text { NACIONAL DE } \\
\text { DEFENSA DE LA } \\
\text { COMPETENCIAY } \\
\text { DE LA } \\
\text { PROTECCION DE } \\
\text { LA PROPIEDAD } \\
\text { NTTFI EPTIIAI }\end{array}$ & $\begin{array}{l}07 / 07 / 2017 \\
19: 38\end{array}$ & $\begin{array}{l}\text { AS-SM-7-2017- } \\
\text { INDECOPH-1 }\end{array}$ & & Bien & $\begin{array}{l}\text { SUMINISTRO DE } \\
\text { MATERIALES DE UMPIEZA }\end{array}$ & 136.385 .28 & $\begin{array}{l}\text { Nuevos: } \\
\text { Soles }\end{array}$ & 3 & 05 \\
\hline
\end{tabular}




\begin{tabular}{|c|c|c|c|c|c|c|c|c|c|}
\hline 2 & $\begin{array}{l}\text { GOBIERNO } \\
\text { REGIONAL DE } \\
\text { PPURA. } \\
\text { EDCACIÓN ALTO } \\
\text { PIURA }\end{array}$ & $\begin{array}{l}28 / 06 / 2017 \\
22: 30\end{array}$ & $\begin{array}{l}\text { COMPRE-SM-1-2017- } \\
\text { UGEL CHULUCANAS- } \\
1\end{array}$ & Bien & 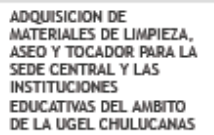 & 37.999 .21 & $\begin{array}{l}\text { Nuevos } \\
\text { Soles }\end{array}$ & 3 & 0 ए \\
\hline 3 & $\begin{array}{l}\text { GOBERENO } \\
\text { REGIONAL DE } \\
\text { UCAYALI SEDEE } \\
\text { CENTRAL }\end{array}$ & $\begin{array}{l}27 / 06 / 2017 \\
20: 22\end{array}$ & $\begin{array}{l}\text { AS5-SM-38-2017-GRU- } \\
\text { GR-CS-1 }\end{array}$ & Bien & 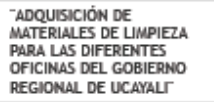 & 60.891.89 & $\begin{array}{l}\text { Nuevos } \\
\text { Soles }\end{array}$ & 3 & 0 咂 \\
\hline 4 & 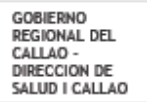 & $\begin{array}{l}26 / 06 / 2017 \\
16: 01\end{array}$ & $\begin{array}{l}\text { AS-SM-3-2017-GRC- } \\
\text { DIRESA-2 }\end{array}$ & Bien & 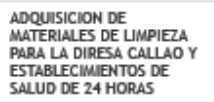 & - & $\begin{array}{l}\text { Nuevos } \\
\text { Soles }\end{array}$ & 3 & 0 ए \\
\hline 5 & $\begin{array}{l}\text { INSTITUTO } \\
\text { PERUANO DEL } \\
\text { DEPORTE }\end{array}$ & $\begin{array}{l}20 / 06 / 2017 \\
09: 45\end{array}$ & $\begin{array}{l}\text { AS-SM-26-2017- } \\
\text { PP/ULL-1 }\end{array}$ & Bien & 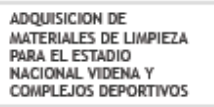 & 213.921 .30 & $\begin{array}{l}\text { Nuevos } \\
\text { Soles }\end{array}$ & 3 & 0 \\
\hline 6 & $\begin{array}{l}\text { GOBERENO } \\
\text { REGIONAL DE SAN } \\
\text { MARTTN-SALUD }\end{array}$ & $\begin{array}{l}19 / 06 / 2017 \\
19: 18\end{array}$ & $\begin{array}{l}\text { AS-SS-S-2017- } \\
\text { OOSEM-CS-1 }\end{array}$ & Bien & 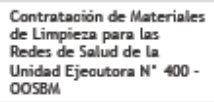 & $50,806.00$ & $\begin{array}{l}\text { Nuevos } \\
\text { Soles }\end{array}$ & 3 & 0 ए \\
\hline 7 & $\begin{array}{l}\text { GOBIERNO } \\
\text { REGIONAL DE } \\
\text { MARER DE DIOS. } \\
\text { HOSPTTAL SANTA } \\
\text { ROSA DE PUERTO } \\
\text { MALDONADO }\end{array}$ & 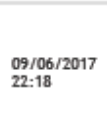 & AS-SM-3-2017-HSR-1 & Bien & 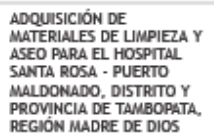 & $92,445.60$ & $\begin{array}{l}\text { Nuevos } \\
\text { Soles }\end{array}$ & 3 & $0 \sqrt{5}$ \\
\hline 8 & $\begin{array}{l}\text { GOBEERO } \\
\text { REGINAL DE } \\
\text { ANCASH - SALUD } \\
\text { UTES HUARAZ } \\
\text { HOSPTITLL VICTOR } \\
\text { RAMOS GUARDIA }\end{array}$ & $\begin{array}{l}\text { O6/06/2017 } \\
15: 05\end{array}$ & $\begin{array}{l}\text { AS-SM-S-2017-HVRG- } \\
1\end{array}$ & Bien & MATERIALES DE LMPIEZA & $63,500.00$ & $\begin{array}{l}\text { Nuevos } \\
\text { Soles }\end{array}$ & 3 & 05 \\
\hline 9 & $\begin{array}{l}\text { GOBIERNO } \\
\text { REGIONAL DE } \\
\text { UCAYALL- DE } \\
\text { HOSPITAL DE } \\
\text { APOYO DE } \\
\text { PUCAUPA }\end{array}$ & $\begin{array}{l}01 / 06 / 2017 \\
13: 41\end{array}$ & $\begin{array}{l}\text { ASS-SM-2-2017-HRP. } \\
\text { CS-1 }\end{array}$ & Bien & 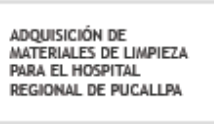 & $76,235.32$ & $\begin{array}{l}\text { Nuevos } \\
\text { Soles }\end{array}$ & 3 & 0 辰 \\
\hline 10 & POOER JUDICIAL & $\begin{array}{l}31 / 05 / 2017 \\
17: 39\end{array}$ & $\begin{array}{l}\text { AS-SM-15-2017. } \\
\text { GG/PJ-1 }\end{array}$ & Bien & 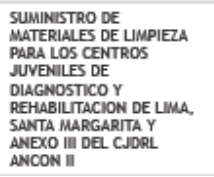 & $231,737.50$ & $\begin{array}{l}\text { Nuevos } \\
\text { Soles }\end{array}$ & 3 & (1) \\
\hline
\end{tabular}

\begin{tabular}{|c|c|c|c|c|c|c|c|c|c|}
\hline 11 & $\begin{array}{l}\text { UNIDAD DE } \\
\text { GESTION } \\
\text { EEUCATINA LOCAL } \\
\text { UGEL O6- } \\
\text { VITARTE }\end{array}$ & $\begin{array}{l}30 / 05 / 2017 \\
18: 51\end{array}$ & $\begin{array}{l}\text { AS-SW-7-2017-UGEL } \\
\text { OS-1 }\end{array}$ & Bien & 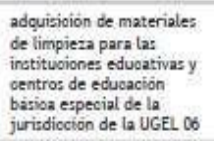 & $90,380.98$ & $\begin{array}{l}\text { Nuevos } \\
\text { Soles }\end{array}$ & 3 & (1) \\
\hline 12 & $\begin{array}{l}\text { PATRONATO DEL } \\
\text { PARQUE DE LAS } \\
\text { LFYENOAS. } \\
\text { FFUPE BENAVIDES } \\
\text { BARREDA }\end{array}$ & $\begin{array}{l}24 / 05 / 2017 \\
17: 03\end{array}$ & $\begin{array}{l}\text { COUPPE-SU-1-2017- } \\
\text { PAMPAL-FBB/MUL-1 }\end{array}$ & Bien & 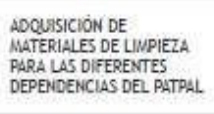 & $46,873.10$ & $\begin{array}{l}\text { Nuevos } \\
\text { Soles }\end{array}$ & 3 & (1) 5 \\
\hline 13 & $\begin{array}{l}\text { MARINA DE } \\
\text { GUERRA DEL } \\
\text { PERU }\end{array}$ & $\begin{array}{l}24 / 05 / 2017 \\
14: 24\end{array}$ & $\begin{array}{l}\text { A5-SM-B-2017. } \\
\text { MGPICONOPERAMA- } \\
2\end{array}$ & Bien & 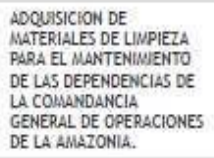 & $117,005.26$ & $\begin{array}{l}\text { Nuevos } \\
\text { Soles }\end{array}$ & 3 & (1) \\
\hline 14 & $\begin{array}{l}\text { GOBIERNO } \\
\text { PEGLONAL DE ICA- } \\
\text { EDUCACCION } \\
\text { CHINCHA-PISCO }\end{array}$ & $\begin{array}{l}22 / 05 / 2017 \\
19: 47\end{array}$ & $\begin{array}{l}\text { DIRECTA-PROC-1. } \\
2017-0 \text { EC-1 }\end{array}$ & Bien & 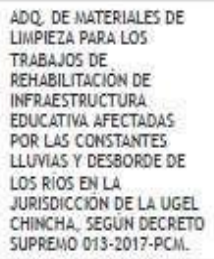 & $154,505.00$ & $\begin{array}{l}\text { Nuevos } \\
\text { Soles }\end{array}$ & 3 & $0 \pi$ \\
\hline 15 & $\begin{array}{l}\text { MUNICIPALIDAD } \\
\text { MISTRITAL DE } \\
\text { WURIN }\end{array}$ & $\begin{array}{l}\text { 17/05/2017 } \\
19: 22\end{array}$ & $\begin{array}{l}\text { AS-5M-2.2017- } \\
\text { CSIML-1 }\end{array}$ & Bien & 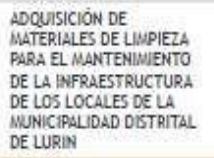 & $82,335.04$ & $\begin{array}{l}\text { Nuevos } \\
\text { Soles }\end{array}$ & 3 & 05 \\
\hline
\end{tabular}


sE@CE

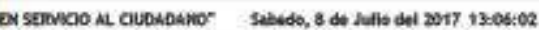

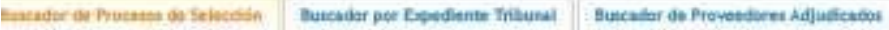

\begin{tabular}{|c|c|c|c|}
\hline codise & $56 \times 52$ & $\begin{array}{l}\text { 9) Canso } \\
\text { detivitoris }\end{array}$ & \\
\hline $\begin{array}{l}\text { Mentres } \\
\text { Singh de } \\
\text { Gividad }\end{array}$ & & $\begin{array}{l}\text { Tpo don } \\
\text { Seloction }\end{array}$ & [Solectibed] \\
\hline $\begin{array}{l}\text { objete de } \\
\text { Contretincisin }\end{array}$ & Sten & Wra. Selecelbn & \\
\hline $\begin{array}{l}\text { Deacritedion } \\
\text { Del objeto }\end{array}$ & muterlaion on LNHEZ & $\begin{array}{l}\text { Afie do is } \\
\text { Convocatents } \\
\text { of }\end{array}$ & 2017 \\
\hline Weriton sevce & Soace 3 & & \\
\hline
\end{tabular}

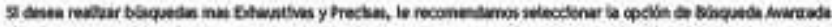

Barpede Nunasato

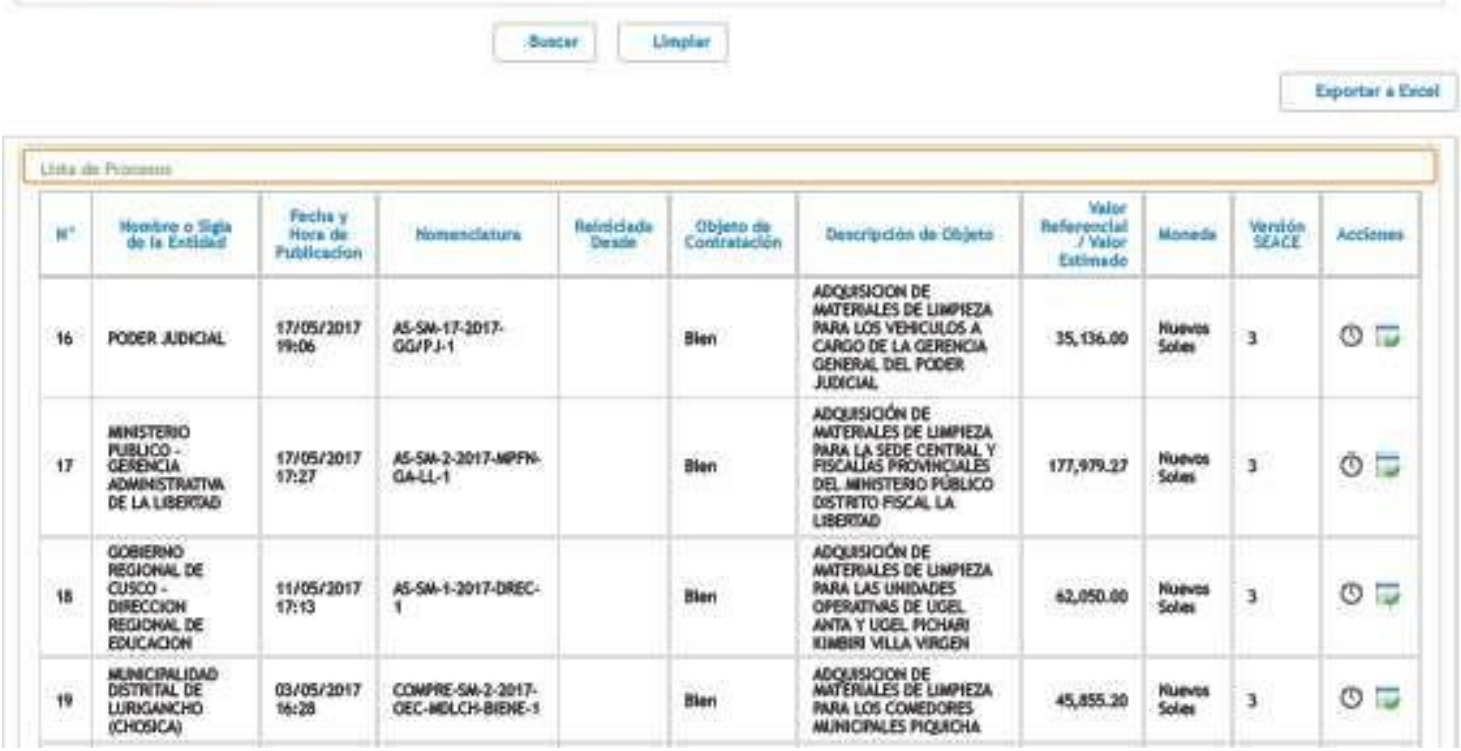




\begin{tabular}{|c|c|c|c|c|c|c|c|c|c|}
\hline 20 & 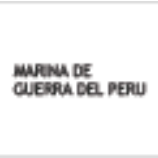 & $\begin{array}{l}28104 / 2017 \\
21: 08\end{array}$ & 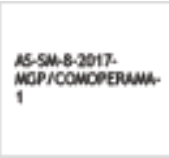 & Blen & 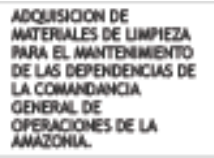 & $117,005,26$ & $\begin{array}{l}\text { noveres } \\
\text { Soles }\end{array}$ & 3 & $0 \%$ \\
\hline 21 & 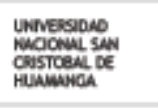 & 27104/2017 & 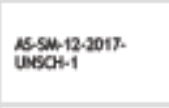 & Blen & 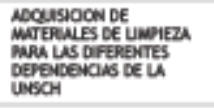 & $82,506,44$ & $\begin{array}{l}\text { noweres } \\
\text { Soles }\end{array}$ & 3 & 0 \\
\hline 22 & 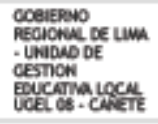 & $\begin{array}{l}27704 / 2017 \\
6651\end{array}$ & 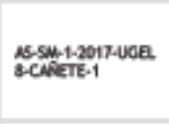 & Blen & 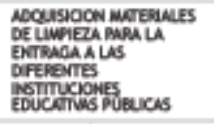 & 158,43600 & Solen & 3 & 05 \\
\hline 23 & 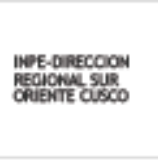 & $\begin{array}{l}\text { 25/01/2017 } \\
17: 15\end{array}$ & 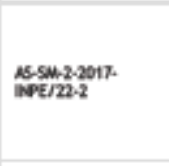 & Blen & 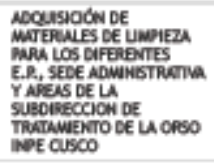 & ... & $\begin{array}{l}\text { Noveres } \\
\text { Soles }\end{array}$ & 3 & 05 \\
\hline 24 & 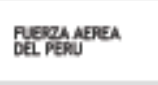 & 21:04/2017 & 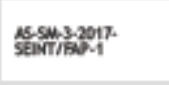 & Blen & 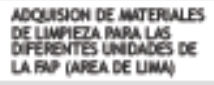 & 321,15804 & Sonem & 3 & 0 \\
\hline 25 & 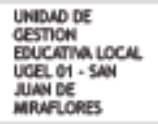 & ${ }_{21: 13}^{20001 / 2017}$ & 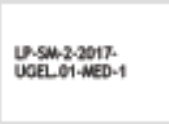 & Blen & 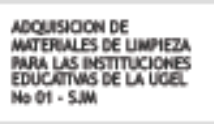 & 549,07500 & $\begin{array}{l}\text { Noveres } \\
\text { Soles }\end{array}$ & 3 & 05 \\
\hline
\end{tabular}

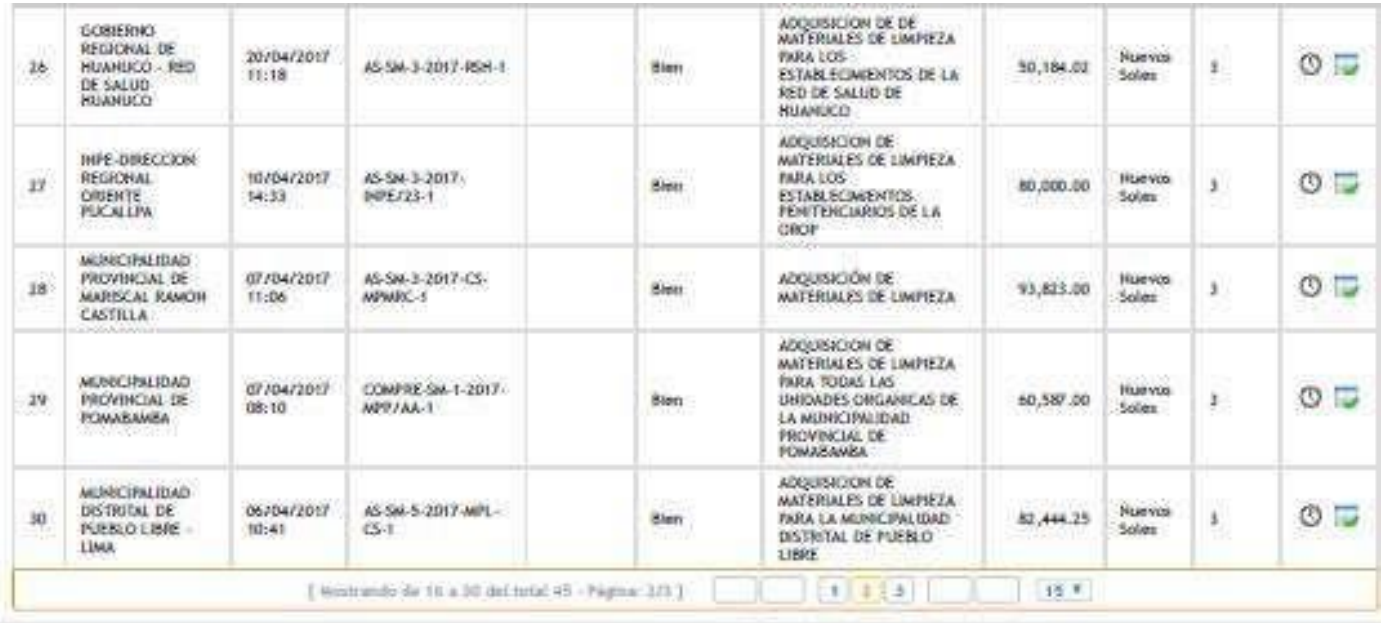


Sabado, o de Jullo del 2017 13:07:21

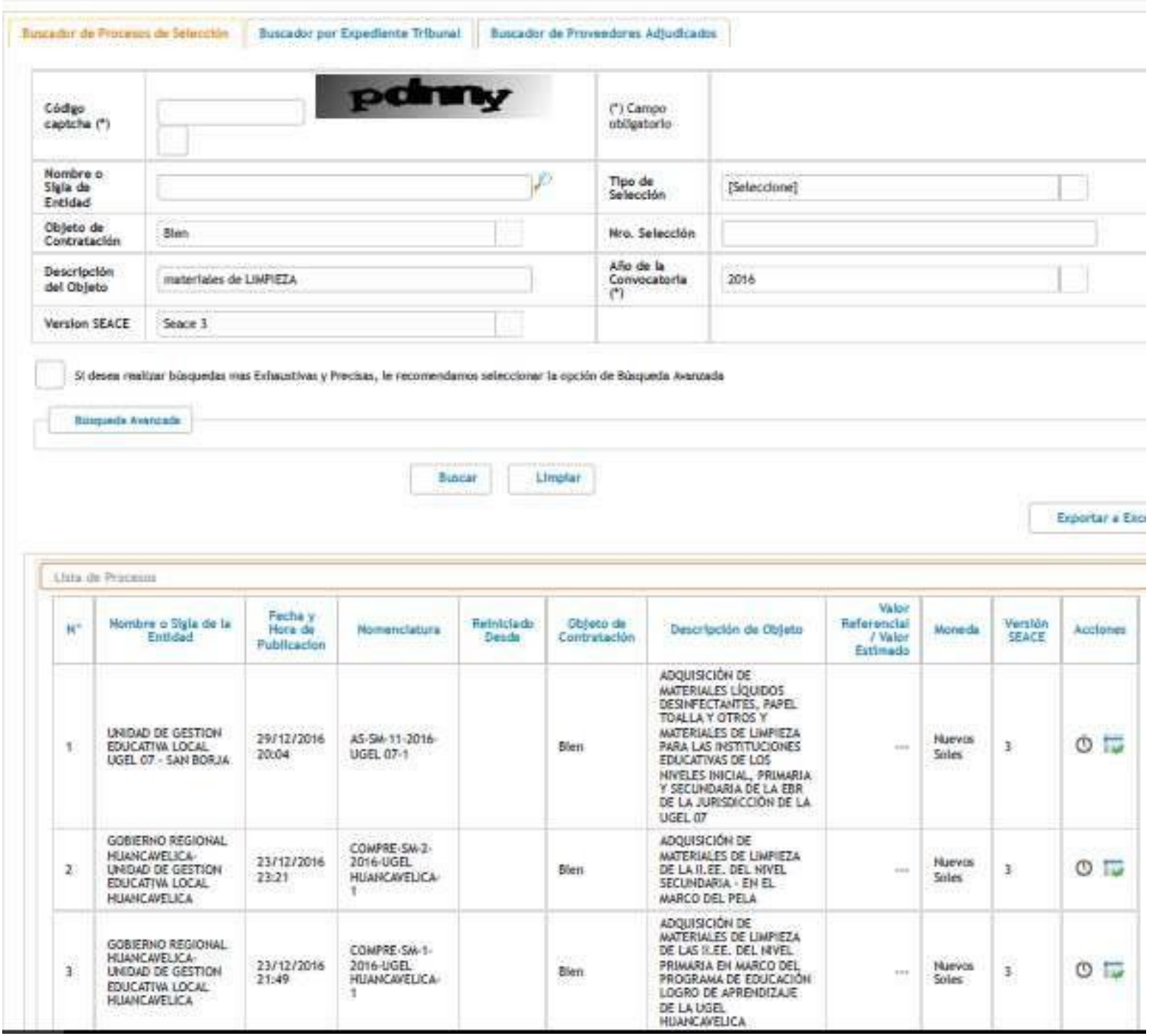




\begin{tabular}{|c|c|c|c|c|c|c|c|c|c|}
\hline 4 & 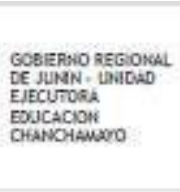 & $\begin{array}{l}12 / 12 / 2016 \\
22=37\end{array}$ & 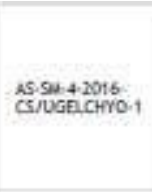 & Eeen & 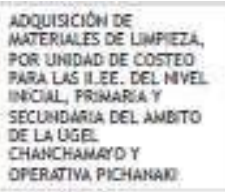 & - & $\begin{array}{l}\text { Nuves } \\
\text { snies }\end{array}$ & 3 & $0 \pi$ \\
\hline 5 & $\begin{array}{l}\text { LNOND DE GESTION } \\
\text { EDUCATIUA LOCAL } \\
\text { USE O3 - IWA } \\
\text { CECADO }\end{array}$ & $\begin{array}{l}30 / 11 / 2016 \\
20: 37\end{array}$ & $\begin{array}{l}\text { NS.92 12.2016- } \\
\text { UGEL 03.1 }\end{array}$ & Dien. & 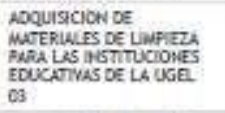 & - & $\begin{array}{l}\text { Pueven } \\
\text { soles }\end{array}$ & 3 & 0 \\
\hline 6 & $\begin{array}{l}\text { Fordo wVIVESes } \\
\text { Se. }\end{array}$ & $\begin{array}{l}30 / 11 / 20016 \\
1806\end{array}$ & 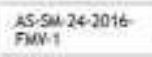 & Elen & 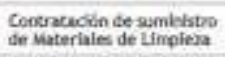 & - & $\begin{array}{l}\text { Nuveres } \\
\text { sonies: }\end{array}$ & 3 & $0 \pi$ \\
\hline 7 & 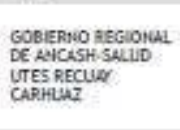 & $\begin{array}{l}24 / 11 / 2016 \\
1816\end{array}$ & $\begin{array}{l}\text { AS. SN-3,2016. } \\
\text { DndE-1 }\end{array}$ & Bien & 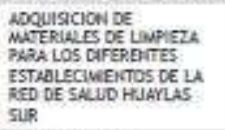 & - & $\begin{array}{l}\text { Nutron } \\
\text { Soles }\end{array}$ & 3 & 0.5 \\
\hline 8 & POCER JUOKCIR & $\begin{array}{l}17 / 11 / 2016 \\
15,4 a\end{array}$ & 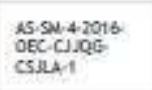 & Ben & 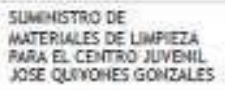 & - & $\begin{array}{l}\text { Heves } \\
\text { soles }\end{array}$ & 3. & 05 \\
\hline 9 & 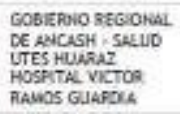 & $\begin{array}{l}14 / 11 / 2016 \\
12-10\end{array}$ & $\begin{array}{l}\text { AS.9N } 13.2016 \\
\text { HVRG2 }\end{array}$ & Den: & MATEPLLEES DE LMPIEZ, & $\ldots$ & $\begin{array}{l}\text { Noveres } \\
\text { soles }\end{array}$ & 3. & (0) \\
\hline so & $\begin{array}{l}\text { MNVEFSIDA } \\
\text { MCIOWL FEDEACO } \\
\text { WLARESEL }\end{array}$ & $11 / 11 / 2016$ & 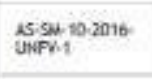 & Bsen & 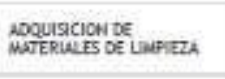 & - & $\begin{array}{l}\text { Heves } \\
\text { Soles }\end{array}$ & 3 & $0 \pi$ \\
\hline "1 & 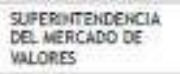 & $\begin{array}{l}07 / 11 / 200+6 \\
19810\end{array}$ & $\sin ^{25.92} \cdot 25.2016$ & Bien & $\begin{array}{l}\text { ADOLISTCION OE } \\
\text { MATERINES DE LNPEZA }\end{array}$ & $\ldots$ & $\begin{array}{l}\text { Nutvon } \\
\text { Soles }\end{array}$ & 3 & 07 \\
\hline
\end{tabular}

\begin{tabular}{|c|c|c|c|c|c|c|c|c|c|}
\hline 12 & 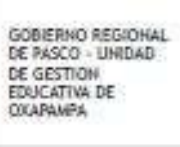 & $\begin{array}{l}28 / 10 / 2016 \\
22: 09\end{array}$ & 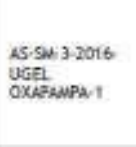 & Blen. & 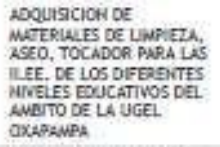 & - & $\begin{array}{l}\text { tweres } \\
\text { soles }\end{array}$ & 3 & $0 \pi$ \\
\hline 13 & $\begin{array}{l}\text { RUERZA AEREA OEL } \\
\text { PERU }\end{array}$ & $\begin{array}{l}28 / 10 / 2016 \\
2051\end{array}$ & 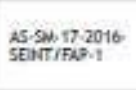 & Blen & 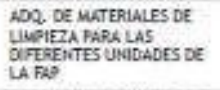 & - & $\begin{array}{l}\text { Puevos } \\
\text { Soles }\end{array}$ & 3 & 0 \\
\hline 14 & 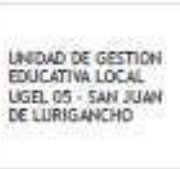 & $\begin{array}{l}2 \mathrm{~B} / \mathrm{70} / \mathrm{are} \mathrm{e} \\
1 \mathrm{R} / 4\end{array}$ & 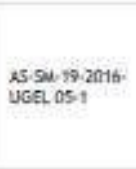 & Bsen & 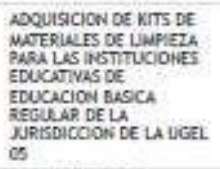 & $\omega$ & $\begin{array}{l}\text { Huever } \\
\text { Soles }\end{array}$ & 3 & $0 \pi$ \\
\hline 15 & 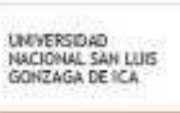 & $\begin{array}{l}21110 / 2016 \\
11: 05\end{array}$ & 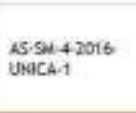 & Blen & 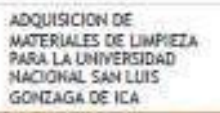 & m. & $\begin{array}{l}\text { Nueven } \\
\text { Soltes }\end{array}$ & 3 & $0 \pi$ \\
\hline \multicolumn{10}{|c|}{ 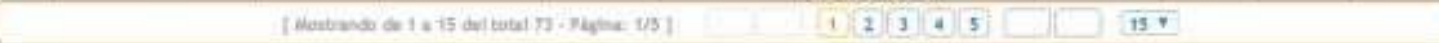 } \\
\hline
\end{tabular}




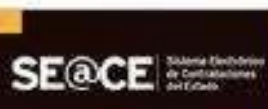

\section{OSCE $=$}

IEN SERMCIO AL CNOLOANO'

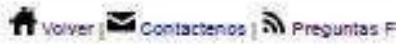

Sasodo, 8 de Jullo det 2017 13:07:36

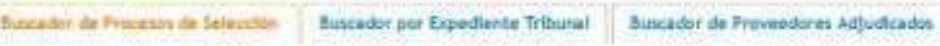

\begin{tabular}{|c|c|c|c|}
\hline $\begin{array}{l}\text { Codse } \\
\text { coptche ip) }\end{array}$ & & $\begin{array}{l}\text { Cicaneo } \\
\text { obisyaterila }\end{array}$ & \\
\hline $\begin{array}{l}\text { Nombre a } \\
\text { Slgia de } \\
\text { Entidad }\end{array}$ & & $\begin{array}{l}\text { Tpoo de } \\
\text { Seleceilis }\end{array}$ & [Selecdorse] \\
\hline $\begin{array}{l}\text { Obseces de } \\
\text { Costratacisn }\end{array}$ & Bim & Ner. Selection & \\
\hline $\begin{array}{l}\text { Descripelas } \\
\text { del Objets }\end{array}$ & maveridies de LavPIg7. & $\begin{array}{l}\text { Mo de lat } \\
\text { Convecatorta } \\
\text { in }\end{array}$ & 2016 \\
\hline Verrioh SEACE & seace 3 & & \\
\hline
\end{tabular}

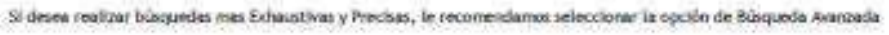

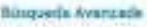

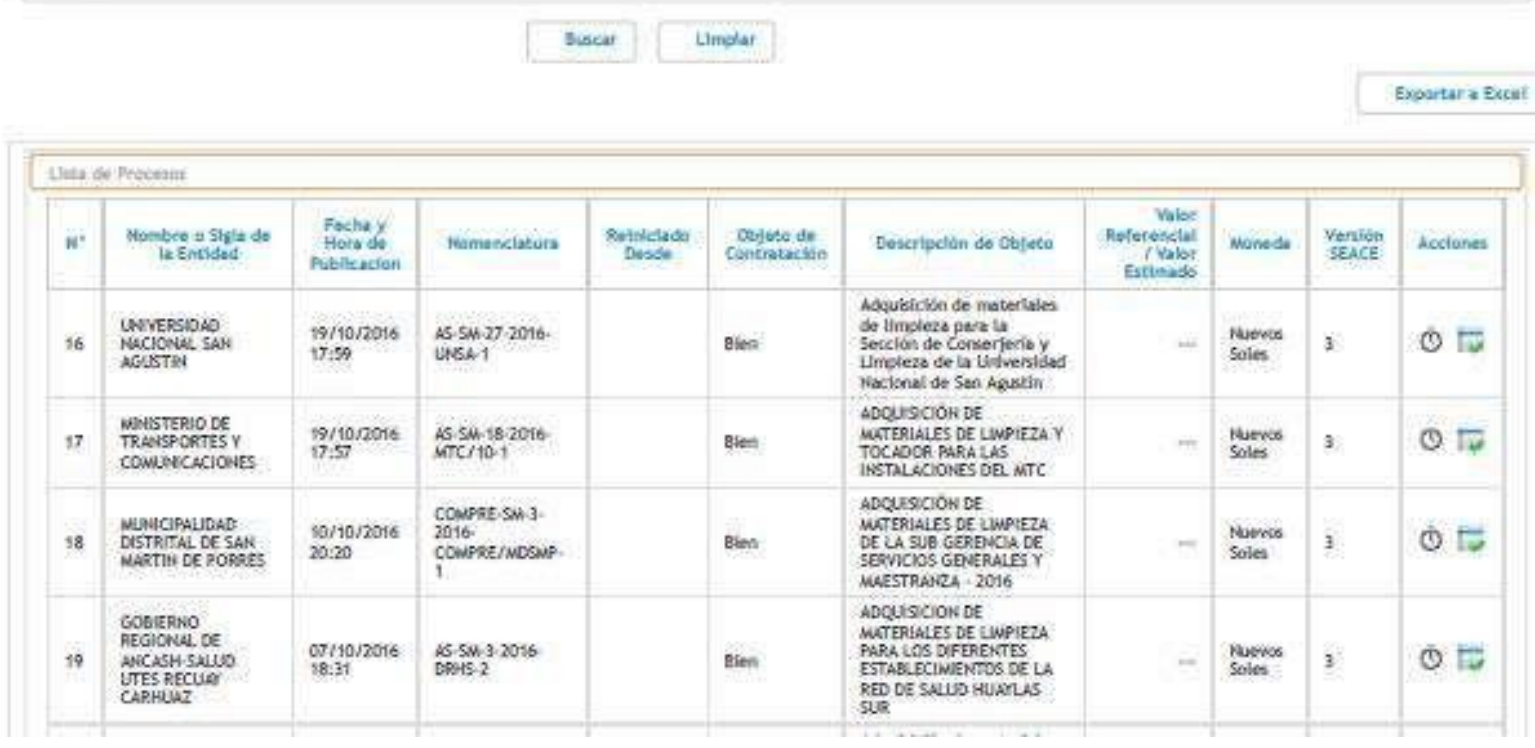




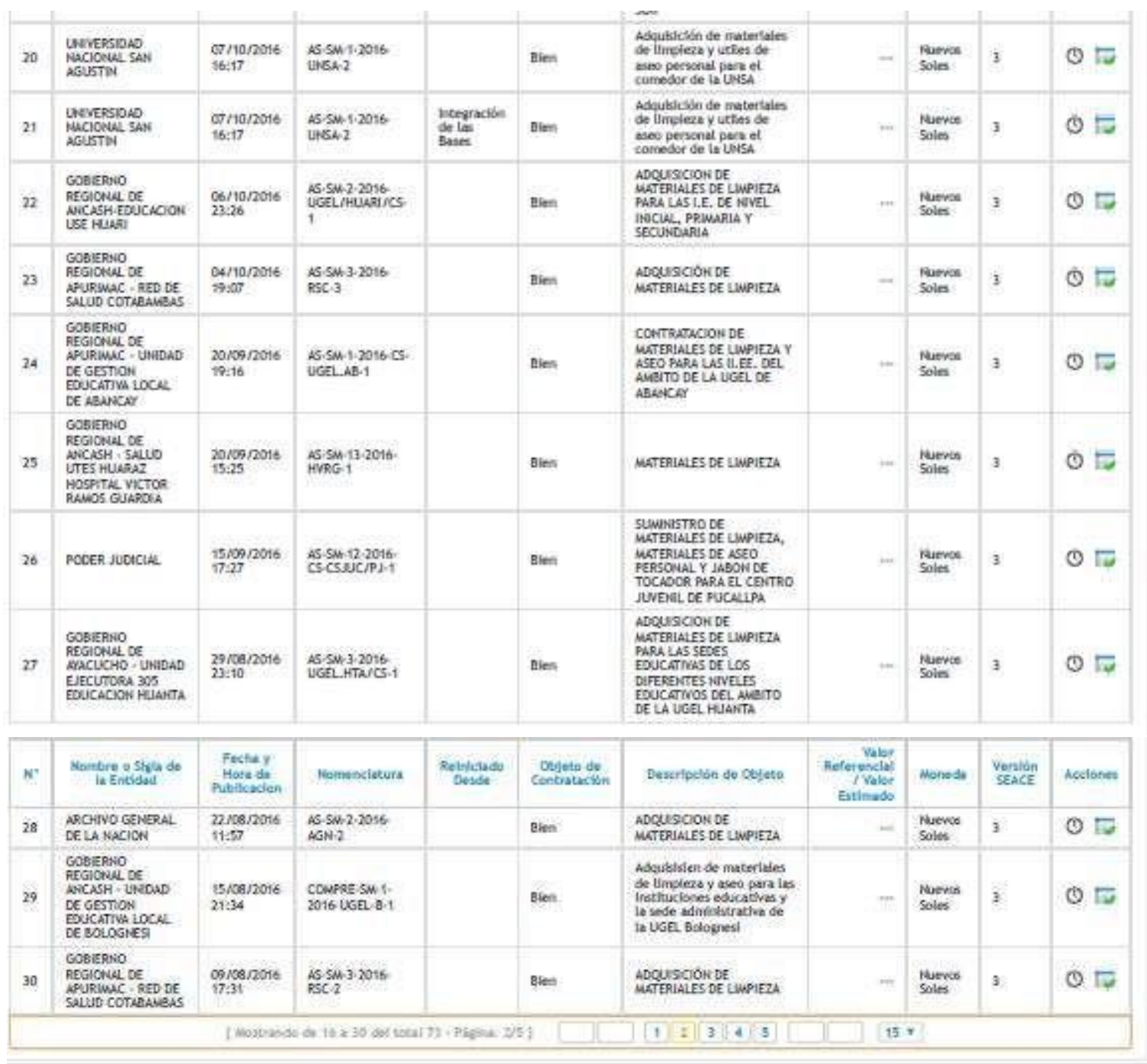

Bibliografía. 
Armstrong, P. K. (2012). Marketing.Mexico D.F.: Pearson Education .

Gray, D. C. (2003). Marketing en la pequeña y mediana empresa.North Vancouver: SelfCounsel Press.

Ipinza, F. D. (2013). El preceso Estratégico un enfoque de gerencia. Ciudad de Mexixo, Mexico: Pearson.

R., D. F. (2003). Conceptos de Administración Estratégica. México: Pearson . Universidad privada Antenor Orrego. (2010). Estudio mercados y supermercados . Trujillo: Investiga.

Macera, D. (21 de 06 de 2015). ¿Cuál es el costo de la corrupción en el Perú? Obtenido de http://elcomercio.pe/politica/actualidad/cual-costo-corrupcion-peru-informe-noticia-1820300 Marketing, I. (2011). Liderazgo en productos de cuidado personal y limpieza del hogar . Lima: Ipsos Apoyo.

KOTLER, Philip. Dirección de Mercadotecnia. Análisis, planeación, implementación y control. España: Prentice Hall 1996.

KOTLER, Philip. Marketing 3.0: From Products to Customers to the Human Spirit. EEUU: Wiley 2010.

Martinez Daniel y Milla Artemio. La elaboración del plan estratégico y su implantación a través del cuadro de mando integral. España: Ediciones Díaz de Santos 2005. 
Navas Lopez, José Emilio; Guerras Martin, Luis Ángel. La dirección estratégica de la empresa, Teoría y Aplicación 3a Ed. Madrid ;Civitas, 2004

Osterwalder, Alexander y Pigneur, Yves. Generación de modelos de negocio. "Un manual para visionarios, revolucionarios y retadores”. España: Centro Libros PAPF, S. L. U. 2011.

Thompson, Arthur a. y Peteraf, Margaret A. Administración Estratégica, Teoría y casos. Decimoctava edición México: McGraw-Hill Educación, 2012.

Joseph Anthony Mongrut Principe. Planeamiento estratégico para la compañía GyM S.A. Lima, Perú, Universidad USIL, 2015

\section{Referencias Electrónicas}


Invera. (15 de marzo de 2015). Hábitos del Mercado de Limpieza del Hogar. Obtenido de http://gestion.pe/empresas/limenas-gastan-casi-s-80-articulos-limpieza-supermercados-2126162

Finanzas, M. d. (2016). Principales Calificaciones de Riesgo Soberano. Obtenido de https://www.mef.gob.pe/index.php?option=com_content\&view=article\&id=222\%3Aprincipalescalificaciones-de-riesgo-soberano\&catid=90\%3Aconsulta-4\&Itemid=101017\&lang=es

Gerencial de Marketing - IGM. (2011). Liderazgo en productos de cuidado. Obtenido de file://C:/Users/joseph.mongrut/Downloads/IGM\%20Liderazgo\%20productos\%20cuidado\%20pe rsonal\%20y\%20limpieza\%20hogar\%202011.pdf

Yaromir Muñoz Molina, P. (2013). Universidad EAFIT ESCUELA DE ADMINISTRACIÓN Y FINANZAS. Obtenido de https://repository.eafit.edu.co/xmlui/bitstream/handle/10784/1404/NaranjoOsorio_LilianaMaria 2013.pdf? sequence $=1 \&$ is Allowed $=y$

“Guía de negocios e inversión en el Perú” por EY, 2016. Recuperado de http://www.ey.com/Publication/vwLUAssets/EY-guia-de-negocios-e-inversion-peru-20162017/\%24FILE/EY-guia-de-negocios-e-inversion-2016-2017.pdf

Carlos Aguirre, (2014). Conexión ESAN. La contribución de la evaluación financiera de proyectos en las organizaciones. Recuperado de 
https://www.esan.edu.pe/conexion/actualidad/2014/05/19/la-contribucion-de-la-evaluacionfinanciera-de-proyectos-en-las-organizaciones/ 